\title{
WestVirginiaUniversity
}

THE RESEARCH REPOSITORY @ WVU

Graduate Theses, Dissertations, and Problem Reports

2019

\section{The Food Bank Fix: Hunger, Capitalism and Humanitarian Reason}

Joshua David Lohnes

West Virginia University, jlohnes@mail.wvu.edu

Follow this and additional works at: https://researchrepository.wvu.edu/etd

Part of the Human Geography Commons

\section{Recommended Citation}

Lohnes, Joshua David, "The Food Bank Fix: Hunger, Capitalism and Humanitarian Reason" (2019).

Graduate Theses, Dissertations, and Problem Reports. 3935.

https://researchrepository.wvu.edu/etd/3935

This Dissertation is protected by copyright and/or related rights. It has been brought to you by the The Research Repository @ WVU with permission from the rights-holder(s). You are free to use this Dissertation in any way that is permitted by the copyright and related rights legislation that applies to your use. For other uses you must obtain permission from the rights-holder(s) directly, unless additional rights are indicated by a Creative Commons license in the record and/ or on the work itself. This Dissertation has been accepted for inclusion in WVU Graduate Theses, Dissertations, and Problem Reports collection by an authorized administrator of The Research Repository @ WVU.

For more information, please contact researchrepository@mail.wvu.edu. 


\title{
The Food Bank Fix: Hunger, Capitalism and Humanitarian Reason

\author{
Joshua David Lohnes
}

\author{
Dissertation submitted \\ to the Eberly College of Arts \& Sciences \\ at West Virginia University \\ in partial fulfillment of the requirements for the degree of \\ Doctor of Philosophy in \\ Geography \\ Bradley Wilson, Ph.D., Chair \\ Karen Culcasi, Ph.D. \\ Trevor Harris, Ph.D. \\ Maria Perez, Ph.D. \\ Cheryl Brown, Ph.D. \\ Adam Pine, Ph.D.
}

Department of Geology and Geography

Morgantown, West Virginia
2019

Keywords: Food Waste, Charity, Hunger, Capitalism, Humanitarianism, Moral Economy, Crisis, Corporate Food Regime

Copyright 2019 Joshua Lohnes 


\title{
Abstract \\ The Food Bank Fix: Hunger, Capitalism and Humanitarian Reason
}

\author{
Joshua Lohnes
}

Drawing on a five-year institutional ethnography of Humanitarian Food Networks (HFNs) in West Virginia, this dissertation explores the moral, political and economic place of the food bank in the corporate environmental food regime. I develop the concept of the food bank fix to theorize the paradoxical relationships between the state, the shadow state, food corporations, local charities and food banks that tie HFNs across the United States together through humanitarian reason. I argue that food banks damp the grinding contradictions of a society awash in food surpluses even as a significant proportion of the population remains at risk of hunger. To buttress this argument, I analyze the geographic process through which the moral impulse of those working to address hunger at the local level is subordinated to institutional logics that resolve crises of overproduction and manufactured food scarcity for a globalized and increasingly integrated food system. I demonstrate how diffuse powers from across this system become concentrated and negotiated at the food bank scale, where an awkward combination of altruism, profit seeking, compassion and rulemaking maintains humanitarian feeding lines in place and linked across space. Theorizing the food banking fix shines a light on one of the glaring contradictions in our food system, namely that regulating food surpluses is itself generative of the food scarcity essential to market rationalities. 


\section{Acknowledgements}

I am grateful to all those who shaped this research into the thoughts that I present in this manuscript form. A special thank you to food charity directors who took time out of their busy schedules to help me understand the complexity of their work. Thank you to staff at Mountaineer and Facing Hunger food bank for trusting me to study and represent your organizations, and for providing feedback and correction along the way.

Members of Conscious Harvest Cooperative in Morgantown kept my thinking on alternatives to dominant charitable food models at the forefront of my mind throughout this project and helped advance my thinking on moral economies, value, gifts, solidarity and mutuality within our complex food system. Special thanks to Dewey, Ted and Mary Hastings for making such a project possible and to Justin Power, Annie Stroud, Andrew Sylvester, Anna Withrow, Allyson Hoch, Megan Govindan, Adam and Kendra Webster, Rick Landenberger, Evan Fedorko, Ashley Reece, Karen Allen, Christine and Ryan Wallace, who all helped shoulder the burdens of my idealism.

This research would have been impossible without the wonderful people in the WVU Food Justice Lab. Many were there for the planting, watering and pruning of the WV FOODLINK project. The fruits of this collective ethnography are theirs as much as mine. Chad Spade, Derek Stemple, Ally Sobey, Tyler Huling, Jessica Foster, Frank Lafone, Clinton Davis, Dillon MuhlyAlexander, Luisa Diaz-Torres, Hilary Kinney, Jessica Crum, Colin Lopez, Tyler Cannon, Gerardo Valera, Rebecca Speer, Amanda Stoner, Caleb Davis, Mohamed Ali, Zachary Summerfield, Sarah Campbell, Jed Debruin, Heidi Gum and Alanna Higgins it has been a pleasure working with you. A special acknowledgement for Amanda Marple and Thomson Gross for co-navigating the intersection of work and graduate school in the lab with me. Greg Elmes' digital cartography class brought us together in Fall 2014 for the what became the long haul and I'm grateful for that too.

I also want to acknowledge the funders that made WV FOODLINK possible starting with Kim Tieman at the Benedum Foundation who first understood the potential of mapping the charitable food landscape in West Virginia for food system change. Thanks also to Cyndi Drennan and Renee Steffen at the Sister's Health Foundation, Bob Boone at the McDonough foundation and Marian Clowes at the Parkersburg Area Foundation. Thank you to all those involved in securing the funds for the USDA Appalachian Foodshed Project, and for helping me to think about this project in light of the many other food access initiatives at the regional scale.

My graduate colleagues provided joy and helpful relief in the midst of material and institutional precarity. Christabel Devadoss, Dave Knieter, Park Muhonda, Maingi Solomon, Jenn Smith, Clinton Davis, Paul O’Keefe Cate Johnson, Kevin Kuhn, Sera Matthews, Josh Wixom, Jessica Dewitt, Jon Burkhart, Kristin Degraauw and Alex Dye I'm thankful that you were there. Along this dissertating journey I also benefited from the counsel of those who had been on it before. Thank you to Jay Aultman-Moore, Joel Beeson and Trey Dunham for providing perspectives on life from the other side. Geography faculty at WVU also helped calm the tremors 
and anxiety of the neoliberal academy. Thank you for the collegiality and for inviting me to balance this work with all of life's other priorities.

Members of my dissertation committee were a constant presence throughout this exercise. Adam Pine, thank you for taking the time to advise me when we happened to be in the same place, despite the distance you have been a formative part my thinking. Cheryl Brown, thank you for inviting me to work on the Appalachian Foodshed Project and sharing an interest in sustainable food futures in West Virginia. Maria Perez, thank you for building confidence in the legitimacy of my ethnographic endeavor and for the regular writing check-ins. Trevor Harris, thank you for teaching me how to think spatially and demystifying quantitative data. Karen Culcasi, thank you for recruiting me to WVU, training me as a geographer and helping me reconcile my research journey from Sinai to West Virginia. Bradley Wilson, thank you for providing me with the intellectual and institutional mentorship I needed to see this project through. I feel privileged to work and learn alongside you, and for the friendship that we've developed in the process. Your hope and determination to make the road by walking is inspiring.

Thank you to my family who loved me so well throughout this process. Jenna thanks for co-laboring through encouragement, patience and a willingness to carry the emotional and material load when I felt I couldn't go on. Evie-Louise, Elias and Jude you kept me grounded in the rich reality of everyday life and constantly reoriented my priorities toward my values. I'm thankful that we've come to call West Virginia home.

I thank God from whom all blessings flow. 


\section{Table of Contents}

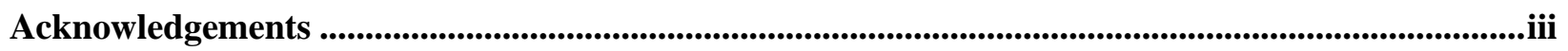

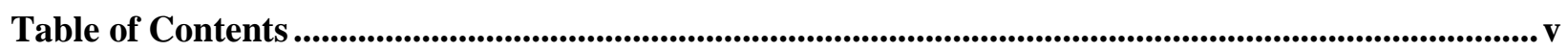

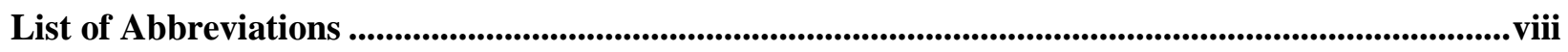

List of Tables \& Figures ..........................................................................................................................................

List of Interviews and Participant Observation .......................................................................................

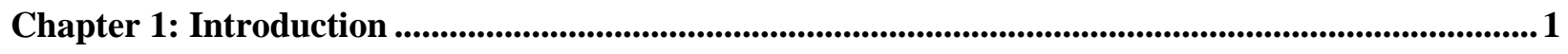

I. Problem Statement and Research Questions ................................................................... 1

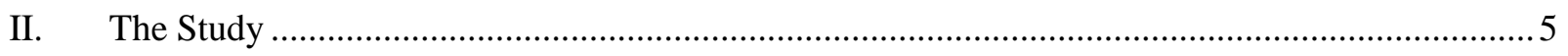

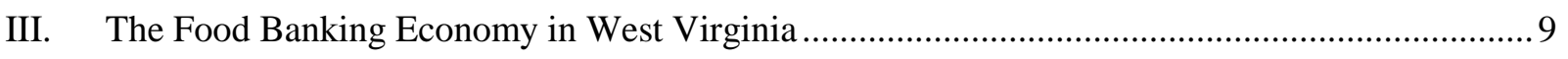

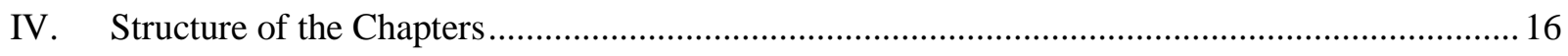

Chapter 2: Between Surplus and Scarcity: Theorizing the Food Bank Fix ........................................24

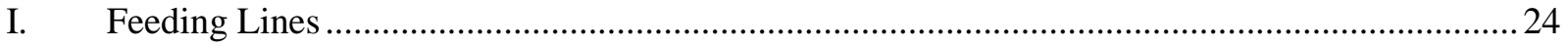

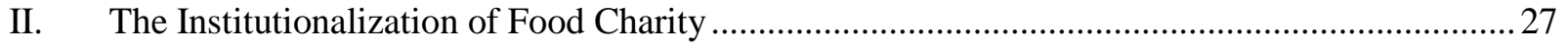

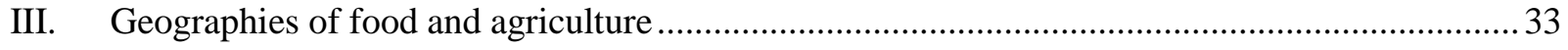

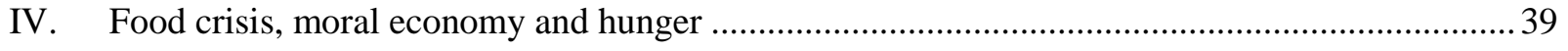

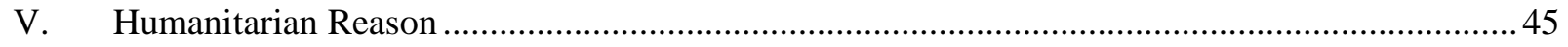

VI. The Food Bank Fix......................................................................................................... 49

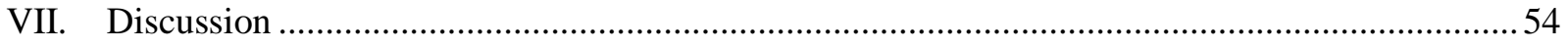

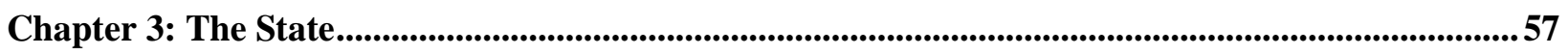

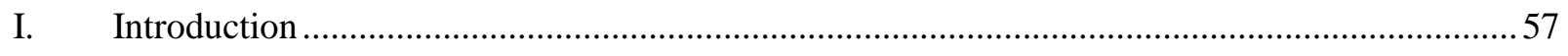

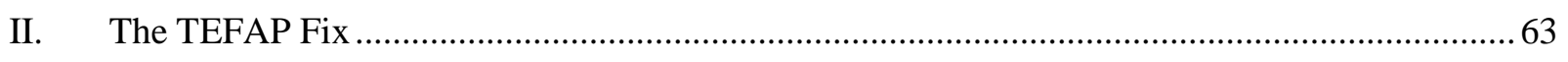

III. Nutrition Entitlement, the Farm Bill and Funding ................................................................ 70

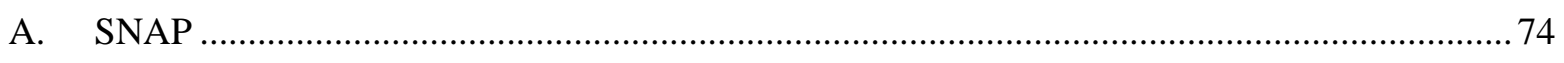

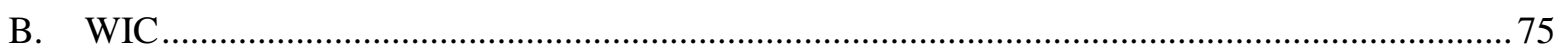

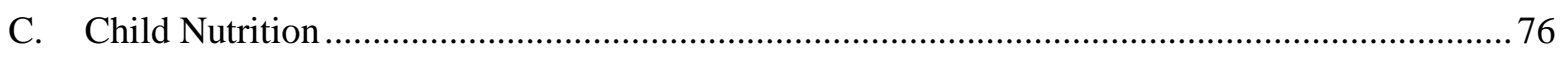

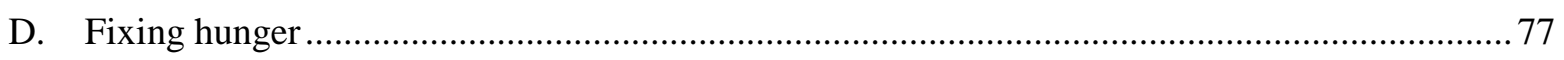

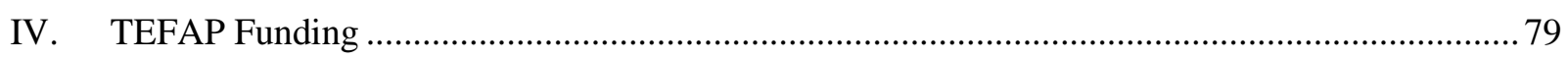

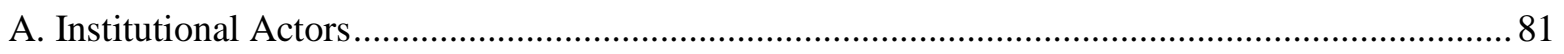

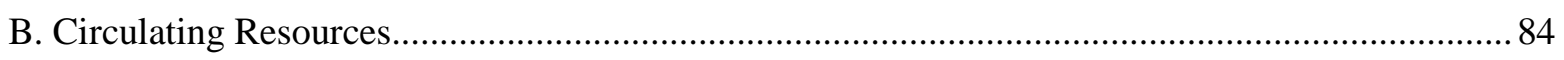

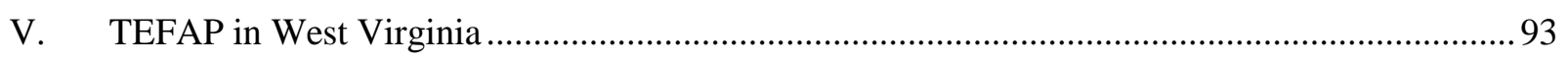

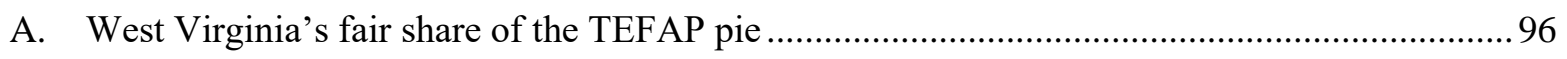




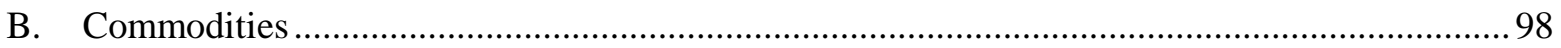

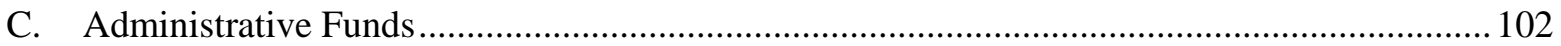

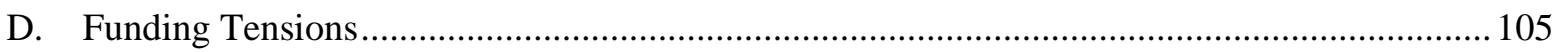

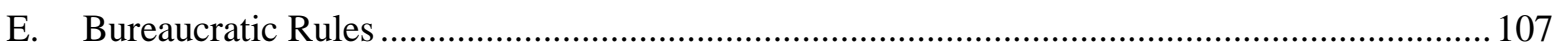

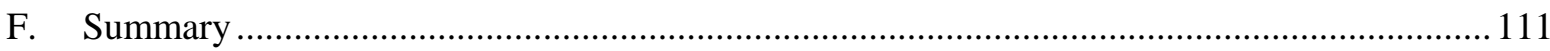

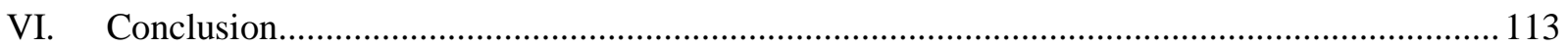

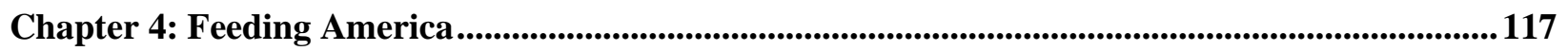

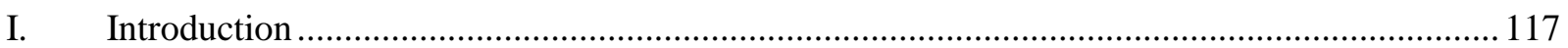

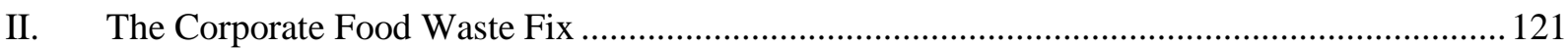

III. Rolling out Corporate Hunger Relief ............................................................................... 125

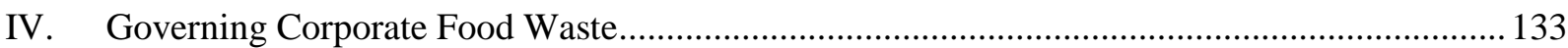

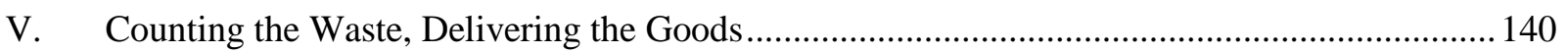

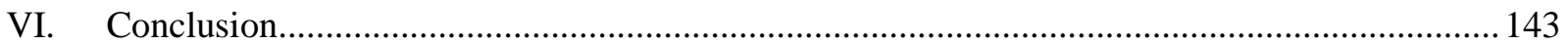

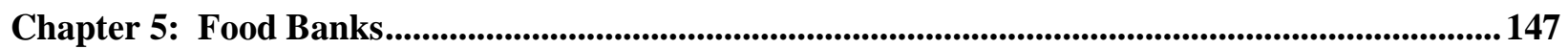

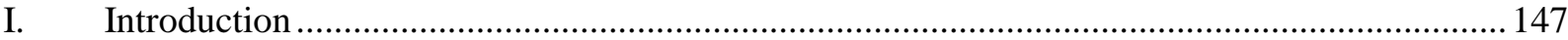

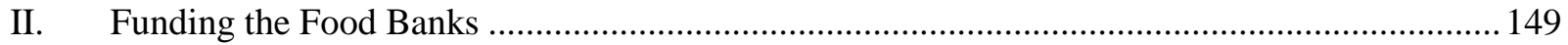

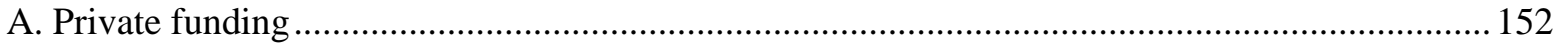

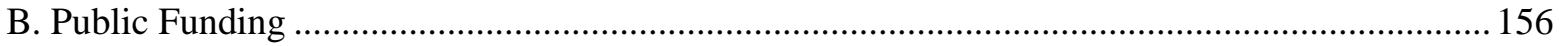

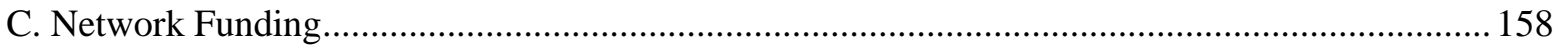

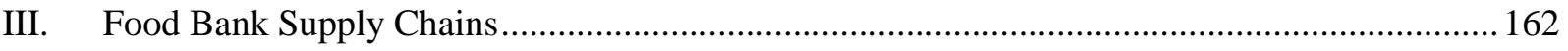

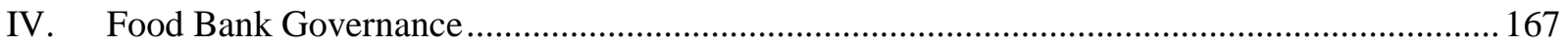

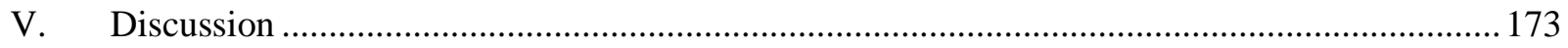

Chapter 6: Local Food Charities ..................................................................................................................................... 177

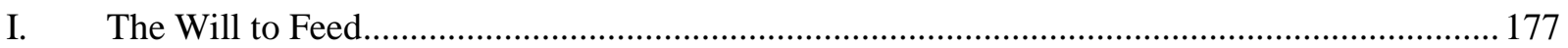

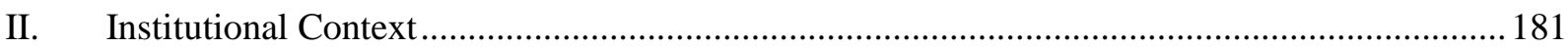

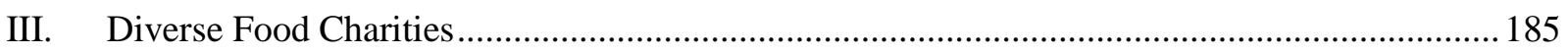

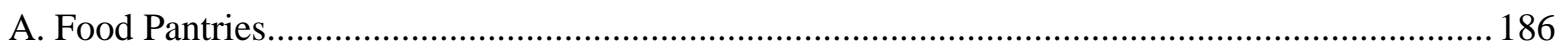

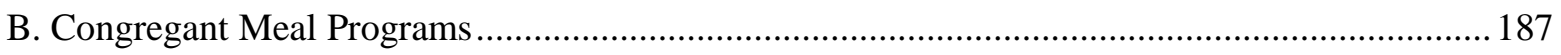

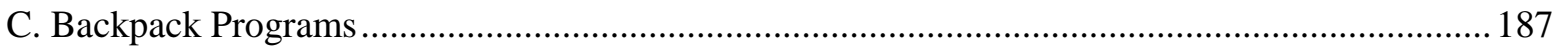

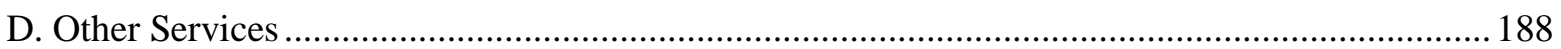

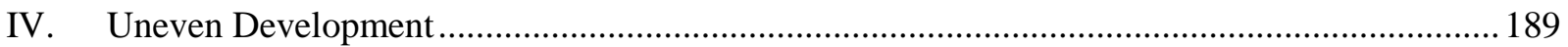

V. Portals and Barriers to Food Waste Revaluation...................................................................... 194 


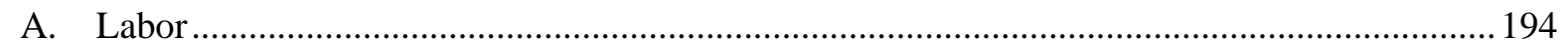

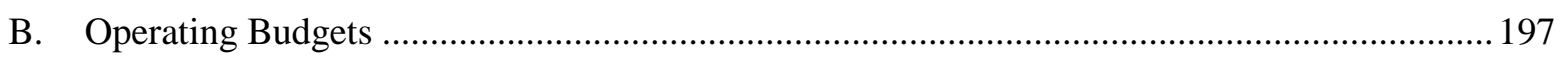

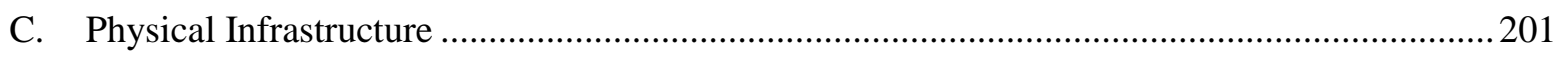

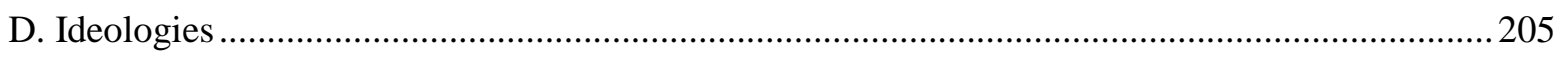

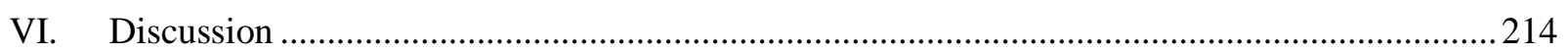

Chapter 7: Overcoming Barriers: The Spatial Strategies of the Food Bank Fix ..............................217

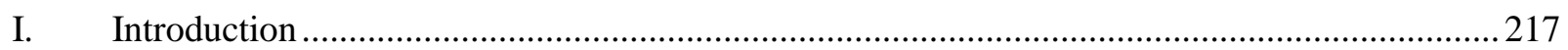

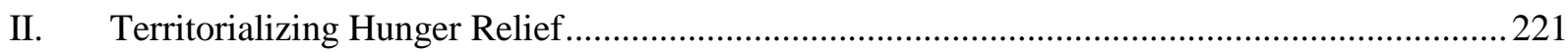

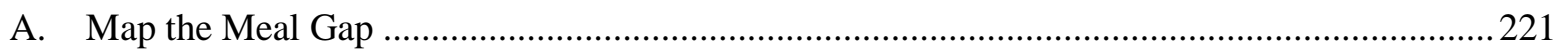

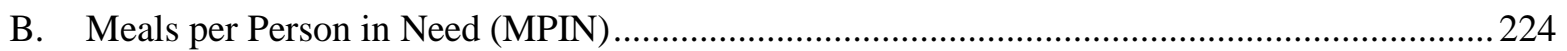

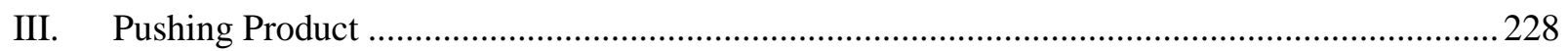

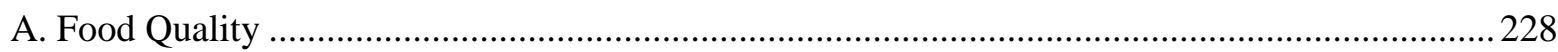

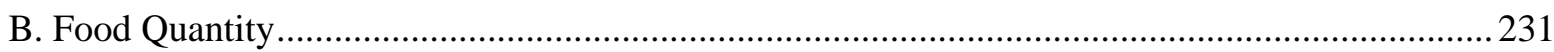

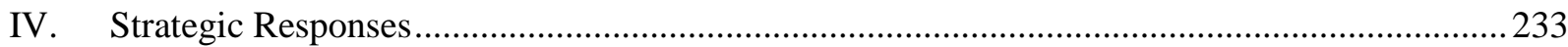

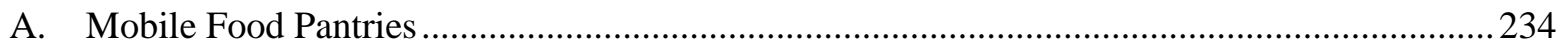

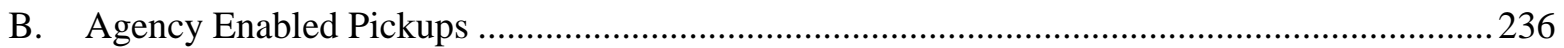

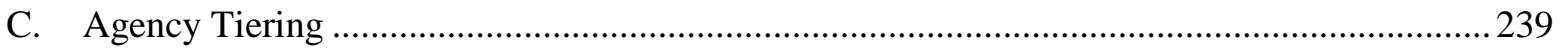

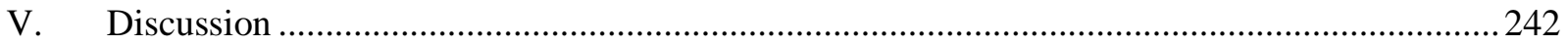

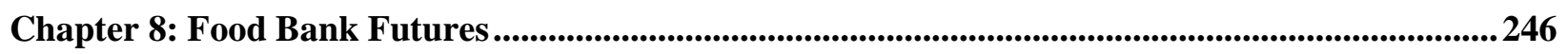

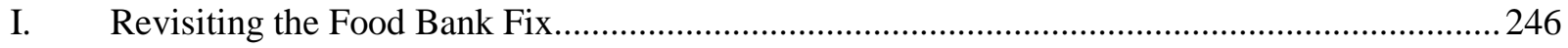

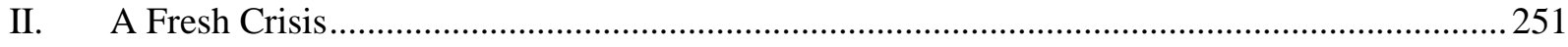

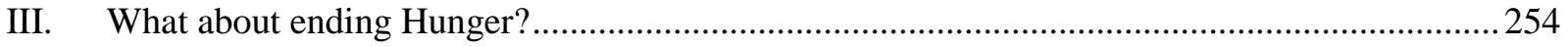

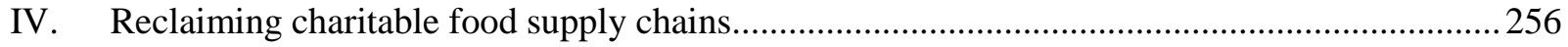

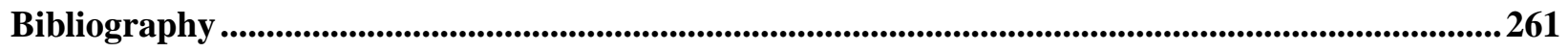




\section{List of Abbreviations}

AGAR

ARRA

AMS

BLS

$\mathrm{CCC}$

CEP

CFSM

CNP

CPS

CSFP

CSR

DGA

FHFB

EFO

ERS

F2E

FA

FAO

FAR

FDPIR

FNS

FRAC

FSA

GIS

HFN

HUD

I\&R
Agricultural Requisition Regulations

American Recovery and Reinvestment Act

Agricultural Marketing Service (USDA)

Bureau of Labor Statistics

Commodity Credit Corporation

Community Eligibility Provision

Core Food Security Module (US Census)

Child Nutrition Program

US Census Current Population Survey

Commodity Supplemental Food Program

Corporate Social Responsibility

Dietary Guidelines for Americans

Facing Hunger Food Bank

Emergency Feeding Organization

Economic Research Service (USDA)

Foods to Encourage

Feeding America

United Nations Food and Agriculture Organization

Federal Acquisitions Regulations

Food Distribution Program on Indian Reservations

Food and Nutrition Service (USDA)

Food Research Action Council

Farm Service Agency (USDA)

Geographic Information System

Humanitarian Food Network

US Department of Housing and Urban Development

Huntington Public Library - Information and Referral 


$\begin{array}{ll}\text { IE } & \text { Institutional Ethnography } \\ \text { IRS } & \text { Internal Revenue Service } \\ \text { LFC } & \text { Local Food Charities } \\ \text { PATH } & \text { Protecting Americans Against Tax Hikes } \\ \text { PROWA } & \text { Personal Responsibility and Work Opportunity Reconciliation Act } \\ \text { MMG } & \text { Map the Meal Gap } \\ \text { MPIN } & \text { Meals Per Person in Need } \\ \text { MFB } & \text { Mountaineer Food Bank } \\ \text { NSIP } & \text { Nutrition Services Incentive Program } \\ \text { NRE } & \text { Natural Resources and Environment (USDA) } \\ \text { NSLP } & \text { National School Lunch Program } \\ \text { PPIP } & \text { Pounds per Person in Poverty } \\ \text { QPR } & \text { Quarterly Poundage Report } \\ \text { RFP } & \text { Request for Proposal } \\ \text { SBP } & \text { School Breakfast Program } \\ \text { SDDP } & \text { Special Dairy Distribution Program } \\ \text { SNAP } & \text { Supplemental Nutrition Assistance Program } \\ \text { TANF } & \text { Temporary Assistance for Needy Families } \\ \text { TEFAP } & \text { The Emergency Food Assistance Program } \\ \text { USDA } & \text { United States Department of Agriculture } \\ \text { WBSCMS } & \text { Web Based Supply Chain Management System } \\ \text { WIC } & \text { The Special Supplemental Nutrition Program for Women, Infants } \\ \text { WVDA } & \text { West Children } \\ \text { WVDHHR } & \text { West Virginia Department of Health and Human Resources } \\ & \end{array}$




\section{List of Figures \& Tables}

Figure 1-1: The Humanitarian Food Network in West Virginia...............................................12

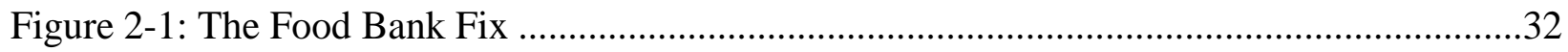

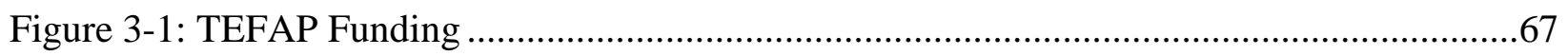

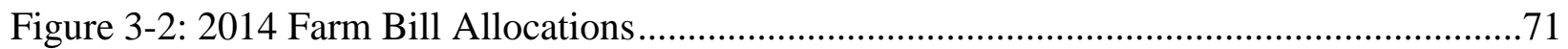

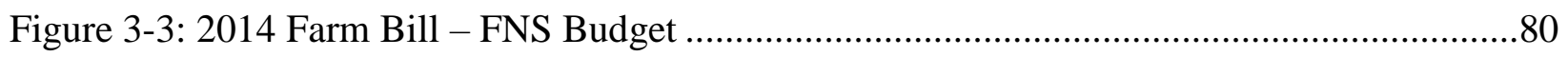

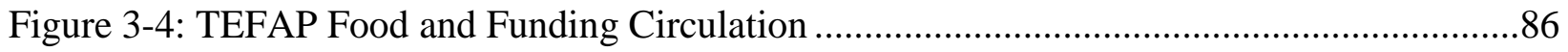

Figure 3-5: TEFAP Agencies - Number of Households Served/Month ..................................96

Figure 3-6: TEFAP Commodities in West Virginia (FY 2017) ...........................................100

Figure 3-7: Vendors fulfilling WVDA TEFAP orders (FY 2017) ........................................101

Figure 3-8: WVDA administrative disbursements to WV Food Banks 2005-2014 ..................103

Table 4-1: Feeding America Leadership and Partnership Network......................................123

Figure 4-1: Corporate Food Donations in West Virginia by Source .....................................129

Figure 4-2: Pounds received by FA network since Bill Emerson Good Samaritan Act .............132

Table 4-2: Feeding America Member Contract .................................................................134

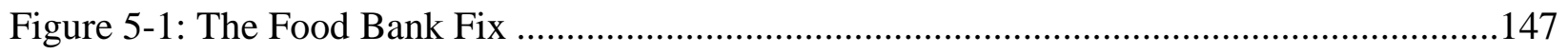

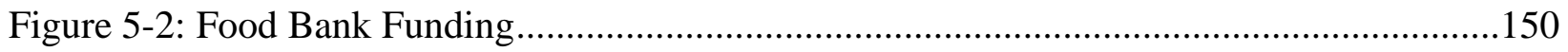

Table 5-1: WV Food Bank Funding by Source ..............................................................151

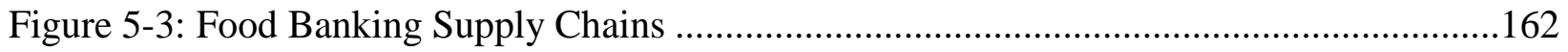

Figure 5-4: Pounds Received by Food Banks in West Virginia - All Food Sources ..................163

Figure 5-5: Food Sourcing Mix in West Virginia Food Banks ............................................165

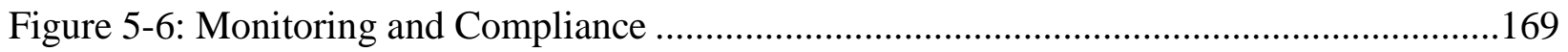

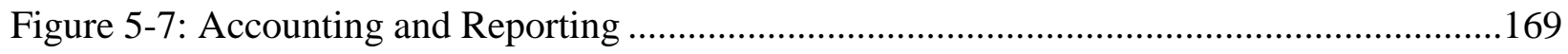


Figure 5-8: Food Bank Territories in West Virginia

Figure 6-1: WV Local Food Charities opened by year 180

Figure 6-2: WV LFCs by type and median participation 185

Figure 6-3: Non-Food Services offered by LFCs in West Virginia. 189

Figure 6-4: Uneven Development and differentiated charitable food environments 190

Figure 6-5: LFC Food Sourcing Strategies in 2016.

Figure 6-6: LFC Staffing Capacity 195

Figure 6-7: LFC Budget Expenditures. 198

Table 6-1: LFC Operating Capacity 199

Figure 6-9: LFC Annual Budget. 200

Figure 6-10: LFC Funding Sources 169

Table 6-2: LFC Infrastructure .201

Figure 6-11: Differentiated Access to Charitable Food Resources among LFCs .207

Figure 6-12: Wood County Emergency Food Co-Op District Service Boundaries. .211

Figure 7-1: Feeding America Compliance Report. .218

Figure 7-2: Map the Meal Gap. .222

Figure 7-3: Pounds per Person Required to Meet PPIP/MPIN Targets..... .226

Figure 7-4: Pounds of Retail Food Waste Recovered by WV Food Banks. .235

Figure 7-5: LFCs authorized to source food from Feeding America retailers. .237 


\section{List of Interviews and Participant Observation}

Food Bank (FB) Interviews/Meetings

1. Facing Hunger -5.14 .14$

2. Facing Hunger -6.19 .14$

3. Facing Hunger -7.15 .14$

4. Mountaineer -8.8 .14$

5. Facing Hunger and WVDOA -11.3 .15$

6. Mountaineer - 7.18.16

7. SEO Foodbank -2.22 .17$

8. Facing Hunger -3.09 .17$

9. Facing Hunger -5.12 .17$

10. Mountaineer -6.28 .17$

11. Mountaineer and Facing Hunger- 10.2.17

12. Mountaineer - 12.19.17

13. Mountaineer and Facing Hunger -10.9 .18$

\section{Local Food Charity (LFC) Interviews}

1. Scott's Run Settlement House

2. St. Ursula Food Pantry and Outreach

3. Barnett Healthy Food Pantry -6.19 .14$

4. Cabell County FRN -6.20 .14$

5. Harvest Time Church and Shelter - 7.16.14

6. Manna Meal - 7.16.14

7. Huntington Information and Referral -7.15 .14$

8. Huntington City Mission -7.15 .14$

9. Wood Co Emergency Food Cooperative - 10.13.15

10. Arnettsville food pantry -3.22 .17$

11. Christian Help food pantry -3.29 .17$

\section{USDA and State Agency Interviews}

1. WVDA Food Distribution Program: Melanie Paul \& Melinda Skaggs-4.3.15

2. KYDA Food Distribution Program: Kevin Peach - 8.15.15

3. USDA - AMS: Commodity Procurement -10.27 .15$

4. USDA - FNS: Household Commodity Programs - 3.6.17

\section{Feeding America (FA) Interviews}

1. Director, Retail Partnerships - 4.23.15

2. Product Sourcing Manager -5.10 .16$ 


\section{Participant Observation}

1. Monongalia County Food and Hunger Committee: 05/13 - 12/17

2. Conscious Harvest Cooperative: 05/13 - 12/17

3. Parsley Bottom Mobile Food Pantry -7.19 .14$

4. Mountaineer Food Bank Agency meeting - 5.1.15

5. Taylor County focus group - Project Hop2e - 5.8.15

6. Food for Preston -5.18 .15$

7. Logan County ministerial association -6.19 .15$

8. Parkersburg Backpack Group - 10.13.15

9. USDA AMS food contractor and supplier industry meeting -10.27 .15$

10. FHFB - WVDA meeting: 11.03 .15

11. FHFB agency meeting: 11.20 .15

12. MFB Hunger Summit - 8.4.16

13. Manna Meal Kitchen and Community Garden -11.4 .16$

14. WVU mobile food pantry event -9.21 .16$

15. Mason Dixon mobile food pantry event -10.26 .16$

16. Food for Preston - 11.28.16

17. FRAC conference - 3.5.17 - 3.7.17

18. MFB Food Bank Hunger Summit - 8.8.17

19. Closing the hunger Gap Conference - 9.11.17 - 9.13.17

20. Monongalia County Pantry Plus Mobile Food Giveaway - 12.13.17

21. MFB Hunger Summit - 8.1.18 


\section{Chapter 1: Introduction}

\section{I. $\quad$ Problem Statement and Research Questions}

The Facing Hunger Food Bank (FHFB) is housed in an old cigar factory in Huntington, West Virginia. The building is one of many warehouses butting up against the CSX rail lines that cut through the city's former manufacturing quarter, a now drab landscape that can be read as one of the many stories of the region's post-industrial malaise. I first set foot there in the spring of 2014 after a year of conducting research among community-based feeding programs housed in church basements and community centers. It was immediately clear that FHFB was a very different institutional expression of the charitable food provisioning I had come to know at the local level. Outside, a fleet of trucks co-branded with corporate sponsor logos were parked at the loading docks. Warehouse staff loaded uniform pallets of canned food onto one landing even as another arrived with a bulk load of unsorted donations from a large grocery chain.

Inside I was greeted by a secretary sitting behind a glass wall. She requested that I record my name and affiliation in the visitor log. I received a nametag and was lead into a conference room where I waited for my scheduled meeting with the executive director. Like the warehouse, the office space was bustling, and I could immediately feel the intensity of a work environment that demanded rigor and professionalism from its staff. I learned about food banking territories, environmental peer groups, accounting systems, surplus food markets, performance metrics, institutional audits, agency cost sharing and a host of terms and concepts that provided a glimpse into a complex hunger relief supply chain. Our meeting was a deluge of new information, so much so that it was difficult to wrap my mind around all the different services performed by food banks and the roles that each staff member played in resolving the demands of food donors, funders and 
other institutional partners. As one of the food bank employees later lamented: "Only those working in food banking really understand the type of work that we're doing every day. There is no good way to communicate all that I do; it just doesn't make much sense to folks on the outside.” (P.O. 8, 10.13.15).

Forty-six million people regularly access free food through private charities (Winefield et. al, 2014). In 2016, 4.5 billion pounds of food was diverted through a network of 200 food banks, a fivefold increase in just 20 years. However, a recent USDA report on food insecurity offered the hopeful news that the rates of hunger that seem to drive food banking logics are decreasing across the country (Coleman-Jensen et. al, 2016). Indeed, paradoxically food banks are drawing up strategic plans to significantly increase their capacity to recover and distribute more food, investing in new infrastructure to accommodate the growing amount of food waste donated by the public and private sectors. The 2014 farm bill legislated a 35\% increase in emergency food commodity procurements (US Congress, 2014) and food retailers increased their donations by 14\% in 2015 (Feeding America, 2015).

The Facing Hunger Food Bank (FHFB) is a critical broker between the national bureaucratic mandates of government, food donors and the needs of each of the 200 local food charities (LFCs) that it serves. As a key agent within a humanitarian food network that distributes aid to individuals and families in need of nutrition, FHFB is a lifeline for people across southern West Virginia. Yet, as I argue throughout this dissertation, food banks like Facing Hunger are more than humanitarian food agencies that provide relief for the hungry; they are fundamental to the processing and revaluing of food surpluses across the agricultural, manufacturing and retail sectors in the United States. While food banks are often framed in terms of resolving hunger, they 
are also charged with fixing a very different problem; recovering food that cannot be sold in the marketplace and redistributing it to local food charities (LFCs).

Two institutions provide access to most of this food. First, the United States Department of Agriculture (USDA) purchases surplus agricultural commodities through The Emergency Food Assistance Program (TEFAP) and allocates a portion to each state. Second, large food corporations donate their food waste to Feeding America (FA) who certifies and empowers its member food banks to redistribute the surplus on their behalf. Food banks warehouse and deliver this industrial food waste. They attract state and philanthropic capital into a logistics infrastructure that can process increasing amounts of surplus food through investments into refrigeration units, trucks, offices, software, marketing and fundraising campaigns. Food banks process food receipts, financial transactions, bills of lading organizing the logistics of food waste recovery and redistribution through a vast network of LFCs housed within faith-based and community centers across the United States.

The dramatic expansion of food banking over the past twenty years in the U.S. and globally has raised alarm bells amongst scholars concerned about the growing reliance of meeting the needs of food insecure individuals and families on the basis of short-term emergency food relief. These concerns are rooted in a long-standing critique of food charity as a strategy for welfare reform and reducing federal entitlements. Janet Poppendieck's (1998) Sweet Charity offered an early and cogent critique of food charity as a "moral safety valve" (p.9) for a society coming to grips with the social outcomes of neoliberal restructuring and economic crises. Her work identified the moral power of fighting hunger through food charity and the tendency of charities like food banks to 
depoliticize debates about poverty and social inequality. ${ }^{1}$ Numerous scholars point to the relationship between hollowing out of state entitlement programs in the U.S. and the rise of food banking across the United States since the 1970s and its impacts on framing charity as a solution to hunger (McIntyre et. al, 2016, Riches and Silvasti, 2014). Yet, as I argue, concerns about the limits of food banking to address poverty and nutritional disparities obscures a less visible dynamic at work: the problem of agro-industrial overproduction and the supply side factors driving the growth of the food banking economy.

Although food banks are charged with resolving the problem of hunger, I argue that they are also key sites for revaluing food waste and resolving crises of overproduction under capitalism (Henderson, 2004, Lindenbaum, 2016, Lohnes and Wilson, 2018). The institutional dynamics involved in this revaluation process are still poorly understood. Drawing upon a five-year institutional ethnography (Billo and Mountz, 2016) of humanitarian food networks (HFNs) in West Virginia, my research explores the moral, political and economic place of the food bank in the capitalist food system. The dissertation analyzes the relationships forged between the state, food corporations and civil society that promote and maintain the food banking economy and how the will to feed is driven by humanitarian reason (Fassin, 2011). To explain how the food bank is designed to resolve crises of overproduction (surplus) and hunger (scarcity) while preserving capitalist hegemony in the food system, I develop the concept of the food bank fix. I demonstrate how diffuse powers from across this system become concentrated and negotiated at the food bank

\footnotetext{
${ }^{1}$ While academic debates persist over whether food charities should be reformed or eliminated, food banks and LFCs remain well entrenched and continue to play an important role negotiating the violence of neoliberal austerity and the progressive possibilities of care-based economies (Cloke, 2016; Pine, 2016).
} 
scale, where an awkward combination of altruism, profit seeking, compassion and rulemaking maintains humanitarian feeding lines in place and linked across space.

Building upon and extending the critique of food banks as insufficient social safety nets, my theory of the food banking fix shines a light on another glaring contradiction of food banking, namely that governing the distribution of food surpluses is essential to capitalist food market stability and profitability. The governance apparatus structuring charitable food supply chains, hidden behind a veneer of nutritional assistance and corporate social responsibility, conceal the capitalist market logics driving the expansion of institutionalized food charity. Like the capitalist food system they are embedded within, food banks operate in a continual state of crisis, particularly in West Virginia where food environments are uneven and philanthropic resources are reaching their limits (Lohnes and Wilson, 2018). The industrial food waste donated to food banks for redistribution is increasing, albeit sporadic and largely unpredictable. Despite their work expanding the availability of donated foods, hunger is not declining but increasing in places like West Virginia. Indeed, even among local food charities and some food bank staff, the frenetic and unsustainable work of revaluing food waste as hunger relief is raising hard questions. Who is benefiting from increases in these food flows? Where are these foods coming from, where are they going and how are they accessed by the different parties involved?

\section{The Study}

My study was designed to understand the administrative structures that shape access to financial and food resources across the many different organizations that make up the food banking economy. Drawing on a rich history of scholarship known as institutional ethnography (IE), the methodology builds on geographical research that seeks "to more fully understand the many 
structures, effects and identities working through institutions as territorial forces" (Billo and Mountz, 2016, p.200). Ethnographic inquiry relies on a long-term commitment to people and places, the cultivation of relationships of trust and mutual obligation through lived experience and willingness to enter the social relations under investigation rather than observing them as an outsider looking in. The practice reveals the processes, meanings and discourses that motivate groups of people to maintain or contest the social order, starting from the abstract messiness of relationships and power dynamics, and working toward concrete concepts to explain historical and geographical complexity (Herbert, 2000; Hardt, 2004).

While ethnographic inquiry has a rich history in geography, IE is indebted to the sociologist Dorothy Smith (1987) who developed the concept of "ruling relations" to explain how institutions significantly affect people's lives through administrative regimes. The methodology is grounded in a bottom up approach to analyzing power through a commitment to engaging with people negotiating complex social activities. Geographers drawing from this methodology have "studied up" to understand the socio-spatial effect of institutions as varied as the Los Angeles police department (Herbert, 1997), the United Nations High Commission on Refugees (Hyndman; 2000), the U.S. border patrol (Nevins; 2001), conservation organizations (King, 2009), Federal immigration bureaucracies (Mountz, 2010), corporate social responsibility programs (Billo, 2012), and the U.N. agency fighting piracy in Somalia (VandeBerg, 2013).

Ribot's (1998) IE of charcoal supply chains in Senegal is one that mirrors my own approach. Bringing disparate actors into relationship across the charitable food supply chain, I studied the food bank as a site where diffuse powers shaping the politics of emergency food relief are concentrated and negotiated. Food banks are spatial entities, central hubs of a national food recovery infrastructure. They organize food waste recovery and redistribution transactions across 
space but cannot be understood outside of the many other organizations structuring their work at different scales. Because each institutional scale has consequential effects on the politics of the food banking economy, understanding them involved a multi-sited center-and periphery approach to data collection. I moved across sites to collect both quantitative and qualitative data. The mixed methods (Elwood, 2009) included participant observation, interviews, archival research and spatial analysis.

The opportunity to transcend organizational boundaries in this way unfolded over a fiveyear process developing WV FOODLINK, a public geography project that fosters food access planning dialogues across West Virginia. I first conducted a community food security assessment in Monongalia county alongside the Monongalia County Food and Hunger Committee, a group of LFC directors and their allies. I regularly attended their monthly meetings to observe the work of organizing food drives, pooling resources and communicating with their donors. I also conducted interviews with agency directors to understand the motivations and challenges of operating local hunger relief charities and to learn about different perceptions of food insecurity in the county.

Following this county level work, I developed a close working relationship with the state's two regional food banks who were enthusiastic at the prospect of gaining geographic visibility over their network of agencies ${ }^{2}$. The WV FOODLINK team surveyed and geocoded the 550 LFCs affiliated with the food banks. A 95\% response rate provided data on LFC staffing and volunteer resources, operational budgets, food and funding sources, storage capacities, service territories and emergency food access pre-requisites. The food banks also provided access to internal datasets, including the amount and types of food distributed to each of their agencies. The geographic

\footnotetext{
${ }^{2}$ Rural food banks usually deliver food at specific pick up points for all LFCs a county to reduce costs of dropping food off to each individual agency. The food banks thus did not know where most of their LFCs were located and welcomed the geographic analysis that WV FOODLINK could provide to their work.
} 
information system I compiled with this quantitative data provided the basis for exploratory spatial data analysis (Anselin, 1999) through which I came to understand food distribution patterns and differences across LFCs specifically in relationship to uneven development (Smith, 1984).

The public engagement inherent to the WV FOODLINK project also opened spaces and conversations that might have remain closed had I not been so intimately involved in co-producing a public resource. As my involvement with the project deepened, so too did my positionality as a researcher. I was solicited by various funders, organizers and political advocacy groups to present our state-wide research findings to their stakeholders. Along with my continued involvement with the food and hunger committee in Monongalia county, I also engaged with anti-hunger groups in Cabell, Fayette, Kanawha, Mingo, Preston, Ohio, Taylor, Wayne and Wood counties. The two food banks also invited me to present at their annual LFC training conferences and to participate in meetings with state officials and other potential funders. Embedding myself within the dynamics and politics affecting food banking networks in West Virginia continued to shape the questions I posed and sought answers to throughout the research process. The expertise, legitimacy and knowledge I built within food banking networks in West Virginia provided access to interview opportunities with institutional actors structuring food banking activities at the national scale.

Because access to food bank resources extends well beyond state borders, my research also extended outside of West Virginia. I conducted semi-structured interviews with federal and state bureaucrats working on USDA commodity procurement, food industry representatives selling food to the US government and FA employees engaged in corporate food sourcing partnerships. I also attended three national conferences that drew charitable food actors from across the country together to collaborate on anti-hunger strategies. Participant observation and interview opportunities at these meetings, along with archival data collected over the course of the research 
process provided insights into the wider institutional dynamics facing the HFN in the United States in general and West Virginia in particular.

I began my institutional ethnography at the local scale of emergency food providers and moved up through the food bank and toward national institutions, seeking answers to new questions as they arose. Rather than focusing on a single organization, I studied the two food banks in West Virginia relationally in conjunction with the many parties involved in charitable food transactions. These include LFCs working to distribute free food at the community level, state and federal bureaucracies regulating the transfer of surplus agricultural commodities and FA certification at the national level. I now turn to a justification of the West Virginia case study placing the dynamics shaping the food banking economy there in the state's socio-economic context.

\section{The Food Banking Economy in West Virginia}

West Virginia is ranked as one of the most distressed states by socio-economic studies tracking well-being including health, income, education and quality of lived environments (e.g. Gallup-Healthways, 2013). This is not a recent phenomenon. The state has historically had one of the highest food insecurity rates in the country. John F. Kennedy proposed to reinstate the food stamp program during a 1959 campaign stop in West Virginia. Similarly, Lyndon Johnson's tour through the state was a political rallying cry for the federal war on poverty of the 1960s. More recently, Jamie Oliver's controversial reality TV show "Food Revolution" centered the fight against unhealthy eating and obesity in Huntington, WV, placing the burden of poor food choices on residents of the "fattest city in America" rather than the obesogenic environments produced by 
inequalities in the wider food system. (Slocum et. al, 2011). West Virginians then have long served (and suffered) as a poster-children for anti-poverty, anti-hunger and now anti-obesity solutioning.

Interventions by government programs and activists have not resolved the structural issues contributing to food insecurity in the state. Today, a long investment decline in the once strong coal, chemical and manufacturing sectors is exacerbating food insecurity problems. Jobs in these sectors have been mostly replaced by low wage and/or seasonal service work. The latter follow the whims of a sporadic tourism trade meant to stave off the state's dependence on extractive industries. The latest census data reports nearly a 5 th of people living below poverty and the state continues to feel the effects of the great recession. As my ethnography was unfolding in 2015, West Virginia was the only state with negative job growth and the country's highest unemployment rate at $6.9 \%$. Labor participation rates are the lowest in the country as many have given up seeking work entirely. Only 53\% of civilians 16 years or older are currently employed or actively seeking employment. The lack of meaningful work opportunities is leading to rapid emigration and population decline, leaving an increasingly ageing population in its wake. $18.2 \%$ of residents are over 65, the highest rate of seniors after Florida and Maine. The state also has the highest percentage of people drawing disability income at 4.15\%. (U.S. Bureau of Labor Statistics, 2015). In the context of this depressed economy, West Virginians are also now facing the starkest opioid crisis in the nation. The social crisis leaves family members caring for dependents left behind by incarceration and overdoses adding further pressures on many household economies.

Household income in West Virginia is a mere $\$ 44,354, \$ 14,000$ below the national median. In 2016 it was thus the second poorest state in the country. Even in places with near full employment, gaps between wages earned and the cost of living are misaligned for the working poor. Along with wage inequality, uneven food environments exacerbate food access problems for 
many residents. Capital flight and demographic shifts lead to grocery store closures in rural towns across the state a desertification of the food retail landscape that adds further time commitment and costs to resident's food sourcing strategies. The latest census data reports nearly a 5th of people living below poverty in the state, and the Food Research Action Council (FRAC, 2016) estimates a $19.5 \%$ food hardship rate, meaning approximately 350,000 people could not cover their food costs at least once over a 12-month period.

In FY 2015, federal food entitlement programs contributed over half a billion dollars (\$589 million) in supplemental nutrition assistance (through SNAP and WIC), free and reduced school meals and emergency feeding programs. Despite few prospects for gainful employment, the factors leading to food insecurity are exacerbated by the state legislature. In recent years a series of draconian laws reducing both labor rights and welfare rolls have passed under the guise of balancing a state budget that faces endemic deficits due to declining coal severance and years of corporate tax evasion. It is within this socio-economic and political context that the HFN in West Virginia must be understood, for it is under tremendous pressure to provide food to an increasing amount of people in need of emergency assistance.

Charities are a critical food sourcing strategy for over 300,000 people in West Virginia, $16 \%$ of the state's population. Two regional food banks in the state deliver food to LFCs spread across a 24,000 square mile territory. Facing Hunger Food Bank (FHFB) in Huntington, is located in a tri-state metropolitan area along the Ohio River and one of the largest cities in the state. It serves LFCs across 17 counties in southern West Virginia, two in Kentucky and one in Ohio ${ }^{3}$. Mountaineer Food Bank (MFB) in Gassaway, is located in a rural town in Braxton county. It

\footnotetext{
${ }^{3}$ LFC data was collected across the 3 counties FHFB services beyond West Virginia borders, but are not included in the scope of this study. FHFB's cross border service area however does provide insights into the way in which state territories affect food banking work.
} 
delivers food to LFCs across 48 West Virginia counties. In 2016 the two food banks collectively distributed 18 million pounds of food from both public and private sources to 550 LFCs (Figure $1-1)$

Both food banks are Feeding America (FA) members, an affiliation that provides them access to large food donors, along with competitive grant opportunities from FA corporate partners. The terms of FA membership delimit each food bank's service area boundary and measures programmatic success across it. Both also contract with the West Virginia Department of Agriculture (WVDA) to distribute USDA commodities provided to the state through TEFAP ${ }^{4}$.

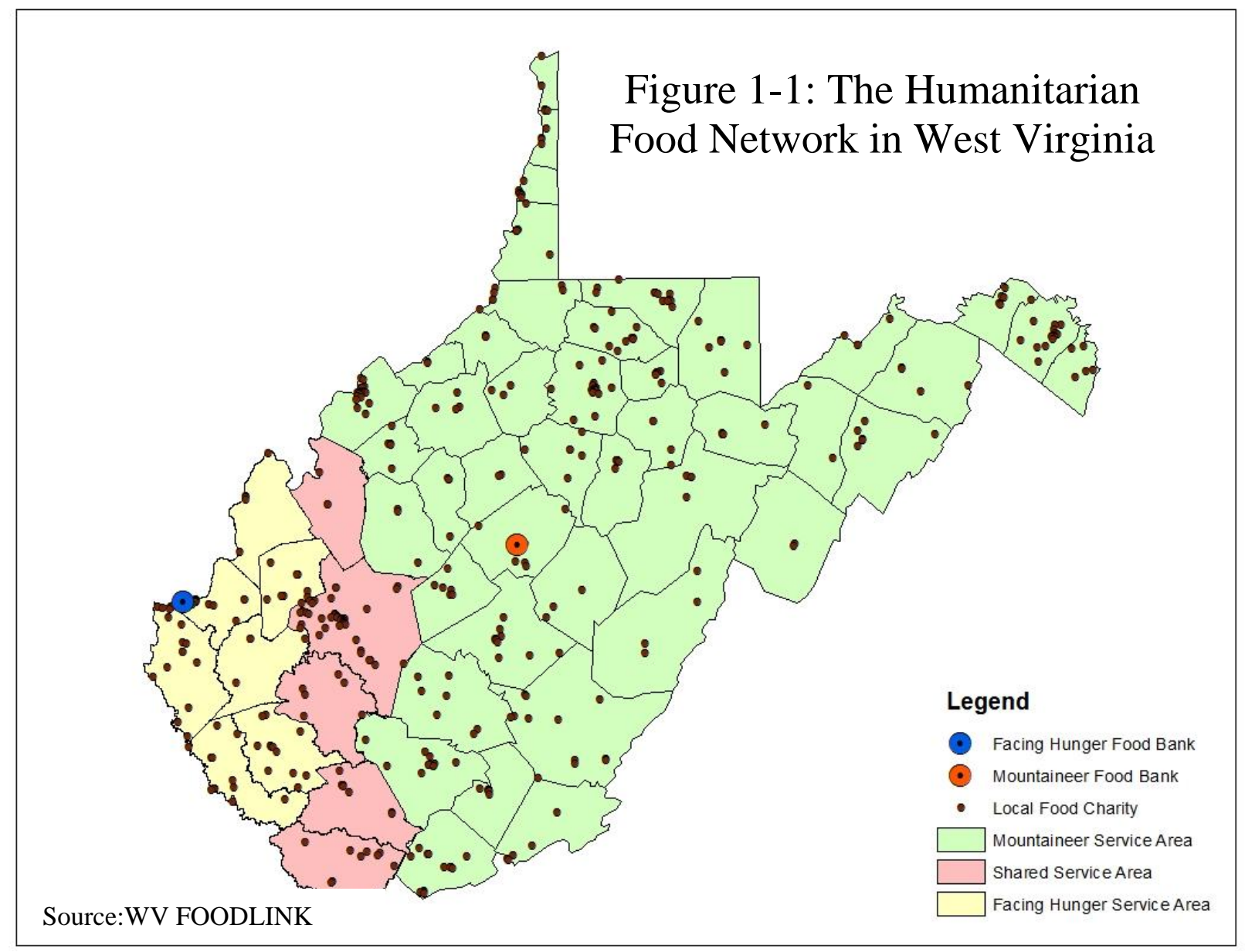

\footnotetext{
${ }^{4}$ The state's two food banks have recently implemented the USDA's Commodity Supplemental Food Program (CSFP) to expand emergency food access to the large population of seniors in need across the state. Because CSFP is currently in a pilot phase in West Virginia the specific effects of this program on the humanitarian food network are not included in the scope of this study.
} 
This public food distribution program defines yet another governance structure for food banks to manage and implement, one also imbued with territorial dynamics.

As large professionalized organizations, the two food banks employ a team of full time staff to manage food sourcing relationships, trucking, warehousing, fundraising, compliance, accounting and other activities involved in operating a charity with million-dollar budgets. Both also focus a significant amount of time on building and maintaining relationships with their local food charities (LFCs). Food banks depend on LFCs to fulfill food orders and ensure that the network remains compliant with the rules set forth in their food distribution contracts with FA and WVDA. Unlike the food banks, the clear majority of LFCs are non-professionalized organizations that rely on volunteer labor to keep their feeding operations in place. The median operating budget of an LFC in West Virginia is $\$ 12,500$, yet the range varies extremely from $\$ 7.5$ million to zero. A few are backed by large anchor organizations that provide a host of social services such as state funded homeless shelters or drug rehabilitation programs. These usually have the resources to pay staff to manage their feeding operations. $35 \%$ of LFCs have at least 1 part-time staff member, the remainder run their programs solely through the 16,000 volunteers mobilized throughout the state to maintain their feeding operations in place. Many staff and volunteers at the LFC level are themselves living on the margins, and some are having trouble keeping up with the increasing administrative demands placed on them by the food bank.

LFCs operate across a highly differentiated geography that includes urban centers and remote rural communities, each negotiating a varying set of factors contributing to food access difficulties encountered by the populations they serve. Like in other places (Pine, 2016), LFCs in West Virginia distinguish themselves in their religious and secular motivations, their perception and relationships to the state, their different understandings of the causes of food insecurity, their 
different ideas of personal responsibility, the different work expectations among staff and volunteers and the different understandings of what constitutes fairness in the food system. Ideologies and individual personalities thus affect the rules and regulations in place at the local level to expand or limit access to emergency food resources. LFCs act in tenuous concert with one another, collaborating and competing, setting rules and breaking them, sharing and hoarding resources.

Not all LFCs are equally dependent on the food bank for their feeding operations. 53 LFCs (10\%) reported that they rely exclusively on food banks to source their food, and a third are at least $80 \%$ dependent. Others are much less reliant on food banks, working with food donors outside of the FA and USDA governance structures. Many also purchase their food stocks, supplementing food bank offerings with choices available in wholesale and retail markets. The combined food budget of all LFCs in the state is an estimated $\$ 10$ million, of which the food banks only capture approximately $8 \%$ through cost share fees. LFCs thus juggle between the food bank, local food drives and food markets to come up with a price/quality/quantity ratio that makes the most sense within the confines of their own institutional capacity.

LFC capacity to fundraise and recruit volunteers also varies tremendously, often informed by the dynamics of uneven capitalist development. This lack of uniformity makes it difficult for food banks to meet projected demand for food in certain places. Food banks counter this problem by operating mobile food pantries that deliver food into counties where brick and mortar capacity is not sufficient to meet their FA mandated Meals per Person in Need (MPIN) distribution targets. Both food banks have also empowered well capitalized LFCs to pick-up retail food waste on their behalf, a decentralization of food recovery operations that further segments LFCs along lines of 
institutional capacity. This transition occasionally produces tensions because it reorganizes the local politics of emergency food provisioning.

Following the national trend, West Virginia food banks more than doubled the amount of food received over the past 15 years from 7.3 million pounds in 2002 , to 18 million pounds in 2016. The overall product mix that year included mostly FA (50\%) and USDA (37\%) foods. The increased amount of food processed by food banks in the state has not been matched by a proportional expansion in funding opportunities to subsidize its distribution. For example, even as TEFAP food allocations have expanded over the past decade, the level of administrative funding has remained flat. This is not unique to West Virginia, across the country TEFAP funding only covers $12-27 \%$ of the costs of running the program (Cabili et. al, 2013). As subcontractors of WVDA, food banks do not receive the full TEFAP administrative allotment either, because the state holds a certain amount of funding to cover its own program expenses. LFCs provide nearly a quarter of West Virginia food bank budgets through cost-share fees. Development staff must then navigate between private philanthropy and grant applications to close financial gaps. Food bank funding streams change from year to year, a fiscal context that makes it very difficult for these organizations to develop anti-hunger strategies and programming that go beyond food recovery.

The food banks pay yearly membership dues to FA to access large private food donors, brand recognition and to receive access to exclusive funding opportunities provided through FA's network of corporate partners. These internal requests for proposals (RFPs) however often push food banks toward programmatic goals that align with donor interests rather than those of the food bank. Mission creep is thus another tension that food banks must negotiate as they work to close budget gaps through grants that are often overtly specific to food industry goals. Corporate and foundation support for food banking work receives a large amount of press and promotion as the 
funds disbursed are often contingent on co-branding obligations. Corporate anti-hunger campaigns make private food industry foundations appear as a major source of revenue for food banks, however charitable contributions from individual donors are the financial backbone of these organizations. Large institutional donors only represented around $30 \%$ of the total private revenue stream in 2016, while MFB and FHFB respectively drew 54\% and 58\% of their private fundraising revenue from a combined 11,450 individual donors.

This overview of the HFN in West Virginia reveals some of the complexities that shape the food bank fix. A significant proportion of the food and money circulating through the network is dependent on the food bank to broker relationships between national institutions providing food and LFCs ultimately distributing it to food insecure households. As the lynchpin of this network, the food bank translates institutional mandates from FA and the USDA for the nonprofessionalized tiers of the shadow state operating feeding programs. Local humanitarian responses to hunger are thus tightly integrated into national bureaucratic structures even though most of the agencies working on the front-lines may not be aware of their place at the far ends of a bureaucracy that is shaped in Chicago and Washington, D.C. This dissertation makes these ruling relationships visible and explains how they come to structure local feeding programs, and indeed the wider moral economy of hunger relief in West Virginia and beyond.

\section{Structure of the Chapters}

The manuscript is organized into eight chapters including this introduction. Five are empirical, book ended by a literature review and conclusion. In chapter two, I draw on theoretical signposts within the literature on geographies of food and hunger that frames food as a central commodity to value relations under capitalism, namely food regime theory (Friedman and 
McMichael, 1989). I link the institutionalization of the food banking fix to the transition from the state driven (or second) food regime toward the corporate (or third) food regime that occurred in the 1980s. I place the rise and institutionalization of food charity within the context of the austerity politics of the neoliberal state and the trend toward highly segmented foodways organized and governed by the private sector.

Existing scholarship on food charity has been helpful to explain its limitations in responding to hunger, and its role in reinforcing the perverse dynamics of a supposedly receding state. I extend this literature by explaining how the food banking fix, as a resolution to crisis in the capitalist food system, is maintained in practice through humanitarian reason (Fassin, 2011). To this end I bring together thinking on the interplay between capitalist crisis, moral economies and food access. I contend that scholars of food charity must remain attentive to the bundle of powers and politics of compassion that structure spaces of vulnerability and economies of care. The ongoing roll-out of the food bank fix is thus not merely a response to the roll-back of public welfare, but a humanitarian technique used to countervail the pressures of the competitive polity organizing the capitalist food system.

Despite the current consensus that food banks are a neoliberal response to a receding state, I argue that the state is one of the dominant powers structuring the food bank fix. Chapter three is thus an extensive look at the state's role in the food banking economy through an in-depth analysis of The Emergency Food Assistance Program (TEFAP). I provide a historical overview of TEFAP and its relationship to federal supply management concerns, placing the role and function of the program (including its recent growth) within the national food policy context laid out in the quadrennial farm bill. I explain the institutional framework within which TEFAP is governed at the USDA and the multiple agencies administering the food orders and contracts that are placed to 
stave off crises of oversupply for US farmers. The rules and regulations associated with the level of funding and food received to administer the program are then explored at the state level, through the relationship between the USDA, WVDA and the state's two food banks and the 350 LFCs that act as state agents to distribute public food to the poor.

The federal bureaucracy that shapes TEFAP makes the program overwhelmingly associated with rules. These rules regulate everything from refrigeration temperature to handling times and distribution frequency. Although the rules are burdensome to navigate, I argue that the bureaucracy serves two primary purposes for the state. First it ensures that surplus purchased by the federal government remains locked in distribution channels that will not disrupt agricultural markets. Local charities are forbidden from exchanging or selling the commodities they receive; they must give them away. Secondly the rules ensure non-discrimination and equitable distribution of these gifts regardless of race, gender, age, or disability. The social justice rules in place work to expand access to emergency food to the widest extent possible and codifies emergency food as an entitlement. The foods provided are much more reliable and of a higher standard than most of the donations provided through private corporate donors. This public bureaucracy then is not only a regulatory apparatus, not only a vehicle for accumulation in the food system, but also a site of struggle over whom emergency food networks should ultimately serve. In many ways the rules informing access to TEFAP provide a basis for thinking about a right to food framework that other charitable food bureaucracies such as FA do not mandate.

Chapter four then turns to the other national bureaucracy involved in the food bank fix. Feeding America (FA) governs its members through a 72-page contract that defines the terms of the relationship between food banks and the national conglomerate across nearly every aspect of food bank operations. In exchange for access to corporate food waste, food banks are contractually 
obligated to comply with policies ranging from Financial Record Keeping and Food Safety to Board Governance and the trademarked use of the FA brand. The contract delimits each food bank's service territory, spatially ordering and disciplining members amongst themselves. It also compels members to account for donated food receipts and measure programmatic success through the MPIN metric. Like the USDA, FA also explicitly forbids food banks or their local affiliates from reselling donated food products, to protect profits on primary circuits.

The agglomeration of large food donors under the FA umbrella paralleled the construction of a legal framework that incentivized food businesses to donate their obsolete inventories to charity. The ongoing centralization and corporatization of emergency food networks through this national brand has seen the food recovery broker grow into the third largest non-profit in the country. Its food and funding partners include powerful agro-industrial actors who are now directly influencing the framing of hunger relief causes, zero-waste initiatives, nutrition education programs and infrastructure improvements throughout the network. In the process, these companies save on reduced disposal fees, boost their image as good corporate citizens and collectively claimed over $\$ 2$ billion in tax credits last year.

Feeding America does not physically handle any of the product it secures from its corporate donors. Instead an accounting technique known as "variance power" provides the legal and institutional framework within which it orders its bureaucracy. Food banks are obligated to report the number of pounds received from FA donors and must often accept whatever foods they provide regardless of quality. FA then consolidates the reported numbers to process tax deductible receipts. By requiring that its members collect, categorize and report data, Feeding America is not only able to process tax receipts on behalf of its national donors, it also captures deep knowledge about emergency food flows across the food banking economy, including those sourced by the state and 
non-Feeding America affiliates. From this knowledge it then develops standards to measure the success and enroll an increasing number of for-profit partners into the network.

Chapter five works to bring together the institutional structures I unpack in the previous two chapters to the food bank scale. I demonstrate how the food bank sits at the center of a network of co-dependencies, frenetically working to resolve problems borne out of the commodification of food in the capitalist system. I analyze the two food banks in West Virginia vertically and horizontally to explain their key position in the politics of access to emergency food resources. The multi-sited methodology (Marcus, 1995; Falzon, 2016) takes a center and periphery approach that reveals differentiated power dynamics and dependencies among the many parties involved in charitable food transaction, powers that are negotiated at the food bank scale. I explain how food banks anchor charitable food supply chains by centralizing funding for the logistical infrastructure necessary to move donated surplus to the needy. I review the different food sources available to food banks over time and their need to constantly (re)adapt to agro-industrial supply chain evolutions. Finally, I map out the governance regime and territorialities that structures food banking work.

The analysis explains how the food bank fix is both a solution and a dilemma for the state and food corporations leveraging charities to maintain the legitimacy of the capitalist food system. Affective labor across the HFN is extremely good at squeezing out efficiencies and resolving the many contradictions involved in feeding the hunger with food waste. Placing the costs of revaluing food waste on the voluntary labor and philanthropic capital provided by civil society however also produces a high degree of freneticism for food banks. The underfunded mandate has led to a fiscal and managerial order that disrupts moral and material values, and places stress on low-paid staff, volunteers and donors, particularly in poor rural states with high food insecurity rates like West 
Virginia. Food banks anchor hunger relief networks in place, yet their institutional fragility is also a problem for a corporate food regime that is doubling down on food banking to address overproduction in the context of food access failure.

Chapter six analyzes the many different actors structuring the food banking fix at the local scale. As the two food banks in West Virginia work to push out increasing amounts of donated product across their service territories the national bureaucratic structures shaping resource allocation and food distribution produces tensions with and among local food charities (LFCs). LFCs are usually not privy to the many institutional tensions facing food banks, and my extensive participation in these networks indicates there is an implicit sense of wariness about what is perceived as their growing power and grip on the emergency food landscape. These feelings often erupt as explicit confrontations. Many of the frustrations that local charities attribute to regional food banks are in fact engendered by the national bureaucracies organizing the public-private response to hunger. Food banks are a part of this assemblage, but ultimately have limited power to shape it, subordinated to the will of actors far beyond the state's borders. Caught between the mandates of their national affiliates and the diversity of their local feeding network, food banks are left to negotiate and resolve the fraught ideologies of food waste revaluation and hunger relief at different scales.

The chapter provides an overview of differences in LFC programming, specifically the uneven development and differing ideological motivations informing their practices. Place significantly affects an LFC's capacity to procure and distribute emergency food resources. I review the way in which the local scale is both a portal and a barrier to food waste revaluation in the food banking economy and differing institutional capacities in terms of labor, funding, physical infrastructure and feeding ideologies. The data reveals that research on charitable food 
provisioning must account for both material and ideological differences among LFCs and the institutional contexts within which they operate their feeding programs. The drive to smooth out and order the food bank fix at the local scale I argue is related to the need to overcome barriers imposed by LFCs to revalue increasing amounts of industrial food waste.

Chapter seven explains the spatial strategies used to overcome local barriers to food waste revaluation. I explain how food banks have become sites of regulation and spatial control that ensures food waste recovery continues to be perceived as an adequate solution to hunger. The focus is specifically on the tools developed by the shadow state (through FA) to legitimize the food bank fix. I analyze the relationship between rationalities of Cartesian hunger relief emanating from FA headquarters and the local realities of distributing increasing amounts of corporate food waste across an HFN that is not equipped to absorb it all. FA frames its food insecurity measurements and interventions as hunger relief strategies, yet I demonstrate why they must also be understood as governance mechanisms that forces a growth-based model on charitable food supply chains.

The most important measurement standard is the meals per person in need (MPIN) metric developed to set distribution targets at the county level. MPIN is a needs assessment based on food insecurity rates developed under the Map the Meal Gap (MMG) project. Food banks must place a targeted amount of food in each county and report that distribution back to FA. Food banks that fail to meet MPIN metrics are placed on probation, potentially losing access to the brand and its accompanying benefits. While the measure is framed as a hunger relief mechanism, when the spatial algorithm is unpacked, and the logics of this governance structure analyzed, it becomes clear that evenly spreading food waste across space is the driving factor behind MPIN. Indeed, so called meals are measured through a pound to meal conversion factor of $1.2 \mathrm{lbs}$ per meal, without any regard for food quality. I argue that FA's technocracy frames the success of its national hunger 
relief efforts, yet in West Virginia, where food banks operate in a resource poor environment, this governance structure places the HFN in a precarious situation as food banks and LFCs struggle to keep up with MPIN targets that increase each year along with the availability of corporate food waste flowing through the national food banking system.

Chapter eight summarizes my findings, drawing on recent trade mitigation commodities currently flooding the food banking economy to reinforce the food bank fix argument as the central theoretical contribution of this dissertation. The compassion driven supply chains that structure the food banking economy through humanitarian reason reinforce relations of dominance and subordination in the capitalist food system. The moral unity of the food bank as a social fix to problems of overproduction and hunger is clearly fraught. The $\$ 1.2$ billion dollars of surplus foods suddenly circulating through charitable food supply chains due to the Trump administration's tariffs have widened the fissures by laying bare the supply side logics co-opting compassion for hunger. Reviewing the contradictions I expose in the data chapters provides an opportunity to think about ways in which LFCs and food banks might take advantage of slippages and pressure points within the HFNs institutional framework as the basis for furthering food justice and food sovereignty coalitions working to build alternative food futures. 


\section{Chapter 2: Between Surplus and Scarcity Theorizing the Food Bank Fix}

\section{Feeding Lines}

Off the national mall in Washington D.C. five men encased in bronze forever wait for their portion of food in front of a closed door. The sculpture is part of the Franklin Delano Roosevelt memorial commemorating the Great Depression that suddenly left millions of people out of work and dependent on food charity to survive. Juxtaposed with this feeding line, two disheveled farmers stare blankly into the distance. The statues recollect the production gluts and commodity price collapse that shattered the lives of agrarian families during the same period. The fallout from the 1929 financial crash led to seemingly irrational decisions on the part of food producers trying to cope with falling prices. Milk poured down sewage drains, oranges soaked in kerosene, corn burned for fuel and arbitrary livestock slaughters did not bode well with the millions struggling to access food in industrialized cities. The paradox of malnutrition amidst food surplus provoked a sense of moral outrage that forced the federal government to respond to "breadlines knee deep in wheat" (Poppendieck, 2014).

New Deal food policies worked to reconcile the dilemma of want amid plenty. Specifically, the Roosevelt administration empowered the USDA to raise farm gate prices by purchasing excess commodities to stave off crisis, many of which were redistributed to the poor as hunger relief. State intervention relieved social discontent and rescued the capitalist food system from its internal contradictions. The 1933 Agricultural Adjustment Act drafted amid this crisis, remains the basis for the quadrennial farm bill that still structures farm and nutrition policy in the United States today. The legislation's evolution has not resolved the underlying problems of overproduction and hunger endemic to our capitalist food system, rather it continues to set into motion a series of 
fixes through which food production and nutrition entitlement have developed into the $21^{\text {st }}$ century (Graddy-Lovelace and Diamond, 2017). Food banking is one such fix.

The feeding line memorial reverberates into our present. In 2016, 4.5 billion pounds of excess food was diverted through a network of 200 Feeding America (FA) food banks (Feeding America, 2017), a fivefold increase in just 20 years (O'Brien et. al, 2006). The 60,000 local food charities (LFCs) integrated into this network raise money and mobilize volunteers to receive, process and serve industrial food waste to 46 million people lining up each month to receive their portion of the excess (Winefield, et. al, 2014). As the amount of food increases, the lines forming to access the surplus are expanding as well. As one food bank director in West Virginia stated "we're just feeding the line, not shortening the line. Even though we want to, the reality is we're a short-term fix to a long-term problem" (FB-1: 7.15.14).

Feeding lines resolve two problems in the United States. First and most obviously, they respond to food access failures at the household level. Feeding lines are a testament to the disaster of a deeply unequal society and the failure of a politics of austerity that drives millions of people into a permanent state of emergency. Secondly, and perhaps less obviously, feeding lines resolve problems of overproduction in the capitalist food system. Massive food surpluses are tied to the organization of value chains in contemporary food systems particularly the avoidance of economic risk by states, speculators, farmers, food processors and retailers. All these food system actors contribute differently yet collectively to the growing amounts of food waste generated by the food industry (Stuart, 2009; Bloom, 2010). Feeding lines offer a convenient vent for this surplus, one that relies on a politics of compassion to motivate and drive the food waste-qua-hunger relief supply chain forward. As Gille (2013) aptly frames the food waste dilemma however "the question 
of which aspects of food waste we should focus on also has implications for whose ability to avoid risk we prioritize" (p.40).

Unlike the 1930s, feeding lines in the context of food gluts no longer provoke a sense of moral outrage. Today, feeding lines exist instead as sites of moral performance, blunting the injustices of a highly unequal society and normalizing a food system that segments eaters along lines of disposable income. Food charity produces a set of values that depoliticize structural inequalities and poverty through an overt focus on solving hunger through food waste recovery. Janet Poppendieck's (1998) influential work on the politics of contemporary food charity framed the growth and social acceptance of feeding lines as a "moral safety valve" for a society coming to grips with the social and economic fallout of dismantling the welfare state on the altar of neoliberal capitalism. Food banks are now part of an "anti-hunger industrial complex" (Fisher, 2017) that benefits entrenched interests in the capitalist food economy. They remain a politically fraught phenomenon, but how they work to achieve institutional legitimacy is still poorly understood. The hidden links between profit and compassion driven supply chains have contributed to the expansion of this moral safety valve, links I make explicit throughout this work.

In this literature review I place food charity within broader food system scholarship, highlighting how food banks fix problems in a capitalist food system that simultaneously produces surplus and scarcity. I first review studies on the institutionalization of food banking in light of neoliberal rationalities. Next, I draw from the literature on geographies of food and hunger leaning heavily on food regime theory to explain the relationship between the state and private industry in staving off crises in global food production networks over time. The most recent changes in capital's relationship to the food system necessitates food banks to resolve the contradictory crises of rampant food waste in the context of household food insecurity. Third, I tie the food bank fix 
within the literature on moral economies and hunger, food access and entitlement theory. Finally, I buttress this theoretical framework by drawing on scholarship on humanitarianism, arguing that food system scholars must attend to the institutional structures and ruling relations that reproduce the social conditions that legitimize an inequitable food system.

\section{The Institutionalization of Food Charity}

Food banks and their LFCs distribute food to people who do not have sufficient incomes to pay for it. Largely sustained through private charitable funds, food banks are a key institutional node in the restructuring of the welfare state and its responsibility to citizens struggling with the vagaries of a capitalist society. Food banks first emerged as a charitable strategy to distribute surplus food to the working poor, unemployed, aged, disabled, homeless, and other food insecure people in North America during the 1970s (Poppendieck, 1998; Riches, 1986). They served a loose network of independent food charities that have gradually been enrolled into a public-private food waste governance regime centered on the food bank as an institutional form. In her book Sweet Charity (1998), Poppendieck argues that there is a fundamental link between the institutionalization of food banking and state retrenchment. The performance of charitable giving by emergency food agencies at the local level legitimized state withdrawal from welfare provisioning by demonstrating that private community-based organizations could fill the void. These voluntary responses to hunger relief intersected with the goals of both the state and food corporations.

"Institutionalization is a good word, because it implies not only that an organization or a cluster of activities becomes an 'institution', but also that it does so in interaction with the other, preexisting institutions of society, and that is certainly true in the case of emergency food. This phenomenon became institutionalized because it fit so well into the agendas of other powerful institutions, particularly government and business" (Poppendieck, 1998, p.140) 
Scholarship on LFCs tends to focus on a single place. Research has shed light on the political and economic factors that lead people to access free food in this way, (Daponte et. al, 1998), the entrenchment of food charities as a long-term food sourcing strategy (Sharon et. al, 2011), and the social (Daponte, 2000) and spatial (Garasky et. al, 2004) differentiations among people accessing them. Studies on soup kitchens and food pantries have also included the role that these play in cultural production (Glasser, 1988; McCutcheon, 2015), the geographies of survival (Heynen, 2008), their potential links to the food justice movement (Dixon, 2015) and their complicated liminal positions between the shadow state and alternative economies (Pine, 2016).

While this body of literature is a helpful starting point to understand the role of food charity in society and the wider food system, it tends to represent local charities as monolithic actors rather than a collection of heterogeneous organizations acting in tenuous concert through an institutionalized humanitarian assemblage. Poppendieck's (1998) sociological analysis connected the dots between the many different actors involved in the rise of humanitarian food networks (HFNs) in the United States. She explained how hunger relief became a cause célèbre that overshadowed anti-poverty advocacy. The evolution of the food banking economy since she published Sweet Charity two decades ago requires a geographical analysis that explains how food charities are now tightly enmeshed in the politics of corporate giving and federal entitlement programming. The institutionalization of food charity as a social phenomenon has thus been identified, but questions remain as to how HFNs work in practice, how they are maintained in place and linked across space and scale.

The changing relationship between the state and its citizens directly contributed to the institutionalization of the food banking economy. The rise of food banks can be traced back to neoliberal reformism promoted under the Reagan and Clinton administrations in the 1980s and 
1990s. Their social and economic policies prioritized workfare over welfare, redrew the boundaries between the public and the private spheres, slashed taxes and public spending while subordinating social policy to competitive market imperatives within the voluntary sector (Jessop, 2002). Food banking remains an important case study for understanding both the rollback and rollout of neoliberalism (Peck and Tickell, 2002). LFCs run by volunteers and funded by philanthropic capital carry the burden of social services previously organized through the state and funded by tax dollars. Research on food banks in North America has explored the symbiosis between public and private hunger relief efforts (Daponte and Bade, 2006; Edwards, 2012), entanglements between corporate and social welfare (Tarasuk and Eakin, 2005) and the neoliberal ideologies driving financial backers and volunteers undergirding the aggregation and redistribution of donated foods (Carson, 2014; Poppendieck, 1998; Tarasuk and Eakin, 2003).

Although scholars have demonstrated that these organizational formations seriously hamper political claims for the right to food (Riches and Silvasti, 2014), food banks and LFCs are still perceived as providing an essential immediate solution to hunger. Indeed, food banking is no longer exclusively a North American institutional form. Emboldened by the successful rollout of HFNs in the global North, food banking went global in the late 2000s and today food banks operate in some 30 countries from Ecuador to Egypt, South Africa to South Korea (Warshawsky, 2011, Global Food Banking Network, 2016). The globalization of food banking illustrates their entrenchment as para-statal institutions governing hunger through food waste redistribution (Warshawsky, 2010).

Research into food banking as a neoliberal strategy has been vital to understanding the limits of private charity in addressing hunger and the problematic power relations associated with non-state actors providing welfare. There is wide consensus among critical scholars that food 
banking produces a set of discourses, values and socially necessary representations that serve to depoliticize the issue of hunger and structural inequalities altogether (Dixon, 2015). However, there is still a gap in the literature connecting this depoliticization to the shifting political economy of free, excess, or surplus foods. Although food charities are widely recognized for their role in emergency food distribution in the context of capitalist crises, their political economic role in permanently revaluing food waste in conventional global food networks has been largely overlooked.

Henderson (2004) first demonstrated that food bank labor and the wider charitable impulse associated with hunger relief efforts enabled capitalist circuits to reinscribe value into surplus foods. However, in the decade since he leveled this critique the evolving role of food banks in revaluing food waste has not received the attention it deserves. Lindenbaum (2016) frames food banks as "re-gifting depots" that pass on leftovers from tax breaks, agricultural subsidies and reduced disposal costs to poor food consumers, but he does not set these value relations within the context of the agro-industrial supply chains that drive this process forward across space, nor does he analyze the institutions that regulate the distribution of these gifts.

Access to surplus food donations by food banks is highly regulated to satisfy both state and corporate mandates. There are hegemonic moral norms ensuring that these distribution channels remain open, namely the perception that gifting discarded foods to address household food insecurity is an unquestionable social good. The concept of diverting food waste to the hungry has gained renewed traction as popular books and documentary films foment a public outcry over the massive amounts of food dumped in municipal landfills (Stuart, 2009; Bloom 2010). Decay induced methane gases and climate altering food miles now re-center HFNs as environmental 
solutions to climate change ${ }^{5}$. This interest coincides with a flurry of grassroots food recovery programs that attempt to connect food otherwise destined for the bin to social service agencies. Recent scholarship has also aligned with some of these same concerns seeking to understand the production of food waste (Parfitt et. al, 2010; Mena et. al, 2011) and its negative ecological footprint (Venkat, 2011; Cuéllar and Webber, 2010; Buzby and Hyman, 2012). The consolidation of environmental and hunger relief discourse into the corporate social responsibility platforms of many food businesses reinforces beliefs that food charities perform a positive social function (Warshawsky, 2016).

The expansion of food donations is leading to a concurrent, yet uncoordinated, expansion of capital and labor investments into the roll-out of the humanitarian response to hunger. Food banks and their LFCs convert devalued foods from producers, manufacturers and retailers in a state of near permanent austerity. They subsidize insufficient operating budgets through philanthropic donors and the labor of volunteers who maintain this network in place. Reprocessing unsaleable food creates opportunities to further legitimize the capitalist food regime (by caring for the poor) and increase capital accumulation by large agro-food actors through reduced tax burdens, artificial price points, waste disposal costs, and positive brand impact. The institutionalization of food charity at these different scales compels food banks to negotiate between the national institutions that enable them to expand access to surplus food while attending to their relationships with grassroots organizations that address emergency needs at the local level (Figure 2-1).

\footnotetext{
${ }^{5}$ The U.S. Environmental Protection Agency's (EPA) food recovery hierarchy places feeding hungry people as its second priority after source reduction, further institutionalizing food banking within the state's ecological rationale and legitimizing food charities as key sites in food waste reduction efforts.
} 


\section{Figure 2-1: The Food Bank Fix}

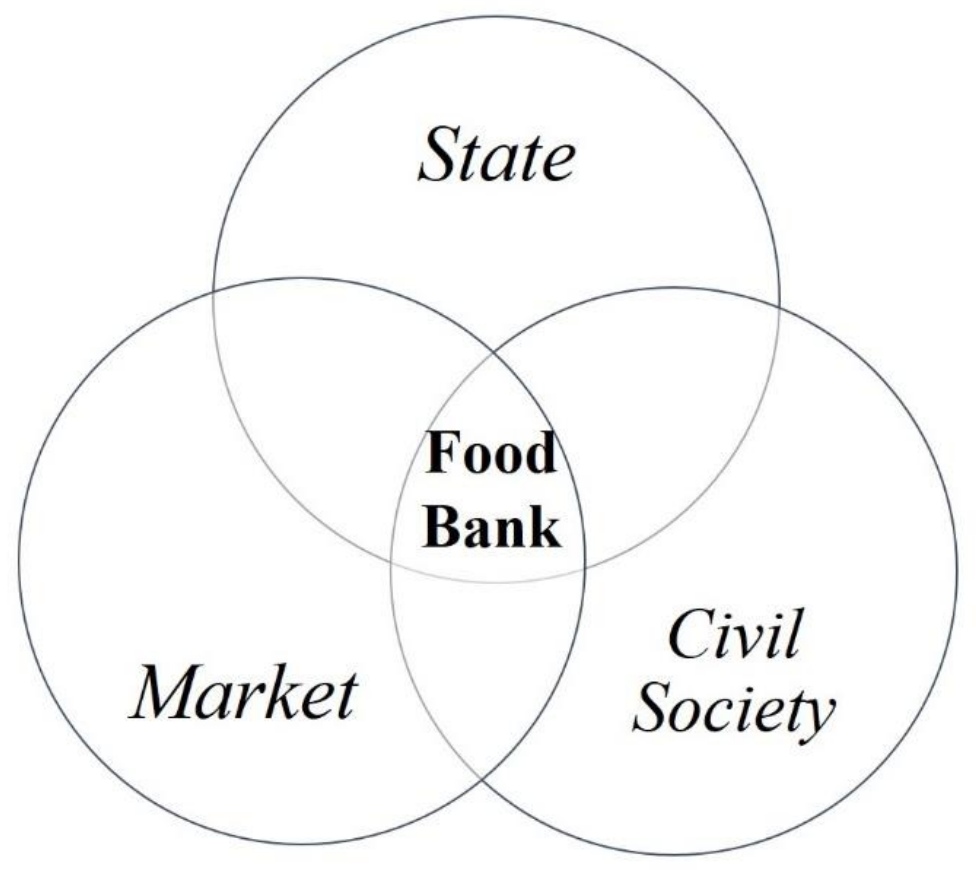

Food banks fix overproduction in a market-based food system through a humanitarian governance framework that leverages compassion for hunger relief to regulate the distribution of industrial food waste across space. As central nodes of the HFN, food banks maintain the physical and social infrastructure necessary to resolve contradictions between capitalist food production, artificial food scarcity and social reproduction (Katz, 2001). In West Virginia, I have witnessed deepening demands on the HFN to process ever greater volumes of food, a factor contributing to the near financial collapse of the state's flagship food bank in 2015 (Lohnes and Wilson, 2018). While the relationship between supply and demand across the HFN is complex, a supply side logic is dominating decision making and further institutionalizing HFNs across the United States. Because the federal government, FA and civil society now frame food banks as frontline institutions for a greener and more ethical economy, food banking must be studied in the context of wider food system trends. 


\section{Geographies of food and agriculture}

Due to the widely accepted view of food banking as a neoliberal governance strategy, many scholars in agro-food studies have largely conceded this corner of the global food system. As such, food banking has received less scholarly attention than other areas such as the alternative food movement. Since 2008 however, there has been a resurgent interest in food banks and food recovery more broadly as the popular answer to food insecurity across the United States. The spotlight cast on food banking can be attributed, in part, to a spike in households turning to charitable food assistance to close budget gaps after the Great Recession (Coleman-Jensen et. al, 2013), yet there are wider forces at work which shape the production, distribution and consumption of donated food waste as hunger relief.

Food consumption marks the end of a social process imbued with spatial politics. Eating connects people in disparate localities from farm fields and feedlots, processing factories and distribution centers to the bodies and households that form the communities, cities, states and institutions subsidizing and regulating food markets (Heynen, 2009). Today food is a fundamental commodity to global value relations and central to the reproduction of waged labor (Araghi, 2003). The commodification of food and its evolution from a life bearing object to an object of social control is tied to the production of hunger under capitalism as profit driven food systems are molded to suit commercial and political interests above human needs (Marx, 1976; De Castro, 1977; Wisner, et. al, 1983; Watts, 1983; Davis, 2004; Vernon, 2007). Agrarian structures have undergone exponential geographical expansion over the past two centuries and most of the foods we eat now clock thousands of miles between the places in which they are grown, processed and then exchanged (Campbell, 2009). 
This spatial restructuring did not happen in a vacuum, rather since the 1870 s a series of global food regimes (McMichael, 2009) accompanied shifting accumulation strategies that ensured profits could be derived from the diets of poor laborers and elites alike. Global food geographies shifted to mirror political economic structures in specific time periods, first under European colonial relations, then in the bi-polar post-WWII order when food became a geopolitical tool with which to influence the development path of newly independent states. Since the 1980s the emergence of a food regime based on private corporate control of the food supply now determines production, exchange and consumption relations therein.

The mechanization of agriculture, the development of artificial fertilizers, pesticides, hybrid seeds and controlled irrigation techniques unfolded in the late 20th century under the banner of production driven "food security" (Goodman and Watts, 1997; Lang and Barling, 2012; Carolan, 2013). Crop yields rose dramatically even as local anti-scarcity strategies were undermined and the number of farmers declined. This so called "green revolution" continues to promise global food security in an era of rapid population growth and the United Nations Food and Agriculture Organization (FAO) has called for a doubling of food production by 2050 (Tomlinson, 2013). While the adoption of industrial farming techniques is on track to meet this expectation, the market mechanisms informing food distributions continually fail to ensure equitable food access while compounding other problems including environmental degradation and exploitative labor practices (Alkon and Agyeman, 2011; Allen, 2013)

The central paradox in our contemporary food system is that problems of household level food insecurity and malnutrition persist in a context of food gluts and agricultural dumping (Patel, 2012; Fitting, 2011, Carolan, 2013) even as states attempt to address these market imperfections through food aid programs (Barrett, 2002; Essex, 2012). The production and distribution of food 
in the 21 st century is trending toward consolidation as a handful of powerful agro-industrial and retail firms concentrated within multinational networks that control inputs, set the terms of farming contracts and influence prices to extract as much monetary value as possible from each food item produced (Goodman and Watts, 1993; Winter, 2003; McMichael, 2009). Friedmann (2005) proposes that we are currently witnessing an emergent corporate-environmental food regime that:

"like past food regimes is a specific constellation of governments, corporations, collective organizations, and individuals that allow for renewed accumulation of capital based on shared definitions of social purpose by key actors, while marginalizing others... Unlike the postwar regime which standardized diets, it is likely to consolidate and deepen inequalities between rich and poor eaters" (p.228)

One manifestation of this phenomenon is the distribution of foods that could not be absorbed by traditional market channels to poor consumers. Many scholars focus on the evolution of the contemporary food regime through the study of ethical commodity chains, retail restructuring or corporate social responsibility programs (Galt, 2013). There has been much less emphasis on humanitarian food networks even though these lie at the far end of a food system increasingly tailored to a consumer's capacity to purchase different types of food. My research seeks to understand how the free food distributed through this network is embedded within the corporate-environmental food regime, seemingly solving the dual problems of household food insecurity and surplus food production yet also reinforcing the trend toward highly differentiated foodways.

The uneven development of food environments contributes to food access disparities. The explosion of research into so called "food deserts" links food choice constraints to demographic and economic spatial analyses usually focusing on the lack of grocery stores carrying healthy food options in low income urban neighborhoods (Walker et. al, 2010). These expert driven supply side analyses of food access disparity problems however are framed around market-based relationships and do not account for the agency of vulnerable households sourcing food (Shannon, 2014). By 
failing to adequately explore food sourcing strategies including the cultural and social practices that affect food consumption patterns among the poor (Pine and Bennet, 2014; Alkon et. al, 2013) the food desert frame tends to naturalize uneven food environments rather than linking these to the reorganization of capitalist food regimes over time (Bedore, 2013).

Indeed, over the past 30 years the production and marketing of foods in the United States has segmented along lines of consumption that mirror disposable income (Winter, 2003). The overall price of food has fallen along with the relative value of wages, yet the industrial production systems processing and delivering this food have contributed to nutrient deficiencies and health problems especially among the poor (Nestle, 2002). Rising rates of obesity, diabetes and hypertension are alarming and most policy interventions continue to seek to reform the consumptive habits and behaviors of individual consumers (Guthman, 2011) rather than address the agricultural subsidies in place that produce markets awash in low-cost unhealthy food options (Patel, 2012).

The rise of alternative food movements including local (Allen et. al, 2003; Allen, 2004), organic (Guthman, 2004) and fair-trade certifications (Wilson, 2010) have all been framed as a tension between civil society's reaction to the industrial food system, and many eaters now engage with ethical supply chains as a form of resistance against the dominant or "conventional" food system (Barnett et. al, 2005). This struggle has redefined the politics of eating and is embodied within practices such as "voting with your fork" to enable sustainable food futures (Pollan, 2006). Aptly summarizing this phenomenon, Julie Guthman (2008) describes a process whereby "the yuppification of food has developed simultaneously with 'McDonaldization', the proliferation of cheap, standardized and nutritionally debilitated food creating a bifurcation of sorts in contemporary foodways" (p. 1175). 
The evolution of alternative food networks has been studied extensively (Goodman et. al, 2012; Maye and Kirwan, 2010; Jarosz, 2008) and come under critique for opening new sites of corporate accumulation (Guthman, 2004), and for being inaccessible to those who do not have the capacity to access fairer foods through exclusionary markets, thus reinforcing social divides (Slocum, 2007; Hayes-Conroy and Martin, 2010; Alkon and Mares; 2012). There are several reasons why alternative foodways have received so much scholarly attention, not least of which is the ease of accessing key informants at these sites and the relatively small institutional scope of their organizational form. The consumptive routes opened by the HFN has received much less focus despite the fact that 46 million people in the United States engage with food charities as a food sourcing strategy every month (Winefield et. al, 2014).

Studies on food charities do not frame free food distributions in the context of differentiated foodways produced by the corporate-environmental food regime. Furthermore, no research project has focused explicitly on the networked social arrangements that enable these local charities to continue accessing surplus foods to distribute as hunger relief. It is difficult and time intensive to bring together the many disparate parts of this network into a single analytical framework. Such an integrated approach however can shed light on the extent to which the humanitarian reason (Fassin, 2011) is now entrenched within a contemporary food system that thrives off the differentiation between rich and poor eaters. While food access failure and hunger relief are not new, my research suggests that HFNs are bearing a larger and larger responsibility for reconciling and resolving late $20^{\text {th }}$ and early $21^{\text {st }}$ century food crises that are now deepening because of the threats posed to capital by rampant income inequality and climate change (Wainwright and Mann, 2018). 
Today, a mere $2 \%$ of the US workforce is involved in food production, freeing the rest of the population to provide labor to other sectors. While this may seem progressive, sovereignty over the foods we provision is tightly coupled to wages and the exchange of money for food. Those left out of this social contract due to low pay, precarious work, inadequate pensions, unemployment or underemployment, discrimination or disability depend on USDA nutrition programs and food charity to close food access gaps. A quarter of all Americans participate in at least one of 15 domestic food assistance programs (Oliveira, 2015). In FY 2016 \$100 billion was spent on food entitlements, $73 \%$ of the USDA's $\$ 138$ billion budget that year. Even as millions depend on the state to close food access gaps, the corporate food system feeds off the benefits of these nutritional subsidies. In the process wealth and power is increasingly accruing to a few entrenched actors, including highly capitalized farmers, manufacturers of equipment, fertilizer and seed inputs, and a consolidated group of multinational food processors, distributors and retailers across global food supply chains (Goodman and Watts, 1997; Pimbert et. al, 2001; Gottlieb and Joshi, 2010).

Food systems rely on manufacturing the consent of people they nourish, and there is thus a necessary moralization involved in resolving crises inherent to the commodification of food. Social norms and moral sentiments influence economic behavior, which in turn are compromised or overridden by economic forces, particularly in times of crisis (Sayer, 2000). How food charity has come to make so much sense in the context of the corporate-environmental food regime, and the ways in which humanitarian reason structuring it is resisted is also key contribution of this research. To this end I now turn to a review of the scholarship on moral economies and the wider politics of hunger relief. 


\section{Food crisis, moral economy and hunger}

Because food is essential for life, it is the basis of implicit mutualities and codes upon which food production and distribution are arranged to ensure that the risk of hunger is minimized for all members of a community. These so-called moral economies (Thompson, 1971; Scott, 1976, Watts, 1983; Fassin, 2009a) are not fixed in place or time but evolve with the struggle to determine how food is governed in relationship to the modes of production that determine its distribution. If food access fails, then the political economic structures in places are also prone to failure or at the very least must be re-worked to mitigate social unrest and maintain the political status quo (Holt Giménez and Shattuck, 2011; Essex, 2012). The ongoing biopolitical ${ }^{6}$ contest over the direction of food provisioning around the world provides an opportunity to think about how the management of food systems under capitalism is inextricably linked to the management of life itself (Fassin, 2009b; Nally, 2011).

Hunger is not exceptional to capitalism, but part of it. Indeed, it is one of the biological drivers that compels labor to enter wage relationships. The history of the modern food system can be read through the evolving social response to its feeding lines as these simultaneously fixed and challenged contradictions inherent to the commodification of food. Mike Davis (2004) explains how food shortages in the colonies of the Victorian era became a constitutive element of colonial capitalism, precipitating the transition of societies and emergent nations into market relations. Images and stories of malnourished subjects helplessly queuing for food aid ran counter to the civilizing narrative of modernism in the metropole that justified a colonial presence abroad.

\footnotetext{
${ }^{6}$ Michel Foucault theorized the concept of biopower in his 1978 lectures "Security, Territory and Populations". Biopolitics is the extension of state power through specific apparatuses that control and regulate populations as a political-economic problem for the state. Foucault's lectures draw heavily on the history of food provisioning to develop theories of biopower, specifically the modern state's propensity to implement policies that avoided food scarcity in the metropole to subdue restless populations that might contest the legitimacy of the state.
} 
Hunger had to be publicly framed outside of colonial relations and the rise of capitalism, a problem borne out of the vagaries of nature, overpopulation and logistical inefficiencies rather than a constitutive element of a changing mode of production. Food shortages served "as forcing houses and accelerators of the very socio-economic forces that ensured their occurrence in the first place" (Davis, 2004, p.61). In other words, the precipitous transition of societies and emergent nation states into market-based wage relationships produced feeding lines.

As these feeding lines extended into the industrialized cities of the global north, a new moral system began to take root in the metropole, placing hunger prominently within the practices of contemporary statecraft. James Vernon's (2007) historical analysis of the institutional responses to hunger across the British empire takes the long view of manufacturing consent for the capitalist food system. Beginning in the $18^{\text {th }}$ century, he traces the construction and representation of hunger in the context of the democratic nation state. He argues that hunger was mobilized in various ways to trigger social action from civil society that would compel the state to act. The demands placed on the state by recently enfranchised citizens compelled bureaucrats to intervene and fix a problem that was no longer perceived as the result of cosmic forces, but rather a manufactured crisis resulting from broken human systems. The state he argues then leveraged hunger as a biopolitical tool through the development of nutrition science and technocratic social programs such as school meals and workplace canteens.

Feeding armies and laborers in rapidly industrializing cities necessitated a governance structure that ensured food allocations were distributed to citizens in a way that met the required caloric intake of growing, working, fighting and ageing citizens. The incitement to discourse around solving hunger produced new networks of power that crystallized into state and supranational food institutions throughout the $20^{\text {th }}$ century. Today this power is also shared with agro-industrial food 
concerns who are increasingly imbricated in these solutions through market-based approaches to nutrition entitlement. Hunger remains a fraught and contestable term (Allen, 2007), one charged with emotional and moral sentiments that are leveraged for different purposes across the political spectrum (Wisner et. al, 1983, Vernon, 2007). On one extremity, some within civil society frame hunger as a social problem induced by uneven development that must be mitigated by the state. On the other end, some champion markets as the best vehicle through which to balance finite resources. In this view food markets should be left to freely produce plenty or want with minimal state intervention. The neoliberal rollback of public entitlements that led to the need for food banking in the 1980s must be understood within the context of both sentiments, rising as a socially acceptable public-private solution to the dual crises of food waste and hunger. Yet the state remains intimately involved in negotiating the political tensions that coalesce around hunger.

The 1930s was a critical moment in the evolution of the food system in the United States. The Great Depression left millions of people out of work and dependent on food charity to make ends meet even as production gluts and a general commodity price collapse shattered the lives of family farmers across the country. Depression induced malnutrition alongside very visible food surpluses forced the federal government to respond to hunger in drastic ways. New Deal food assistance programs blunted the perception of a malfunctioning food economy and mitigated the potential for deep structural reforms that would prevent the simultaneous production of food waste and hunger. Strategic discourses of scarcity obscured agricultural surplus through federal food assistance programs that reinforced and consolidated growing US imperial power across the globe (GraddyLovelace and Diamond, 2017). New interest groups and lobbies formed around the shape of this federal food policy and programs that were initially conceived on behalf of the poor ultimately adapted to mandates of the private food sector (Poppendieck, 2014). 
Today food assistance programs continue to exist at an awkward intersection of large agroindustrial interests and food insecure households. The Supplemental Nutrition Assistance Program (SNAP) that finds its genesis in 1930s commodity surplus relief for example now provides a halftrillion-dollar subsidy to food retailers across the country through the 2014 farm bill even as SNAP provides a vital social safety net for over 40 million people. Other federal food assistance programs that compliment SNAP (e.g. School meals, WIC...) are also a large source of revenue for the food industry. As these programs institutionalized, they blunted the perception of a malfunctioning food economy and mitigated the potential for the deep structural reforms that would be needed to eliminate the paradox of surplus and scarcity endemic to the capitalist food system.

It is within the context of the current erosion of these food entitlement programs that the moral economy of the food bank fix crystallizes. Access to resources must be understood within a web of social relations that includes "technology, capital, markets, labor, knowledge, authority, identity and social relations" that promote or deny people from engaging in economic systems, and the attendant distribution of benefits and burdens therein (Ribot and Peluso, 2003, p.173). Food access then is not fixed or unidirectional but shaped by contingent socio-spatial relations. People and organizations are only able to maintain access to food resources by cultivating relationships with those who have control over those resources. Inversely, those in advantageous access positions are also very often dependent on disenfranchised groups to maintain their privileged power positions. Such interplays of social relations across time, place and scale produce bundles of power that must be analyzed in tandem to fully understand how people and organizations access resources through different institutions.

As these complex and intertwined bundles of power differ and morph, the social geographies of food access reshape spaces of vulnerability (Sen, 1982; Watts and Bohle, 1993). A conjunctural 
change (e.g. fall in commodity prices), development intervention (e.g. gender or childhood development programs), new regulation (e.g. tax incentives or tariff) or social movements (e.g. fair wage campaign) can reorganize access to food in a very short period (Bassett, 1988; Schroeder, 1997; Wisner et. al, 2003; Wolford, 2010; Fitting, 2011). In the case of charitable food, both monetary value and moral values shape access to the surplus foods distributed to households laying claim to them. The tension between these two forms of value is always present yet differs at each HFN node.

Physically moving donated foods from place to place is dependent on much more than access to capital and labor. It is also dependent on the ability to access the narrative surrounding the (re)production of empathy for hunger related causes. As Henderson (2004) aptly noted after spending extensive time volunteering at a regional food bank, the food commodities flowing through this network do not map neatly onto normal circulations of capital but rather operate as "a separate circuit for the realization of use value and for the suspension of exchange value" (p.490) where commodities flowing through the network gain a new life through the production of specific "socially necessary representations" (p.505) of both food banking work and food aid recipients. Access to the means of representation over the need for charity in society is then also important to take into account in any study of the food banking economy.

The moral codes produced by the food banking economy resolve crises of overproduction and surplus labor central to the capitalist mode of production (Harvey, 1982). I understand the ongoing roll out of the food bank fix as the expression of a 21 st century moral economy that responds to social anxiety over a food system that manufactures scarcity, not despite, but through its massive surpluses. Food access failures linked to the systematic dismantling of the state's social safety net over the past four decades has brought about a situation in which discarded surpluses 
from a market-based system that thrives off scarcity are recovered and aggregated by food charities for donation as hunger relief. Because food is the basis for both biological and social reproduction, access to this charitable food quickly becomes a highly contested moral issue. The HFN can thus be understood as part of an institutional assemblage that manufactures consent and legitimizes quiescence for an unjust capitalist food system (Gramsci, 1971).

Food banks do not solve hunger. Yet the food banking myth plays a key role in structuring access to food and indeed the organization of value relations under capitalism. People contributing money and labor to recover surplus foods in an economy of care (Razavi and Staab, 2012) concerned with hunger, social inequity or religious duty confront actors guiding the biopolitics of food provisioning through a productivist food security model where markets awash in food are supposedly the best protection against scarcity (Nally, 2011). At times these actors embody multiple economic subjectivities (Gibson-Graham, 1996) and are confronted with intersecting political positionalities. Each represents the problem to be addressed and then solved from a slightly different angle, producing new knowledge and discourses in the process and vying over the set of values and governance structures that ultimately shapes the social geography of HFNs in the United States. As a core part of the contemporary biopolitics of food provisioning, the food banking economy reinforces dominant social hierarchies, while mitigating the moral outrage of a food system that places profits above people.

The profit of large food firms is now intimately tied to charity as the circulation of donated food waste is ever more tightly integrated into an appendage of agro-industrial supply chains. The marriage between food industry philanthropy and the anti-hunger movement is consummated through the state, foundations, corporations, food banks, local charities and individual donors who play a collective role legitimizing corporate tax credits and positive media exposure for donors 
while exonerating the food industry from its role in the production of food scarcity at the household level. The territorial, logistical and physical feeding lines that form out of this governance structure adapt to the mandates of food donors, not to the needs and obstacles of people confronting hunger, or those local charities laboring to serve them. Because food is essential to life, this dissertation is also ultimately a study of the changing moral economy of hunger relief under the corporate food regime (McMichael, 2009). To explain how this moral economy is shaped in relationship to food banking, I turn to the literature on humanitarian reason.

\section{Humanitarian Reason}

Humanitarianism is a key instrument of the international order (Barnett, 2011), and a growing field of inquiry for scholars studying the politics of aid and emergency assistance (Hyndman, 2000; Bornstein and Redfield, 2011; Kapoor, 2013, Richey and Chouliaraki, 2017, Pallister-Wilkins, 2018). Contemporary responses to human suffering wrought by armed conflict, natural disasters, mass migrations, environmental degradation, food and water shortages (to name but a few) are organized through a diverse constellation of actors. These include supranational institutions, state governments, foundations, NGOs, individual donors, relief workers and the victims they seek to help. In the process of managing precarious lives, humanitarian interventions develop governance mechanisms that come to occupy key positions in the contemporary moral order, whereby the suffering and misfortune of victims supplants concerns about inequality and injustice. The deployment of this humanitarian reason is paradoxical, for the politics of compassion is both a politics of inequality and a politics of solidarity, one that binds relations of dominance and assistance into a socially palatable framework of concern (Fassin, 2011). To put it differently, 
humanitarianism manages suffering populations while providing an outlet for people living in positions of privilege to channel their compassion for the misfortune of distant victims into action.

The representation of suffering has deep implications in shaping imaginaries and moral framing of social problems. As the practice of governing precarious lives, humanitarianism must consider every person as equal, yet the subjectivity of the moral values that structure the delivery of aid cannot be divorced from a politics that reinforces tenacious social hierarchies. These often produce institutional distance between givers and receivers of aid as the former represent and frame tragedies, exposing suffering and grief on behalf of the latter. The social distance between protagonists (agents of care and victims of misfortune) reduces people to biological lives to be saved rather than biographical lives to be understood.

The humanitarian governance through which this saving takes place also produces institutional distance between the various organizations deploying humanitarian actions, with misaligned motivations informing the rules structuring caregiving. The production and dissemination of a "new lexicon of moral sentiments" (Fassin, 2009, p.6) mobilizes a politics of compassion that occludes claims for justice and human rights while lifting the burden of privilege many feel about living in an unequal world order. Despite its contradictory refractions, humanitarianism has become one of the most powerful consensual forces of our time, occupying "a key position in the contemporary moral order" (p. 247).

From a historical perspective, the intensification of humanitarian action across the world since the $18^{\text {th }}$ century forces a consideration of the tight links between the mobilization of compassion and the expansion of market and state power (Reid-Henry, 2013). From a geographical perspective, the structural relationship between the metropole and the periphery, as a constitutive element of humanitarianism (Lester, 2002), forces a consideration of the way in which systems of 
care are organized across space and scale. This includes the governance mechanisms and territorial frameworks that come to shape the allocation of resources to aid recipients.

The moral drive to fix hunger is intimately tied with the evolving politics of humanitarian reason. As I discuss above, the struggle to define and regulate hunger was borne out of humanitarian sympathy for victims of starvation across the British empire in the $19^{\text {th }}$ century and the malnourished poor left behind by the rapidly industrializing cities of the metropole (Vernon, 2007). The networks of power that formed around those moral sentiments coalesced and formalized into the institutions that translated the political will to alleviate suffering into mechanisms for governing hunger. These institutions included the rise of nutritional sciences and its accompanying metrologies, the expansion of the welfare state to address their scientific findings and the opening of new markets catering to this social concern for hunger relief (e.g. school cafeterias). This assemblage evolved alongside the changing political and economic winds of imperial ambition, yet always attune to the moral perspective that society brought to bear on victims of hunger.

Barnett's (2011) periodical nomenclature of the humanitarian endeavor, closely mirrors the food regime transitions historicized by Friedmann and McMichael (1989). Imperial humanitarianism, from the late $18^{\text {th }}$ to early $20^{\text {th }}$ for the first food regime $(1870-1930)$, postWorld War II neohumanitarianism for the second (1930-1970), and the current era of liberal humanitarianism for the third (1970-present). This link, between the evolution of humanitarian sentiment and the organization of the moral contract undergirding our food system, is I contend not coincidental but rather points to the relationship between changing social positions to human suffering within an evolving accumulation process in the food system. 
The contemporary food banking economy coalesces around humanitarian reason as a means through which to legitimize the current corporate environmental food regime. Food surpluses have always expanded the networks of power of actors ruling over their respective food regimes (Graddy-Lovelace and Diamond, 2017), and the food bank is now a site within which that power is negotiated. The moral drive to fix hunger through the food bank is intimately tied with ruling relations regulating the availability of food and the hungry subjects being governed through this surplus. Actors within this humanitarian food supply chain access food by operating within highly differentiated institutional contexts to move food gifts along their course, a trajectory organized and governed at multiple scales through national and state laws, technocratic food insecurity models and management contracts which set forth the rules determining how food waste may be accessed at each network node and whom may access it. These rules are often misinterpreted, bent or broken, a deviance justified by a moral economy of hunger relief that does not always neatly align with its political economic counterpart.

Returning to Vernon's (2007) modern history of hunger, how it came to be viewed and managed as a social problem by the state, markets and civil society, we must contend with his idea that "there is no universal object of humanitarian compassion; compassion has always been contingent, a product of history and politics, time and place" (p.32). The food bank fix today leverages a politics of compassion that governs hunger in very particular ways, one whose motivations and impulses must be closely heeded by any scholar concerned with food justice and food sovereignty. Whether these politics are informed by religion, reason, profit or a failure of the imagination for an alternative we must not forget that when it comes to humanitarianism, "the present is contingent and there are more possible futures than those we are routinely encouraged to see" (Reid-Henry, 2013, p.760). 


\section{The Food Bank Fix}

Melissa Wright (2006) argues that capitalism relies on myths as "socially useful lies" (p.4) that claim unquestionable authority, cloak political situations and shape the possibilities and limits of social action. The food banking fix is one such myth. It is sustained through the idea that hunger can be addressed through food waste recovery, that linking the two is a win-win solution rather than a perverse reinforcement of social inequity. The market-based food system that drives overproduction, food waste and hunger must be protected by the state, and increasingly the shadow state (Wolch, 1990) through Feeding America. The food bank fix, I argue, maintains the stability of primary food markets, while mitigating the moral outrage of a food system that produces scarcity to generate profit.

I use the term food bank fix to theorize the paradoxical relationships between the state, the shadow state, food corporations and local charities that tie the food bank together. The term is inspired by David Harvey's (2001) theory of the spatial fix. According to Harvey, spatial fixes crystallize in moments of crisis, when capital accumulation imperatives necessitate a reorganization of people, networks and built infrastructure into secondary and tertiary circuits that secure the conditions for profit in primary exchange circuits. Food banks emerged in the 1980s to fix problems of over overproduction and under consumption in primary food markets. They are a secondary circuit that absorbs surplus food and staves off crises of overaccumulation in the food system.

The state purchases surplus agricultural commodities to maintain farmer profitability and distributes these foods to the poor. Federal rules accompanying surplus distributions are burdensome to navigate and funding to manage the program is insufficient. Yet TEFAP anchors 
the network through public capital infusions and a reliable source of food. Feeding America (FA) provides access to foods donated to food banks by national food corporations. The certification and public recognition associated with the FA brand gives corporations legitimacy in the humanitarian and philanthropic space but also imposes a strict accountability and governance regime upon regional food banks that does not neatly overlay with local realities. The territorial, logistical and physical feeding lines that form out of this public-private governance structure adapt to the mandates of food donors, not to the needs and obstacles of people confronting hunger, or the local charities laboring to serve them.

Food banks are aggregation and distribution hubs where food surplus is allocated to a network of 'front-line' food charities. On the supply side, food banks work with the state and food corporations who donate food waste as charitable gifts. These gifts come with bureaucratic strings attached, obligations that require food banks to account for food receipts and deliveries based on donor driven criteria and to ensure that their LFCs apply those rules. On the demand side, LFCs order and receive this donated surplus from the food bank based on their different financial and organizational capacities. Although it may appear that food banks are working to address hunger, their overarching social function is to process, distribute and account for surplus food disposed by the state and food corporations. A West Virginia food bank director summed up the work of her organization as follows:

"A food bank is a very complex organism, there are constantly so many fires to put out. It is a collision of different management styles trying to meet demand with scarce resources while fulfilling the mandates of bureaucracies such as the USDA and Feeding America" (FB-2, 7.14.14)

Food banks must work with the variable capacity and capricious ideologies of their local partners to resolve hunger "from below", while executing differing mandates from national donors writing the rules that inform access to surplus food resources "from above". Such a position breeds 
complexity and misunderstandings over the logics ultimately driving the food banking economy forward. Food banks are fixed between the imperatives of national bureaucracies pushing food waste out through a charitable infrastructure and their LFC affiliates working to address food access failure at the local level. Caught negotiating these differing moral demands, their legitimacy relies on catering to either end of a vast and poorly understood public-private assemblage that I explain in detail throughout this work.

Food banks are complex because they are not merely a response to economic crisis, they are also a social response to hunger, a channel for people's moral impulse to fix a collective social problem. The moral drive to fix hunger endemic to capitalist food systems is intimately tied to the evolving politics of humanitarianism (Vernon, 2007). Drawing on feelings of compassion for victims of misfortune, humanitarianism promotes notions of solidarity while reinforcing a politics of inequality, a paradox that binds relations of dominance and assistance into a socially palatable framework of concern organized through a diverse constellation of actors. These include national governments, foundations, NGOs, individual donors, relief workers and the victims they seek to help (Barnett, 2010; Bornstein and Redfield, 2011; Fassin, 2011).

The moral practice of humanitarianism developed alongside the modern capitalist state, functioning as a liberal diagnostic that now serves as a key instrument of the international order (Reid-Henry, 2013). Humanitarian discourse justifies imperial ambitions (Mitchell, 2017) and state violence (Weizman, 2012), and opens new sites of accumulation on the borderlands of global capitalism (Middleton and O'Keefe, 1997, Donini, 2010). The will-to-care for suffering people is thus tangled up with entrenched social hierarchies. Today's marketplace is increasingly moralized (Shamir, 2008), tying consumers, products and humanitarian causes together to save the world (Richey and Ponte, 2011). As the lines between compassion and profit are blurred, it is urgent to 
attend to the ways in which moral geographies are mapped to privilege one structure of care over another.

As the basis for both biological and social reproduction, food access is a highly contested moral issue. Ensuring that everyone is fed is wrapped up in codes and obligations ritualized through millennia of social cohesion and religious tradition. As capitalism breaks apart the communal bonds that serve to mitigate the risk of hunger in times of crisis new institutional forms fill the void, eventually mirroring the scale of the problems created. These institutions circulate new moral sentiments and values that legitimize and justify the adaptive responses to the vulnerabilities produced (Thompson, 1971; Scott 1976; Watts, 1983; Davis, 2008, Vernon, 2007, Fassin, 2009a). Food banks are extremely complex institutions because they negotiate social tensions over the value of food waste on its journey from market obsolescence toward people vulnerable to hunger. As institutional brokers between the food industry, the state and local charities serving the poor, food banks are central to a moral economy that resolves tensions surrounding the monetary value, use value and moral values associated with surplus food and hunger.

While the food bank is largely perceived as facilitating the transfer of surplus foods to feed the poor, I argue that those transfers are controlled to ensure they do not disrupt the profit imperatives driving the food system writ large. Powerful actors govern this network from above and set the rules that determine how these foods should be gifted along a compassion driven supply chain. In 2016, the federal government spent $\$ 700$ million with private contractors to offload market disrupting agricultural surplus into local charitable food circuits. Some of the largest corporations in the world leveraged those same circuits to donate and write off $\$ 2.3$ billion from their tax bills. 
The networks of power that institutionalize food charity in the United States intersect with the material and moral conditions of a deeply unequal society. On the material side, a financialized food system overproduces food to generate shareholder profit (Burch and Lawrence, 2009) even as exclusionary market principles leave millions of people without access to a nutritious diet (Araghi, 2003). On the moral side, manufactured food scarcity mobilizes compassion to recover and redistribute wasted foods that could not be sold (without significantly depressing market prices). Food banks provide the physical and social infrastructure for this awkward alliance of capitalist profit-seeking and charitable care-giving to co-exist.

In this regard, recent work by Ekers and Prudham (2018) provides a helpful extension of Harvey's spatial fix by placing it alongside Gramsci's (1971) concept of hegemony and ideological struggles begot under capitalism. Gramsci argues that dominant power relations are reinforced and legitimized by a dense network of civil society organizations that complement the work of the state. The social struggles over the political and economic alliances that regulate everyday life are attempts to achieve moral unity and quiescence for an ideology. The food bank is inherently ideological, a cultural struggle between social classes and institutions, including the state, in the pursuit of the hegemony over the capitalist food system and the commodification of food that ensues therein.

The food bank fix is achieved by subordinating the moral impulse of those working to alleviate hunger at the local scale to institutional logics that reduce local autonomy and secure profits for private firms. As compassion for victims of hunger is leveraged and commodified to revalue food waste, the burdens of negotiating these dissonant values across the HFN produces tensions among charities of varying sizes and ideologies as they are integrated into a governance structure that includes state nutrition policy and corporate food interests. Actors operating at 
different scales of this assemblage struggle over the values and governance structures that ultimately shape HFNs in the United States. Like all struggles under capitalism, the one to leverage humanitarian sentiment to stave off food system crisis is one laden with power dynamics and uneven resource allocation, a struggle in which those on the periphery are never fully tamed to the will of the powerful, yet also often not fully aware of the powers that be.

\section{Discussion}

The food bank fix resolves the dual crisis of food waste and hunger in the context of a capitalist food system that governs the production of food scarcity through overproduction. The institutionalization of the food banking economy mirrored the expanding powers of the corporateenvironmental food regime to accumulate capital, deepening inequalities between rich and poor eaters. The crisis has engendered new political alignments between the state, the market and civil society that have come to structure a $21^{\text {st }}$ century moral economy centered on resolving food access gaps through charitable giving. The food bank lies at the center of a humanitarian governance structure that orders and represents the distribution of surplus food to the hungry as an unquestionable moral imperative. In the process however, it also produces institutional distance between the many different social actors involved in co-producing this institutional assemblage, and indeed the victims of hunger it seeks to help.

By bringing together literature on geographies of food and hunger, moral economies, crisis theory, access and humanitarian reason my aim is to push food system scholars in general, and those studying food charity in particular, to understand the institutionalization of food banking as a multi-faceted fix to a deep running food system crisis. When considered within the history of the capitalist food system, the food bank is still a novel institutional form, one that can still be 
leveraged to reclaim power over the future direction of our food system. After all, to quote Henderson (2004):

"the food bank is a contingent, nonnecessary (even though explicable) site of politics, discourse, and agency, which happens to have surfaced in society. It has not surfaced accidentally, as Poppendieck brilliantly demonstrates, but, rather, it has surfaced very much through a galvanizing of political and discursive structures [...]. For all of that, 'hunger' is still a site where discourses of moral obligation and social justice are given at least some play." (p.501)

The rise of the food bank fix cannot be divorced from the feeding lines that extended from the colonies, into the metropole and back out again, drawing in the process a cartography of hunger relief that has shaped our moral imaginaries. This map is by no means static. Billions of pounds of food waste are being recovered in the here and now to stave off hunger across the United States. The social and physical infrastructure in place to organize the distribution of this food is not about to disappear. The food bank and the constellation of actors that undergird it however might be articulated differently. The socially necessary representations that cement food charity in our imaginary do not have to further enable the corporate-environmental food regime to encroach its power over the management of food and life. Yet to demythologize the food bank fix and reengage with a politics of hunger that emancipates its victims we must first understand the institutional structures that govern it. In the following five chapters, I provide a thorough review of the bundle of powers that food banks negotiate in their attempt to resolve hunger through food waste recovery. My hope is that understanding how the state, corporations and civil society work to structure our feelings and inform our actions to deliver "free food" to the poor might enable us to take a step toward collectively creating new ways of caring that confronts that power and enables us to reclaim the right to surplus food, thereby reshaping our food system's future to work for people over profit. 


\title{
Chapter 3: The State
}

\begin{abstract}
"One can define the state as an ensemble of socially embedded, socially regularized and strategically selective institutions, organizations, social forces and activities organized around (or at least actively involved in) making collectively binding decisions for an imagined political community. State power can be understood in turn as a power relation that is mediated in and through this institutional ensemble. It is not exercised by the state as such; the state is not a subject. Nor does it originate entirely within the state itself or from among the state's personnel. Instead, it depends on the balance of forces within the wider society as well as within state apparatuses" - Bob Jessop, The future of the capitalist state.
\end{abstract}

\section{Introduction}

When Abraham Lincoln authorized the USDA in 1862 he called it the "people's department" because he envisioned it significantly affecting the lives of every American. At the time, the country was still mostly agrarian with $50 \%$ of the population dependent on farming for their livelihood. Over its 150 years, the USDA evolved alongside the industrialization of agriculture, the urbanization of society and the nation's multiple social and economic crises. The largest of these remains the 1929 financial crash, whose ensuing bankruptcies left the United States economy in severe economic depression. As recently proletarianized millions were laid off and no longer able to source food by exchanging wages, farmers faced devalued assets and markets awash in surplus product. The paradox and moral outrage of want amid plenty saw the USDA grow in stature as New Deal interventionist policies expanded agricultural price supports and nutrition assistance programs (Poppendieck, 2014).

The relationship between nutrition and agricultural overproduction continues to inform food policy interventions in the United States (Graddy Lovelace and Diamond, 2017). As I argue throughout this chapter, the food bank plays an increasingly prominent role in resolving the contradictions of a society awash in food, yet still rife with food insecurity. Humanitarian food networks (HFNs) are widely perceived as a private food relief network responding to neoliberal 
economic policies of a waning public sector. My findings however demonstrate that the state remains a critical institutional actor in the wider food banking assemblage. Widespread belief in market triumphalism forces scholars today to understand the role of the state in structuring the markets that feed off austerity regimes. State institutions should be understood as social relations that are continually reinventing themselves to secure the necessary public legitimacy for their authority to govern (Jessop, 2002). The USDA is a key site of struggle within the state's apparatus, acting as broker between local, regional and global constituencies. Its food and nutrition policies work to balance social welfare domestically while writing and enforcing rules that protect US farm interests in domestic and global markets. These markets do not emerge in a vacuum, they are not merely ideological principles, rather they must be built and maintained through state intervention.

Although its role in society is not always visible, the USDA is an important institution in the moral economy of food provisioning in the United States. As national food policy filters through layers of federal bureaucracy, to states and on to consumers, the critical role played by the USDA in the food system, the wider economy and indeed the lives of nearly every person in the country, is often hidden. The USDA balances and mitigates the unpredictability of food markets for farmers and consumers, while ensuring the safety of food products and the viability of future crop production. Capitalist food systems do not emerge in a vacuum, they are regulated and maintained by the state to direct the invisible hand of the market with a strong regulatory fist (Watts, 1994). Those working within the confines of the USDA's multifaceted institution draw satisfaction from the idea that their work resolves the crises inherent to a market-based food system. A USDA bureaucrat summarized the sentiment that motivates this regulatory work: "A lot of us believe in what we're doing, it keeps us coming to work every day. We are here for two 
reasons, to help US agriculture and to provide food to those who need it. We all believe the same thing" (USDA-2, 10.27.15)

Without the state, food banks would implode. The federal government and state governments have been active in both the destructive "roll back" and creative "roll out" moments of the institutionalization of food banking (Peck and Tickell, 2002). The state regulates tax relief for private charitable food donors and the state injects public commodities and money into food banks. Scholarship on food banking however has not fully developed the role of the state in undergirding and regulating food banking economies. Lindenbaum (2016) contends that food banks play only a minor role in state activities. Warshawsky (2010) argues that food banks are a response to state roll-backs, parastatal institutions of a neoliberal governance regime. Poppendieck (1998) recognized the critical role of government as the "silent partner" (p.121) in the roll out of emergency food provisioning, a stabilizing force that fostered the rise of HFNs in the 1980s and 1990s. Her analysis of the state's role in this process however is fractured across her argument about the rise of charity as a moral safety valve that justified the roll back of food and welfare entitlement programs.

According to Harvey (1982), the state is the most important channel for the flow of value into social infrastructure through large capital investments into the built environment such as dams, airports, roads, water and sewage systems and other components of the consumption fund. My central argument in this dissertation is that food banks are an infrastructural fix that resolves the dual problems of surplus labor and overaccumulation along agro-industrial supply chains. The food bank's physical imprint on the food access landscape is expanding, not outside of the state, but embedded within its shifting power relations. In this chapter, I look specifically at the role that the USDA plays in maintaining the viability of food banking economies through The Emergency 
Food Assistance Program (TEFAP). TEFAP provides large amounts of high quality food and yearly administrative funds that anchor food banks and the wider HFN in place. As I discuss in the next chapter, the state also shapes tax policies that spur market incentives to donate obsolete corporate inventories to charity.

The food bank fix could not have been achieved without state intervention. By providing food, funding and philanthropic stimulus to roll out the HFN infrastructure, the state must be understood as the harbinger of food banking, not merely civil society's response to state retrenchment. Since 1983, the federal government has provided nearly $\$ 1.8$ billion in administrative funding to maintain food banks in place, a consistent capital injection no private firm or foundation would ever undertake. The 4.6 billion pounds of food appropriated as TEFAP entitlement over that same period ${ }^{7}$ further spurred the capitalization of food banks by private philanthropic capital. Food banks are highly dependent on TEFAP to provide a steady supply of nutritious foods to people across their service areas. Federal commodities accounted for $40 \%$ of the total food mix distributed by the two food banks in West Virginia last year. However, the funding that these organizations receive from the state to manage this work represents only 12 to 27 percent of their operating budget (Cabili et. al, 2013). The remainder must be raised by costsharing with their local food charities (LFCs) and from private third-party philanthropic sources.

TEFAP is a very small cog in a massive state agricultural policy machine. The program purchases domestic food commodities for poor US residents at risk of hunger, explicitly coupling agro-food interests with the biopolitics of food provisioning (Nally, 2011). TEFAP itself is an assemblage working within the USDA's many overlapping and oft contradictory missions. The program is administered by two different agencies. First, the Food and Nutrition Service (FNS)

\footnotetext{
${ }^{7}$ Again this figure does not include CCC "bonus" foods, I estimate the total number of pounds distributed over the history of the program to be closer to 12 billion.
} 
manages entitlements appropriated through the farm bill and passes these on to state governments (e.g. WVDA in West Virginia). Second, the Agricultural Marketing Service (AMS) works to mitigate the adverse effects of price volatility for farmers. AMS contracts with private food industry actors to relieve market gluts and redirect surplus commodities into nutrition entitlement channels. TEFAP's multi-agency mandate provides a fascinating window into the USDA as an institution and the broader contest over the social role played by the state in food banking economies.

Like all USDA nutrition programs, there are rules and regulations surrounding the distribution of TEFAP resources that significantly affect food banking geographies, ruling relations that I explain and analyze below. Uncovering the relationship forged between state and private actors through TEFAP, also poses questions about the role that other state driven nutrition programs play in the wider food system. Well beyond the scope of this dissertation, it is important to note here that SNAP and WIC regulate and subsidize retail food markets. School nutrition programs provide a vent for excess farm product, while boosting private food service sales under state reimbursement contracts. Unpacking the politics of access to nutrition programs unveils the power dynamics that dictate the social parameters shaping public food entitlement in its various forms. These rules structure the right to food in different places and dictate the distribution of financial benefits derived from the commodification of food under capitalism. Unpacking the ruling relations of the TEFAP program here thus provides a glimpse into the moral economy of the contemporary capitalist food system.

The chapter is structured as follows. I first present the state as the primary force stimulating the initial capitalization of food banks in the 1980s. I highlight the awkward coupling of farm industry concerns with emergency hunger relief during a time of social crisis in the wake of Reagan 
and Clinton era welfare cuts, and then Obama era recovery efforts after the 2008 financial crisis. The history and evolution of TEFAP provides the basis from which to theorize the state as a key ideological driver of the food banking fix, and its ongoing role in maintaining private charitable programs that address overproduction and hunger. Next, I place TEFAP in relationship to the farm bill that funds it, briefly discussing the historical and institutional links between the largest of the 15 USDA nutrition entitlement programs namely SNAP, WIC and school-based child nutrition programs. Third, I explain the politics of access to TEFAP resources that sustain food banks, and the geography of TEFAP food and funding allocation across the HFN. Finally, I analyze TEFAP supply chains at the state level through my West Virginia case study. I explain the legal geography that informs the distribution of commodities and money at the local level, and the contentious place that TEFAP holds in the politics of feeding across the state.

I conclude by arguing that although TEFAP is a bureaucratically burdensome program that may serve the financial interests of a limited number of federal food contractors, it is nonetheless one that opens a space within which to discuss the important role the state still plays in the charitable response to hunger. The governance mechanisms, checks and balances arrived at through a long history of democratic consensus, maintain a degree of social justice and civil rights obligations on the part of participating charities. TEFAP foods must meet federal nutrition standards and source a certain percentage of their foods from small and medium sized businesses that spreads the wealth generated through state contracts more evenly across the economy. As social goodwill over anti-hunger causes is increasingly channeled toward private firms through their cause marketing initiatives (chapter 4), TEFAP offers an opportunity to think about the state, not only as a regulatory apparatus, not only as a tool of capitalist accumulation, but as a site of 
struggle and important vehicle through which to push back against the consolidation of the food system into a few powerful corporate actors.

\section{The TEFAP Fix}

The TEFAP program finds its origins in response to two distinct crises linked to the transition toward a post-fordist accumulation regime (Harvey, 1989). First a period of deep economic contraction during the recession of the 1970s and early 1980 led to food access failure. Rather than responding with an expansion of food entitlement programs as had historically been the case since the 1930s however, the Reagan administration's neoliberal ideology tightened eligibility standards for public entitlements and made important cuts to food stamps, school meal programs, summer feeding programs and WIC (Poppendieck, 1998). Along with the roll back of welfare and other social service programs, many poor households were forced to shift their limited resources to cover new housing and heating costs, creating endemic household food access shortfalls. Unemployment and inflation was high during this time and many families visited soup kitchens and food pantries for the first time because they could no longer afford to buy food.

Along with these socio-economic factors, the creation of the TEFAP program is linked to a second crisis of overproduction, namely a massive liquid milk and cheese glut. In the late 1970s and early 1980s, the federal government had been purchasing and stockpiling over 500 million pounds of cheese and butter in state food warehouses across the country to stabilize milk markets and protect dairy farmers from bankruptcy. The state's capacity to intervene in this way was enabled by the institutional scaffolding built under New Deal Era food policy, namely the Commodity Credit Corporation (CCC). Created in 1933, CCC is a state enterprise under the general supervision of the secretary of agriculture "for the purpose of stabilizing, supporting, and 
protecting farm income and prices" (Commodity Credit Corporation Charter Act, (62 Stat.1070; 15 U.S.C. 714), 2012).

The paradox of mountains of cheese rotting in government storehouses in a context of rising homelessness and food insecurity rates was picked up by the national press and became a rallying cry for anti-hunger groups exposing contradiction in federal food policy. Political pressure on the new Reagan administration to act led to the creation of the Special Dairy Distribution Program (SDDP). In 1981 "government cheese" was released from CCC warehouses for distribution to the poor through non-state charitable actors, setting in motion a decentralizing logic made particularly apparent in Reagan's statement accompanying his authorization of SDDP:

"At a time when American families are under increasing financial pressure, their government cannot sit by and watch millions of pounds of food turn to waste. I am authorizing today the immediate release of 30 million pounds from CCC inventory. The cheese will be delivered to the states that request it and will be distributed free to the needy by non-profit organizations" (December 22, 1981).

Because of the temporary intent behind SDDP, there were very few rules and regulations pertaining to the distribution of this food. States could opt in if they wanted the surplus cheese (and later butter) and local agencies handled the distribution with full discretion to determine who was needy. Local empowerment, the promotion of volunteerism and the devolution of government responsibility aligned with the neoliberal agenda espoused by Reagan ideologues who wanted to limit the size of the federal bureaucracy. Lipsky and Thibodau's (1988) in depth review of the evolution of the politics of the TEFAP program during this time provide insight into the laissezfaire logic of such policies:

Shortly after the President's announcement, the Food and Nutrition Service (FNS) of the USDA notified states of the guidelines that would govern the distribution of cheese. There is every indication that the Special Dairy Distribution Program (SDDP), as it was called, was intended to be a relatively informal giveaway of surplus cheese with a minimum of rules and regulations. States were to enter into a contract with the FNS for receipt of the product. The contract specified that upon delivery states were to distribute cheese to traditional providers of congregate meals and to community food banks. The states were 
to place orders with the FNS, which would make a final determination on a state's allocation on the basis of population. No explicit eligibility criteria were imposed on the states, though they were implicit by virtue of the composition of recipient agencies. Thus, the federal government was to supply food; the states were to arrange for local allocation and distribution; voluntary nonprofit organizations were to be responsible for giving it away (p.225).

Under pressure from states, food banks and local agencies lacking the financial resources to manage the influx of this public food, the U.S. Congress passed legislation authorizing a $\$ 50$ million appropriation to subsidize administrative costs of running the program. Under Title II of P.L. 98-8 (The Jobs Bill), Congress created a successor to the SDDP in 1983 under the name Temporary Emergency Food Assistance Program (TEFAP). The same legislation also expanded the types of commodities offered to states to include other CCC purchases including cornmeal, flour, honey and rice. The need for oversight, transparency and accountability of expanded food and funding disbursements created new layers of bureaucracy, further institutionalizing the program. Designed as a temporary fix, the sudden availability of free surplus available at participating charities led to the depletion of commodity inventories in less than 5 years. Rather than reverse the adverse effects of welfare reform to solve this problem, The Hunger Prevention Act of 1988 directed $\$ 120$ million toward the annual purchase of farm goods in addition to existing CCC contracted excesses and the $\$ 50$ million earmarked to manage distribution logistics. By 1990, TEFAP's name was officially changed to The Emergency Food Assistance Program reflecting the permanent place it had come to secure in the USDA's nutrition assistance programming. Food banking was formerly fixed in place as an appendage of federal food policy. Besides a hiatus between 1994 and 1996 in which a commodity glut meant no monies were allocated to TEFAP purchases, the program stabilized into a steady $\$ 140$ million appropriation every year through 2009. 
By 1996 the Personal Responsibility and Work Opportunity Reconciliation Act (Clinton's Welfare Reform Law) further rolled back public entitlement programs all but decimating the Temporary Assistance for Needy Families (TANF) program. PROWA led to a further roll out of and structuring of TEFAP, defined the formula used to allocate food and funding to each state and codified the role of Emergency Feeding Organizations (EFOs) in that distribution, a classification that further entrenched food banks as primary outlets for government food distributions (Poppendieck, 1998).

The fallout from the 2008 financial crash resulted in mass layoffs across the United States. Unemployment quickly rose from $4 \%$ to $10 \%$ and consumer spending plummeted with the loss of economic confidence. The Obama administration responded with a large expansion of TEFAP through the American Recovery and Reinvestment Act (ARRA). Alongside a spike in commodity purchases, ARRA administrative funding for TEFAP more than doubled in FY 2009 and 2010 and $\$ 6$ million dollars in infrastructure grants were made available for food banks to expand their storage and distribution capacity.

Six years later, as debates raged about the need to cut SNAP and other food entitlement programs that had ballooned following the recession, the 2014 Farm bill quietly increased the amount of funds appropriated to purchase TEFAP foods expanding funding for the program by $35 \%$ through 2023. The administrative appropriation to manage the logistics of distributing TEFAP remained at a meager $\$ 50$ million a year, while funds for the purchase of commodities increased steadily plateauing at a planned $\$ 400$ million between 2018 and 2023 (Agricultural Act of 2014). This was the largest proportional increase to a federal nutrition program under the bill that shapes and projects future US food policy. While other entitlement programs are constantly 
under threat from a U.S. Congress currently bent on reducing the state's food entitlement costs, TEFAP is on a healthy growth trajectory (Figure 3-1)

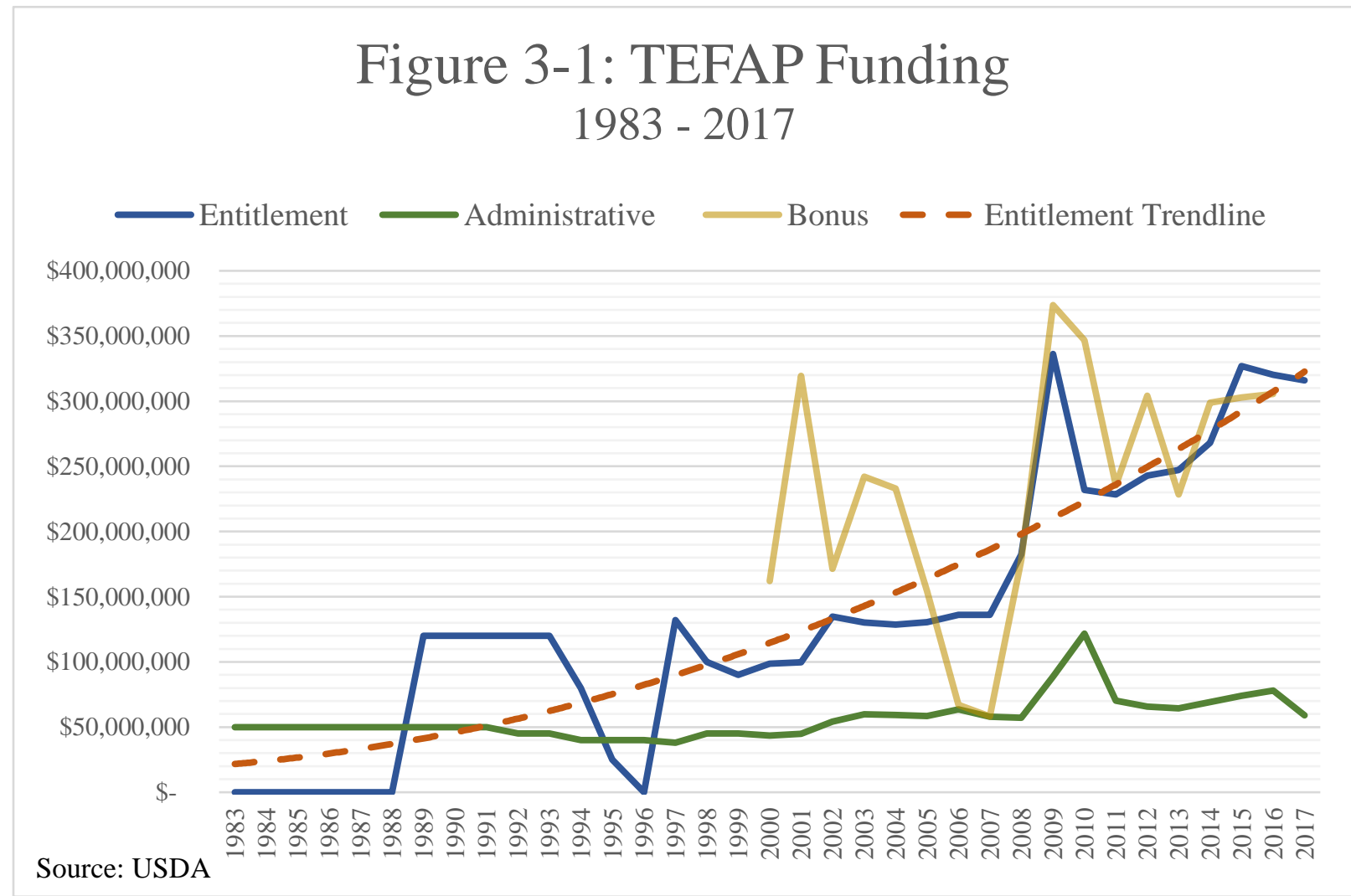

TEFAP entitlement is money appropriated by Congress and allocated to states to purchase agricultural commodities through FNS. This food is supplemented by so called "bonus" commodities purchased by AMS to offload production excesses and stabilize gluts from targeted industries $^{8}$. Geopolitical factors play a role in the availability of TEFAP "bonus" foods. Following the annexation of Crimea in 2014 for example, the embargo and export restrictions on Russia led to a rise in frozen chicken donated circulating through TEFAP. The Trump administration's recent tariff policies have also seen an explosion of TEFAP foods circulating through the HFN. These

\footnotetext{
${ }^{8}$ I was not able to secure historical data on TEFAP "bonus" food purchases prior to 1999
} 
"bonus" commodities arrive on an ad hoc basis and do not include administrative support for the labor and infrastructure necessary to move millions of pounds of extra food around to LFCs.

TEFAP regularly includes high quality specialty foods such as cherries, dates, figs, nuts, salmon and other products not typically part of the local canned food drive. In FY 2014 for example AMS purchased $\$ 33,098,705$ worth of dried, canned and juiced cranberries after requests made by the U.S. Cranberry Marketing Committee struggling with high supply and low prices. Food banks across the country then received an influx of cranberry products to deliver to their LFCs. These requests are often processed by marketing orders, industry groups that are a part of the USDA governing apparatus. Authorized under federal law since 1937, marketing orders are considered an "instrumentality" of the USDA overseen at the discretion of the Secretary of Agriculture?

The liquidation of agricultural surpluses to feed the hungry is not a novel initiative for the federal government. The history of American nutrition assistance policy is intimately tied to resolving overproduction along agricultural circuits. The significant evolution in this case was SDDP's and later TEFAP's overt enrollment of private charities to distribute the surplus, rather than relying on county-based government programs as had been the case in the New Deal era. This does not negate the state's role, rather TEFAP reorganized it by playing a major role in subsidizing, formalizing and centralizing the voluntary sector's response to hunger. It also legitimized the need for what were previously ad hoc and uncoordinated networks of emergency food providers (Lipsky \& Thibodeau, 1988). Daponte and Bade's (2006) review of the evolution of private food assistance networks in the United States summarizes the interaction between public and private responses to the state's humanitarian logic in the early stages of the TEFAP program:

\footnotetext{
${ }^{9}$ For a comprehensive list of AMS marketing orders refer to: https://www.ams.usda.gov/rulesregulations/moa/commodities
} 


\begin{abstract}
"The Reagan administration believed it had found the optimal solution to hunger. [Commodity redistributions] pleased farmers by stabilizing prices and appeased (and distracted) the anti-hunger community. By providing for operational support to the private food assistance networks, the program also pleased the food industry, which in addition to donating food out of goodwill, found that it could use the network as an outlet for disposing of food for which it might otherwise have had to pay salvage costs" (p.677)
\end{abstract}

As I examine in chapter 4, the state also funded the formation of the coalition of food banks under the Second Harvest banner (now Feeding America) from 1976 to 1982. Since 1996, the Good Samaritan Act has also catered state tax policy to the food industry to facilitate the transfer of manufacturing and retail surplus into food banking circuits. Earlier still, the federal government encouraged the creation of food pantries and the network of LFCs that emerged out of the Community Action Network in President Johnson's war on poverty in the 1960s. The state has thus been present in the roll-out of emergency food programs for nearly a century, truly the "silent partner" that begot the food banking economy.

The legacy of Reagan's neoliberal idealism has left millions dependent on emergency food aid in the United States. $20 \%$ of this food is purchased by the federal government from private industry concerns. Even as his administration advocated for self-regulating markets, reduced tax burdens, cuts to social welfare and nutrition programs, his and all subsequent executive administrations put in place mechanisms to govern the redistribution of food surpluses generated in part by state subsidies to agro-industrial concerns. Today TEFAP is a regular and uncontested line item in each iteration of the farm bill, one that is in fact projected to grow in the next iteration. A relatively small nutrition entitlement in the overall budget, it nonetheless plays a critical role in capitalizing and fixing food banks as an appendage of state policy.

In the following section I review the way in which TEFAP is governed at the federal level and how the program fits within broader national food and nutrition policy. I do this by first placing TEFAP in the context of the 2014 farm bill that currently authorizes its existence. I next map the 
relationships between TEFAP and the food banking economy through an overview of the key institutional actors sourcing food and administering the program. I explain how the purchase of federal food commodities are contracted with private for-profit firms, and how this entitlement is then allocated to state level agencies. My analysis of a seemingly mundane bureaucratic process ultimately serves to highlight how the USDA, and by extension capital investments by the federal government, serves as one of the key hegemonic social blocs maintaining food banks in place.

\section{Nutrition Entitlement, the Farm Bill and Funding}

Out of the roots of 1930 s food policy fixes, the USDA has overseen the intermittent expansion of state nutrition assistance into different programmatic branches. These have been nurtured and pruned along with the shifting political winds of the past century. Formerly known as food stamps, the Supplemental Nutrition Assistance Program (SNAP) is the largest of these programs. An outgrowth of the initial commodity distribution schemes of the 1930s that connected national farm surplus to needy households, SNAP is today a cash-equivalent entitlement used by millions of households whose income falls below $130 \%$ of the federal poverty line. Because all federal food entitlement is needs based, participation in domestic food aid programs has historically been countercyclical, expanding as the economy contracts. For example, each 1 percent rise in unemployment leads to 1 million new participants enrolled into SNAP. These programs are also significant stimuli during times of economic crisis. Drawing again on SNAP as an example, the USDA's Economic Research Service (ERS) estimates that each \$1 billion increase in SNAP expenditure, stimulates wider economic activity by $\$ 1.79$ billion, creating nearly 10,000 jobs across a variety of sectors from agriculture to transportation, food manufacturing and retail. (USDA-ERS, 2017). 
The majority of the USDA's operational budget comes from the farm bill. Renewed approximately every five years this massive piece of legislation is a hotly debated food policy tool that outlines the level of funding each branch of the USDA can be expected to receive, and the rules associated with the disbursement of those monies. Despite attempts by many legislators to separate nutrition entitlement and food production programs, the 2014 farm bill maintains the status quo set in 1973 wrapping food producers and consumers together into an omnibus legislation. The union maintains a symbolic link between the production of and access to food in the United States.

There are four major funding allocation categories in The Agricultural Act of 2014. Crop Insurance administered by the Farm Service Agency (FSA) is meant to shield farmers from crop failures. The commodity program jointly administered by the Agricultural Marketing Service (AMS) and FSA buys corn, wheat, soybeans, rice, cotton, peanuts, dairy, meat, poultry, fruit and

\section{Figure 3-2: 2014 Farm Bill Allocations (\$ billions)}

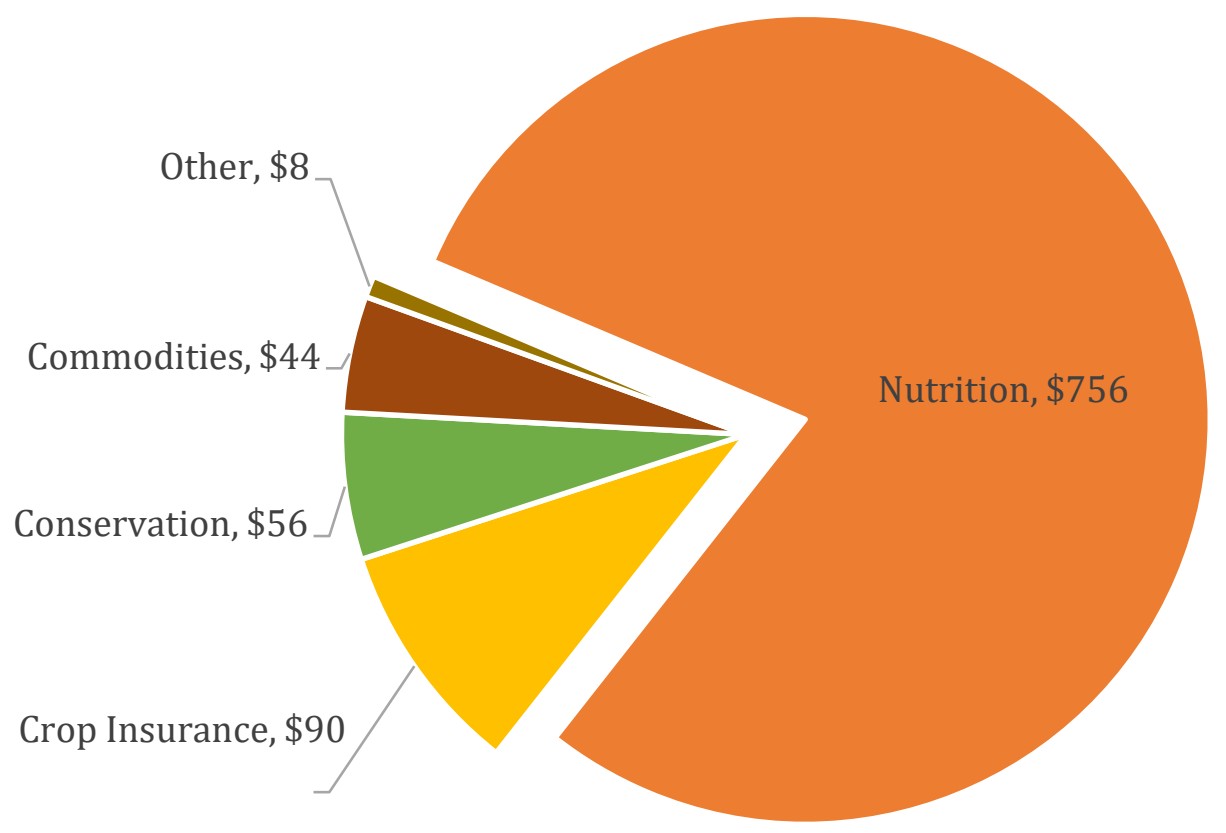

Source: USDA 
vegetable products and other nationally produced foods to maintain steady farmgate prices. Programs administered by Natural Resources and Environment (NRE) encourage soil conservation and ecologically sound farming methods including the protection of forests and wetlands. Finally, with a $\$ 756$ billion budget, the USDA's Food and Nutrition Service (FNS) has by far the largest piece of the farm bill pie (figure 3-2).

The federal government provides massive public capital inputs to nutrition programs to address its historical mandate to subsidize and maintain the viability of the agricultural sector, balance overproduction and mitigate household food insecurity. It does not do so coherently however. US nutrition programs administered by the USDA are an entitlement patchwork that reflects the fractured response to widespread food access failures at different historical moments, and the variable political will to respond to social demands for the right to food over the past 90 years. There are 15 nutrition assistance programs administered by FNS. I focus below on the three largest including Supplemental Nutritional Assistance Program (SNAP), Special Supplemental Nutrition Program for Women, Infants and Children (WIC) and Child Nutrition programs which include the National School Lunch Program (NSLP) and the School Breakfast Program (SBP). The brief review provides context for my later discussion and analysis of TEFAP in the overall food policy mix and the role that it plays in cementing the food bank fix among a host of other nutrition programs that connect surplus food to food insecure households ${ }^{10}$.

Before diving into TEFAP's role in the wider food system, I briefly review the major nutrition entitlement programs available to poor consumers to contrast these with TEFAP's function. Although TEFAP is funded as an anti-hunger program, it is clearly centered on agricultural surplus removal. Furthermore, TEFAP is one of the few FNS programs whose

\footnotetext{
${ }^{10}$ Hoynes and Schazenbach (2015) provide a well referenced review of the history and economic impacts of US food and nutrition programs in a study conducted on behalf of the National Bureau of Economic Research.
} 
eligibility is determined at the state rather than the national level. Other than the requirement that states and U.S. Territories abide by the Code of Federal Regulations, there are no standardized approaches to TEFAP across jurisdictions. Each administers the program differently, leading to a fractured TEFAP assistance landscape across the country. States differ in their modes of commodity distribution, the number of charitable contractors they employ to implement the program, the income criteria used to determine need, and the allocation of resources across their territories. Some support the food banking infrastructure with state levied funds, while others rely solely on federal administrative money (Jacobs, 2016). The lack of coherence in the TEFAP program allows for flexibility but also produces uneven capitalization of the HFN across the country. As an anti-hunger program therefore, TEFAP remains fractured and problematic with regards to household level entitlement access.

There are many common features across other FNS programs. They are all means tested, meaning they are limited to qualifying individuals and households with limited income (and sometimes limited assets). Although not initially designed as complimentary programs, they all share the same goal of ensuring adequate nutrition for vulnerable populations. The U.S. social safety net is itself a patchwork of initiatives ranging from welfare cash disbursements (TANF) to public housing (HUD) and healthcare (Medicaid/Medicare). Important to note is that these other welfare programs are pass-through funds provided at the state or local level, whereas most food and nutrition programs are administered at the federal level providing a basic floor for protecting food insecure households that is similar across the country.

There are also many ways in which these programs differ. First, each target specific populations from the near universal eligibility for SNAP, to the narrow age and gender requirements for WIC, to students enrolled in K-12 schools for child nutrition programs. Second, 
income eligibility also differs from $130 \%$ of the federal poverty line for SNAP to $185 \%$ poverty for WIC, to free or reduced meals for children based on a sliding household income scale. Third, the distribution of benefits varies considerably across programs. SNAP is a cash equivalent payment that covers all food products with a USDA nutritional label, along with fruits, vegetables and seeds and seedlings. WIC employs a much narrower prescriptive voucher system that focuses on nutritional quality and quantity for pregnant and breast-feeding mothers, and children up to 5 years of age. WIC vouchers are only redeemable at select retailers who are monitored by statelevel agencies to ensure they regularly stock approved WIC food products. Eligibility for WIC vouchers is also contingent on regular check-ins with local WIC offices where participant health is monitored, and nutritional education provided. Students participating in child nutrition programs receive a direct provision of meals from the school cafeteria whose cooks are required to conform to USDA nutrition guidelines. Fourth, the programs vary in the ways in which families phase out of them based on income changes. The so called "cliff effect", an abrupt end to nutrition entitlement due to a life change (e.g. pay raise or child ageing out of WIC) or a seasonal shift (e.g. school vacation) often leads individuals and households into emergency food assistance programs. Many source foods from charities even though their income may be too high to qualify for SNAP for example.

\section{A. SNAP}

SNAP (formerly known as Food Stamps), is the most important food provisioning program for needy families. $75 \%$ of the FNS budget is allocated to $1 / 6^{\text {th }}$ of US households to purchase groceries every month at authorized retail locations. Food retailers can participate in the SNAP program by stocking a mandated staple food minimum in four different categories including vegetables or fruit, dairy products, meat, poultry and fish, breads and cereals. The relatively lax 
retail requirements mean that SNAP dollars are redeemable at nearly every food retailer from gas stations to big box supercenters and increasingly at local farmer's markets as well. Retailers are provided with a direct cash equivalent for all the food items they sell under this program. SNAP benefits are calculated on a household basis through the Thrifty Food Plan (Babb, 2017) disbursing on average $\$ 257$ per household or $\$ 125$ per individual, which translates to approximately $\$ 4$ per person/day. SNAP also acts as an indirect subsidy to food retailers who benefited from the wide increases in enrollment in the wake of the 2008 Great Recession (Shannon, 2016). Beyond the value provided to the retail sector, SNAP also directly mitigates economic hardship experienced by families across the United States. A 2014 study established that SNAP lifted 4.7 million people out of poverty, including 2.1 million children (Short, 2014).

\section{B. WIC}

WIC aims to improve birth outcomes and support healthy development of infants by providing nutritional services, education and cash food vouchers to low-income pregnant and postpartum women, infants, and children under the age of five who are at nutritional risk. Documented immigrants are also eligible for WIC. All participants must be deemed to have a nutritional risk factor, however virtually all financially eligible applicants fulfill this requirement due to their potential for dietary deficiencies. ${ }^{11}$ WIC benefits do not vary according to income, and those who qualify receive the full package of vouchers which includes free access to WIC approved foods. These are chosen for their nutritional qualities including protein, calcium, iron, vitamin A and C. This translates to a monthly allotment of baby food (including formula) for children under 1 year of age, and juice, fortified cereal, eggs, cheese, milk, dried legumes or peanut

\footnotetext{
${ }^{11}$ Factors include low maternal weight gain, inadequate growth in children, anemia, dietary deficiencies, obesity and other nutrition-related medical conditions. Risks can also include homelessness and migrancy, drug abuse and alcoholism.
} 
butter and canned fish for mothers and their non-infant children. States work with approved food retailers to determine the types of foods allowed under the program, most often the cheapest available items or the store brands of the authorized store. As the corporate retail landscape has consolidated over the decade the number of places to redeem WIC vouchers has declined, leading to an overall drop in WIC participation rates, particularly in rural areas (Andress and Fitch, 2016). The symbiosis between WIC and state approved retailer outlets raises questions about the dependency of the program on placating corporate food interests, though to my knowledge no study has yet undertaken such an analysis.

\section{Child Nutrition}

NSLP and SBP combine to meet nutritional needs of low income students in K-12 schools. Predecessors of NSLP date back to the Great Depression when the federal government began distributing surplus farm commodities to schools with significant populations of malnourished children. The program formalized under the 1946 National School Lunch Act. SBP emerged much later as a hegemonic contest between black activists and a federal government keen to respond to perceived threats posed by the Black Panther Party's free breakfast for children program in inner city communities across the country during a period of heightened racial tensions in the 1960s and 1970s (Heynen, 2009). SBP was piloted in 1966 and permanently authorized in 1975. Both programs follow the same eligibility criteria. Children from households below $130 \%$ of poverty receive free meals, while those below $185 \%$ received reduced cost meals. Children above these thresholds may also purchase subsidized meals. School districts receive a cash subsidy from the state equal to $\$ 2.98$ for free lunch, $\$ 2.58$ for reduced lunch and $\$ 0.28$ for paid lunch. Breakfast subsidies are $\$ 1.62, \$ 1.32$ and $\$ 0.28$ respectively. The community eligibility provision (CEP) piloted in 2011 and formalized in 2014, allows school districts with a large proportion of qualifying 
students to adopt a universal free meal program for all students, an evolution that has significantly increased participation rates in child nutrition programs across the country.

Approximately $20 \%$ of the foods served in K-12 schools across the country are sourced from federal commodity purchases passed on to states. This percentage varies across school districts, depending on the financial resources available at their disposal to purchase food. Subsidized food commodities are available to purchase by county school boards from the state level agencies administering the program. Most school districts however also work and collaborate amongst themselves to source from private food service companies such as Sysco due to the wider choice selection and integration with the supply chain needs of large feeding operations. ${ }^{12}$

The 2010 Healthy, Hunger-Free Kids Act made major changes to nutrition outcomes under child nutrition programs, expanding requirements from a minimum calorie per meal metric to include daily and weekly food group servings. These include specific targets such as vegetable variety and whole grains. Schools that achieve these standards receive an additional $\$ 0.06$ payment per meal. The Act also gave the USDA authority over the nutritional standards for all foods sold in schools (e.g. vending machines). I have found that this standard often creates conflict over the recent roll-out of K-12 school food pantries and charitable backpack programs, because private charities do not have to conform to the same nutritional requirements as foods sourced by county school boards.

\section{Fixing hunger}

I reviewed these federal nutritional entitlement programs to signal how each promotes a different fix to hunger under the capitalist food system. Food access failures do not happen in a

\footnotetext{
${ }^{12}$ In North Central West Virginia for example 17 county school districts have formed a cooperative to coordinate their school meal purchases and access the economies of scale pricing that comes with that collective buying power.
} 
vacuum, they are intricately connected to wider political economic dynamics and indeed the hegemonic contest over whom should bear burden of ensuring that all people receive adequate nutrition. SNAP, WIC and Child Nutrition programs all resolve specific contradictions that emerged out of food access crises at different moments in time. The retail landscape that informs most food sourcing strategies today is vastly different than it was in the 1930s when many of the foundational bricks of these programs were laid (Bedore, 2013). Farm production and food processing is likewise constantly changing as private firms seek a competitive edge in a food regime that is by no means fixed (McMichael, 2009). Hunger is not an exception in a capitalist food system but a constant part of it. Because food is a commodity, the production of food scarcity provides the basis for profit whether that profit comes from the exchange of wages or the exchange of public funds that subsidize inadequate or inexistent wages.

What I want to make explicit here is that nutrition programs have evolved with the state as part of a long and uneven history of consensus achieved within the imperfect and fraught democratic process of modern statecraft (Vernon, 2007). Revisiting the epigraph that opened this chapter, we must think of these public anti-hunger programs, the farm bill they fit within and the USDA more broadly as part of the "ensemble of socially embedded, socially regularized and strategically selective institutions, organizations, social forces and activities organized around (or at least actively involved in) making collectively binding decisions for an imagined political community" (Jessop, 2002, p.6). In the following section I hone in on TEFAP as a small but highly significant piece of the federal food entitlement puzzle. I argue that it is instrumental in fixing food banks in place through a state strategy of linking agricultural overproduction to hunger relief programming. It also serves to fix hunger into the permanent social imaginary of the US public, depoliticizing its causes and enrolling private actors into a well-rehearsed response that legitimizes 
a capitalist food system that produces hunger. The roll-out of HFNs by the state has reinforced and structured the need to feed, devolving the state from its responsibility to secure social security and equity. The state is thus not disappearing through the food bank; it is strategically re-aligning to reproduce itself in light of the emergent corporate environmental food regime (Friedmann, 2005).

\section{TEFAP Funding}

The food banking economy depends on one of the seemingly most insignificant slices of the farm bill pie (figure 3-3). Far from being irrelevant however, the 2014 farm bill legislated TEFAP funding to grow by $35 \%$ between 2015 and 2018, a higher rate of increase than any other federal nutrition program. In the grand scheme of a trillion dollar bill a few hundred million may seem trivial, but I argue that TEFAP punches well above its weight in terms of the value it generates for the state to legitimize its role in securing the corporate food regime. Commanding a mere $1 / 4$ percent of the FNS budget, this program seeks to reduce the impact of entitlement cuts in other areas while generating new forms of value in agro-industrial supply chains by differentiating markets. In this case TEFAP creates novel food markets that exclusively serve the poor through the HFN. Reflecting on the history of the program and the current Trump administration's Reagan like economic posturing, the household programs operations branch chief at the FNS thought that TEFAP may continue to gain importance in the coming decade.

"Right now, TEFAP is at its highest allocation ever at $\$ 350$ million per year and next year will be $\$ 400$ million. Could it go up to $\$ 1$ billion? I think the [Trump] administration would like it to because there is a direct relationship between TEFAP and industry. I mean it's not huge, but $\$ 350$ million is nothing to sneeze at!" (USDA - 4, 2.15.17) 


\section{Figure 3-3: 2014 Farm Bill - FNS budget detail}

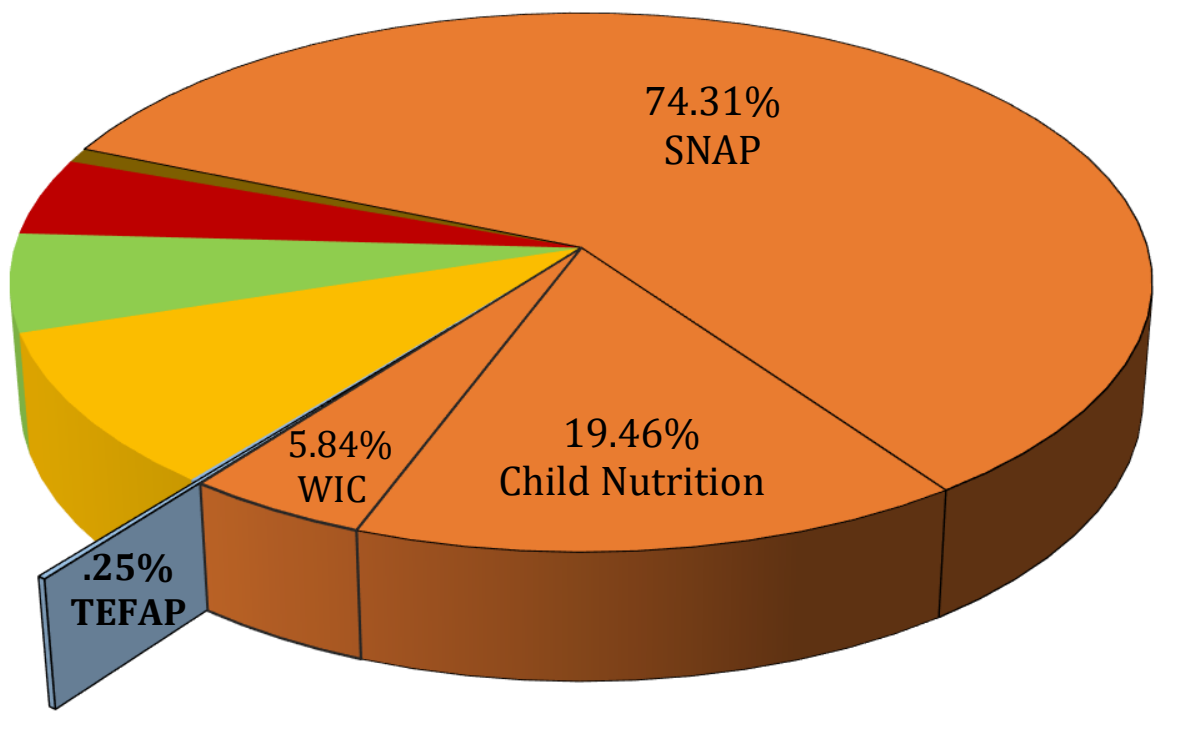

$\square$ Crop Insurance $\quad$ Conservation $\quad$ Commodities $\square$ Other

Source: $U S D A$

The $\$ 350$ million mentioned are strictly appropriations for TEFAP food entitlements. There are in fact three different sources of funds that keep the program running: entitlement foods, "bonus" foods and administrative support.

TEFAP operates across multiple public agencies within the USDA, an administrative nesting that veils the important social function that the program plays in the food banking economy and indeed the wider food system. FNS focuses on implementing nutrition policy for vulnerable households. AMS works to protect agricultural markets and farm interests. FSA regulates commodity contracts with private industry. Finally, states administering TEFAP vary their application and programmatic approach ultimately producing a fractured roll out of TEFAP across the country. The nesting of TEFAP within these many institutions further contributes to the lack of public understanding behind the intent and distribution of benefits begotten out of this program. 
By uncovering the institutional actors in this convoluted supply chain, I explain how TEFAP fits within a wider nutrition entitlement safety net that is itself poorly understood. While the poor benefit tremendously from state benevolence so too do private interests facilitating the transactions upon which the redistribution of state nutrition funding depends. Prior to reviewing each of these funding streams, it is helpful to understand the role of each institutional actor within the state in administering the flow of TEFAP resources.

\section{A. Institutional Actors}

\section{Food and Nutrition Services (FNS)}

FNS administers all 15 of the USDA nutrition programs. Its food distribution division manages 4 household commodity programs including TEFAP. Other direct food distribution programs include the Commodity Supplemental Food Program (CSFP) and Nutrition Services Incentive Program (NSIP) both targeted to food insecure seniors and the Food Distribution Program on Indian Reservations (FDPIR) targeted to Native American communities. FNS also manages all the commodity purchases for school nutrition programs, a much larger program ${ }^{13}$. TEFAP is in practice closely aligned with many aspects of school nutrition programs, although it is separate in its administrative oversight ${ }^{14}$. Within the USDA, FNS is on the customer side of the equation overseeing commodity orders on behalf of states by communicating and monitoring their entitlement allocations, creating purchase bids, reconciling funding and reporting as well as advocating for states and recipient agencies among other branches of the agency. FNS also ensures that states comply with TEFAP rules under the code of federal regulations. FNS tends to operate

\footnotetext{
${ }^{13} 20 \%$ of school foods are surplus commodities purchased by the federal government.

${ }^{14}$ Many state agencies couple TEFAP with their Child Nutrition program administrations, particularly on the food ordering side.
} 
primarily on behalf of food insecure households and the subcontracting entities that are responsible for serving them at the state level.

\section{Agricultural Marketing Service (AMS)}

AMS administers programs that create marketing opportunities for meat, poultry, fruit and vegetable surplus removal. They contract with the food industry to purchase commodities selected by states under their TEFAP entitlement. In partnership with analyses from ERS, AMS anticipates food market trends, works directly with private vendors to set up procurement bids, awards contracts and oversees quality standards of sourced commodities. AMS also processes all TEFAP "bonus" commodities as surplus removal under the section 32 program it administers (see below). Industries experiencing market gluts reach out to AMS to make a case for surplus removal. No individual firm can make a surplus removal request, rather an industry association must approach the agency and make a case for why the USDA should purchase overproduced farm goods. Ultimately the Secretary of Agriculture has final authority over "bonus" purchases. AMS is primarily focused on industry concerns, making sure agricultural markets are stable and that requests for surplus removal are legitimate based on the economic indicators available.

\section{Farm Service Agency (FSA)}

FSA oversees the purchase of grain, dairy, peanut and oil products, commodities which come under a different set of price support rules. FSA also manages the storage of CCC inventories in over 10,000 warehouses across the country. While food aid concerns at FSA are especially targeted at international programs, it also plays a role in the domestic food system by policing and governing AMS commodity contracts, issuing notices to deliver after bids are awarded and providing an additional level of oversight over the bidding and contract award process. FSA 
commodity purchases division has recently been reorganized to fall under the purview of AMS an ongoing transition that began in fall of 2016.

\section{State Agencies}

TEFAP is executed through contracts signed between states and the USDA, as determined by the code of federal regulations governing commodity distribution programs in the United States (7.CFR. 250). TEFAP has its own set of rules outlined in (7. CFR. 251) spelling out the purpose and scope of the program, the responsibilities of the multiple parties administering it, the availability and allocation of these commodities, the eligibility of local organizations distributing the food and the responsibility and authority of the various parties across the TEFAP supply chain. States in turn sign binding contracts with EFO partners of their choosing (usually regional food banks) to distribute TEFAP commodities across their territories. The mandated contractual relationship between state agencies and EFOs reads:

"Prior to making donated foods or administrative funds available, State agencies must enter into a written agreement with eligible recipient agencies to which they plan to distribute donated foods and/or administrative funds. State agencies must ensure that eligible recipient agencies in turn enter into a written agreement with any eligible recipient agencies to which they plan to distribute donated foods and/or administer funds before donated foods or administrative funds are transferred between any two eligible recipient agencies." (TEFAP code, 251.2)

States may choose which organizations they work with to allocate their TEFAP share but these must be charitable institutions. A charity in this case can be public (e.g. hospital, retirement home) or private with tax exempt status (e.g. faith based or 501c3). Regardless of their legal standing, EFOs must be involved in activities that provide food assistance to needy persons. There are two types of feeding activities that these TEFAP agencies can be involved in. 1) Household distributions, meaning food is distributed in bulk for preparation at home, typically a 3-day supply for each person in the household. 2) On site consumption such as soup kitchens where food is prepared and consumed in situ. A key difference between the two is that participation in the first 
is subject to a means test on the part of food recipients, they must fall below an income threshold to access food. The second prohibits means tests and anyone, regardless of income, must be served food on a first come first served basis.

Each state government designates an agency to oversee the administration of the TEFAP program across their jurisdiction. Following the federal model and rooted in the founding laissezfaire principles of the program, states have significant leeway in choosing how to manage TEFAP. Because the HFN has evolved dramatically since the program's inception in the 1980s, state based TEFAP administrations reflect its fractured and uncoordinated implementation across the country. In 2013, the Washington Department of Agriculture was reassessing its TEFAP administrative model and funded a national survey of all TEFAP state agencies to determine the various administrative strategies of this program at the state level ${ }^{15}$ (Jacobs, 2016). Key findings from the study revealed that there is no standardized approach for how TEFAP is operated in every state allowing for maximum flexibility based on the state's population needs and the charitable food infrastructure available in situ. The downside however is that systems improvement based on best practices are limited because they may only work among states with similar TEFAP configurations.

\section{B. Circulating Resources}

TEFAP is maintained through a convoluted funding cycle that includes three separate appropriation of federal funds. The first two pots of money are used to purchase agricultural commodities. The third is administrative funding to operate the program at the state and food bank level. These resources are divided and allocated based on a formula that determines the amount of

\footnotetext{
${ }^{15}$ Prior to this survey, there was very little data available regarding how TEFAP was being rolled out across the country because the USDA does not publish records or reports of state-based implementation schemes.
} 
food and funding received by each state. I review each funding stream and the way they are distributed across the food banking economy below. The difficulty in understanding how public funds are used in the food bank fix is to quote Marx (1976) "not in comprehending that money is a commodity, but in discovering how, why and by what means a commodity becomes money" (p.92).

Figure 4-4 provides a sketch of TEFAP resources circulating through the food banking economy. Most notable is that although money (and its derivatives) circulates widely among different entities, food purchases are made with private contractors, who act as for-profit agents of the state to source and deliver food. Although it is far beyond the scope of this study, there is an important case to be made for an analysis of the politics of federal food contracting and the distribution of benefits therein ${ }^{16}$. AMS purchases are highly regulated. The Master Solicitation for Commodity Procurement is a 52-page contract used to outline the rules and regulations of the bidding and delivery process that secures domestic federal food commodities from private vendors. The contract ensures that these vendors conform to Federal Acquisition Regulations (FAR), Agricultural Acquisition Regulations (AGAR) and AMS policies and procedures.

Rather than an analysis of the contracting side, mine is one that unpacks the different types of foods received by states under the TEFAP program and the funding sources that inform those distributions. I focus on TEFAP entitlement, "bonus" foods, administrative funding and fair share resource allocation at some length here because each provides a different facet of the state's function in building out the humanitarian social infrastructure that repurposes food waste as hunger relief. The governance mechanisms that emerged out of TEFAP's progressive institutionalization

\footnotetext{
${ }^{16}$ The politics of public food contracting is a vast and underexplored avenue of food system research. Beyond domestic entitlement programs, federal food contracts include FEMA emergency food relief, USAID food for peace programs, DoD and V.A. food procurement all of which rely on private contractors to deliver food commodities and services on behalf of the state.
} 
helps to clarify how the state has played a key role in consolidating capital flows within the food banking economy, over the past 30 years, a food and funding injection that no single food firm could undertake on its own. Although the food resources provided to the HFN today pale in comparison to the amount of corporate food waste distributed by the network (chapter 4), the state

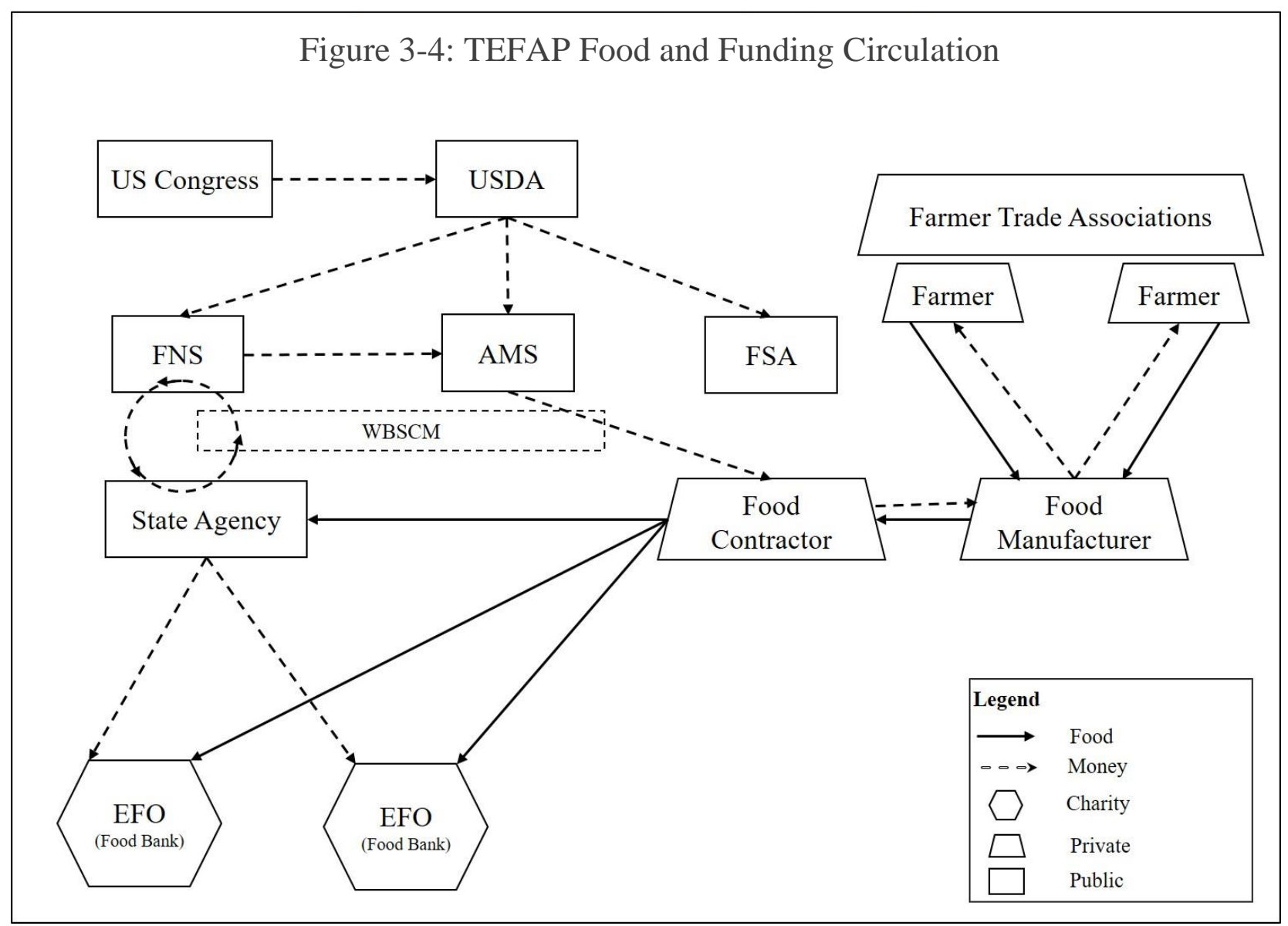

remains a critical institution maintaining food banks in place. My analysis here provides a summary of the mechanisms it uses to do so.

\section{Entitlement Foods}

TEFAP food entitlements are allocated to states through the FNS as outlined in the farm bill ${ }^{17}$. Because the program is legislated to be run at the discretion of state governments, the entitlement

\footnotetext{
${ }^{17}$ The appropriation of these funds must be re-authorized under yearly budget proceedings, and thus TEFAP can be affected by the immediacy of political expediency or even government shut-downs.
} 
funding is passed from FNS on to state agencies working to source and distribute TEFAP foods across all US territories under federal jurisdiction ${ }^{18}$. In the case of West Virginia for example, the administrative entity receiving TEFAP entitlement is WVDA. Each state's entitlement must be spent down with FNS over the course of the fiscal year, however they cannot spend it on whatever foods they find in the open marketplace. The state food entitlement is in fact a very prescriptive process. FNS develops a catalog of authorized foods every spring that states can purchase by type and packaging size with pricing estimates based on historical AMS contracts:

"We look at trends, so for example for the past 5 years corn has cost this much, we estimate it based on that. We try to make lists that include offerings in other programs too, such as Indian Reservations. We like to include TEFAP because it provides volumes to those other smaller household programs. 3 truckloads could turn into 5 or 6 with TEFAP and that volume could bring down the overall price for states." (USDA-4, 2.15.17)

FNS has no visibility over the bidding and contract award process because it is a separate branch of the USDA. At times prices listed and the prices ultimately contracted with vendors many months later do not match the FNS commodity catalog due to external market factors, and decisions must be made about which orders will be cancelled to make up the difference:

"We try to get as much information as possible from [AMS] you know, but they tell us this is proprietary information because it's a contract. Again, we don't deal with any of the contracting side of things, so we can't know or influence that. Sometimes it does go over, like was the case recently with the cheese, where it was $\$ 20$ million, and the bids came in at \$23 million. Well the system automatically cancels it in the order received to adjust, but we look and say, now wait, that's New Hampshire that got cancelled, and they only have 1 truck, let's not cancel that one. California maybe has more and can handle a cancellation. So, we try to be equitable like that if we go over, it usually works out" (USDA-4, 2.15.17)

States place their food orders with FNS on a quarterly basis when it opens the ordering window. They may spend all their entitlement funds in a single quarter, but most spread it out over the year to provide food banks with as steady a food supply as possible. As I discuss at greater length in chapter seven, TEFAP deliveries remain very intermittent. Funds for these orders are

\footnotetext{
18 This includes overseas territories such as Puerto Rico, Guam and the Virgin Islands.
} 
placed in a state account, but as virtual currency, only exchangeable for USDA commodities. An AMS official described the circulation of entitlement funds across the many different transacting parties as follows: "It's like a giant checkbook, except you can only spend the money with us" (USDA-3, 10.27.15)

The closed funding stream and ordering process is managed through the USDA's Web Based Supply Chain Management (WBSCM) software system. WBSCM serves to provide market information to the various contracting parties, although again states and the FNS cannot access information pertaining to the food contracting side of the equation as this is the proprietary purview of AMS and federal food contractors. States place their orders based on the amount of entitlement funds they have available and the pricing information available in the catalog offering for that year. Individual state orders are transferred to FNS who vets them, combines them into an order request to AMS who then sets up bids with private contractors. An actual cash transaction takes place only once a bid is awarded to the private food vendors contracted to deliver the foods to its destination, usually a regional food bank. TEFAP entitlement contracting is a multi-month process from the time the catalog is put together, the ordering window opens for states, through procurement and final delivery. As a testament to the complexity of these food orders, a recent FNS webinar titled "The lifecycle of a sales order" includes training from 3 different USDA employees and over 30 procedurally intensive slides. (USDA- FNS, 2017). Ordering TEFAP entitlement foods is thus extremely complex requiring technocratic expertise at many different institutional levels to pull off.

\section{Section 32 - "Bonus" Foods}

The second funding source for TEFAP is so called "32 money", named after section 32 of the Agricultural Adjustment Act Amendment of 1935 signed by Roosevelt in the New Deal Era. The 
law makes $30 \%$ of all import duties collected from customs receipts available to the Secretary of Agriculture to remove surplus foods from normal market channels and encourage domestic food consumption. The purpose was to purchase price-depressing foods and dispose of them through exports and domestic donations to the needy through schools and charitable institutions. This funding stream remains in place nearly a century later, translating today to approximately $\$ 10$ billion per year to divert US agricultural surplus from regular trade channels into government programs. Monies from the program are administered by AMS, which redistributes most of it (\$8.3 billion in FY 2015) back into FNS child nutrition programs. In FY 2015 section 32 funds were used to purchase $\$ 771$ million worth of commodities for market removal, \$306 million of which were earmarked for emergency removal of surplus commodities, primarily cranberries, tart cherries, chicken products, raisins and canned salmon. While some of these "bonus" foods were made available to school meal programs a large proportion also circulated through the TEFAP program and the wider HFN across the country. (Monke, 2016)

Section 32 money is not an entitlement. It must not be regularly appropriated by congress and is a separate and independent funding stream within the USDA. As such it is not affected by the whims of political expediency nor government shutdowns. Section 32 provides the USDA Secretary with significant discretion in the manner in which billions in public funds are used across the food system each year.

"Bonus foods are a factor of industry, not particular companies. At AMS we are constantly looking at what's happening on the market, it's macro-economics. For example, if the cranberry industry is overproducing, they have too much supply, that would drive down prices, they come to us and say we'd like you to consider buying product from us. We deny individual companies with oversupply. Usually it's the chairman of the board of an industry association making the request" (USDA 2 -10.27.15)

AMS economists analyze the requests to determine whether there is indeed an oversupply that would significantly affect that industry. The analysis then goes through multiple vetting 
processes and signatures before it is ultimately authorized by the Secretary of Agriculture. Those I interviewed at the USDA about the "bonus" program were adamant that the process was free of politics and special interests and solely about saving farmers in distress, but when I pressed whether the "bonus" purchases were publicly available for review there was some discomfort in answering the question: "This is not public, because the information could mean different things to different people. It's the process that matters [...] None of it is lobbying! The primary purposes of the buys is to keep the industry healthy, they have told us that and we vet it thoroughly $[\ldots]$ In fact often we are buying at cost, they are not necessarily making money" (USDA - 10.27.15).

A USDA-ERS study comparing the benefits to farmers of the TEFAP and Food Stamp programs concluded that "bonus" foods purchases have a much higher rate of return for farmers than their TEFAP entitlement purchase equivalent. The latter is a wholesale market transaction that goes through several middle men (processing, wholesale services, delivery etc.) each taking a slice of the contracted pie. At the time of the study, TEFAP entitlement purchases returned 27 cents for every dollar spent to farmers. In contrast "bonus" purchases as a surplus disposal program returned approximately 85 cents for every dollar to farmers (Levedahl et. al, 1994). While TEFAP has evolved considerably over the past 20 years, the benefit of "bonus buys" on the industry has remained steady. The process of authorizing a "bonus buy" is a long one, yet contract finalization brings joy to the staff engaged in channeling industry requests through the multiple bureaucratic channels toward authorization. During the introductory remarks at the 2015 Annual AMS Industry procurement meeting, the AMS administrator referenced the joy that it brought her to see a "bonus buy" come to completion: "Yesterday I was making one of these phone calls informing the folks, the stakeholders, that we were making a buy and there is nothing that makes me happier than when we're able to advance a section 32 bonus buy" (PO-8, 10.27.15) 
Like entitlement foods, "bonus" foods are ultimately redistributed to states, who pass them on to food banks and their LFC partners, spreading their flow across the country through charitable channels. However, "bonus" foods are not accompanied by a commensurate administrative funding allotment for program expenses. The available food is difficult to turn down because it is often demanded by LFCs who are always seeking more food sources in their community. At times however, the products delivered are not wanted by LFCs in the volumes provided as was the case with the cranberry products, which are still circulating within the HFN in West Virginia over two years later ${ }^{19}$. As I discuss in the following section, LFCs do not incur any costs for USDA foods in West Virginia, however administrative funding for the TEFAP program, particularly the lack of funding for "bonus" foods, remains an important bone of contention for food banks (chapter 7). While the "bonus" program significantly alleviates economic hardship for farmers under economic strain, it tends to create further financial vulnerabilities for the charitable entities processing and distributing these foods.

\section{Administrative Funds}

The farm bill allocates funds for states to administer TEFAP. As I discuss in chapter 7, these monies fall well short of covering the costs involved in ordering, receiving and redistributing federal commodities to LFCs. Costs also include the labor involved in training and monitoring local agencies on the sound implementation of the program, as well as accounting and reporting program usage statistics back up the bureaucratic chain of command that reports to Congress. To make matters worse, over the past few years Congress has not appropriated the full $\$ 100$ million administrative funding authorized under the farm bill, releasing instead only \$54 million in 2016.

\footnotetext{
${ }^{19}$ In a somewhat hilarious turn of events, a WV food bank director recounted how she had received USDA cranberry donations from a US postal service food drive. Food pantry clients that had received a bag of dried cranberries had no use for them, donated them back and these were delivered back to the food bank. Cranberry saturation stories were a prominent feature of my ethnographic experience in West Virginia.
} 
This stunted appropriation is divided between states, who are obligated to "pass through" a minimum of $40 \%$ of their TEFAP administrative funding to their EFOs (e.g. food banks). States must provide a cash or in-kind match for any federal funds retained for state purposes and the level thus differs widely among states. TEFAP also allows state agencies to convert up to $10 \%$ of their food entitlement to administrative funding. In FY 2012, states converted 6.7\% (\$17.5 million) of their TEFAP entitlement into administrative dollars. Administrative money only covers around a quarter of the costs of distributing commodities for food banks, thus there is significant pressure on states to pass through as many dollars as possible. The majority pass on more than $90 \%$ of TEFAP administrative funds to their contracted feeding organizations, but these must still rely heavily on volunteer labor and fundraising to cover the costs of implementing TEFAP. The passthrough rates to EFOs distributing the food do vary from state to state ranging from $40 \%$ to $100 \%$. The median administrative pass through rate is $94 \%$, yet these also vary widely from year to year depending on the fiscal policies in place at the state departments managing TEFAP at a given time.

\section{The Fair Share Allocation}

TEFAP food and funding is divided between states based on a statutory formula derived from poverty and unemployment statistics in each state. The so called "fair share" proportion is an index weighted at $60 \%$ of households living below poverty and $40 \%$ of the previous year's average unemployment rate. Statistics are drawn from the Census Bureau for the former and the Bureau of Labor Statistics for the latter. Every year the proportion of food and funding provided to states is recalculated based on updated statistics from these two federal agencies. Although poverty and unemployment are not necessarily the most telling food insecurity indicators (Gundersen, 2011), the formula's codification in 1996 now makes it difficult to change, considering some states would gain at the expense of others losing out on resources if the formulas were revisited. 


\section{Summary}

TEFAP resources circulate through a host of social actors informed by different ideologies motivating the labor that they contribute to the food banking economy. The governance of these resources is a patchwork of federal laws passed during different time periods that empower the USDA with money to allocate food and administrative funds to achieve specific program goals. In this case TEFAP maintains food banks in place to fix problems of agricultural overproduction linked to food policies that promote the commodification of food through productivist food security models. The federal money that circulates is by no means circular, it ultimately serves very particular social interests including that of the capitalist state, who requires a coalition of forces to legitimize its survival. I now turn to my West Virginia case study to explain how this convoluted supply chain impacts the politics of feeding in the state, and the tensions that TEFAP's complexity elicits at the local level.

\section{V. $\quad$ TEFAP in West Virginia}

The rollout of the TEFAP program in West Virginia mirrors the institutionalization of the HFN across the country. The first food bank in the state opened in 1981, the same year that the Reagan administration first released government cheese stores as part of SDDP. Today, two food banks distribute TEFAP foods to approximately 350 agencies spread across each of the state's 55 counties, providing government commodities to 100,000 households every month. WVDA contracts with the USDA to implement TEFAP under authorization from the state legislature. Until 2001, the West Virginia Department of Health and Human Resources (WVDHHR) was the agency overseeing the distribution of TEFAP. It was transitioned to the West Virginia Department of Agriculture (WVDA) to gain efficiencies with the Child Nutrition Program (CNP) commodities 
that WVDA was already administering through its warehousing facility in Ripley, WV. State governments have discretion over how to organize the distribution of TEFAP foods across their territories $^{20}$. WVDA contracts with Mountaineer Food Bank (MFB) and Facing Hunger Food Bank (FHFB) who raise grant and private charitable funds to subsidize the costs of the TEFAP program (Chapter 7). The food banks in turn subcontract with LFCs to redistribute this food across the state's 55 counties free of charge. As of 2017, FHFB subcontracted with 176 LFCs and MFB with 215.

Food pantries, soup kitchens and community centers have adapted to the shifting demands of the TEFAP program investing in infrastructure to deliver this public good including cold and dry storage capability, distribution systems and accounting techniques. These private food charities are not uniform entities, as I explain in chapter five they are in fact extremely heterogeneous. Their commonality in this case lies in their enrollment in a national governance regime that facilitates giving away surplus agricultural commodities to needy households on behalf of the federal government.

In this section, I explain the tensions that result from administering a state program through private charities. I provide different perspectives from the WVDA and the two food banks as they apply federal rules and navigate tensions between the public-private nature of the program. I review how TEFAP resources including entitlement, "bonus" and administrative funds, are distributed across the state. Next, I turn to the battle over privatization of the TEFAP program in West Virginia in the early 2000s. I argue that tensions between WVDA and MFB emerged out of inadequate federal administrative allocations. West Virginia is a resource poor state where food

\footnotetext{
${ }^{20}$ Delaware for example chooses to manage the entire TEFAP program from the state office and warehouse, passing food and administrative funding directly on to LFCs. In West Virginia, contracting with hundreds of different LFCs distributing TEFAP foods across a vast rural territory would be a significant administrative burden on the state considering the limited funds it receives to operate TEFAP
} 
banks are butting up against the philanthropic limits of communities facing economic crisis, and constantly seeking to capture revenue sources wherever possible, even at the expense of further hollowing out other parts of the public sector. Finally, I review the application of TEFAP rules in West Virginia, arguing that they uphold social justice and civil rights obligations on the part of charities participating in TEFAP, extending the state's gaze and influence into charitable spaces, a controversial hybridity for many LFC directors. The rules also serve to ensure that agricultural surplus purchased by the federal government will not be resold but remain locked in distribution channels that protect primary food markets. 


\section{A. West Virginia's fair share of the TEFAP pie}

TEFAP commodities are available in every county in West Virginia. However, these foods are unevenly distributed based on the variable capacity of LFCs in different places (Chapter 6) and the arbitrary calculation of need in each county. The map of TEFAP agencies across the state (Figure 4-5) shows pockets of high concentrations of TEFAP foods and other areas where it would be difficult for low income residents to fully access this entitlement. Although the two food banks are doing their best to evenly allocate their TEFAP share across space, their distribution remains ad hoc, a situation borne out of the absence of federal distribution directives at the local level that I reviewed above.

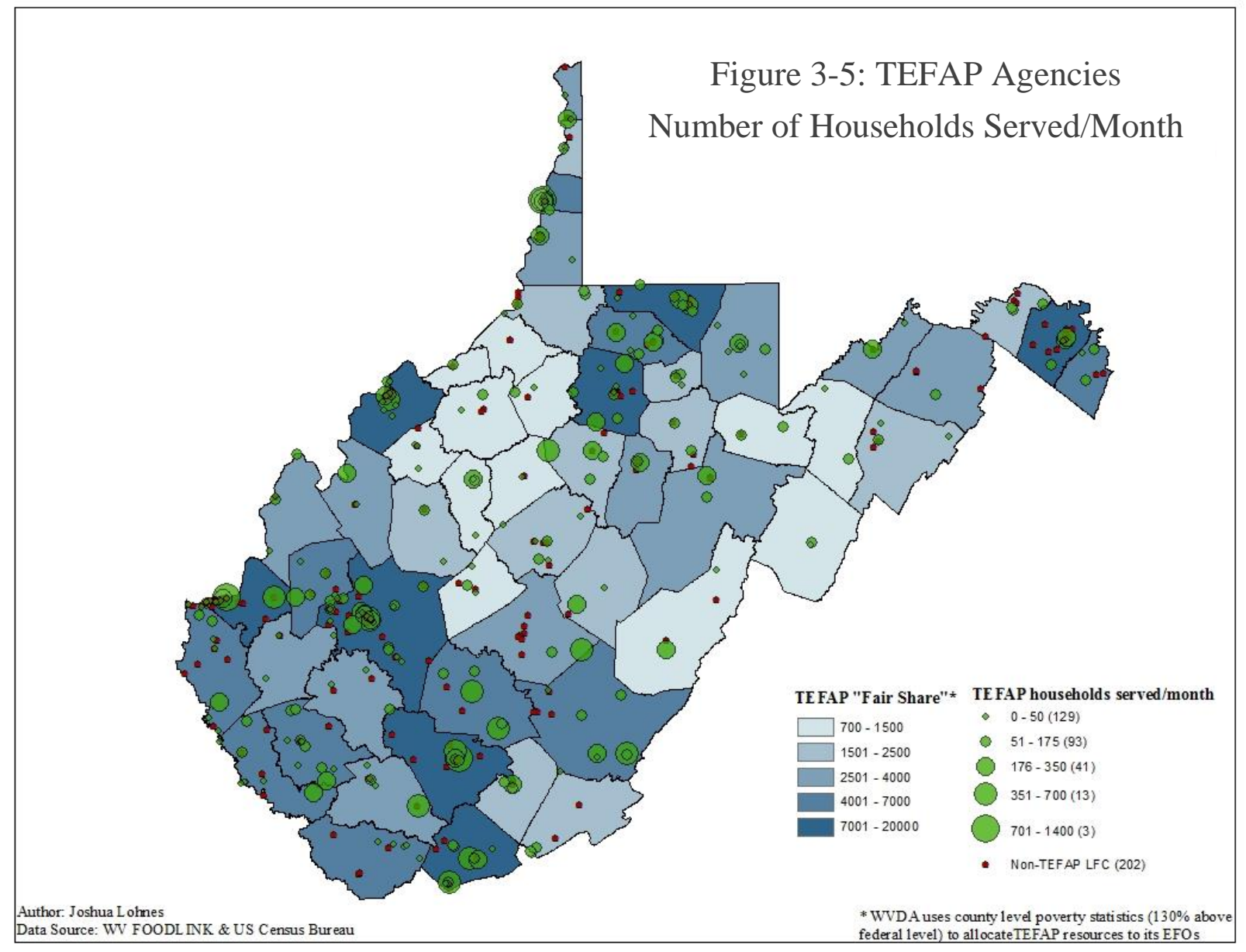


West Virginia had 327,764 people living below poverty or $0.6566 \%$ of the national total based on 2014 statistics. It also had an average of 51,120 unemployed persons, $0.5766 \%$ of the national total. Based on these statistics, the state of West Virginia received $0.6246 \%$ of the total federal TEFAP appropriation for both food and administrative entitlements in FY $2016^{21}$. This formula translated to a food entitlement allotment of $\$ 1,773,917$ and an administrative grant of $\$ 339,786$ for the WVDA. The same formula is used to allocate "bonus" foods between states.

The few people familiar with the workings of this formula in West Virginia expressed frustration with the fact that a calculation based on poverty and unemployment does not accurately reflect the level of need in the state, where a large proportion of the population have stopped being counted by the Bureau of Labor Statistics (BLS) because they are no longer actively seeking work, and many are disabled or living on inadequate social security income. The poverty measure is likewise a somewhat arbitrary rate, that many sense no longer accurately reflects the socioeconomic dynamics of rural mountain communities. Furthermore the 2-year-old statistics are often not up to date with the situation "on the ground", and the allocation is thus not in sync with the large layoffs the state was experiencing over the course of my study in the manufacturing and resource extraction sectors. Unemployment checks expire after just 26 weeks. Depending on the time of year, it could take upwards of 78 weeks for TEFAP to catch up to reality. In other words, many in West Virginia feel that the TEFAP fair share allotment between states is not actually quite fair.

West Virginia's fair share does change every year to reflect the evolving demographic and economic situation nationwide. As the overall proportion of the TEFAP pie is adjusted, state agencies negotiate variable amounts of entitlement to spend down. The sporadic nature of the

${ }^{21}$ TEFAP fair share $=$ national percentage below poverty $\mathrm{x} 40 \%+$ national percentage of unemployed $\mathrm{x} 60 \%$. In West Virginia this formula translates as follows: $0.6566 \%$ x $40 \%+0.5766 \% \times 60 \%=0.6246 \%$ 
TEFAP food flows is a factor of a convoluted ordering process. Unplanned "bonus" receipts, combined with the yearly allotment of resources calculated for each state, produces a TEFAP geography that changes from year to year. Food banks and their LFCs are left to bear the burden of negotiating variable amounts of food and funding from this program alongside the many other uncertainties they face (Chapter 5). They are also at pains to explain to LFCs why TEFAP foods fluctuate wildly from month to month and year to year. WVDA opts to use county level poverty statistics to allocate resources to its EFOs, namely the number of people living at or below $130 \%$ of the federal poverty rate. Other states have different allocation formula that cater to the needs of their HFN constituency. This variable resource allocation geography creates its own set of tensions and misunderstandings throughout the HFN in West Virginia.

\section{B. Commodities}

TEFAP entitlement and "bonus" foods are delivered to MFB and FHFB. Entitlement commodities are ordered on a quarterly basis by WVDA. The two food banks do not have any input into what the state chooses to order from the FNS catalog, a frustration that the directors are currently petitioning program administrators to mitigate. Some states allow their EFOs to order foods directly from FNS, others empower food banks to collectively make decisions as to how to make the best use of entitlement resources and communicate that to the state agency which then processes the purchases. The lack of control over TEFAP entitlement resources is particularly frustrating for food banks because they need to constantly explain to their LFCs that they are powerless to dictate the types of foods that arrive through the system. While proteins are the most sought-after commodity from agencies, these are more expensive, and WVDA prefers to order canned vegetables and other lower cost items to stretch their TEFAP entitlement dollars. 
At the yearly MFB agency meeting, a food bank staff member read off the expected list of TEFAP entitlement to 100 or so bewildered LFC directors in the room.

"January green beans and corn, February canned carrots and vegetable mix, March mixed fruit, canned peaches and corn, April canned potato slices, May canned pears, green beans and corn - you see folks, they like corn, there is nothing wrong with that but I'd like to see them shake it up a bit. [...] October corn and green beans. I sound like a broken record don't I, are they vegetarians now or what? [laughs and groans]. Where's all the meat? I don't know why [WVDA] doesn't know that the most commonly donated food items in canned food drives are corn and green beans [...]. Don't panic now, I'm not saying that's all you're going to get that's just what we know is coming, that's the allocation they have ordered, and I have no idea why there is no meat" (PO-17, 8.8.17)

The perception that WVDA should be faulted for not ordering appropriate foods from FNS

received push back from the state administrator in charge of both TEFAP and CNP commodity orders. At a separate meeting between FHFB and WVDA the food bank director brought up her problems with LFC frustrations over the TEFAP commodities available for distribution. On the Kentucky side of the counties she served TEFAP entitlement included beef stews and other highly sought-after food items, why couldn't West Virginia try to mirror the other TEFAP products available in her warehouse? He had clearly heard the complaint before:

"Look if we're not careful we can wipe out our whole entitlement in 13 or 14 truckloads. It costs me $\$ 120,000$ for a load of beef, but just $\$ 15,000$ for a load of corn. We are part of a wider region in terms of our orders. PA is the largest buyer, and we often get left-overs [bonus foods] from Puerto Rico's share, although I hear that they are now building refrigeration in their warehouse, so we may be getting less of that. Look people can't look past their noses sometimes. I give you food, here is food for two weeks or whatever, but they don't want it they just want the meat right now" (FB -5, 11.3.15) 
Beyond the problematic prescriptive household food choices that such a hierarchical system engenders, the WVDA dilemma speaks to a wider conundrum faced by all TEFAP pass through agencies, namely how to allocate scarce resources in a market that is itself somewhat arbitrary. Because food banks could be flooded at any time with "bonus" products that are not foreseen when entitlement orders are placed, state agencies often order blind to what foods are coming down the pipeline. The graphs below provide an overview of the TEFAP foods that circulated through the state in FY 2017. Figure 3-6 analyses the commodities by source (entitlement vs. bonus) and by poundage. While the state did heed some of the complaints by ordering beef stew last year, most

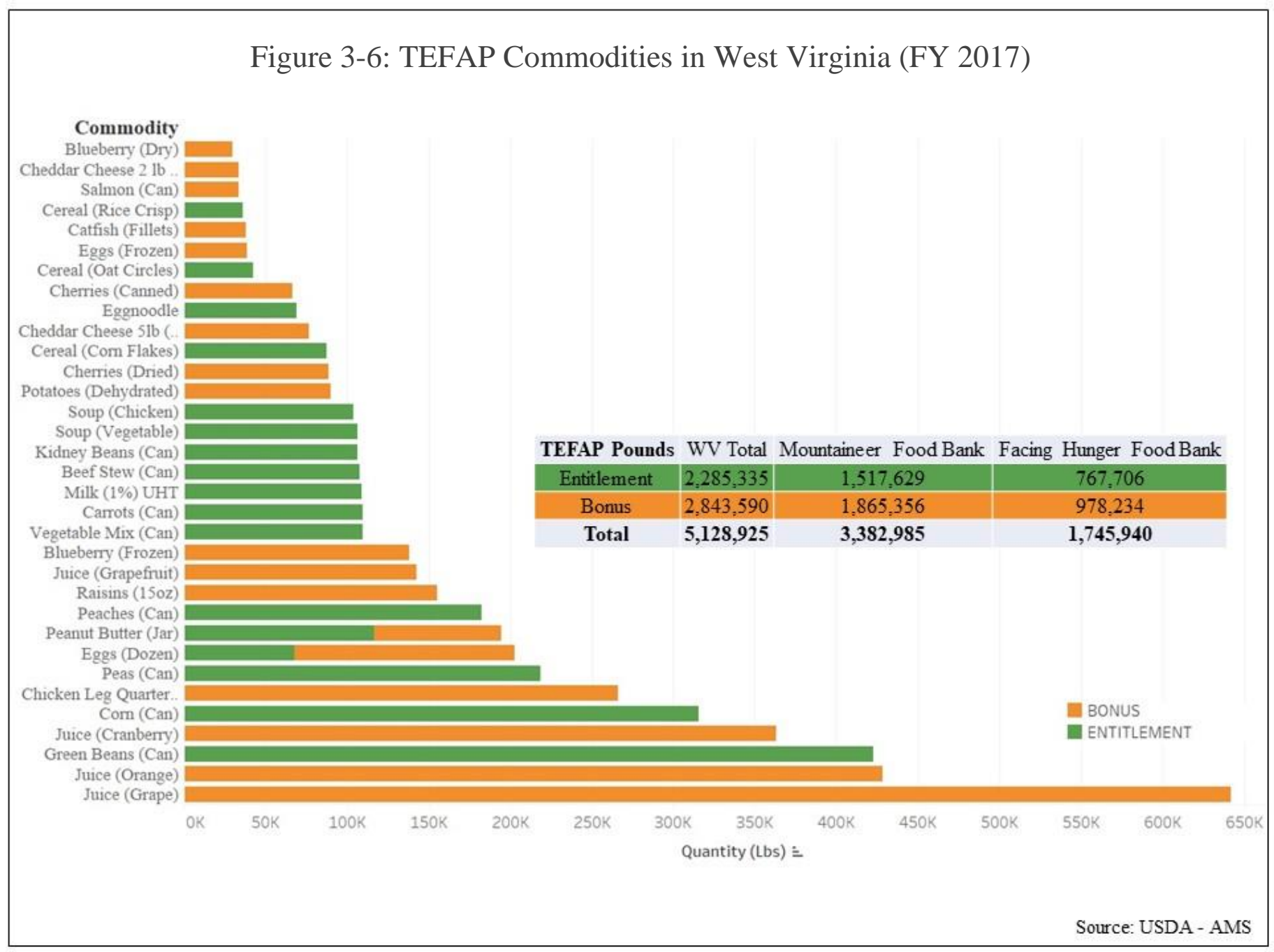


of the entitlement remained lower cost vegetables, legumes, and canned fruit. Bonus foods did include a significant amount of protein such as catfish, eggs, frozen chicken and peanut butter.

Figure 3-7 analyses the private contractors providing these foods on behalf of the federal government. Burnette Foods, Inc. based in Michigan was the only firm to fulfill both entitlement and "bonus" orders last year. All others were firms concentrating on fulfilling contracts for either entitlement or section 32 solicitations. My hypothesis is that this reflects the niche markets that these private for-profit actors operate in. Cherry Central Cooperative, another Michigan based firm

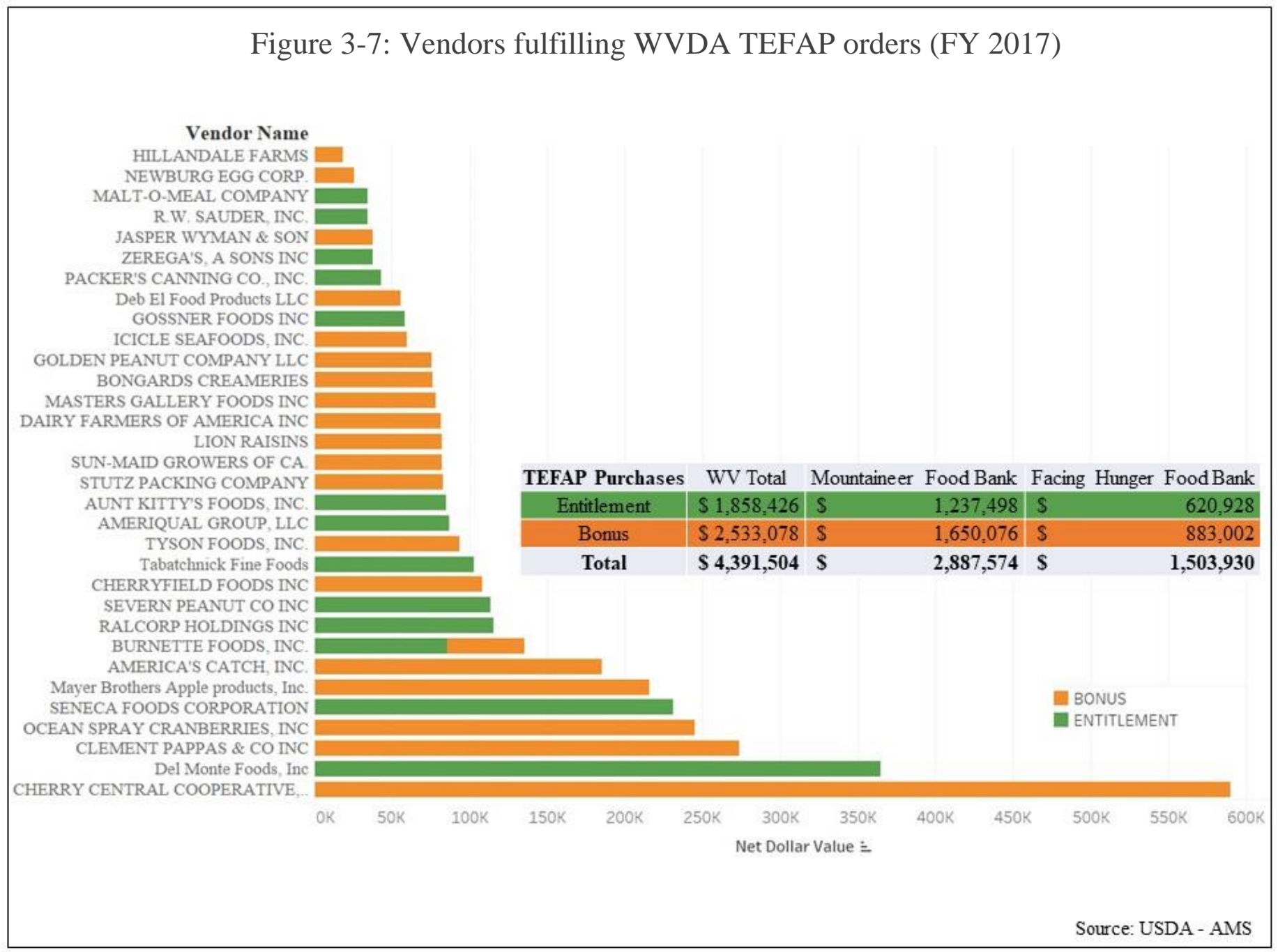


earned $\$ 600,000$ in revenue selling food to TEFAP in West Virginia alone ${ }^{22}$, fulfilling both dried and canned cherry bonus buy orders approved in April 2016 (see above).

\section{Administrative Funds}

TEFAP commodities must be received, receipted, handled, transported to LFCs, and then accounted for by the number of households participating in the program. This costs money, some of which is reimbursed by TEFAP administrative funding. As I reviewed above, state agencies have discretion over the amount of administrative funding to pass on to their EFOs. In FY 2014 for example, WVDA retained $28 \%$, the second largest retention rate in the country at that time. After pressure from the two food banks struggling with budget crises and the state's own fiscal squeeze WVDA must match all funds not passed through), by FY 2016 it was only retaining 5\%. The total that year amounted to $\$ 25,828$ for the state, who had to come up with a $\$ 25,828$ match to remain compliant with the program rules.

WVDA works with a relatively small budget to oversee the TEFAP program. Food orders are placed with FNS but TEFAP is delivered directly to the two food banks, excepting occasional bonus foods which end up in the state warehousing facility if floor space at the food banks is lacking. The state is responsible for reporting the use of administrative funds back to the USDA and works to ensure that food banks and their affiliate TEFAP agencies remain compliant with federal laws concerning the use of pass through funds, the distribution of food and social justice concerns. In 2009 the WVDA hired a full time TEFAP coordinator for the first time to oversee this work, conduct trainings with local TEFAP agencies and audit these same agencies to ensure their ongoing compliance with federal mandates.

\footnotetext{
${ }^{22}$ No West Virginia firms contracted with the federal government to provide food to the food banks last year. Well beyond the scope of this study an analysis of the spatial distribution of TEFAP contract awards would be extremely helpful toward understanding which constituencies gain the most economic benefit from the TEFAP program.
} 
Responding to the national TEFAP survey this employee responded to a question about strengths and weaknesses of the TEFAP program as follows:

I am the only TEFAP coordinator in the state of West Virginia and did not have a predecessor. They created my position in 2009 when I was hired. Before that time, the CNP school inspectors would attempt to monitor TEFAP agencies in the summers when school was not in session. Since I've been in the position, I feel that the program has become more organized and consistent. I have developed Food Pantry Applications pursuant to USDA regulations that most of my pantries are now using. I have also been very inundated with traveling throughout my state to conduct mandatory Civil Rights trainings to all front-line staff at our participating food pantries and soup kitchens. I have also expanded my job duties to include extensive outreach to rural areas in our region that are in desperate need of food assistance programs. I am in the process of designing a web page for WV TEFAP and would like to have that up and running in the next six months." (Jacobs, 2016)

The added position helped to homogenize TEFAP policy with LFCs across the state and strengthen WVDA oversight over the program. The hire however was also perceived by food banks as a somewhat unnecessary duplication of their own efforts that took away administrative resources that they felt would be better used in their own operations. The frustration is compounded by the lack of coherence of funding from WVDA. The convoluted billing process to reimburse

Figure 3-8: WVDA administrative disbursements to WV Food Banks $2005-2014$

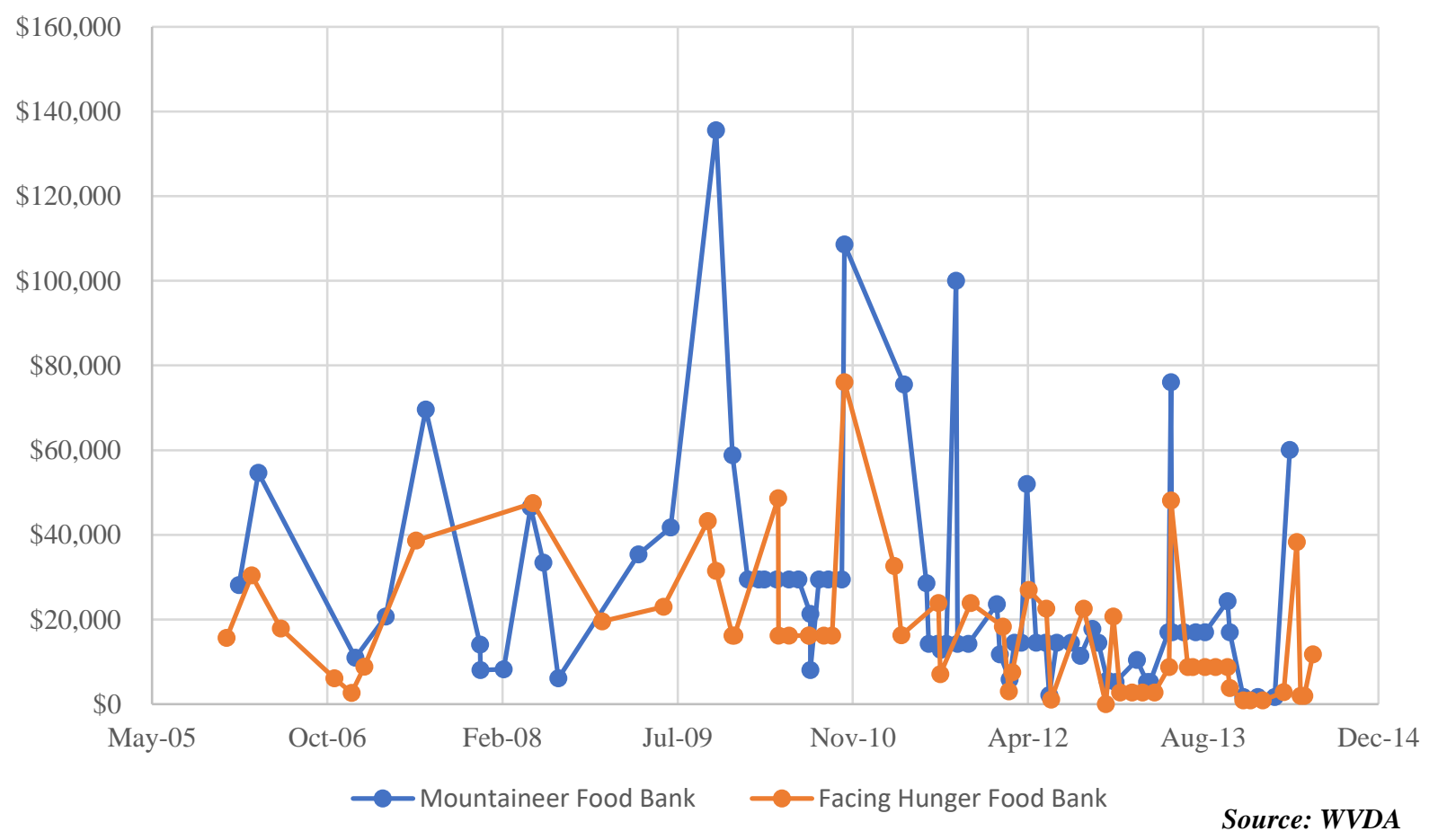


food banks for their TEFAP related activities contributes to the freneticism of the food banking economy in the state (Chapter 5). Analysis of a decade of WVDA TEFAP reimbursements (Figure 3-8) offers a window into the sporadic funding streams that MFB and FHFB operate under to deliver public food across the state.

An MFB director bemoaned inefficiencies and late payments from WVDA for the TEFAP services her organization rendered on behalf of the state:

\begin{abstract}
"They have not paid us since January [8 months], they owe us $\$ 191,000$ at this time. We have to record every time we touch USDA foods! We bill for that time rounding up to the nearest 15 minutes. Then I have a calculation that says of the 40K I spent this month I can charge $18 \mathrm{~K}$ to the USDA. But WVDA won't let me bill, they say, no you can only invoice for $\$ 17,220$. And it just kills us, it kills us. This is money we could spend feeding more people, doing what we're supposed to be doing instead of... Our contract says we have to have an audit on June $30^{\text {th }}$, but they haven't done that yet and they're saying they won't release the funds until that is done. We did the work in February, March, April, May they should pay us! This is not the first time it's an ongoing problem you know, it has been. It's third world country crap is what it is! It's crazy, it's not right and I have bitched. Their freezer broke in their warehouse, their roof fell in, they lost food and stuff. Who is paying for this, what is going on with this?" (FB-4, 8.8.14)
\end{abstract}

The perception that WVDA provides a burdensome and unnecessary bureaucratic layer runs deep across the HFN in West Virginia. Food banks monitor and oversee their TEFAP LFCs as sub-contractors, a responsibility they argue is much more involved than the state's. The perception is that WVDA is drawing down or holding back payment of administrative funds that would be better used if passed on to food banks: "It seems to me that they keep the lion's share of the money and we do the lion's share of the work" (FB-12, 12.19.17) said one food bank employee regarding the convoluted funding streams subsidizing the distribution of TEFAP foods. The state has slowly empowered the food banks as they demand more control over the administration of the commodities that they are responsible for fundraising to distribute. In 2009, WVDA transitioned to directing all TEFAP commodities from deliveries from their state warehouse directly to the food 
banks. The story of this transition lies in the political pressure to privatize the program and take it out of state hands entirely.

\section{Funding Tensions}

The tension over TEFAP administrative funds erupted into the public sphere in 2001 during TEFAP's transition from WVDHHR to WVDA when MFB saw an opening to privatize USDA commodity distribution programs in West Virginia. Along with some of its local representatives, MFB mounted a campaign to convince the state legislature that its central geographic location in Gassaway, WV, along with the lean administrative efficiencies it had achieved as a large not-forprofit would enhance TEFAP's impact for vulnerable West Virginians and save costs for the state $^{23}$. MFB proposed to contract directly with the federal government, taking on the full administrative burden of placing and receiving entitlement and "bonus" food orders, delivering commodities to FHFB and in the process managing the entire administrative fair share allocation, enhancing its control over the federal dollars funding the HFN in the state. Reading from their privatization proposal summary the move was touted as a trend setting moment across the wider national food banking economy:

"The time for privatization is now, with the governor and legislature wrestling with another year of budget cuts, and the increasing demand for more West Virginians needing assistance from food programs. Either the State legislature (with approval from the Secretary) or Governor Manchin can designate Mountaineer Food Bank as the agency responsible for handling these programs. This unique partnership will make West Virginia shine as an example to other states. West Virginia would be the only state handling these programs to the food bank, showing other states how to stretch their financial resources to meet the community needs." (Mountaineer Food Bank, n.d.)

In light of MFB's near financial collapse in 2015 (Lohnes and Wilson, 2018), the state's ultimate decision to maintain WVDA as the primary agency contracting USDA commodities now

\footnotetext{
${ }^{23}$ MFB also sought to take over administrative responsibilities of Child Nutrition Commodities arguing that it would pass on savings upwards of $5 \%$ to the county school boards. It also wanted to appropriate the Homeland Security strategic food reserve.
} 
seems prescient, but the political battle over who would ultimately determine TEFAP's ruling relations in West Virginia was an 8-year process that left divisive scars on the wider HFN, and rumors of state corruption or food bank power grabs at the LFC level. A compromise was reached in 2009 with more pass through administrative funding and direct receipt of commodities for food banks. The WVDA bureaucrat that navigated this process recounted:

\begin{abstract}
"It was kind of an appeasement but it also just kind of made sense to not directly receive the commodities. It was not efficient, nor could it be justified so we conceded that. But when [MFB] saw the volume and the scope of what we had been doing they were like "oh"! Because we would sit on the food until the food banks could take them and make regular deliveries out to them, but it doesn't work like that with the USDA. The USDA says, here it is, take it. It's overwhelming but then you've also got these periods that are very limited, and I just think that MFB did not fully understand what they were requesting." (USDA-1, 4.3.15).
\end{abstract}

Paradoxically, even as the state devolved responsibility for the execution of the program, the changes gave WVDA more visibility over TEFAP than it had ever had. WVDA compensated the loss of administrative control by hiring a full time TEFAP coordinator to monitor the food banks and their LFCs. A new contract between the state and food banks obligated the latter to report all their TEFAP LFCs to the WVDA at least once a year, a move that again did not go over well with the food bank director at the heart of the privatization battles. The WVDA employee in question recounted that:

"she would send her agency list and it had it stamped in big red letters, PROPRIETARY INFORMATION ONLY, and you couldn't even read what the information said, it was ridiculous. She was just not very pleased that they had hired me for that position, she didn't want one of our people going out to her agencies." (USDA-1, 4.3.15)

The hiring of a full time TEFAP coordinator was perceived as further drawing resources that the food bank needed to run its programs, duplicating existing monitoring efforts and adding unnecessary layers of bureaucracy to what was already becoming a very rule intensive program. The dust has settled on the privatization battle and under new food bank leadership these frayed relations are being rewoven. The food banking economy ultimately depends on the institutional 
security of a pass-through government agency like WVDA and the state resources it can leverage to function. WVDA is now primarily involved in ordering food commodities from FNS and ensuring that federal rules are applied across its territory. The food banks would still appreciate more influence in the latter. WVDA's role in the TEFAP program might be summarized by the Secretary of Agriculture's chief of staff response to whether the expectations of his position had changed since he first took the position:

"It's surprising, but I don't really deal with food and farming much. $90 \%$ of what we do at
the department is regulatory. I had no idea getting into this. Mostly federal regulations you
know, we're just the pass down from federal to county level. And there are so many
different programs we just focus on making sure the rules of each are applied." (PO-9,
11.3.15)

\section{E. Bureaucratic Rules}

The TEFAP program in West Virginia is overwhelmingly associated with rules. Although TEFAP foods provide a nutritious and reliable source of food for LFCs participating in the program, throughout the course of my research I heard many complaints from local TEFAP charities, and staff at the two food banks, about the burdensome bureaucracy and red tape they confront to participate in the program.

"Ultimately our work is to get food out to people, but sometimes the bureaucracy of the business overwhelms it. There is so much paperwork! Are we feeding people or getting information from them? TEFAP is especially bad, we are losing TEFAP agencies because it's just too much work for them. Rules have gone from a few pages to a book. I mean, how much can you burden volunteers with this? I've volunteered for a lot of things before, but one thing is for sure, I've never volunteered to do paperwork!" (FB-6, 7.8.16)

The heavy bureaucratic burden is especially sardonic considering the initial laissez-faire impulse to provide surplus commodities with no strings attached to the states that laid claim to them. As the program formalized into a permanent fix, the need to structure, regulate and set the terms of public food distributions grew. While the burdensome rules are often blamed on WVDA at the local level, the state agency is merely interpreting and applying the USDA's interpretation 
of federal laws and executive orders that change along with political winds. Mandated TEFAP paper trails ensure that the many rules of the program are upheld. Codified in law, these regulations are interpreted at different institutional levels of the food banking economy and applied somewhat unevenly from place to place. I have already discussed how each state's implementation of the program differs significantly based on the leeway that each has to design TEFAP to suit their needs. At the local level, the state's rules should in theory apply across the jurisdiction. In practice however, TEFAP rules are often bent or broken. This deviance is justified through ideologies that reinforce fears of an overbearing state, or simply due to logistical and institutional constraints of the mostly volunteer labor force managing such a formalized federal program. As a result, TEFAP LFCs are faced with constant re-training and disciplining, the former via agency visits and yearly food bank conferences, the latter via the threat of cutting access to TEFAP commodities entirely. In chapter five, I review how commodity distribution rules at the federal level produce awkward territorialities and tensions between the two West Virginia food banks. What is important to reiterate here is that food banks act as institutional bridges between LFCs distributing TEFAP foods and the WVDA contracting with the federal government. Food banks maintain contact with their LFCs at minima through monthly food orders. They hear their many concerns and even as they are powerless to improve program functionality, they must work to distribute TEFAP commodities equitably across their vast territories. Food banks must also discipline agencies that do not comply with TEFAP rules, or the internal systems set in place to ensure that the program operates efficiently across the 361 participating agencies. LFCs therefore act in tenuous concert, directed by food bank administrators to spread TEFAP commodities out as evenly as possible and respond to spikes in demand in times of crisis. 
For an LFC to become an approved TEFAP agent, it must apply with the food bank assigned to their county, not with the state. A food bank staff member performs a site visit to determine whether the applicant has the staffing resources, cold and dry storage capacity, cleanliness standards and opening hours to be eligible for the higher standards demanded by TEFAP food distributions. There are no written guidelines that dictate pre-requisites for participation in TEFAP, rather foodbanks act as informal gatekeepers, overseeing and vetting the individual LFCs participating to ensure they can apply the rules. "I visit the location, and when I'm there I go over all that is entailed, show them what is expected of them and what they get. If I just send them the paperwork and I'm not there in person to explain everything, it gets really confusing" (FB-12, 12.19.17)

The agreement to participate in TEFAP is a WVDA contract signed by LFCs and their food bank that outlines the responsibilities of each party. The contract ties LFCs distributing federal commodities to the following rules:

- Must keep regular hours and be accessible to the general public.

- Must not charge recipients for the USDA commodities provided.

- Food Pantries must maintain data about each household served including:

- Physical address (when available)

- Number of people in household

- Signature attesting self-declaration of income (below $130 \%$ of poverty) and/or current SNAP recipient

- Must not exclude participants on the basis of race, color, national origin, gender, religion, age, disability, political beliefs, sexual orientation, and marital or family status based on including but not limited to:

- Title VI of the Civil Rights Act of 1964

- Section 504 of the Rehabilitation Act of 1973

○ All requirements imposed by the USDHHS (45 CFR Part 84)

- Age discrimination act of 1975

○ Title IX of the Education Amendments Act of 1972

- USDA regulations (7 CFR Part 15)

- Display in a visible and accessible area the "And Justice for All" posters and Civil Rights complaints forms.

- Ensure Civil Rights training is provided to all staff and volunteers on an annual basis.

- Maintain accounting records identifying source and distribution of all USDA foods

- Only request USDA foods that will be distributed 
- USDA foods will not be sold, exchanged, or otherwise disposed of without approval

- USDA foods will not be used to further political interests of any party

- Maintain records for 3 years of programmatic activity

- Report loss or damage of foods

- Provide adequate personnel for the distribution of USDA foods

- Monitor all storage facilities at least once every 72 hours

- Label USDA foods by packing date, contract number, and vendor data

- WVDA and USDA may monitor LFC at any time

- LFC may terminate agreement with 30-day notice and must return all USDA foods in storage

- Non-compliance with any of above rules will result in termination of agreement

In addition to this formal contract, food banks create an additional governance layer in an effort to ensure that they meet their own obligations to WVDA and by extension the USDA. These rules also ensure that the program operates efficiently across the network of agencies.

- Agencies may not require a referral for client participation.

- Agencies may combine the distribution of TEFAP with other donated foods so long as TEFAP rules are respected for that distribution.

- Commodities are to be distributed in original packages, for household consumption only.

- Hoarding USDA commodities is prohibited

- Each agency distributing TEFAP must make a public service announcement once every two years via radio or newspaper

- Agencies must submit a quarterly report.

- Agencies that do not submit a quarterly report on time will not receive their USDA allocation

- Agencies that do not order for two consecutive allocation will automatically be removed from TEFAP and must request reinstatement

- New agencies must complete a 90-day probationary period.

- New agencies will be considered on an "as needed basis"

I provide this extensive list of rules to demonstrate why LFCs feel overburdened by the bureaucracy involved in distributing state food to their clients. I argue that these rules serve two very specific purposes for the state. First and foremost, they ensure that agricultural surplus purchased by the federal government remains locked in distribution channels that will not be resold on secondary markets. The food bank fix for the state serves to transfer capitalist value from primary production circuits to a secondary consumption fund that does not disrupt existing agricultural and retail markets. LFCs are strictly forbidden from reselling federal foods, doing so would undermine the goals of the program to not disrupt retail market prices. From the earliest 
days of the program for example, when the dairy industry pushed back against SDDP for reducing the price of cheese at the store because it was now readily available at local charities, the Reagan administration quickly curtailed the flow of cheese distributions into charitable networks (Lipsky and Thibodeau, 1988). Today ERS economists keep a close eye on the economic impacts of surplus removal. If charities were to sell the food, such analyses would not be coherent. The compulsory gift of public foods is thus one major ruling relation in the food banking economy.

Secondly, TEFAP rules seek to ensure non-discrimination and equitable distribution of public foods regardless of race, gender, age, or disability, approaching a right to food framework that other charitable food sourcing channels such as FA do not mandate. Social justice rules are in place to expand access to emergency food to the widest extent possible, ensure equitable distribution and non-discrimination. The power that these rules confer to their enforcers (e.g. the food banks) does lead to tensions across the HFN in West Virginia. As I explain in chapter six, these are regularly bent or broken either due to a lack of resources or an ideology of feeding that shapes LFC perceptions of whom is worthy of care and under what circumstances.

\section{F. Summary}

TEFAP in West Virginia must be understood through the federal laws and agencies that sanction the program, and their relationship to the wider food system. A West Virginia state bureaucrat with over 15 years' experience administering the TEFAP program at both WVDA and WVDHHR explained that the benefits of the program were poorly understood by others working on nutrition programs at the state level.

\footnotetext{
"We're an island, we're wholly separate, if not excluded we're certainly not included. We call ourselves the island of misfit toys because we're isolated financially and even then within the department, within our own division there are people that don't know what we are doing. There are people in our department going to talk to the food banks that don't even know we exist! We're isolated at the state level and the USDA level, our programs do not seem to communicate well, there is no network of collaborators connecting the dots
} 
between them. We've made personal efforts and inquiries as to why this is so disjointed and even our [FNS] regional offices which have been very responsive to our needs, there is no real connection between the commodity programs and the remaining functionality of those other nutrition programs like SNAP, WIC, School meals, summer feeding and so forth.” (USDA-1, 4.3.15)

The amount of funding and types of food received creates tensions and frustrations across the state as local actors do not fully comprehend the extent of the socio-economic forces that shape TEFAP beyond West Virginia. These tensions erupted in 2001 in an 8-year privatization battle between MFB and WVDA, the former pressing to further hollow out the state by channeling all funds through the state's largest food bank. Although this did not ultimately occur, the pressure to privatize did re-organize the TEFAP program across the state. My case study reveals how the public-private implementation of this federal nutrition program, which ultimately serves to resolve overproduction along agro-industrial supply chains, is itself fraught. The frustration over the implementation of such an abstruse program was expressed by another WVDA bureaucrat as follows:
"You know a lot of things look good on paper but when they're actually implemented, I've never actually seen in practice private and public services be successful as far as integrating. Each has specific areas of responsibility and that doesn't tend to go well but I don't know, it just doesn't seem to play out the way it may" (USDA-1, 4.3.15)

The 350 LFCs that subcontract with MFB and FHFB to distribute TEFAP at the community level ultimately combine into a legal geography that seeks to ensure federal laws are applied across a highly differentiated HFN, one informed by oft conflicting ideologies and motivations driving their hunger relief work (Chapter 6). Food banks and LFCs distribute state-owned commodities even as they operate outside of the institutional confines of the state. The social and administrative distance between hundreds of LFCs subcontracting as federal agents of the USDA embodies the bureaucratic inefficiencies and freneticism produced by a neoliberal ideology that privileges private actors to deliver social services. While charities entering this public-private relationship 
are touted as nimbler actors than the state, the lack of institutional uniformity creates confusion, frustration and misdirected resentments between the various contracting parties. The devolutionary logic allows each party to redirect responsibility for administrative problems to an institutional layer it may ultimately have very little experiential or theoretical knowledge of. As charities working along the TEFAP supply chain work to maximize benefits and create efficiencies that makes sense to their individual operations, the sense of collective social purpose is ultimately undermined. It seems the state may also be fracturing solidarities across civil society's anti-hunger community through the TEFAP program.

\section{Conclusion}

TEFAP fits within the state's broader nutrition entitlement strategy as outlined in the farm bill. The program is unique in that it rolls many different public and private agencies into its programmatic goals. The convoluted governance structure that results makes it difficult for actors engaging with TEFAP to understand its social function outside of their individual siloed feeding programs. I reviewed the different mandates within the USDA and how FNS, AMS, and FSA each focus on separate and oft contradictory parts of the U.S. food system. State pass through agencies also must negotiate many different interests leading to significantly different implementations of TEFAP across their jurisdictions.

I reviewed the private interests that inform the roll-out of the TEFAP program, the distribution of benefits therein and the difference between entitlement, "bonus" and administrative funding. The legal geography of the fair share allocation, codified in 1996, is problematic because the statistics used to inform the distribution of TEFAP commodities across space are not matched to the socio-economic realities that contribute to hunger in local communities. This is problematic 
for food banks in West Virginia who are powerless to shape their food and funding allocation. Food banks must negotiate access to these resources through the WVDA bureaucracy, who holds them accountable to effectively distribute federal product across their network of private LFCs. This situation produces significant tensions between the various parties involved in TEFAP distributions.

As I write this however, the Trump administration's FY-2019 budget proposal is suggesting a 50\% reduction in SNAP benefits to be replaced with a 14-day supply of federal commodities through the nationalistic branding campaign "America's Harvest Box" (Shapira, 2018). The program would mirror the laissez faire ideals of the Reagan administration, federal funding for commodity purchases but no administrative appropriations and few directives for states on how to distribute these boxes. The burden, it is assumed, would be carried by civil society and logistically coordinated by food banks. While such a proposal has little chance of passing in its current form the fact that it is now a part of the national conversation demonstrates how the food bank fix continues to play a critical role in the state's food policy apparatus. TEFAP's prescriptive programming limits consumer choice while boosting the revenues of entrenched farm and food industry interests. Such policies hinder the development of local and regional food economies even as the charities distributing these foods face budget crises.

Although many scholars argue that food banks are evidence of a receding neoliberal state (Warshawsky, 2010), I have demonstrated throughout this chapter that the charitable food landscape cannot be understood outside of the state. The neoliberal roll-out of the TEFAP program (Peck and Tickell, 2002) maintains food banks as an appendage of state policy, stabilizing markets through the enrollment of for-profit and charitable actors into its mandate. On the one hand the state fixes its century long problem of overproduction and achieves quiescence from agricultural 
producers and food industry interests. On the other hand, the state fixes hunger and legitimizes the ongoing rollback of other welfare and food entitlement programs by distributing food resources to low income families, again mitigating the social unrest that might otherwise result from food access failures. The TEFAP fix must be understood as a critical part of a food banking economy that is itself imbricated in the wider agro-industrial food system. The state's capital injections into this economy has physically fixed food banks in place, investing over $\$ 1.7$ billion into program infrastructure and administration and at least $\$ 10$ billion into food commodities, spurring private philanthropic capital to also inject money into warehouses, refrigeration, trucking, office spaces and food banking labor.

In 1984 the federal government provided 5 times more food to food banks than private food firms donating their obsolete inventory. Although today that ratio is now flipped, and private corporate donations organized through Feeding America (FA) have overtaken TEFAP donations, the federal government remains an important institutional anchor for food banks. As I demonstrate in the following chapter, the state also played a key role in developing the early federation of food banks under the FA brand. TEFAP's investment into the food banking economy's infrastructure is much more significant than what any private firm or even collection of firms could have contributed to the network. Today, the market is often triumphantly posed as a viable solution to hunger. The state however is intimately implicated in shaping these markets, both the formalized ones that are apparent in retail spaces, and the hidden ones that facilitate the flow of food and money across the HFN. In the following chapter, I explore the way the food bank fix also serves to legitimize the corporate food regime in much greater depth, maintaining the viability of food markets that serve the interest of large agro-food corporations. However, the corporate social responsibility (CSR) campaigns that promise to provide meals to the needy do not need to 
legitimize their activities in the same way as the state, forgoing concerns about civil rights and democratic transparency altogether in their attempt to revalue their food waste through charity. 


\section{Chapter 4: Feeding America}

"In communities big and small across the country, there are families struggling with hunger. By working together during this campaign with our suppliers, customers and friends at Feeding America, we can help secure 200 million meals that will help those who need it most"

- Kathleen McLaughlin, President of the Walmart Foundation

"No family in a community we serve should ever go hungry, and no food in a store we operate should ever go to waste. More than 40 percent of the food produced in the U.S. each year goes unconsumed, while one in eight people struggle with hunger. That just doesn't make sense. As America's grocer and one of the largest retailers in the world, we are committing to doing something about it.

- Rodney McMullen, Chairman and CEO Kroger Corporation

"Everything we receive is receipted to corporate Walmart and Kroger by store date and product category. We have to receipt to Feeding America, they give credit back to the stores. If we receipt for 80 pounds and they gave 100 pounds they get mad at us"

- $\quad$ Product Sourcing Manager, Mountaineer Food Bank

\section{Introduction}

The links between food corporations and food charities are more and more visible. Large food retailers now regularly encourage their customers to engage in the fight against hunger through cause marketing campaigns that provide meals to people in need while promising to reduce the negative environmental impacts of food waste. Walmart's Fight Hunger Spark Change campaign was launched in 2014 to provide 4 billion meals to people struggling with hunger by 2020. In 2017 the Kroger corporation followed suit with its Zero Hunger | Zero Waste plan to donate 3 billion meals by 2025, the same year it meets the goal of zero food waste across the company. In West Virginia, food bank trucks branded with these corporate sponsor logos travel the state's roads reminding motorists that the food bank and its business partners are "working together for hunger relief". 
Yet, Kroger and Walmart do not provide meals to people. Rather they donate their food waste to hunger relief organizations. This nuance is important because their corporate benevolence relies on partnerships with independent civil society organizations. In this chapter I argue that seemingly autonomous food charities are increasingly subsumed within the logics of corporate business practices and their attendant corporation social responsibility (CSR) campaigns. Today, food charities are ever more reliant on the relationships they forge with the private sector to execute their missions, a marriage that is realigning power relations across the food banking economy. Commitments by companies such as Kroger and Walmart to end hunger and reduce the environmental impacts of food waste secures cultural legitimacy in the marketplace while improving brand loyalty and increasing shareholder returns (Warshawsky, 2016).

The ethical regimes imposed through CSR affect political, social, economic and environmental landscapes as non-state actors facilitate or contest the corporatization of resource access across specific geographies (Billo, 2012; Thieme et. al, 2014). As I have learned, the incentives driving the distribution of corporate food waste across space as charity are unclear and highly fraught. The costs of delivering meals to the poor are unevenly distributed among the many parties involved in the gift transaction. For-profit businesses and non-profit groups need a thirdparty to resolve the contradictions along this complex and unwieldy hunger relief supply chain. That third party is Feeding America (FA), one of the largest non-profit charities in the United States.

Today, food corporations rely on FA to process food waste donations through a wellordered network of food banks. Each food bank is held accountable to distribute food waste as hunger relief through its membership agreement with FA, which standardizes an operating procedure and centralizes power within a non-profit organization largely beholden to the profit 
motives of private companies. Although FA is central to the ongoing roll-out of the food banking economy, there is a large gap in the literature on how this powerful organization governs the corporate food waste donated to charity. Henderson (2004), Warshawsky (2010), and Lindenbaum (2016) all drew empirical evidence for their path breaking work from food banks operating under the FA umbrella. However, I seek to extend their arguments through an explanation of FA's role in using food banks as appendages of agro-industrial supply chains to "fix" the problem of food waste and hunger relief.

In the previous chapter I argued that the state is instrumental in fixing the food banking economy in place through The Emergency Food Assistance Program (TEFAP). Appropriations for TEFAP have increased steadily since 2008, yet these public food sources now pale in comparison to the food waste donations secured through FA corporate partnerships. In 2016, 3 billion pounds of food was donated to FA food banks by private firms, a number that has doubled in less than a decade. The state remains intimately involved in this process through a tax regime that incentivizes corporations to participate in the food banking economy. As I demonstrate in this chapter, FA operates within the highly professionalized tier of the shadow state (Wolch, 1990; Milligan, 2007), monitoring the relationship between food corporations and charitable food organizations distributing donated food waste to the poor. FA holds food banks accountable through a member contract that coalesces a fractured group of independent food charities into a vertically integrated governance structure and supply chain.

FA brokers relationships between corporations and food banks by centralizing food waste donations through its certified charitable distribution channels, delivering both material and discursive goods on behalf of its corporate partners. Member food banks must conform to network wide practices or face the scepter of declining donations and a struggle for fiscal survival in a 
philanthropic environment that increasingly demands the legitimacy of professionalized institutions. I show how FA organizes and executes the work of this shadow state by leveraging food banks to legitimize the corporate food regime (McMichael, 2009) and its hegemony over the anti-hunger industrial complex (Fisher, 2017). In sum, my central focus in this chapter is on the effects of corporate power and the FA shadow state over food banking operations in West Virginia. By analyzing the relationships forged between food corporations, food banks, FA and the state (through the tax code), I argue that FA's governance structure further legitimizes the corporate food regime.

I begin with a historical overview of the tightening relationship between food banks and the food industry over the past 40 years and the way in which food banks were made to adapt to industry standards to continue accessing food waste donations from the private sector. The state was an early participant in the federation of food banks under the Second Harvest banner and continues to be a key actor tying food banks and food corporations together through a tax regime that incentivizes businesses to engage in charitable food donations. I review the progressive removal of liability, tax deduction incentives and fair market valuations that encourage corporations to become involved in hunger relief programs.

Next, I analyze the politics of knowledge that inform the distribution of donated food waste. Internal monitoring and evaluation is standard practice across the voluntary sector, particularly among professionalized organizations. FA defines needs through Map the Meal Gap, a geographic information system that quantifies the number of missing meals across each county in the United States. It then evaluates its member food banks through a supply side model that ties the number of meals that must be delivered in each county to the national food waste recovery totals, in effect pushing a growth-based imperative on the HFN. Food banks must account for every 
pound of corporate food waste circulating through their networks to meet their distribution targets.

The metric translates nicely to corporate campaigns that promise to deliver meals to people in need. However, as I demonstrate in chapter 7, the burdens of making the system function fall upon food banks and LFCs who must find the resources necessary to close the meal gap despite the oft inadequate mix of food from the donors pushing these imperatives.

Finally, I analyze the political-legal assemblage that vests FA with the authority to determine property and access rights to corporate food waste. A strict accounting regime is in place to ensure that corporate food waste travels transparently through a network of not-for-profit agencies toward its intended end of satiating hungry bodies and claiming tax breaks. FA's authority depends on compliance by its food bank members and it closely monitors their activities, threatening to cut off corporate food supplies to food banks that do not meet their contractual obligations. I also explain the effects of this governance structure in West Virginia as the two food banks in the state work to execute national directives while navigating tensions among LFCs enrolled into FA's framework at the local level.

\section{The Corporate Food Waste Fix}

Established in 1979 under the name Second Harvest, FA grew into the country's preeminent anti-hunger organization by aligning its mission with large food companies that supported the expansion of a national charitable food infrastructure. With $\$ 2.4$ billion in revenue on its balance sheet last year, FA is now the 3rd largest charity in the United States (Forbes, 2017), significantly shaping the politics, practices and discourse surrounding charitable food provisioning. FA consolidates its 200-member food banks into a unified voice when developing

food sourcing strategies and anti-hunger programs providing political clout to the network by 
steering national anti-hunger policy through its advocacy and lobbying efforts ${ }^{24}$. This consolidation comes with new channels for accessing foods from large commercial wholesale and retail firms, however it also comes with strings attached such as bureaucratization, depoliticization and the dislocation of food banks from the local agencies provisioning of hunger relief services.

FA's growing influence over the food banking economy parallels the concentration of corporate power across the global food system (Clapp and Fuchs, 2009). The relationships FA establishes with large food and funding partners (Table 4-1), and the exclusive access to donations and grant opportunities it then brokers for its member food banks concentrates power within a board of directors heavily invested in food industry concerns, blurring the lines between profit seeking and compassion. Matt Knott, the current FA president for example, was formerly an executive for PepsiCo. The board also includes representatives from Kroger, ConAgra, Walmart, General Mills and the U.S. Dairy Export Council. These are some of the most powerful corporate food firms in the world. FA's power to shape the charitable food sector elevates the organization as a key arbiter legitimizing the anti-hunger activities of food corporations vis-à-vis the state and the public.

In many ways FA represents a neoliberal response to the failure of the U.S. market economy to meet the food needs of all consumers. As a broker between food corporations and food banks, FA's cause marketing campaigns sell food waste recovery as a charitable response to food access failures (e.g. hunger), thus acquitting the private food sector from the responsibility to address food insecurity by paying higher wages, lowering food prices or supporting state led income redistribution (e.g. raising corporate taxes). Private firms lean on FA to promote their

\footnotetext{
${ }^{24}$ Feeding America co-sponsors the National Anti-Hunger Policy Conference with the Food Research Action Council (FRAC) every year, significantly shaping the discourse and lobbying efforts around food entitlement and nutrition related causes.
} 
charitable and market-led answer to hunger, while exerting increasing control over a food banking economy that depends on state, community and philanthropic capital not necessarily provided by those corporations ${ }^{25}$ to achieve their goals.

\section{Table 4-1: Feeding America's Leadership and Mission Partnership Network}

\begin{tabular}{llll}
\hline \multicolumn{1}{c}{ Food Processing } & Food Retail & Finance \& Philanthropy & \multicolumn{1}{c}{ Other } \\
\hline Bimbo Bakeries & Albertson's & All State & Abbot Laboratories \\
Campbell's & Big Lots & Ameriprise Financial & American Idol \\
Cargill & BJ's & Anschutz Family Foundation & Arm \& Hammer \\
Coca Cola & C\&S & Anthem Foundation & Bristol Myers Squibb \\
ConAgra Foods & Food Lion & Bank of America & Caterpillar \\
Dannon & Kroger & JP Morgan & Clorox Company \\
Dean Foods & Publix & Linda \& Keith Monda & Doris Christopher \\
Flowers Foods & Sam's Club & Morgan Stanley & Macy's \\
General Mills & Supervalu & Nationwide & Monsanto \\
Kellogg's & Sysco & PWC Charitable Foundation & Nielsen \\
Kraft & Target & Safeway Foundation & Proctor \& Gamble \\
Mars & UNFI & The David Tepper Foundation & The Cheesecake Factory \\
Mondelez International & US foods & The Howard Buffett Foundation & The Pampered Chef \\
Nestle & Walgreens & The Jilot Family & Unilever \\
PepsiCo & Walmart & The Kresge Foundation & Valero \\
Perdue & Winn Dixie & The Lincy Foundation & CVS \\
Smuckers & FA partners contribute to at least one of six key operation areas. These include product \\
Tyson & donations, philanthropy, disaster relief, cause marketing, in-kind contributions and \\
White Wave & employee engagement & \\
\hline Source: http://www.feedingamerica.org/our-response/about-us/partners &
\end{tabular}

FA is reacting to the neoliberal pressures of a receding state by actively participating in the roll out of public-private partnerships that expand the role of the private sector in ordering, controlling and disciplining the delivery of social services such as hunger relief (Rose, 1999; Jessop, 2002, Peck and Tickell, 2002). Following this logic, the hunger relief sector in the United States is expanding under economic policies that devolve the delivery of state services to private

\footnotetext{
${ }^{25}$ As I review in chapter 5, large institutional grant makers (e.g. Walmart foundation) only provided around $15 \%$ of the operational budget for the two food banks in West Virginia in 2016. They drew the majority of their private funding from local donors.
} 
organizations with social missions. 501(c)(3) not-for-profit organizations like FA remain tied to the state through the tax code but fall outside of traditional democratic politics, operating through internal by-laws that govern the board of directors of each organization. Furthermore, as I have found through my research, FA rolls out a set of compelling managerial techniques that demand its food bank members distribute increasing amounts of private sector food waste regardless of the quality of the foods received. Unlike the foods received through TEFAP (chapter 3 ), the products donated by the private sector do not have to meet any nutritional standards. In chapter 7, I describe how the requirement to move obsolete corporate inventories regardless of quality produces tensions at the local level. As one food bank director in West Virginia put it:

"The things that I have to give to people are often things that you and I won't buy. We walk right past it. Sometimes we'll receive things and I just say, I'm not distributing that, I don't think you want me to identify that you donated that product. They want the credit for the donated food, and then we go into a county, we have our compliance standards so we want the credit for putting that food out." (FB-9: 5.12.17)

This tension between food quality and food quantity lies at the heart of the dilemma faced by food banks as they work with FA to address hunger through corporate food waste. Corporate campaigns promise to deliver meals to people in need, yet FA measures the success of its food banks through the quantity of food they distribute, not its quality in terms of a balanced meal. While corporations claim that they are providing "meals", food bank staff and LFC volunteers scramble to provide balanced food offerings through TEFAP, local food drives and purchases because corporate food waste, while plentiful, is not always nutritionally balanced. The conundrum between quality and quantity speaks to the power of the corporate food sector to frame and claim the work of HFNs through FA to achieve their promotional goals. By writing and enforcing the rules that govern food banking activities, FA ensures that food waste recovery continues to serve the interests of its corporate partners, even when these frustrate the goals of non-profits working 
to address hunger. Before turning to the application of these rules in practice, I first detail the rise of FA as a broker between the interests of private food firms and local charities.

\section{Rolling out Corporate Hunger Relief}

The past forty years of charitable hunger relief in the United States is a story of its progressive alignment with the food industry. In 1967, John Van Hengel opened St. Mary's food bank in Phoenix, Arizona with a \$3,000-dollar loan, donated warehouse space and a few volunteers $^{26}$. He convinced local businesses to donate their food waste for redistribution to organizations that fed the needy. It was the first organization of its kind. Van Hengel and his team gleaned and redistributed 275,000 pounds of food to 36 LFCs in the first year. The board president was an executive at a regional grocery chain, establishing early ties between food banking and private food interests. The team soon enlisted wholesalers and manufacturers who began donating food excess by the truckload. The concept spread and by 1977 eighteen cities had established food banks, many enrolling Van Hengel as a consultant (Martin, 2005; Poppendieck, 1998).

Realizing the potential of these novel anti-hunger institutions, the federal government approached St. Mary's Food Bank with a proposal to organize the nascent food banking industry into a network that could develop standards, share best practices, and negotiate collectively with large food manufacturers. In 1979, Van Hengel established Second Harvest with \$1.5 million dollars in grants from the Community Services Administration ${ }^{27}$ (CSA). Beginning with a federation of 13 food banks, Second Harvest quickly grew to 44 members by 1982. In 1984, shortly

\footnotetext{
${ }^{26}$ Van Hengel was inspired by his experiences volunteering at a local soup kitchen. The need for food resources coupled with stories of the poor rummaging through grocery store dumpsters to recover food waste compelled him to find a more efficient way to organize charitable food recovery and distributions.

${ }^{27}$ CSA was the Nixon administration's successor to the Office of Economic Opportunity administering the Johnson's war on poverty. Grants were provided through 1982 when the agency became restructured into the Department of Housing and Urban Development (HUD).
} 
after the USDA formalized state support to food banks through TEFAP (Chapter 3), Second Harvest moved its headquarters from Phoenix to Chicago to be closer to key food industry headquarters. Private donations grew rapidly, as did the number of food banking organizations that paid membership dues to access institutional benefits afforded by the coalition. By 1985, the number of food banks affiliated with Second Harvest reached 203.

The agglomeration of large food donors under the FA umbrella paralleled the construction of a legal framework that incentivized food businesses to donate their obsolete inventories to charity and take advantage of the fair market valuation ${ }^{28}$ (FMV) deductions permissible under the federal tax code (Van Zuiden, 2012). An early obstacle to donating food was the fear of legal liability. If a consumer became ill, businesses producing, transporting or previously marketing that donated food did not want to be held responsible. California first passed a Good Samaritan law absolving food donors from this risk in 1977, and by the late 1980s all 50 states had some form of Good Samaritan laws on the books. As Second Harvest operations expanded across the country and donated foods increasingly crossed state lines however, the lack of legal uniformity prevented the organization from acting in concert to broker tax deductions for national level donors.

In 1996, Christina Vladimiroff, then CEO of Second Harvest, testified before Congress in support of the Bill Emerson Good Samaritan Food Donation Act: "Our experience is clear, there are companies that want to donate food and grocery products, but are fearful of contributing because of the varying state laws regarding their liability for what would otherwise be a generous act of donation" (H.R. 104-661). President Clinton signed the bill into law absolving C corporations from liability, save in cases of gross negligence. Food corporations no longer had to

\footnotetext{
${ }^{28}$ FMV is the selling price of the donated product minus the costs of acquiring the product (Cost of Goods Sold) divided by 2 . In other words, donors can write off half the unrealized profits from not having sold the item. Charitable contributions from a $\mathrm{C}$ corporation for a given year may not exceed $10 \%$ of their taxable net income.
} 
navigate 50 different state laws and could now take full advantage of federal tax incentives through a clearly defined FMV for donated food products. The law successfully increased food waste donations to charity from the private sector doubling donations from 900 million pounds to 1.8 billion pounds in the period between 1996 and 2002 (Obrien et. al, 2004).

In 2000, Second Harvest merged with the national food rescue group Foodchain to capture the efficiencies they had developed along perishable food supply chains ${ }^{29}$. The two entities combined under the new name America's Second Harvest. The merger came at the behest of Second Harvest board members and funders wary of redundancies that would limit the food industry's integration with non-profit feeding networks. ConAgra for example strongly supported the merger and their CEO Bruce Rohde explained the industry perspective in the following terms: "Increased food industry efficiency is mandating increased efficiency for hunger-relief
organizations. To be most effective and to feed as many people as possible, organizations
like America's Second Harvest have to be ready and able to capture food quickly and move
it quickly." (PR Newswire, 2000) The merger was the largest ever for the nonprofit sector, consolidating corporate power over the national charitable food landscape and further institutionalizing food banks as brokers between food businesses and LFCs distributing food to the needy (Eig, 2000). Negotiations over the merger also laid bare tensions over concentration of power. The centralization approach made it easier to adapt to food industry goals at the cost of drowning out the voices of those on the front lines of hunger relief work:

"On the table was the proposal to decentralize the combined organization such that the rank and file - the food pantries, soup kitchens and other thousands of agencies that interacted with poor people every day - would have equal power as the 200 -odd food banks. A number of the 'old guard' vehemently opposed this proposal, instead preferring to keep the focus of the new organization on food banking.[...] The merged entity remained focused

\footnotetext{
${ }^{29}$ Foodchain operated 150 programs across the country that recovered 300,000 pounds of hot, prepared foods from catered events and restaurants for redistribution to charities. Second Harvest concentrated almost exclusively on securing non-perishable goods for its food bank networks and benefited from the institutional expertise and infrastructure that accompanied the merger.
} 
on the politically sanitized matters of food distribution and logistics, allowing it in turn to further become in synch with its corporate donors" (Fisher, 2017, p.206)

In 2008 America's Second Harvest changed its name again to Feeding America (FA), moving away from the idea of providing scraps or seconds to "more fully engage the public in the fight against hunger" (Feeding America, 2008). The rebranding effort successfully engaged more corporate partners in cause-marketing campaigns at a time when millions of households turned to food charity in the wake of the Great Recession. Monetary donations jumped by $33 \%$ and food donations increased by $15 \%$ in the first year of the new marketing strategy (Bryson York, 2010). 2008 was also the year that food bank supply chains went through a major shift from manufacturing toward retail food waste sources. An FA employee with 20 years of experience explained some of the factors driving the transition:

"When the recession hit some manufacturers said OK, it's a financially unstable time we're not going to launch many new products and mergers and acquisitions slowed down. And typically for us when there are new product introductions, line or brand extensions and a whole bunch of M\&As it's a benefit to our food banks because somewhere along the line things are going to screw up. [...] Manufacturing is still a large part of what moves through our network but the increase year to year from that channel is smaller, tighter, more difficult to gain. At the same time the industry was going through big changes. Retail exploded when Walmart and Sam's club got on board. [...] We had been pounding on their door for years and they were at a point in their corporate thinking that sustainability was front and center for them and thinking about how they were going to practice what they preach. The size and scope of the FA network could really work for them, you could have food banks and agencies covering all of their stores and the lightbulb went off." (FA$1,4.23 .15)$ 


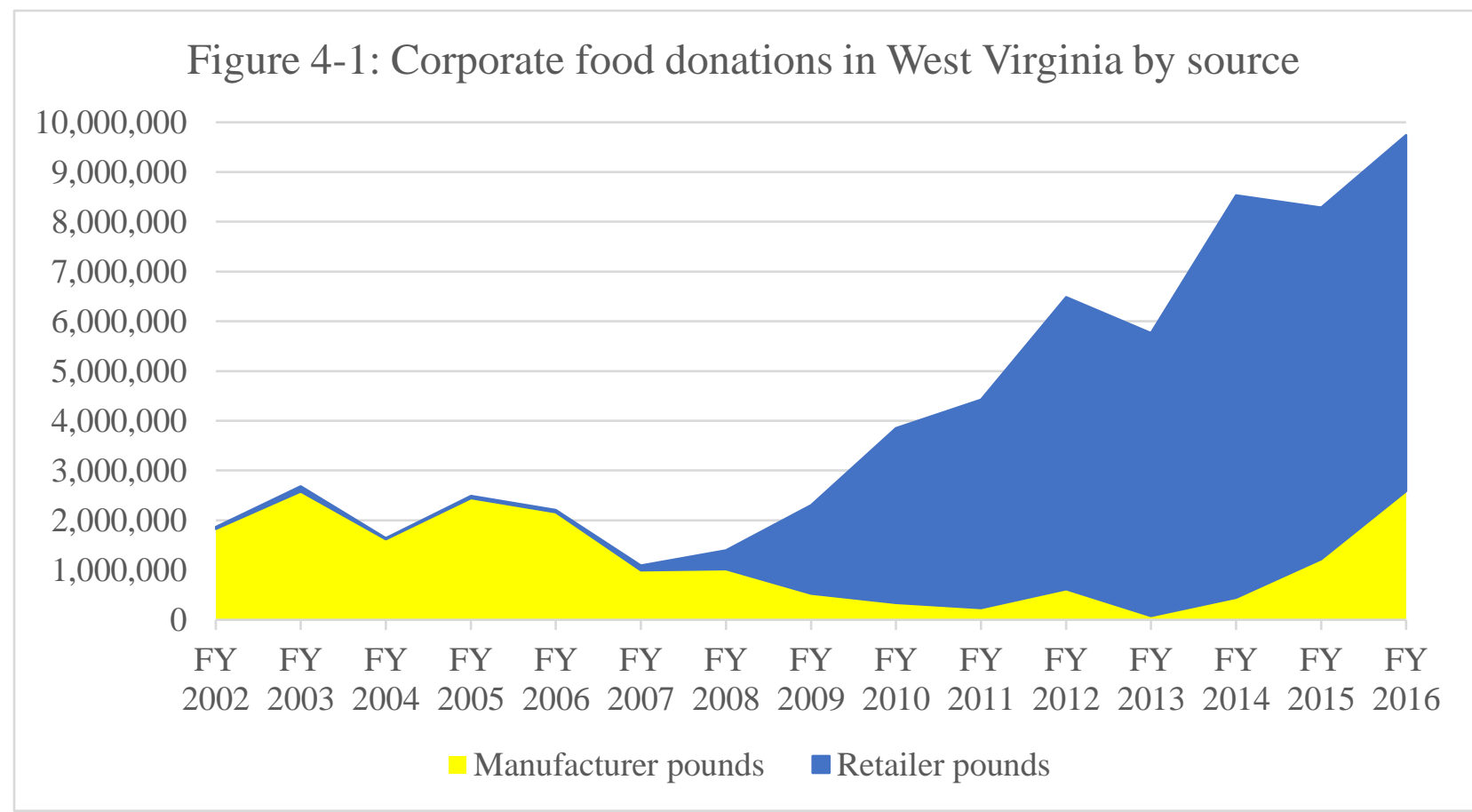

In just a few years, the enrollment of new retail partnerships significantly changed the types

of foods received by food banks and the way that these were accessed. As retailers began integrating FA's new cause marketing campaigns food banks received more and more food to distribute (Figure 4-1), but unsorted retail food waste was also much more labor intensive to process than the uniform pallets historically donated by food manufacturers. A food bank director in West Virginia recounted the changes at the local level over this same period as follows:

\begin{abstract}
"In '07 donations were way down; they were very low. Very little for us to bid on, to get donations through Feeding America and stuff. It really concerned me at that time. I saw product change. One year you get all salad dressing then cereal, it was constantly changing like that. You didn't get donations from Kraft and all those people, was just drying up. [...] In 2008 [FA] said we are partnering with retailers. In June we had 5 Sam's stores in our service area [...] in October we were doing 30 some Krogers. Then in May 2009 we picked up at 17 Walmarts, and in June 2009 we picked up 18 more Walmarts [...] That's when that started, our whole face changed [...] Before we bid on food and it came at the bottom of the hill, we had it on inventory and people ordered it, that is how the system was set up. Now we have to go to that store, figure out how to transform it into something. Do you do this by the case, by the pound etc.? It was a real challenge." (FB-3, 8.8.13)
\end{abstract}

Although it appeared that this transition to retailers happened overnight, it was planned years ahead of time to cope with foreseen supply chain evolutions at the national level. The plan 
was first introduced at the national FA conference in 2003, five years prior to its full implementation in West Virginia. An FA product sourcing manager recalled the push back received from food bank members after the announcement about the coming transition to retail food waste supplies.

\begin{abstract}
"We told [food banks] about this great opportunity to work with Walmart and other retailers which meant picking up food 3 or 4 times a week including produce, dairy, meat, nutritious foods their agencies needed. Everyone was up in arms. Are you crazy? We can't go to three times a week with a truck, we have 50 Walmart's, how do we handle produce? We'll take the meat and be happy, we don't want the other stuff. We said, here is the deal, we are all in and it will be a great opportunity." (FA-2, 5.10.16)
\end{abstract}

As manufacturing donations dried up food banks at the mercy of food industry changes had little choice but to adapt and follow the waste where it was being generated at the retail level. In West Virginia, trucking routes were reorganized to pick up food from an increasing number of retail donors spread across the state. To facilitate the transition FA made grants available to purchase additional trucks, hire retail donation coordinators, and enhance the capacity of LFCs to pick up donations directly from their local stores. So-called "agency enabled pickups" are now part of food sourcing best practices pushed by FA and today 140 LFCs in West Virginia source food directly from FA retailers on behalf of the food bank (Chapter 5).

Meanwhile, FA continued to lobby congress to extend the scope of tax relief for food businesses. The discourse that prefigured legislative debate around tax incentives centered on the excessive amount of food wasted along industrial food supply chains each year, and the need to connect this food waste to the hungry. In a statement supporting expanded tax cuts for donors, Bob Aiken, a former FA CEO stated: "We know that millions of pounds of food that is safe for consumption ends up in landfills every year, and we also know that our network of food banks is now providing food to 46 million people so this is food that is much-needed by those we serve" (Feeding America, 2014). Corporate benevolence could only go so far, private firms were hungry 
to leverage their relationship with FA for more tax relief. Years of FA lobbying efforts to amend the tax code were rewarded through the Protecting Americans from Tax Hikes Act (PATH Act), which took effect on January $1^{\text {st }}, 2016$.

The PATH Act increased the cap of allowable charitable contributions for food corporations from $10 \%$ to $15 \%$ of net income and codified an important court ruling for the food banking industry by expanding the Lucky Stores, Inc. v. Commissioner of Internal Revenue case nationally $^{30}$ (U.S. Internal Revenue Service, C.F.R. 26-170). The law allows retailers to assess a uniform FMV on the original selling price of their donation no matter the quality of the product being donated. In other words, while food items nearing expiration lose value in the marketplace over time due to spoilage or expiration, they no longer do if they are converted to a charitable gift. By expanding opportunities for private firms to write off their obsolete inventories, the PATH act provides long-term incentives for food companies to integrate their food waste donation programs and CSR campaigns into existing food banking circuits.

The amount of food donated to the FA network has risen fivefold since the Good Samaritan law passed over 20 years ago, yet its impact on reducing hunger is tenuous. Even as corporations increased their supply of donated food waste each year, food insecurity rates continued to fluctuate wildly between $10 \%$ and $15 \%$ over the same period. In fact, despite doubling the amount of food circulating through the HFN since the Great Recession, food insecurity rates today remain higher than their 2008 levels (Figure 4-2). The diversion of public resources away from the state to encourage food waste donations to feed the hungry raises critical questions over the moral

\footnotetext{
${ }^{30}$ The Internal Revenue Service contended that Lucky Stores donations of four-day old bread did not warrant a full retail value tax deduction. They argued that the industry practice of most bakers was to discount aged bread and thus the fair market value should be half the retail price. Lucky stores would have received no tax benefit at this valuation rate and thus brought the issue to tax court. The judge ruled in favor of Lucky stores determining the value of surplus bread inventory donated to a qualified charity was the same as the full retail price of that bread.
} 
economy of corporate driven hunger solutions and the loss of democratic process with regards to the food and nutrition options available to poor citizens.

Second Harvest developed to support regional food banks that did not have the organizational capacity nor the political clout to negotiate with large food donors on their own. Today under the FA banner, food corporations have come to exert significant control over food

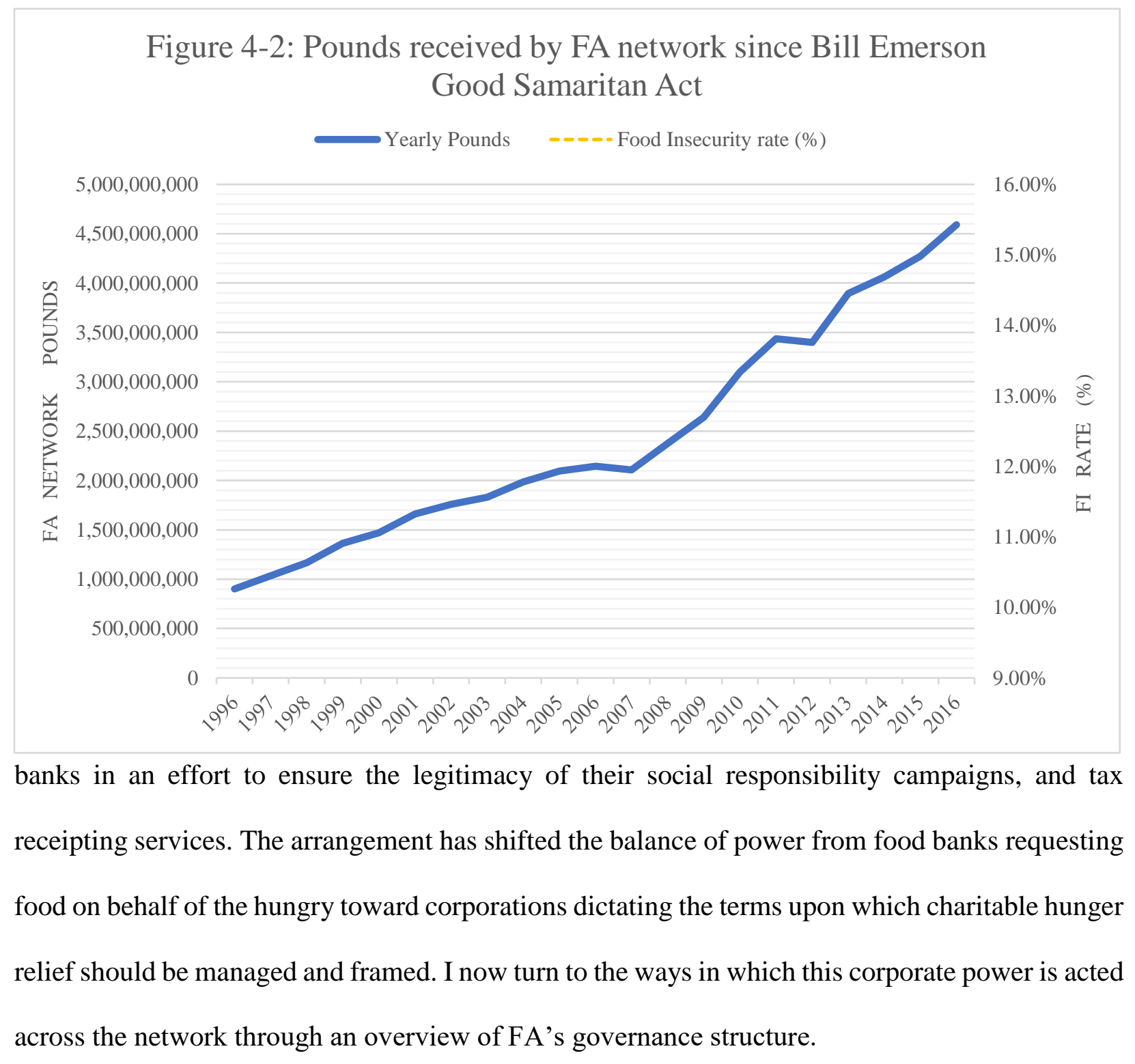




\section{Governing Corporate Food Waste}

As I detailed above, FA's institutional apparatus organizes corporate food waste supply chains to capture a growing amount of the tax-deductible food donations. The political-legal assemblage that enables this supply chain to function vests FA with authority to determine property and access rights over the donated waste circulating through its certified food banking distribution channels. Drawing on the food industry expertise of its corporate partners, FA consolidates a large swath of retail and manufacturing food donors under its organizational umbrella, centralizing food waste donations through a well-ordered network of member food banks. FA governs these members through contractual obligations between the two parties that defines the terms of the relationship and further centralizes this federation of food banks into standards that "establish and maintain a credible, safe and effective national distribution system for [donated] product" (FA member contract, 2014).

Tax deductible receipts provided to businesses donating to a $501 \mathrm{c} 3$ must meet the criteria outlined in the Internal Revenue Service (IRS) code 170(e)3, namely that donations be provided "for the care of the ill, needy, or infants". FA is far removed from the people ultimately consuming the food waste that it receives from private firms and cannot monitor its distribution to the needy. Because of this social distance, FA has constructed a series of rules to govern charities along this unconventional supply chain. The rules seek to ensure that food donations travel transparently through a non-profit pipeline toward their penultimate satiation of a hungry body. To this end, FA requires that all LFCs receiving food throughout its network prove and maintain updated records of their $501 \mathrm{c} 3$ status with their member food bank ${ }^{31}$. It also requires all members to follow the

\footnotetext{
${ }^{31}$ Churches and other faith based organizations are automatically considered tax exempt and not required to apply for 501(c)3 status from the IRS. However, food banks must still maintain records of this special exemption on file for each of their members. In West Virginia, 80\% of LFC affiliates are faith-based organizations.
} 
letter and spirit of the IRS code 170(e)3, regardless of whether the donor reports these food gifts as tax deductible donations at the end of the year or not. This latter rule is of key importance to understanding how corporate food waste becomes enclosed within a charitable food supply chain that benefits the food industry.

Table 4-2 summarizes the 72-page contract outlining the many rules governing food donations and the obligations of each party across the FA network. FA food banks are required, through their executive staff, to maintain strict adherence to the rules, policies and procedures outlined in the FA contract. The document is revised and renewed every few years to adapt to industry changes including updated tax codes, food safety laws or general evolutions in food sourcing and distribution strategies. Every aspect of the food banking business is covered, leaving room for independent organizational decision making within very strict procedural confines.

Table 4-2: Feeding America Member Contract

\begin{tabular}{llll}
\hline \multicolumn{1}{c}{ General Terms } & \multicolumn{1}{c}{$\begin{array}{c}\text { Administrative } \\
\text { Requirements }\end{array}$} & \multicolumn{1}{c}{$\begin{array}{c}\text { Management \& } \\
\text { Governance }\end{array}$} & $\begin{array}{c}\text { Non-Compliance } \\
\text { Policies }\end{array}$ \\
\hline Service Agreements & Community Support & Staffing & Probation \\
Service Area & Compliance Auditing & Board of Directors & Suspension \\
Member Fees & Record Keeping & Distribution Partners & Termination \\
Communication & Financial Stability & Organizational Structure & Service Area \\
Conflict Resolution & Insurance & Use of FA Name & \\
Logo \& Trademark & Legal Obligations & Warehouse and Storage & \\
\multicolumn{1}{c}{ Local Agencies } & Operations & & \\
\hline Eligibility (501c3) & Allocation & Food Safety & \\
Documentation & Distribution & Facilities & \\
Record Keeping & Reporting & Handling & \\
Monitoring & Inventory & Training & \\
\hline
\end{tabular}

The contract explicitly prohibits food banks from selling or exchanging food, unless these are deemed unfit for human consumption, (e.g. spoiled) in which case food banks are permitted to sell to a third-party such as composters or animal feed processors. No foods fit for humans however 
can be sold, they must be gifted. LFCs must in turn sign a binding contract with their FA food bank prohibiting the resale of all foods received. At no point may an LFC connected to the FA network offer food in return for labor either. If a volunteer wants food, they must follow the same access rules as those they are serving to secure it. The main effect of these regulations is that any food bank or LFC receiving FA product must raise money and recruit volunteers to give this food away, the labor and distribution costs cannot be subsidized through the sale of the food commodity they handle as would be the case in most functioning food markets.

FA compliance and capability officers work to ensure that contracts are upheld, checking in with food bank boards and executive staff, and performing regular audits. Along with the member contract, FA orders its charitable food supply chain through the $170(\mathrm{e}) 3$ interpretive guide, formerly known as the "Gray Area Issues Report". The 29-page guide outlines every possible situation, or "gray area", in which a food donation may not actually constitute a taxdeductible gift and could therefore potentially violate the terms of the FA contract. The interpretive guide is regularly re-interpreted by FA tax lawyers, and certain provisions make their way into the FA contract to clearly differentiate black from white. The guide provides direction for situations as varied as food bank employees eating donated food in the lunchroom, monetary donations from needy food recipients and allowable food bank cost share service fees. It also clarifies LFC eligibility guidelines based on specific populations. For example, union workers on strike are not deemed to be needy and should therefore not be provided with corporate food waste. Foster care family support programs similarly do not qualify. Prison-based programs are ineligible as are hospitals or schools that are members of a municipality. Native American tribal organizations qualify as long as they are registered 501(c)3, bringing their feeding activities on sovereign 
territories into relationship with the federal government. Non-profit food cooperatives are also presented as risky LFC partners because they also sell food to their members.

Non-performing food banks can be placed on probation for failing to meet FA standards. Suspension or termination of the contract leads to a loss of access to donations secured through FA's corporate partnerships. Because food banks now depend so heavily on corporate food sources, exclusive grant opportunities and the brand recognition that FA provides to sustain its own philanthropic outreach, this carrot and stick approach has been highly successful, bringing uniformity to what is otherwise an amorphous group of organizations providing hunger relief across the country in food environments that vary tremendously from place to place.

FA's raison-d'être depends on linking corporate anti-hunger causes to the 200 food banks that it governs, and it is thus heavily invested in their success. To ensure that its members are complying with the rules, FA regularly organizes webinars and conferences specific to different food bank staffing roles (agency relations, development, logistics, executive staff etc.) FA's internal food banking nerve center provides a web-based platform through which accounting, finance, marketing, fundraising, agency relations and food sourcing experiences are shared and discussed throughout the FA network, a vehicle that reinforces self-disciplining of members amongst themselves. Hungernet, the name for this FA intranet system, also consolidates data into a central repository by serving as the accounting, reporting and ordering infrastructure for the national network. The value of this training and managerial oversight for food banks is tremendous. One food bank director explained that FA support helped her steer her struggling organization in the right direction.:

“Our relationship with Feeding America has made me a better executive director. If I didn't have their database to scour for industry best practices, I wouldn't know what I'm doing. Just the networking that they provide is worth it to me. Feeding America holds their food banks to the highest standards, by partnering with them we show potential partners that we 
are not just a fly by night organization. [...] Of course Feeding America is concerned about putting their name on our operation. When they ask a major donor to give food or money they know it is safe because they are monitoring us." (FB-1, 5.14.14)

It is important to note that there are still food banks across the United States that continue to operate without an FA affiliation, but these are increasingly struggling to maintain relationships with their food donors and adapt to supply side changes as corporate donations are increasingly centralized through the FA network. One non-affiliated food bank director for example recounted:

"One day one of my long-time donors just stopped giving food to me overnight. They said I wasn't a Feeding America affiliate and their corporate made them stop giving to us. I don't know how FA has that kind of power but they're snatching my people away from me." (PO-18: 9.13.17)

Many FA food bank directors question whom the national organization is ultimately serving, but continue relying on the FA brand and its corporate partners to access food. FA food banks in turn act as regional power brokers ordering the recovery and distribution of donated corporate food waste across their service territories (Warshawsky, 2010). LFCs are grafted onto this governance structure through their contractual obligations with FA food banks, vertically integrating local charities with national rules and norms that benefit large agro-industrial food concerns. At issue is how the social claim to industrial food waste is structured and whom is able to decide the terms upon which it is distributed. Only a small percentage of the billions of pounds of food waste circulating through this gift economy are actually reported to the IRS as tax deductible donations. The remainder would therefore not come under the rules interdicting the resale of these foods, nor require these to explicitly serve the needy.

"Many donors do not decide until tax preparation time at the end of the year which donations will be listed as standard deductions, and which will be applied to the enhanced deduction available under IRS Code 170(e)(3). Because of this, Feeding America requires Members to follow IRS Code $170(\mathrm{e})(3)$ requirements at all times for any inventory donation from a donor." (FA 170(e)(3) Interpretive Guide, 2016, p.5)

By treating all donated foods as tax-deductible gifts, FA encloses charitable food supply chains and ensures that food waste will not flow out toward other purposes, including alternative 
and diverse economic practices that might disrupt profitability along primary food commodity circuits. As I reviewed above, the PATH act expanded enhanced tax deduction caps from 10 to $15 \%$ of yearly net revenue for food items. Many large food donors quickly reach this ceiling and thus cannot possibly claim all of the foods they donate to FA over the course of a year as a write off with the IRS. This was confirmed by the FA director of retail partnerships during a conversation about the relationship between corporate food donations and tax incentives:

\begin{abstract}
"Large national FA donors cap out on their charitable giving, often without even sometimes taking into consideration the food that they donate, so the food is just kind of extra. It may not impact their bottom line in terms of taking a deduction, but where it impacts their bottom line is they are not paying for dumping or disposal fees and then they have a wonderful story to be able to tell in every community that they are located on what they are doing to decrease waste and lessen their carbon footprint and at the same time feed people in that community where the store is operating." (FA Interview, 4.23.15)
\end{abstract}

Along with cause marketing benefits and large savings on dumpster fees, food corporations that work with FA can also rest assured that the foods they donate will not disrupt their primary business activities. This strict application of the $170(\mathrm{e}) 3$ tax code is not uniform across the voluntary sector. Other parts of the shadow state have much looser interpretations of the law that allow surplus donations to be resold. Goodwill Industries for example repurposes gifts of clothes and household items for sale in a secondary market that generates revenue for its employment training and job creation programs. Similarly, Habitat for Humanity has a network of "Re-Stores" that accept donations from construction firms offloading their oversupply of building materials, resold to consumers at a discount to support and subsidize their housing programs.

FA has the capacity to raise funds through large scale fundraising campaigns in partnership with some of the world's largest corporations. Food banks are permitted to charge cost-sharing fees to cover the financial burdens of distributing corporate food waste to LFCs. Food charities at the local scale however continually struggle to raise enough money to maintain their operations in place. Many rely on income generators such as thrift stores, bake sales, raffles and other innovative 
fundraisers to stay afloat, market practices that cannot involve the resale of any donated foods. The prohibition to resell corporate food waste to cover operational activities leads to major vulnerabilities across the network. A 2014 national FA survey of local agencies found that over $65 \%$ are worried about their ability to continue providing services to due to a lack of funding. (Winefield et. al, 2014). In West Virginia, this number is even higher and each year LFCs shut their doors due to a lack of operating funds (Morrison, 2011).

Unlike clothing or construction materials, food is a highly fraught commodity intimately tied to the social reproduction of a capitalist workforce (Marx, 1976; Essex, 2012). In a marketbased food system already facing crises of overproduction, the threat of secondary markets disrupting retail price points is of tremendous concern to food businesses. The USDA protects and regulates agricultural overproduction through crop insurance, price support and commodity purchase programs such as TEFAP (chapter 3), protections that serve to provide price floors for food producers. As the primary institution writing and policing the rules governing charitable food organizations across the shadow state, FA absorbs and regulates excess food supplies across the manufacturing and retail sectors through rules that discipline the food banking economy.

Food regimes have always involved state institutions to ensure that crises inherent to the capitalist food system do not disrupt the accumulation imperatives that drive food markets forward (Graddy-Lovelace and Diamond, 2017). I contend that the corporate food regime is now also dependent on the shadow state, through FA and its network of charities, to mitigate problems of overproduction and waste along corporate food supply chains. Like TEFAP, FA prohibits the resale of donated food, enclosing corporate food waste by tightly governing charitable food supply chains. To fully realize the food bank fix, FA has also engineered accounting techniques that 
operationalize the food banking economy by requiring member food banks and their LFC agents to report the number of pounds recovered from its corporate partners in situ.

\section{V. $\quad$ Counting the Waste, Delivering the Goods}

Unlike its member food banks, FA does not warehouse or distribute any food. It does however officially take ownership of the food it secures from donors, no matter where these originate, and immediately re-gifts them to one of its member food banks. This practice, known as variance power, provides the legal and institutional framework within which FA processes tax deductible receipts on behalf of its corporate food donors. In the technical language of FA's auditors, this accounting technique reads as follows:

"Feeding America reports the fair value of gifts of donated food and grocery products over which it has control (i.e., variance power) as unrestricted public support and, shortly thereafter, as expense when granted to member food banks" [...]. The approximate average wholesale value of one pound of donated product at the national level, which was determined to be $\$ 1.67$ and $\$ 1.70$, respectively, during 2016 and 2015, was based upon a study performed by Feeding America. Many of the national donors donate food and grocery products directly to local members. Beginning in 2011, Feeding America entered into written contracts with national donors to distribute grocery products directly to its local members. (KPMG, Feeding America Audit, 2016)

Regional food banks and their LFCs act on FA's behalf to pick up corporate food waste from the manufacturing plants and food retailers donating product to the network. Although these agents have physical control over the donations, legal ownership remains with FA until the item is formally expensed. The expense in this case is a "re-gifting" to the food bank, who must in turn re-gift it directly to a needy person or a local not-for profit serving the needy. FA food banks (and LFCs participating in retail pickups) are contractually obligated to report the number of pounds received from FA donors. FA then consolidates the reported numbers to process tax deductible 
receipts for their corporate partners, at which point the food is finally released on paper as a gift to the needy.

This accounting regime structures a large part of the daily operations of food banking staff. An accountant describing the intensity of the data collection required of him to comply with FA obligations commented on the growing demands placed on food banks and their LFCs to track food donations from the private sector. "People used to use paper to collect all this information and frankly I don't even know how they did it!" (FB-2. 6.19.14). There are currently only two database management software systems capable of processing the expanding scale of food sourcing and distribution data shaping the food banking industry. The first is a system developed by FA, the second is a third-party software provider called Primarius. Both food banks in West Virginia use Primarius because the FA software is cost prohibitive and geared toward the needs of large urban organizations. Although Primarius licensing and maintenance fees are not as high, they still require a significant investment by the two food banks, upwards of $\$ 10,000$ a year each. Primarius provides a food banking information system that tracks donations along with LFC orders, distributions and billing. The inadaptability of this software to local and regional food banking geographies however is a constant source of frustration for food bank staff that must rely on it to conform to their contractual obligations.

"Primarius is pretty horrible for us. It was designed to fit [all food banks] but doesn't really end up fitting anyone well. We can't do individual modifications to the software because it would mess up the update when that runs through every year. For example, it's designed as a dock-pick up system, which works for urban centers, but most of our orders are deliveries. The system forces us food banks into a certain mode of operation even if it's not our preferred way of working" (PO-11: 8.4.16)

A lot of labor time is spent inputting data into these systems to generate the correct reports for FA. Accounting for food receipts and redistribution is a critical mechanism through which FA structures and governs the HFN. By requiring that its members collect, categorize and report 
donation data, FA is not only able to process tax receipts on behalf of its national donors, it also captures deep knowledge about food flows across the food banking economy including their source, their cost and their type. From this knowledge FA then develops standards to measure the success of its individual food bank services through prescriptions such as the Meals per Person in Need (MPIN) metric (Chapter 7), and Foods to Encourage (F2E) the latter an emergent form of nutritional governance ${ }^{32}$. The geographic knowledge accumulated through this hierarchical reporting structure provides FA with the power to legitimize its grasp on the national charitable hunger-relief model by compelling food banks to achieve certain standards of food delivery, further legitimizing the narratives built around CSR campaigns.

FA does not have variance power (e.g. legal control) over donations outside of its formalized network of corporate donors. To capture an even larger proportion of the food waste calculus, FA has recently partnered with Google to develop a nationwide food waste tracking system called "Meal Connect". The video advertising this new system to prospective food donors, explains that the existing FA infrastructure is the most reliable and hassle-free vehicle through which to process their food waste:

\begin{abstract}
"You earn your living providing food for people on a daily basis so you know more than anyone the effects of food waste and hunger in your community. You wish there was more you could do to help. Meal connect, the convenient free and safe way to reduce waste and connect surplus meals with food insecure neighbors. It allows easy real time tracking for your recovered and excess food, saving you time, lowering your costs, creating hassle free tax deductions, and making a positive impact. Simply post your excess food product and your local FA food bank will do the rest. You'll quickly receive a confirmation letting you know when your donation will be collected. We adhere to the same food safety guidelines you do, so you can be sure you're providing nourishing meals to your neighbors. Reducing food waste and assisting people facing hunger with Meal Connect. Part of the nation's largest domestic hunger relief organization, Feeding America." (Feeding America, 2018)
\end{abstract}

\footnotetext{
${ }^{32}$ Food banks must track all FA donations by 24 different product types (e.g. breads, dairy, juice, pasta, grains, household items etc...). 13 of those 24 are used to evaluate the nutritional value of the food distributions across a food bank's service territory.
} 
The meal connect program is currently being piloted in a few metropolitan areas and being rolled out gradually across the FA network of food banks. On the website, a live calculator computes the number of pounds recovered, ticking up by 1000s a minute at the time of this writing for a total of 820 million pounds donated since the application's launch in June 2017.

By designing a national platform to link local food donations directly to LFCs, FA and Google have created the framework for a central data repository for all food recovery activities in the country, including those that do not originate through a formal FA partnership. In many ways, FA is returning to the roots of the Foodchain organization it merged with in 2000. After the merger, FA abandoned the much more labor-intensive work of recovering local food excess, concentrating instead on building up the food banking infrastructure for its larger corporate food donors. The most recent "Meal Connect" fix integrates LFCs within the FA governance framework through practices such as "Agency Enabled Pickups" that were first rolled out in 2008. FA is seeking to capture and consolidate its imprint on the charitable food landscape, responding to a host of other grass-roots food recovery platforms that have surfaced to leverage smart-phone geolocation technologies to connect food excess to food charities. With the large resources behind it, meal connect has the potential to monopolize the local food recovery market, further consolidating FA's power across the HFN.

\section{Conclusion}

Competition over resources within the shadow state bifurcates civil society along lines of volunteerism and expertise. Uneven professionalization creates social distance between administrative centers that regulate and oversee the distribution of resources, and the communitybased organizations that these were initially set up to serve (Milligan, 2007). On one end of the spectrum are small volunteer based "grassroots" organizations that address local needs through 
local partnerships. On the other are non-profits tightly linked to government or industry concerns who operate according to the prevailing logics of corporate culture in a market society (Dahrendorf, 2003). With its formalized corporate donor base and over $\$ 2$ billion balance sheet, FA is a non-profit that fits within this highly professionalized and corporatized tier of the shadow state.

As a parastatal institution, FA blunts crises borne out of the commodification of food by facilitating the distribution of corporate food waste to the poor through a charitable food supply chain that maintains profitability for private food corporations. Just as the state fixes crises of overproduction in agricultural markets by leveraging food banks in its surplus removal programs, so too is FA instrumental in maintaining food banks as a fix that secures the hegemony of the corporate food regime. Corporations capture a significant amount of public goodwill through CSR campaigns co-branded with FA. These campaigns engage consumers to patronize their stores and purchase their products, legitimizing their own positions within the market-based food system that maintains the conditions for both hunger and food waste.

My analysis of FA's role in the food banking economy reveals the fraught relationship between a tax regime that serves the interests of dominant food companies and the food scarcity framework they depend on to realize profits. Over the past decade, FA has emerged as the centralizing force tying the interests of food corporations and food banks together into a governance structure that facilitates the transfer of corporate food waste to the poor. Following David Harvey's theory of the spatial fix "individual capitalists tend to over-accumulate in the primary circuit and to underinvest in the secondary circuit" $(1989$, p.65). FA coordinates the secondary charitable food circuit by organizing its member food banks through its member 
contract, compliance and auditing regime, ensuring that charitable food supply chains continue to function on behalf of corporate interest.

FA has engineered accounting techniques that allow it to take ownership of donated food items without ever physically processing them. This technique however requires strict reporting standards from member food banks and their LFC agents that pick-up food from FA donors at the local level. FA has recently sought to expand its reach in the food recovery space by enrolling nonaffiliated donors into its accounting regime through the meal connect application. Processing tax write offs for smaller local businesses donating food will provide even more visibility over charitable food waste flows at the national scale. While the efficiencies achieved by FA have led to a massive growth in food donations, smaller local and regional charities bear the administrative burden of counting and processing the increasing amount of food waste flowing through the HFN, ultimately working on behalf of corporations seeking tax relief.

The coupling of food markets with food charity raises important questions about whom is ultimately benefiting from food waste donations. Indeed, it is the labor and local fundraising capacity of food banks, and the charitable impulse of their grassroots network of LFCs that ultimately gives FA any reason for existing. Without their efforts to construct and maintain the built brick and mortar infrastructure recovering, processing and distributing corporate food waste to the poor, there would be no vehicle for corporations to revalue their food waste and improve their image in the marketplace. To this end, we must also question the emergent metrics that structure civil society's ideas about charity and further legitimize the need for corporations to address hunger.

As I outline in the following chapters, the local scale is the last frontier to profitability along the food waste hunger relief supply chain. While FA is currently working to expand the 
scope of its accounting regime through the meal connect application, there remains a highly fractured, diverse and uneven group of LFCs bearing the collective brunt of revaluing food waste on behalf of FA and its corporate partners. There are varying levels of institutional capacity at the local level, different feeding ideologies, different degrees of compliance and deviance that make it difficult for FA food banks to move the increasing amounts of food that they receive as donations from the corporate sector. The local politics of feeding do not always conform to the governance structures put in place by FA, a resistance that further complicates the social dynamics driving the food bank fix. 


\section{Chapter 5: Food Banks}

\section{I. $\quad$ Introduction}

In the previous two chapters I highlighted the role of the state and the corporate philanthropic arm of the shadow-state in the food banking economy. My analysis of the two food banks in West Virginia in this chapter describe the tense dynamics surrounding the institutionalization of food charity across scales. Indeed, regional food banks must negotiate between the national institutions that enable them to expand access to surplus food waste while attending to their relationships with grass-roots civil society organizations that address emergency needs at the local level (Figure 5-1). The central argument of this dissertation is that food banks fix overproduction in a market-based food system through a humanitarian governance framework that leverages compassion for hunger relief to regulate the distribution of industrial food waste across space. As central nodes of the humanitarian food network (HFN), food banks maintain the

Figure 5-1: The Food Bank Fix

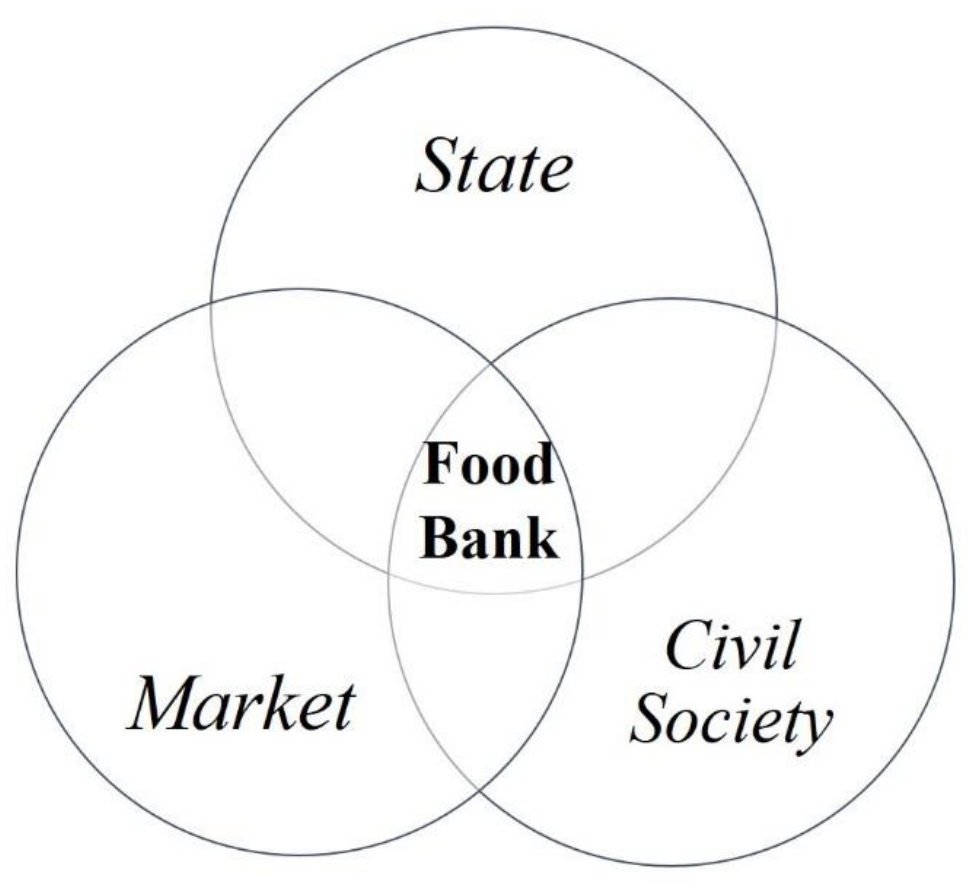


physical and social infrastructure necessary to resolve contradictions between capitalist food production, artificial food scarcity and social reproduction (Katz, 2001).

While food banks operate on multi-million-dollar budgets, they do not directly serve vulnerable households ${ }^{33}$. Local food charities (LFCs), which I explore in detail in chapter 6, provide the free food, case management and other social service referrals to food insecure clients. Food banking work is thus not as visible as that performed by LFCs, where community food drives and local fundraising appeals tend to dominate perceptions of food charity for the public. This institutional distance I argue, also veils the social dynamics that maintain charity as an entrenched food entitlement option for so many struggling to close food access gaps. Because institutions are spatial entities, studying them involves moving across sites and scales, transcending organizational boundaries to understand linkages that bind its component parts (Billo and Mountz, 2016). The interplay of social relations across space produces bundles of power that must be analyzed in tandem to understand how people, communities and institutions negotiate access to resources (Ribot, 1998; Ribot and Peluso, 2003).

In this chapter, I analyze the two food banks in West Virginia vertically and horizontally to explain their key position in the politics of access to emergency food resources. The multi-sited methodology takes a center and periphery approach that reveals differentiated power dynamics and dependencies among the many parties involved in charitable food transaction, powers that are negotiated at the food bank scale. I first explain how food banks anchor charitable food supply chains by centralizing funding for the logistical infrastructure necessary to move donated surplus to the needy. Second, I review the different food sources available to food banks over time and

\footnotetext{
${ }^{33}$ Although many food banks do operate direct food distribution programs such as mobile food pantries, these are usually coordinated in conjunction with a local charity who organizes volunteers and recruits participants. Food banking staff rarely develop relationships with the end-consumer benefiting from their services.
} 
their need to constantly (re)adapt to agro-industrial supply chain evolutions. Finally, I map out the governance regime that structures food banking work.

My analysis explains how the food bank fix is both a solution and a dilemma for the state and food corporations leveraging charities to maintain the legitimacy of the capitalist food system. Affective labor across the HFN is extremely good at squeezing out efficiencies and resolving the many contradictions involved in feeding the hungry with food waste. Placing the costs of revaluing food waste on the voluntary labor and philanthropic capital provided by civil society however also produces a high degree of freneticism for food banks. The underfunded mandate has led to a fiscal and managerial order that disrupts moral and material values, and places stress on low-paid staff, volunteers and donors, particularly in poor rural states with high food insecurity rates like West Virginia. Food banks anchor contemporary humanitarian hunger relief networks in place, yet their institutional fragility is also a problem for a corporate food regime that is doubling down on food banking to address overproduction in the context of food access failure.

\section{Funding the Food Banks}

Mountaineer Food Bank (MFB) and Facing Hunger Food Bank (FHFB) negotiate a variety of funding streams to keep their operations afloat. Development staff fundraise from private philanthropy, federal sub-contracting and wholesaling to make ends meet (Figure 5-2). The financial resources available from private funders and corporate grant makers change from year to year as do federal TEFAP administrative pass through funds (chapter 3). This budgeting context makes it very difficult for food banks in West Virginia to plan, let alone develop strategies that address the root causes of food insecurity in the communities that they serve. 


\section{Figure 5-2: Food Bank Funding}

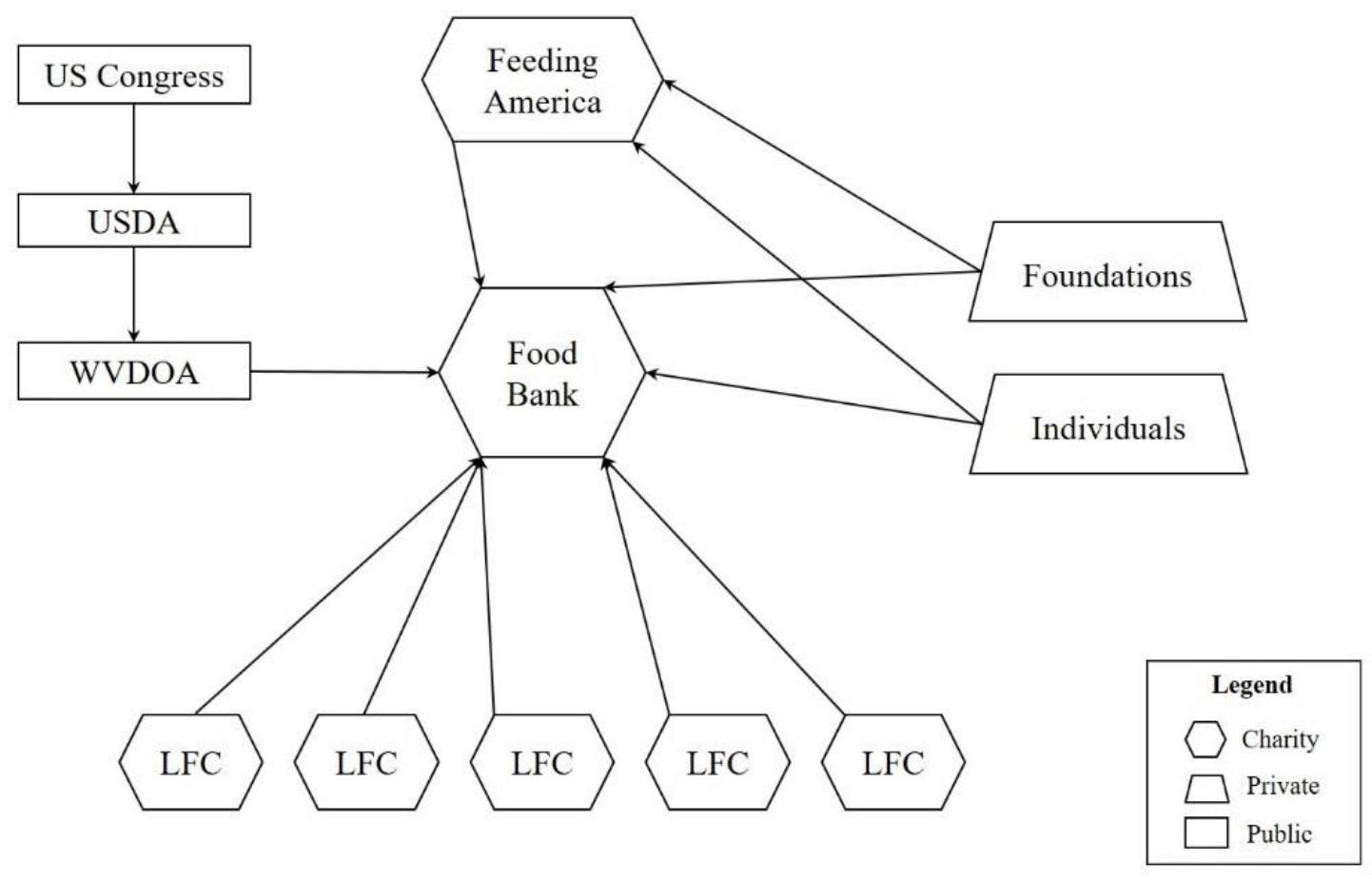

Food banks are charities, but they are asked to run state programs and operate complex food logistics operations that require business acumen. A food bank director outside the state put it quite bluntly: “Those that didn't understand that food banking was like running a business, they are no longer around. It is a business and you have to think that way. You have to be sustainable and you have to learn how to say no, not all funders are a good fit" (FB-7, 2.22.17). The freneticism, precarity and internal contradictions of the various pots of money subsidizing food banking activities is one of the major difficulties facing these institutions, particularly in West Virginia where demand for emergency foods is high and the fundraising capacity of the local donor base is low. The two food banks in the state operate in a state of endemic financial pressure to deliver the services demanded of them from their LFCs and the national institutions they rely on to maintain a steady source of food. 
It costs $\$ 3.6$ million a year to operate the state's two food banks. Over the past few years, both organizations have faced times when it was difficult to meet their financial obligations, and neither are able to accumulate emergency reserves. "It's hard enough to get operating expenses to cover my costs for the year so how am I supposed to save up for a rainy day?" (FB-3, 7.15.14). Operating in a seemingly continual state of crisis, food banks in West Virginia then mirror the financial situation of many of their LFCs and indeed their clients who find themselves one financial emergency away from insolvency.

West Virginia food banks depend on multiple revenue streams, often juggling between them to fulfill institutional mandates, or execute specific mission goals that spring up at different times. "That TEFAP money is going to help with my compliance with Feeding America. We have an audit coming up, I'm going to use it to buy more freezers, help with pouring gravel out back and tackle pest control" (FB-11.3.15). Table 5-1 provides a snapshot of the share of each food bank's revenue source in 2016. Private donors are the largest funders, supplemented by cost

\begin{tabular}{llccccccc}
\hline \multicolumn{7}{c}{ Table 5-1: WV Food Bank Funding by Source } \\
\hline & Private & $\mathbf{\%}$ & Public & $\mathbf{\%}$ & Network & $\mathbf{\%}$ & Total \\
\hline Mountaineer & $\$ 1,549,175$ & $60 \%$ & $\$ 466,645$ & $18 \%$ & $\$ 583,500$ & $22 \%$ & $\$ 2,599,320$ \\
\hline Facing Hunger & $\$ 602,580$ & $53 \%$ & $\$ 263,784$ & $24 \%$ & $\$ 259,244$ & $23 \%$ & $\$ 1,125,608$ \\
\hline WV TOTAL & $\mathbf{\$ 2 , 1 5 1 , 7 5 5}$ & $\mathbf{5 8 \%}$ & $\mathbf{\$ 7 3 0 , 4 2 9}$ & $\mathbf{2 0 \%}$ & $\mathbf{\$ 8 4 2 , 7 4 4}$ & $\mathbf{2 2 \%}$ & $\mathbf{\$ 3 , 7 2 4 , 9 2 8}$ \\
\hline $\begin{array}{l}\text { National Food Bank } \\
\text { Median }\end{array}$ & $\$ 3,089,014$ & $66 \%$ & $\$ 710,677$ & $15 \%$ & $\$ 885,170$ & $19 \%$ & $\$ 4,684,861$ \\
\hline
\end{tabular}

sharing by LFCs and public monies from the state. Both organizations operate with budgets well below the national food bank median and even their combined revenues fall well short of the financial capacity of most Feeding America (FA) food banks. This is striking for a state that has one of the highest food insecurity rates in the country, a paradox that demonstrates how food charity is itself enmeshed in the dynamics of uneven capitalist development. I provide an overview of the three different funding streams as a window into this reality. 


\title{
A. Private funding
}

Like all food banks, private revenue sources make up the bulk of operating budgets for MFB and FHFB. These are donations by individuals and foundations, the latter usually accessed through a competitive grant process. Food banks fundraise to meet day to day expenses including payroll, fuel costs, truck maintenance, utilities, rent or mortgage payments. Staff are often paid out of multiple funding sources, a juggling act that requires them to wear many different hats to justify drawing down funds from different pots of money. Mission creep is often a tension that the board and executive staff must negotiate as they seek opportunities from grant makers. Requests for proposals from funders do not always align with strategic goals at the food banks, and difficult decisions must be made as to whether to dedicate time and resources toward developing new programs to subsidize other expenses and maintain key staff positions funded:

\begin{abstract}
"Many of the grant opportunities released to us from Feeding America have no use to the work we are involved in, we are not going to do kitchen-based classes because we don't have a kitchen here on site, and we can't just start a nutrition program because we get a grant. Typically, these RFPs are not very much funding anyhow, around $\$ 10,000$. It's a 12 page proposal, you need someone with an MA degree who can write them, and they are quite competitive across the country." (FB-3: 7.15.14)
\end{abstract}

Institutional funders tend to push grant recipients toward their own programmatic goals.

During the shift from manufacturing to retail donations for example, Walmart made grants available to FA to help its food banks train and develop LFCs to pick up donations from their stores (chapter 7). The grants funded retail waste recovery activities across the network, helping to ensure that the FA retail partnership program was a success. Merely enabling agencies to act on behalf of their regional food banks was not sufficient however, and the need for oversight of their local retail food recovery activities became clear a few years into the program. In recent years, Walmart has shifted its focus to fund retail donation coordinator positions at the food bank to broker the relationship between LFCs and retailers, a task that has evolved into a full-time job. 
"Retailers are now making a lot of grants available for agency capacity, they understand that if the food bank can't get to your store, the agency can do it, but for that to happen they need coolers, blankets, thermometers, assistance paying for gas. All this infrastructure is needed that falls under our agency capacity umbrella. In the past agency capacity was a part time person, but there are a bunch of grants out there now to fund retail donation coordinators." (FA-5.10.16)

Private grant funding for food banking activities is thus often tied to food sourcing and industry supply chain dynamics I describe in the following section. Caught in fundraising strategies that evolve and tug them in different directions, food banks must also cope with the expectation that they will find ways to make these time sensitive (e.g. 1 to 2 year) subsidies sustainable over the long term. Sustainability plans are part of almost every grant proposal request. As one program officer at a large foundation funding both food banks put it: "We don't like to fund orphans; we want to build up the capacity of these organizations to stand on their own two feet (P.O. 2.9.15). Food banks must thus continually (re)construct narratives that will reduce their long-term dependencies on private subsidies, a challenging prospect when the business model is so heavily dependent on private charitable contributions.

MFB and FHFB both have a full-time development staff member responsible for framing the present need for funds in light of future programmatic sustainability. These key positions maintain relationships with private donors through direct mailings, grant proposals and program reports. MFB and FHFB cannot afford to hire highly experienced development directors, a lacuna that tends to translate into inexperienced staff navigating complex grant management processes and pressures to bring in the funding that keeps the operation afloat, a combination that often leads to burnout. Well-endowed non-profits, including many food banks in the FA network, have entire development teams to work on donor relationships and storytelling, a significant advantage in the competitive context of private fund solicitation. West Virginia's resource poor food banks do not have this luxury. Over my four years of action research with the food banks in West Virginia, staff 
members in these development positions have been quite transient. Internal hires often filling the role after their predecessors leveraged their food banking development experience to find more stable work opportunities elsewhere.

Corporate and foundation support for food banking work receives a large amount of press and promotion as the funds disbursed are often contingent on co-branding obligations. While it seems as though these funders are a major source of revenue, charitable contributions from individual donors are in fact the financial backbone of these organizations. Large institutional donors only represented around $30 \%$ of the total private revenue stream last year while MFB and FHFB respectively drew $54 \%$ and $58 \%$ of their fundraising revenue from a combined 11,450 individual donors averaging $\$ 100$ per gift.

"It's hard to get grants for operating expenses, getting our own [undedicated] funds to fill in the gaps is very important. But our problem is that we don't have individual donors that have consistently given for years and years. For the past 3-4 years we've been tracking what we call major donors. It's on the low end, one or two thousand dollars is our high even though for most organizations this category start at \$5,000." (FB-3: 7.15.14)

Per capita income in West Virginia is one of the lowest in the United States and the capacity of the two food banks to solicit funds from individual donors in the state has a threshold. Because donations from individuals tend to mirror economic factors including consumer confidence and the availability of disposable income, donations are often at their lowest when the need for emergency food is at its highest. This paradox is heightened by donor fatigue, a serious issue that development staff confront due to the repetitive narrative framing food insecurity and hunger. The need is always urgent, yet never resolved:

\footnotetext{
"As a donor you don't want to keep hearing about the need for more money, it feels like you're drowning if you get $\$ 1,000$ from someone and tell them the next year that the need is even greater. People want to hear that their contributions are helping us work ourselves out of a job, that the population in need is shrinking because of the assistance that we're able to provide, but they do not have a realistic perception of what that means. You might have good intentions and can read about it all you want but unless you are involved in any level you don't really know what that means." (FB-3, 7.15.14)
} 
As critical as private donations are to food banking operations, they are also temporally uneven, following the rhythms of tax season and civic duties to contribute toward hunger relief causes during the holidays in November and December. Food banks receive the bulk of their private contributions at the end of the calendar year and the financial well dries up after the festal season. These sporadic and unreliable contributions also face competition from emergent social issues placing food banks in the oft awkward position of needing to legitimize their work in light of other societal problems such as the opioid crisis.

"I'm competing with very sexy issues! As you know we've got a huge drug problem in the state right now, and in the food sector people are more interested in giving to obesity prevention and local agriculture stuff like that. Well you might be running a very innovative drug rehabilitation program, but you know what, I'm the one feeding the addicts and their children!"' (FB-5, 11.3.15)

Awareness and affect for social causes evolves, and food banks must continually renegotiate socially necessary representations that cater to funder perceptions to frame and justify their food recovery activities (Henderson, 2004). Private contributions are the largest source of revenue for food banks, yet they also remain the ficklest and most unpredictable. As foundations pair their grant opportunities with specific programmatic goals and individuals are drawn toward other causes, food banks tend to compliment the food waste recovery and hunger relief master narratives with other causes and initiatives, such as health, nutrition education or economic development to maintain access to critical private funding sources. Industrial food waste recovery work is thus increasingly framed around obesity and diabetes prevention or local food system development a contradiction that is currently redefining food banking and adding new institutional pressures to bear on the food bank fix. 


\section{B. Public Funding}

Over a quarter of FHFB's budget came from public sources last year and 18\% for MFB. The majority of this revenue stems from TEFAP administrative funds ${ }^{34}$. While it appears that the state subsidizes food banking work in West Virginia at a higher rate than elsewhere across the country, a close reading of these statistics reveals instead the low level of private and network funds received in comparison to other places. TEFAP administrative funds are allocated to states (chapter 3) and the West Virginia Department of Agriculture (WVDA) ultimately dictates the level of pass through resources to the two food banks fulfilling their mandates. 2/3rds of states pass through over $90 \%$ of their federal administrative funds to the food banks that distribute TEFAP foods. In FY2014 WVDA only shared 72\% of TEFAP administrative funds with the organizations working on their behalf. This was the second lowest "pass through rate" in the country. WVDA hires a TEFAP coordinator to monitor local agencies whose salary and transportation expenses are drawn from the state's overall TEFAP allocation. Food banks do not feel they receive the administrative support warranted for this position and would prefer the full funding and monitoring that comes along with it, but the state does not want to cede control of this oversight role.

When the low pass through rate compared to other states was brought up in a planning meeting with the WVDA commissioner's chief of staff and the director of the commodities program, their response was to encourage the food banks to find innovative public-private fundraising solutions to fill their budget gaps. These included schemes such as a food bank scratch off ticket through the state lottery system, and a food bank license plate program with the Department of Motor Vehicles "you've got that whole front bumper to sell to people" (FB-5,

\footnotetext{
${ }^{34}$ WVDA is currently piloting the Commodity Supplemental Food Program (CSFP) with the two food banks in a select number of counties across the state. CSFP is a USDA-FNS program targeted specifically toward senior nutrition, whose administrative funding rates are much more favorable to food banks than TEFAP. The growth of this program may thus increase the level of public funding to food banks in the coming years.
} 
11.3.15). Ultimately state officials were not willing to consider the role that food banks played in executing their mandates and could not think of these organizations beyond charities that were to rely primarily on the private sector to run their programs. "It's like the saying goes, one man's welfare is another man's tax break, it's a very difficult time to be asking money from the state right now" (FB-5, 11.3.15)

As I reviewed at length in chapter 3 there are significant tensions surrounding allocation and timely disbursement of public funds to the two food banks. Federal law allows states to pass through $100 \%$ of its administrative budget to food banks and even convert $10 \%$ of their food dollars to administrative dollars, yet FHFB and MFB have had a very difficult time convincing state level decision maker to increase appropriations for food banking activities. Over the past few years, West Virginia has faced budget deficits due to a sharp decline in severance taxes related to falling rates of coal extraction. Rather than generating revenue for the shortfall through alternative taxation programs, legislators working to pass a state budget in the 2016 and 2017 sessions opted for cuts to social service programs instead, a development which places an even heavier burden on food banks to provide emergency food to their LFCs and does not bode well for future advocacy efforts to increase public funding for food banking operations.

Still, there is a nascent coalition of West Virginia farmers and food bankers that have expressed an interest in lobbying the legislature to develop a public program that would mirror support for agricultural surplus purchasing in neighboring states ${ }^{35}$. Agriculture is perceived as an economic development avenue that could boost WV exports and increase state revenues. A state funded vent for ungraded seconds would mitigate risk for farmers as they weigh the costs and risks

\footnotetext{
${ }^{35} \mathrm{KY}, \mathrm{OH}$ and PA have established surplus removal programs akin to TEFAP, purchasing excess foods from their farmers for redistribution by charities. The Pennsylvania Agricultural Surplus System (PASS), the Ohio Agricultural Clearance Program (OACP), the Kentucky Farm to Food Bank (KFFB) program provide templates for the rollout of such a program in WV.
} 
of expanding production. If the state funds such a program without considering the administrative support costs necessary to operate it however, it may exacerbate existing vulnerabilities at the food bank level. Furthermore, such programs do not replace the effectiveness of robust state entitlement programs such as SNAP and WIC and may add to the perception that food charities are able to close food access gaps in lieu of other cash-equivalent public entitlement.

In an effort to increase access to public funds, West Virginia food banks are now working with WVDA to pilot the Commodity Supplemental Food Program (CSFP). Similar to TEFAP, this USDA nutrition program provides food boxes to qualifying seniors over the age of 60 . CSFP administrative pass through rates are much higher than TEFAP, and both food banks have expressed that a large part of their motivation in implementing this program is the added revenues that would be generated for their overall operations. What is important to note is that the public funding stream from TEFAP, and increasingly CSFP ties West Virginia food banks into a closeknit relationship with WVDA and by extension the USDA. Federal funds undergo much more stringent auditing processes than private donations, and food banks must closely track and justify the use of state funds. The labor involved in managing these funds on the accounting side is quite involved and again requires a level of expertise that LFCs accessing TEFAP foods do not have to negotiate. This invisible service ensures that public foods reach those laying claim to them at the local level, but also adds to the freneticism of day to day food banking activities.

\section{Network Funding}

Local food charities (LFCs) play a larger role than the state in subsidizing West Virginia's two food banks. Approximately a quarter of food banking revenue comes from their LFCs, a proportion that is again higher than the national median due to the comparatively limited funds received from private donors. The heavy reliance on local charities to close budget gaps is 
concerning because many LFCs are themselves stretched thin and vulnerable to closure due to declining funding levels, and the difficulty of replacing an ageing volunteer workforce (chapter 6). Following this money reveals that an extensive network of local churches and community organizations are ultimately contributing to their regional food bank's viability. Network funds are collected from LFCs in three different ways.

1. Cost Sharing: Food items ordered through the food bank have a per pound cost share price. As a state entitlement program, all TEFAP foods are free to participating LFCs. Privately donated foods however usually incur a cost-share fee. The maximum shared maintenance rate set by FA for all food banks is 19 cents per pound. Food banks have discretion to set this number lower and this is usually done for food items that the food bank wants to move quickly such as fresh produce or an over-abundance of a certain type of donation (chapter 7). Last year the network paid a total of $\$ 494,104$ to food banks as a compensation for the labor and logistical expenses involved in recovering and processing corporate food waste on their behalf.

2. Delivery fees: Delivery fees are charged on a per-pound basis for all non-TEFAP foods. As a cost saving measure, West Virginia's two food banks do not make deliveries to an agency's door. They opt instead for central drop off sites in each county where LFCs pick up their food orders, a system that reduces trucking costs across a mountainous road network. LFCs in closer proximity to the food bank drive there to pick up their orders at the dock and save on delivery costs. Across the network, agencies paid food banks a total of $\$ 128,280$ to deliver their food orders last year. The state's two food banks lose money on TEFAP deliveries and depending on fuel costs may or may not break even on the delivery fees charged for donated foods. Food deliveries are thus not a significant source of revenue for the food banks. 
3. Purchasing program: Profit margins from the wholesale purchase program are the most promising revenue generator for the state's two food banks. Many agencies purchase food from local retailers to supplement food drives and products made available by the food banks. Some have higher food budgets than others, but the median LFC sources $30 \%$ of its food through local purchases. The food banks would like more of their LFCs to leverage their potential for economies of scale and are working to convince their agencies to allow them to coordinate the bulk purchase of supplementary foods, passing cost savings on to their member agencies. At the last two MFB annual conferences a table visually displayed the difference between shopping for foods at a local Kroger retailer and spending those same dollars with the food bank. "What will $\$ 30$ buy?" was the question posed to onlookers. On one side of the table $22.5 \mathrm{lbs}$. of food accompanied the itemized Kroger receipt. On the other side, $158 \mathrm{lbs}$. of food were displayed with an MFB invoice.

The two food banks are only capturing $10 \%$ of an estimated $\$ 10$ million spent on food purchases throughout their network of LFCs, and they thus see significant room for growth in this area. Purchasing food on behalf of their agencies could generate much needed operating revenues while offering important savings for LFCs. The purchasing program is gaining momentum although many LFCs express a preference to maintain as much control as possible, warry of further centralizing their food sourcing with the food banks. A director bemoaned the difficult reality of organizing LFCs to coordinate bulk purchases:

"I ask my agencies, how much do you all want to pay for peanut butter? But they don't want to give me that kind of power for some reason, it takes a lot of education to help them to understand that we are offering this because we're all in this together" (FB-5, 11.3.15).

The purchasing program requires buy in from many LFCs placing advance orders to make the cost savings viable. Navigating the tensions between delivering foods no longer apt for retail markets and promoting a wholesale program that draws members away from retailers to shop with 
the food bank is challenging. Profit margins from the program generated $\$ 205,927$ in revenue for the food banks in 2016. These are undedicated funds that can help directors fill gaps in other parts of their budgets or develop new strategic programs. "It's a good funding source for us but it's a delicate balance too, we don't want our agencies to feel like we are just another Sam's club membership" (FB-6, 7.18.16).

As institutional donors encourage their grant recipients to generate sustainable revenue streams, network funding is the most viable long-term revenue generator for food banks. The variable capacity of LFCs (chapter 6) and their own revenue shortfalls, makes it difficult for WV food banks to place additional fundraising burdens on their network of LFCs. Paired with the oversight role that food banks already play across the network, and their perception as powerful rule makers, it appears as though enrolling LFCs into a cooperative funding structure that can float food banking activities over the long term will continue to be a challenge. 


\section{Food Bank Supply Chains}

Food banks draw in overproduced foods from across the food system. Sources include agricultural commodities purchased by the federal government (chapter 3), obsolete inventories

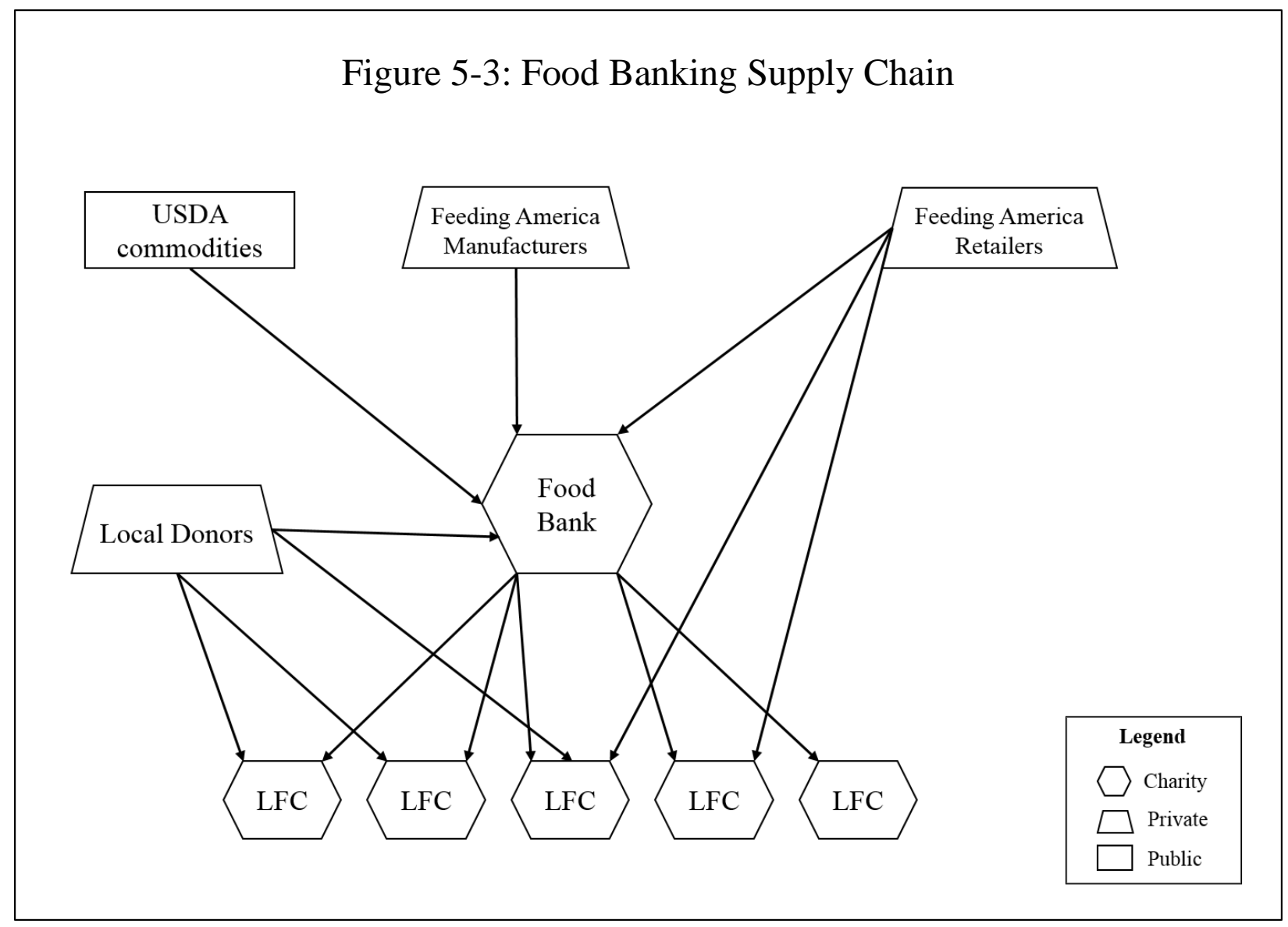

offloaded by national food corporations affiliated with FA (chapter 4), and non-FA affiliated local donors. Food banks work to aggregate unsaleable foods within this convoluted supply chain for redistribution to a diverse network of LFCs working to address food access problems at the local scale (chapter 6). When this supply chain is sketched out, the food bank's central position within the HFN becomes quite clear (Figure 5-3).

The amount and types of food donated from these numerous sources is inconsistent from year to year, and food banks must constantly adapt to supply chain changes far beyond their control. Following national trends, West Virginia food banks more than doubled the amount of 
food distributed over the past 15 years from 7.3 million pounds in 2002, to 17 million pounds in 2016. Donations spiked in 2009, as the economic recession and wider food system changes stimulated the growth of food banking activities (Figure 5-4). The increase is usually associated with rising demand for emergency food resources at a time when millions of households faced job and asset losses. However, as I have argued throughout this dissertation, food banks serve as critical appendages of agro-industrial supply chains, and focusing on supply side factors reveals how this increase is also tightly coupled to shifts in public policy and the evolution of business practices across the food industry.

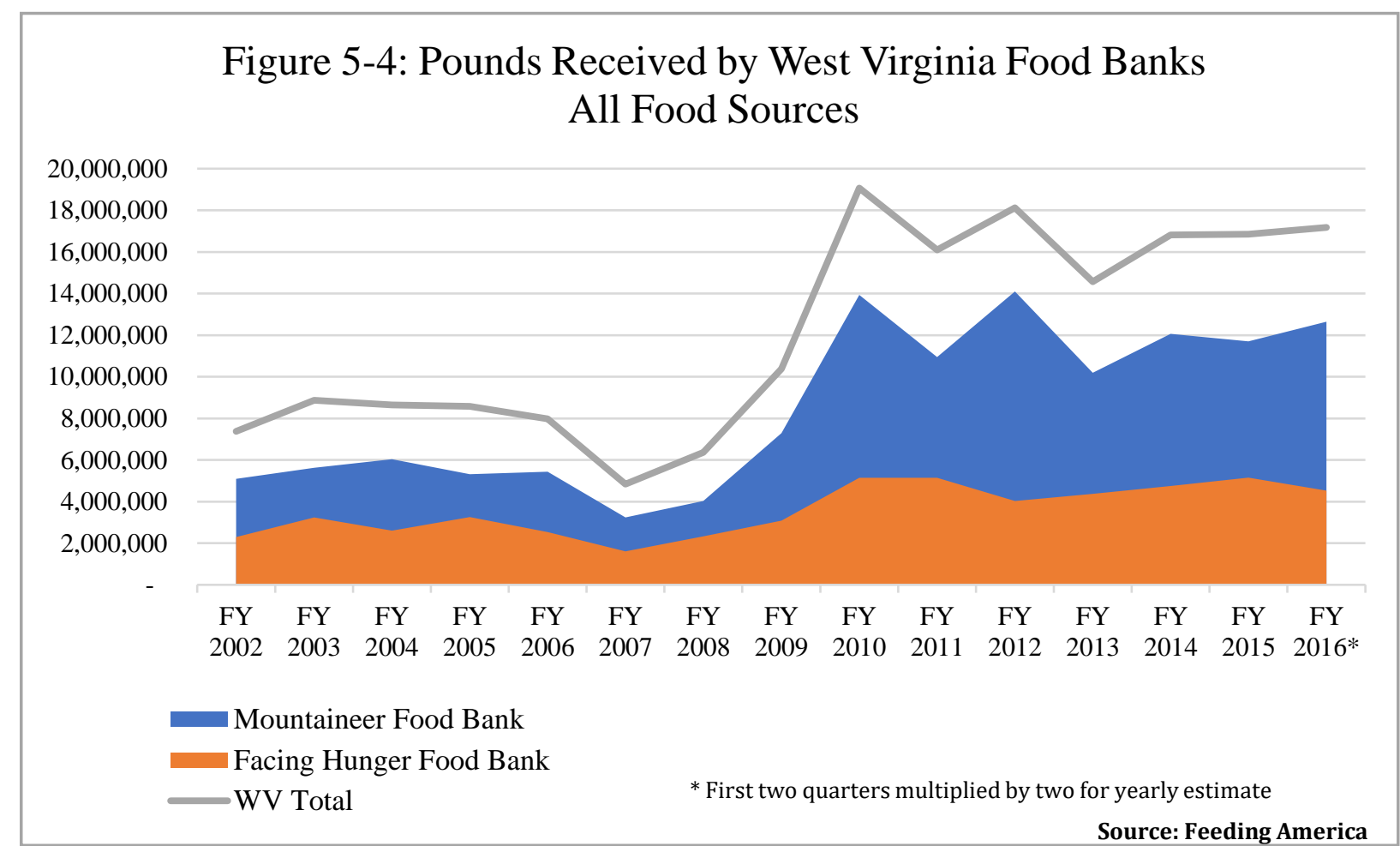

On the agricultural production side, the USDA was keen to support farm gate prices during a time of weakening consumer demand. The 2009 American Recovery and Reinvestment Act increased TEFAP funding to $\$ 700$ million as part of the Obama administration's effort to mitigate the socio-economic fallout of the financial crisis (Cabilli et. al, 2013). TEFAP food allocations fluctuate based on unemployment and poverty rates in each state, congressional appropriations in 
the farm bill and market forces determining the allocation of so called "bonus" foods to stave off industry specific overproduction crises (chapter 3).

On the food industry side, the consolidation of large food manufacturers, the adoption of supply chain efficiencies through RFID technology and attendant just-in-time logistics combined to reorganize food waste streams. A sharp decline in donations from food manufacturers was mitigated by the integration of large food retailers into the FA network (chapter 4). Supply chain revolutions across the private sector changed both the types of foods received by food banks and the way in which these were accessed. As manufacturing donations dried up, food banks at the mercy of food industry changes had little choice but to adapt and follow the waste where it was being generated at the retail level. Prior to this transition, most FA foods circulating through West Virginia were sourced from manufacturers out of state. As retailers began integrating their supply chains into donated food circuits, the two food banks received more and more food to distribute, albeit foods that required more labor to sort than ever before. Trucking routes were reorganized to pick up food waste from an increasing number of donors spread across the state. The overall amount of donated foods from FA sources increased, but the sudden supply side shifts also reorganized food bank geographies (chapter 7).

The final source of food that food banks rely on are in-state donors not affiliated with FA. Over the past decade the two food banks averaged 3 million pounds of food from this source. Examples of such donations include:

Disaster relief: Food banks in West Virginia are part of the state's disaster preparedness network and are mobilized to process food donations originating both in and out of state in times of crisis. 
Special events: Food banks recover food waste generated by large events. In 2016 for example, the national Boy Scout jamboree provided 25 large truckloads of food to Mountaineer Food Bank in just one week.

Hunters: Organized by the West Virginia Department of Natural Resources, the Hunters Helping the Hungry Program provides processed venison to food banks during hunting season. Since the inception of the program in 1991, nearly 1 million pounds of meat has been donated to the state's two food banks.

State prisons: Inmates grow food on land managed by the WV Department of Corrections, a significant proportion of which is donated to food banks.

WV farmers: Farmers donate ungraded seconds to food banks. In the 2017 legislative session WV lawmakers passed the farm to food banks bill authorizing farmers to deduct $10 \%$ of the donated product up to $\$ 200,000$ per year from their state taxes.

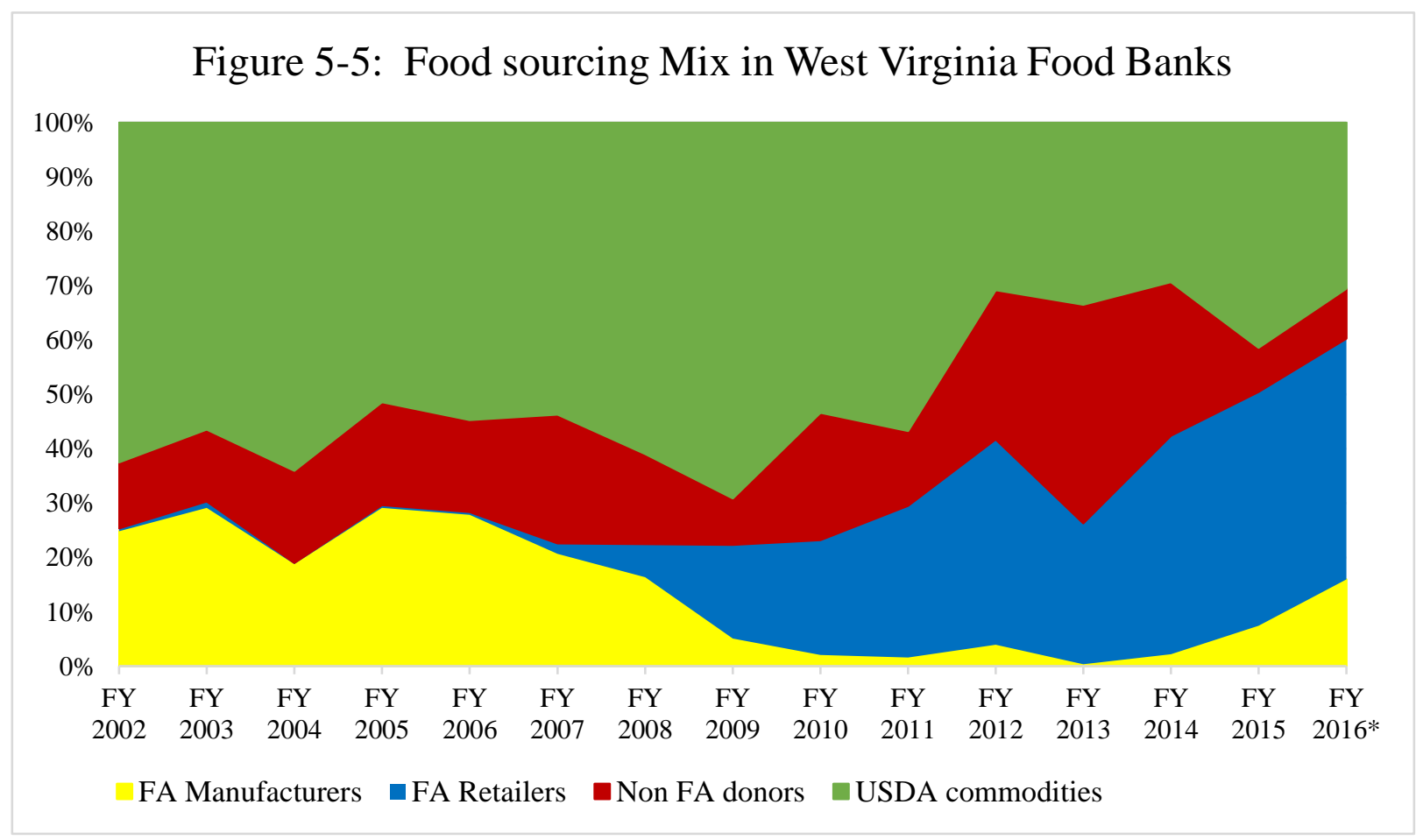


When each food source category is analyzed as a percentage of the overall food mix over a 15-year time series (Figure 5-5), the freneticism of food banking work comes into fuller view. The transition in FA food sources from manufacturers to retailers is the most obvious shift and the one that has had the most reverberating impact on the HFN in West Virginia. In 2016, 40\% of the overall food mix was generated through retail donors, a tremendous increase in a relatively short period of time. Because West Virginia food banks operate in "food poor" environments where there are fewer private donors than in many other parts of the country, TEFAP foods account for a much larger percentage of the overall food mix than many other food banks across the country. Forty-one percent of food distributed in 2016 was sourced from the federal government, whereas the national food bank average stands at $21 \%$. The fluctuation in TEFAP allocations is also visible when set against other food sources.

Although the food banking economy recovers increasing amounts of surplus food it does so based on supply chain dynamics over which it has very little control. As such there is little predictability in terms of food quantities or qualities, making it difficult for staff to plan how best to supplement what is oft an inadequate mix of food waste from across the agricultural, manufacturing and retail sectors. Food bank staff must make do with what they have on the warehouse floor at any given time, while also constantly ensuring that they are planning for the next shipment to arrive, constantly adapting their food sourcing strategies to follow the waste where it is being generated along agro-food supply chains.

These supply side upheavals are accelerating along with the pace of retail food consolidation and technological change. A food bank director related how she came back from the 2017 FA conference "scared to death" at the food sourcing changes projected over the coming 
years by food sourcing managers at FA. The effects of reworking food supply chains around online

businesses like Amazon Pantry and Walmart Grocery will be significant:

"It's already impacting my Walmart donations as they are figuring out how to go online. You don't want to stop at the store, go on Amazon prime and get your groceries. Donations from Walmart dropped by 125,000 pounds this year, Sam's club increased theirs by 60,000 so we didn't feel as much but Kroger too is being encouraged not to put as much out. They are projecting a 20 to $25 \%$ reduction, that's bad for us!” (FB - 5.12.17).

The nascent restructuring of food retailing into 'the cloud' will be the next major food sourcing shift to affect HFNs across the country. Food banks are rarely considered in supply chain changes, expected to adapt as polymorphous institutions at the service of a market-based food system that leverages food banks as a humanitarian vent to offload their food waste. It remains to be seen how food banks in West Virginia will cope with the upcoming changes. Stretched as they already are by the difficulties of raising sufficient funds to cover the costs of running their operations, they have very little room to maneuver within a food waste supply chain that is beyond their control. Added to these financial and food supply stresses are the rules and governance structures within which each food bank must operate to continue accessing food.

\section{Food Bank Governance}

West Virginia's two food banks have very little control over the financial and food resources that fix their activities in place. Their institutional legitimacy depends on following the rules and standards set forth by the national institutions governing their work. Food banks disburse federal commodities and corporate food waste at the local level, vesting them with a significant amount of power over HFNs at the regional scale (Warshawsky, 2010). Yet this power is not absolute and can only be understood within the pressures placed upon their work by the USDA and FA governance structures. Legal and contractual obligations from above ensure compliance to specific institutional logics (figure 5-6). This power is also maintained and reproduced from 
below as food banks enroll LFCs into an accounting regime that counts people, food and money (Figure 5-7). The multi-scalar governance regime embeds food banks into territorial relations with one another wrapping LFCs into a complex national charitable food geography.

The USDA operates on a state-based territorial framework. In West Virginia food and funding for TEFAP is allocated to the West Virginia Department of Agriculture (WVDA), who in turn partners with charitable organizations to distribute federal commodities across its jurisdiction (chapter 3). WVDA has full discretion in distributing West Virginia's TEFAP share. Its policy is to ensure even allocation across the state's fifty-five counties based on the same formula used by the federal government to calculate TEFAP entitlement at the state scale.

As WVDA agents, MFB and FHFB are compelled to execute these territorial logics through their diverse network of LFCs, only some of which meet the requisite standards to distribute federal commodities. TEFAP rules enforced at the local level ensure that LFCs comply with food safety laws, income-based means tests and civil rights principles that enfranchise food recipients. At the food bank level, monitoring ensures transparency of the food and funding resources received from the state, that the foods are handled appropriately and that distributions are evenly allocated based on WVDA rules. Food banks are also responsible for quarterly reports to WVDA regarding the number of households served by the program at every site. The state then consolidates this information from each food bank and passes the information back up to the USDA, who in turn reports back to the US Congress which legislates federal food policy. 
Figure 5-6: Monitoring and Compliance

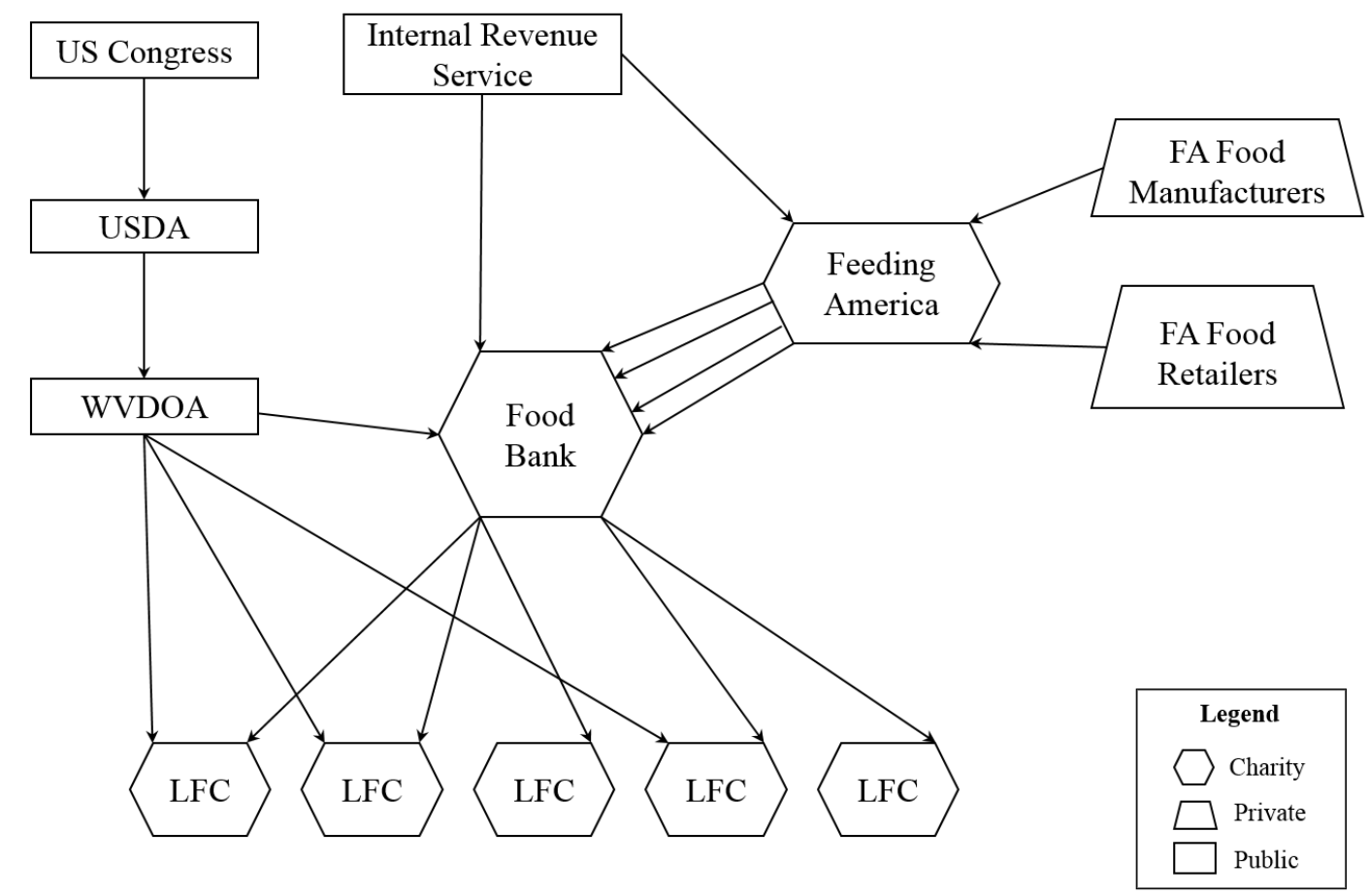

Figure 5-7: Accounting and Reporting

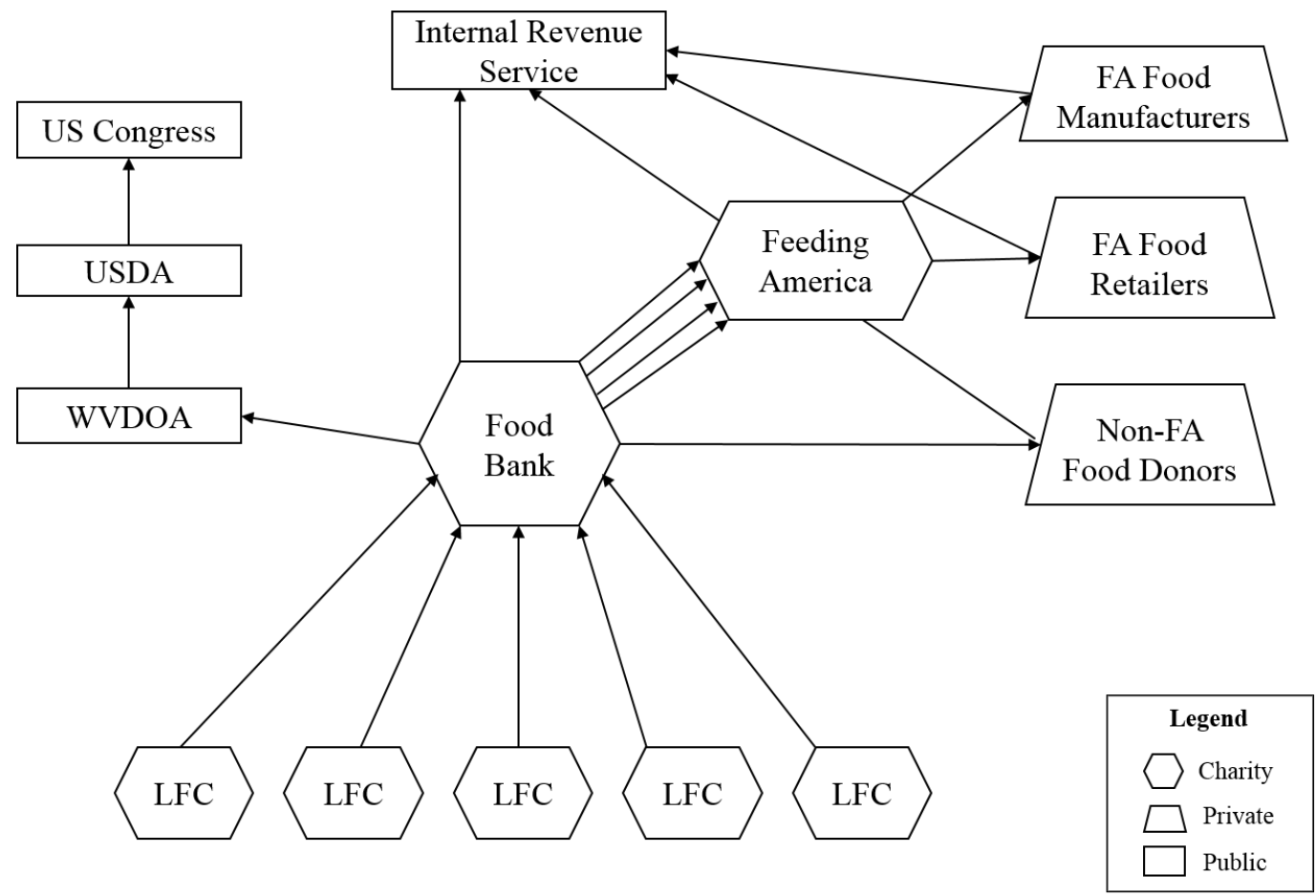


WVDA also sets the geographic boundaries within which each food bank is to distribute TEFAP foods. In 2009, following the funding allocation tensions I reviewed in chapter 3, WVDA made the decision to have TEFAP commodities delivered directly to the two food banks, rather than its central warehouse. While the decision saved money it also affected distribution logistics. USDA cost control rules state that vendors delivering commodities cannot make more than three stops along their route and must deliver at least $25 \%$ of their load at each stop. For FHFB to receive enough food to reach that $25 \%$ threshold, their TEFAP service area was expanded to include five counties outside of its FA service area.

Unlike the TEFAP governance structure, FA does not operate on a state boundary logic. Instead it governs its member food banks through legacy territories inherited over the ad hoc evolution of independent food bank operations. Some of the largest food banks in the country are in urban areas, but these often only serve one or two counties. Rural food banks on the other hand may serve fewer people across many more counties. The FA member contract (chapter 4) formalizes each of its member food bank's service area. The primary purpose of these boundaries is to order and discipline food banks amongst themselves. For example, because MFB sources and delivers food in West Virginia's two 'panhandles' its trucking routes are regularly extended into Pennsylvania and Maryland. However, MFB is not permitted to solicit food or funding in those areas because this would infringe on the Pittsburgh and Western Maryland food bank service territories, both also members of FA.

Figure 5-8 visualizes food bank territories in West Virginia. The boundaries are important to understand because they affect the capacity of each organization to solicit food and funding. FHFB is responsible for delivering TEFAP commodities in the red shaded area which includes Boone, Jackson, Kanawha, McDowell and Wyoming counties. MFB is responsible for recovering 
and delivering FA food in that same area. While most LFCs across the state are only affiliated with one food bank, this interstitial zone creates a situation in which nearly 40 LFCs must work with two food banks to separately source federal surplus and corporate food waste. The reasoning behind this territorial overlap is not well understood by the affected LFCs, divorced as they are from the state and national institutions drawing the lines. The seemingly nonsensical boundary is a source of frustration because LFCs must navigate between two ordering and accounting systems and the directives of two different agency relations coordinators, in effect bringing their work under their oversight.

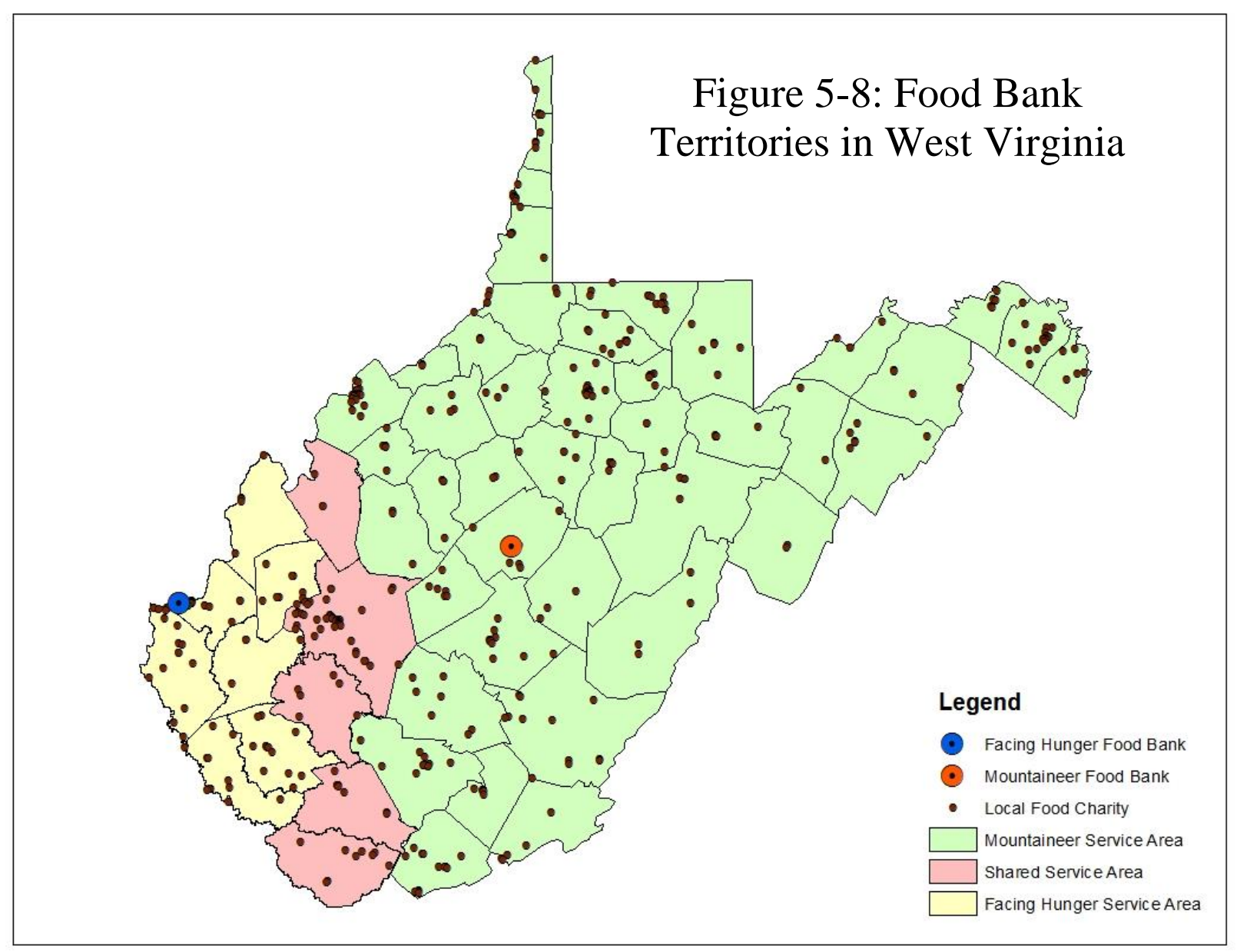

Although food banks ostensibly exist to serve LFCs, the latter have no say in the territorial relations they come under at the regional scale. In 2014, LFCs in Kanawha County unsuccessfully 
petitioned FA to reassign their county to FHFB under the perception that the Huntington based food bank provided higher quality foods than its counterpart in Gassaway ${ }^{36}$. Yet the territorial tension is not merely about food delivery, it is also about the financial resources and donor relations that are forged to maintain food banking operations in place. Per their FA contract, FHFB is not authorized to fundraise in the five counties outside of its FA jurisdiction because it would be encroaching on another FA food bank's donor base. Because TEFAP administrative funding only covers approximately $20 \%$ of the costs of running the program, FHFB is compelled to distribute TEFAP commodities in these five counties at a loss, without the possibility of recuperating the difference from local monetary donations as would be the case elsewhere. The charitable subsidy must be raised in other places across its FA territory.

WVDA is aware of the tensions that this territorial problem creates for the food banking economy in West Virginia. However, redrawing TEFAP boundaries to overlay with FA's territories would mean that FHFB would not be eligible to receive any TEFAP foods because it would not meet the $25 \%$ delivery threshold defined by the USDA that I discussed above. WVDA lobbied FA to redraw their food bank boundaries in West Virginia to match the WVDA TEFAP borders, but to no avail. A WVDA bureaucrat intimately familiar with the process recounted the difficulties it faced in mitigating the situation as follows:

"We spoke with a representative from Feeding America about redistributing counties, but they were not open to that suggestion at all. At the time, the director of one of the food banks was very well connected to people there and perhaps some political maybe even nepotistic issues they weren't going to do anything to take away counties from that food bank even if it helped the process, they're very territorial. [...] These are complex issues. They're politically entangled, some are legislative issues, many different things that are very complex"

\footnotetext{
${ }^{36}$ The perception that FHFB delivered better food of higher quality food was largely due to the fact that they only provided TEFAP commodities there, whereas MFB delivered corporate food waste that is not tied to any food quality standards.
} 
While FHFB and MFB could agree amongst themselves to reorganize their FA service territories to align with WVDA TEFAP distribution logics, MFB does not want to give up exclusive access to the resource rich Kanawha County, where the state capital Charleston comprises a large donor base and access to political capital. An FHFB food bank director presented the situation as follows:

"Kanawha County has a lot of donors and food retailers. It's a rich county! I can understand why Mountaineer wouldn't want to pull it. Boone county OK, it would probably be a relief, but Kanawha I'd imagine would take a lot of donors. It would be of poor taste for me to go to Kanawha to solicit donations because they aren't technically one of our [FA] counties." (FB-3, 7.15.14)

Food banking territories play a very important role in allocating resources to the food banking economy across the country, a geography governed by FA and the USDA based on differing logistical and ideological motivations. The Meals per Person in Need (MPIN) metric I review in chapter seven, adds yet another territorial dimension to these overlapping and at times contradictory governance structures. Food banks are at the center of a multi-scalar institutional assemblage where diffuse powers shaping access to food and funding across the food banking economy are negotiated. Their work is linked to spatial processes unfolding across the food system and indeed wider socio-economic trends. Food banks carry the burden to resolve and fix institutional incongruities along charitable food supply chains, concentrating the many demands to deliver food from state and corporate partners to LFCs, while working in a constant state of competition over scarce resources.

\section{Discussion}

Drawing on my case study of the two West Virginia food banks, I have demonstrated how these institutions are central nodes of an expanding HFN that is intimately connected to food system dynamics far beyond the state's borders. Food banks are tasked with resolving two 
contradictory crises borne out of capitalist development. The first is the crisis of surplus labor that leads to food precarity and hunger. The second is the crisis of overproduction of food in a marketbased system that produces scarcity to maintain profitability. The dual mandate seemingly resolves the conjoined problems of food waste and hunger, even as both paradoxically continue to deepen alongside the tightening governance structures that have come to shape contemporary food banking work.

I explained how increased food flows from the state and private corporations has created vulnerabilities for food banks that rely primarily on financial contributions from civil society to maintain their operations in place. The uneven and ad hoc nature of the various funding streams available to continue distributing food waste to the poor requires a near constant reframing of the food bank's hunger relief strategy in light of competing social causes. Furthermore, food banking systems are disrupted and reorganized as food recovery operations adapt to technological changes that maximize efficiencies and profits along agro-industrial supply chains. This tension creates a high degree of freneticism for food banks which, like the capitalist food system it is embedded within, operates in a continual state of crisis.

Food banks are wrapped into a national governance regime that orders the flow of resources and food, an oversight that places their work within overlapping territorial frameworks. The network of LFCs that work within local communities to address hunger from below depend on the food bank to access free or low-cost food resources. Food banks must tightly govern their LFCs to ensure they meet their distribution targets and that food quantities are accounted for, yet they are powerless to change the frameworks and measures upon which their institutional legitimacy depends. If they do not execute rules from above, they face the scepter of probation and loss of access to the foods that community-based organizations rely on to address food access failures at 
the local level. Food banks should thus be understood as key sites of struggle between the demands of the capitalist food economy to maintain the conditions for profitability and civil society's moral response to hunger.

The drive to centralize and fix the food bank as the social response to food waste and hunger is confronting tensions across a highly decentralized network of non-profit organizations. The gears of the public-private national governance structure that shapes and regulates HFNs grind up against a locally diverse volunteer run feeding network producing conflicts that are not experienced by the donors rushing to revalue their food waste through the food banking economy. Caught between the mandates of their national affiliates and the frustration of their local charities, food banks are left to negotiate and resolve the fraught ideologies of hunger relief at different scales. As HFNs are ever more tightly enrolled into a national food waste revaluation apparatus, many are beginning to question why food banks and local food charities are policed to conform to institutional goals that do not align with local realities.

The key question I raised in this chapter, and indeed throughout this dissertation, is whom the food bank fix ultimately serves? The moral unity of the food bank as a social fix to problems of overproduction and hunger is clearly fraught. The contradictions I have exposed provides an opportunity to think about ways in which LFCs and food banks might take advantage of slippages within this institutional framework as the basis for building alternative food futures. While food banks are currently subordinate to dominant relations of power in the food system, they are also capable of resistance because they occupy such a central role in the food waste-qua-hunger relief supply chain. This resistance cannot be an individualized response however, and a project that rewrites the call to charity toward food justice (Dixon, 2015) must build solidarities between local level emergency food providers and their food banks to push back against the monopolistic 
institutional dynamics that limit their ability to enact transformative food system change in their communities. 


\title{
Chapter 6: Local Food Charities
}

\author{
"I just want to feed hungry people. It's in my DNA and I can't help it honey" \\ - Food Pantry Director, Kanawha County
}

\section{I. $\quad$ The Will to Feed}

Marcia runs a food pantry just north of Huntington, West Virginia. The operation was started by her parents in the 1960s when the 3-car garage behind their house was converted into a place to store food to give away to neighbors in need. The food pantry eventually got so large that her father retired to manage it. In Marcia's words, her parents were motivated to help their neighbors because they knew how hard it was to make ends meet with 5 daughters. Marcia took the food pantry over 2 years before her father's death. His last words to her were "keep the pantry open and don't turn anyone away" and she continues to keep his legacy alive by raising funds, volunteering and praying that God would make ends meet every month. This prayer is answered in surprising ways as "angel donors" provide food and funding in times of need. Today her husband Fred does the leg work and she processes all the paperwork. They run the operation on an average budget of $\$ 650$ a month. Revenue sources include a $\$ 500$ monthly gift from the World Missionary Alliance, a Texas based faith group, and $\$ 150$ in local donations, $\$ 100$ of which comes from Marcia and Fred's regular tithe.

I highlight this story to reinforce the point that the impulse to alleviate hunger in local communities is a powerful force driving the humanitarian food network (HFN) forward. The people that operate Local Food Charities (LFCs) are the care givers of an affective economy working to organize resources and distribute food to people who do not have sufficient income to pay for it. Although food waste recovery is increasingly a part of the hunger relief discourse at the local level, the will to feed is the primary motivation that compels individuals to labor on behalf of others. Every month, 300,000 people, $16 \%$ of the state's population, access food from the 550 
LFCs affiliated with West Virginia's two food banks. LFCs rely on their relationship with food banks to source surplus foods that could not be sold on primary markets. Food banks depend on the emotional and caring labor of volunteers and low-paid staff who give of their time, creativity and energy to anchor this charitable food economy in place. A West Virginia food bank director captured this symbiotic relationship:

"[LFCs] are members of the community that people [in need] feel comfortable coming to, they are religious organizations and social services. They are your neighbor or people you're friends with. Without [LFCs] we wouldn't be able to do anything. We function to get resources and use our economies of scale, but they are the channels of our network. They are our hunger relief foot soldiers. We can get as many donations as we want, but if we don't have partner agencies it doesn't do us any good.” (FB-1, 7.15.2014)

LFCs operate in the shadows, often visible in their public appeals for food and funding, yet tucked away from the public eye in church basements and low-income community centers. Many LFCs operate on word of mouth alone, warry of being overwhelmed with demand and not having enough food to provide for clients they regularly serve. Those running and operating LFCs are often living on the margins themselves, accessing food resources through their work and blurring the lines between volunteer and patron (Dickinson, 2017). The geographies of survival embedded within local charitable food economies are linked to wider socio-spatial processes including uneven development and the management of surplus labor under capitalist social relations (Heynen, 2009).

LFCs are the ends of a secondary food circuit absorbing industrial food waste and resolving crises of over accumulation of food and labor (Henderson, 2004). The complication for Feeding America (FA), the USDA and their regional food bank agents is that LFCs are not monolithic actors in an undifferentiated charitable complex. The local scale of this food destruction network (Lohnes and Wilson, 2018) is highly disordered, a collection of heterogeneous organizations with different capacities and motivations. Adam Pine's (2016) ethnographic comparison of 4 LFCs in 
Duluth, MN, revealed key differences in the way LFCs respond to hunger. While they share a common social function linking surplus industrial food to vulnerable households, their work is also informed by oft contradictory ideologies. Pine notes that LFCs distinguish themselves in their religious and secular motivations, their perception and relationships with the state, their different understandings of the causes of food insecurity, their different ideas of personal responsibility, the different work expectations among staff and volunteers and the different understandings of what constitutes fairness in the food system. He goes on to argue that as a permanent part of the shadow state, food pantries and soup kitchens operate in the liminal space between alternative economies of care and the pressures of neoliberal social welfare policies.

Sustained through private charitable funds and volunteer labor, LFCs exploded onto the contemporary foodscape in the 1980s and have continued to expand in number reaching an estimated 60,000 as of the last FA Hunger Survey (Winefield et. al, 2014). As the food banking economy formalized and the amount of food waste available for distribution expanded, so did the local infrastructure supporting its distribution. In West Virginia, the timeline of this LFC expansion reveals a pattern that conforms to the roll-out of TEFAP (chapter 3) and the growth of food waste donations by corporations through FA (Chapter 4). 35\% of all LFCs currently operating in the state opened after 2008 (Figure 6-1). 
LFC openings peaked in 2012 with 19 new agencies enrolling in food bank memberships that year. The trend line portends steady growth of this mode of food delivery in the coming years, yet despite this expansion, LFCs cannot be understood as franchises rolled out with any inherent logic, spatial or otherwise. They are not unitary subjects, their everyday practices, meanings and performances vary as the collective spirit of the mostly volunteer staff differs from place to place. I heard multiple times throughout the course of my research "if you've been to one food pantry in West Virginia, you've seen one food pantry in West Virginia”. Because no two LFCs are alike,

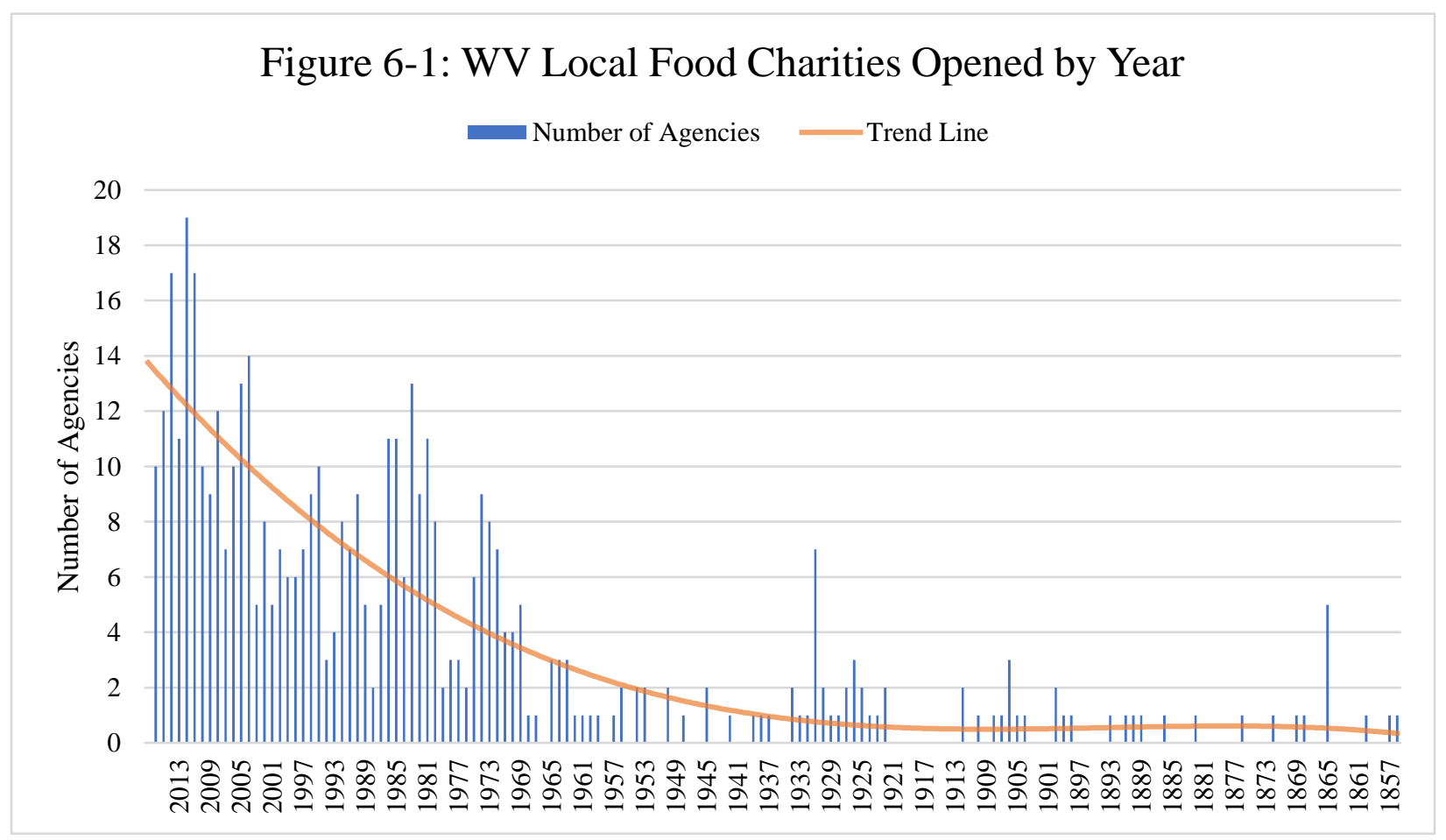

the resources and social networks each has access to vary tremendously as do the services they offer and the rules they put in place to limit or expand access to the food they give away.

Unlike their food bank counterparts, LFCs are unprofessionalized members of a highly centralized response to food waste recovery as hunger relief. LFCs are part of their own nodal networks of care, yet their dependence on food banks to source food enrolls their activities (and by extension civil society's response to hunger) into the food bank's governance structure 
(Warshawsky, 2010). In chapters 3 and 4, I explained how the USDA and FA play a prominent role structuring the work and programmatic goals of regional food banks. The question I pose in the next two chapters is what effect the ongoing institutionalization of food banks as territorial forces (Billo and Mountz, 2016) has on ordering LFCs into a logic of hunger relief that reinforces corporate interests, and in turn how LFCs affect and shape their food banks.

Building on Pine (2016), I demonstrate how the liminal space that LFCs operate in complicates the overarching goal of the food bank to resolve hunger through industrial food waste. The wide range of perspectives, ideologies and institutional capacities at the local level frustrates the food bank fix and ultimately the corporate food regime's relationship to charity. Scholarship on food assistance agencies to which Pine and others contribute (Glasser, 1988, Poppendieck, 1998, Daponte et. al, 1998; Daponte, 2000, Garasky et. al, 2004, McCutcheon, 2015) formulates a cogent critique of the performative side of charitable food's ideology. Yet the material fixity of LFCs as "a powerful system of fortress and earthworks" (Gramsci, 1971, 238) that legitimize the current social response to hunger through food waste recovery, has not been adequately analyzed. If as Gramsci contends, ideologies are expressed performatively (via meanings, symbols and practices) and physically within landscapes and institutions that shape them, then we best be attentive to the built environment and social infrastructure within which charitable performances take place.

\section{Institutional Context}

This chapter links the work of 515 LFCs in West Virginia to the work of the two regional food banks in the state. I first analyze the diversity of the decentralized network of feeding programs, identifying some of the key differences among LFCs that combine to frustrate the food bank fix. These include the types of services provided by LFCs and the scale of their operations, 
their institutional capacity including labor, operating budgets, infrastructure and organizational cultures that differentiate access to charitable food in each place. Second, I analyze how uneven capitalist development (Smith, 1984) links charitable food to wider socio-economic dynamics that inform the availability of charitable food for poor households. As access to financial resources in different locales varies, so does the capacity of communities to be "charitable". I conclude the chapter by highlighting some of the conflicts that have emerged as the food bank works to structure and govern its LFCs to adapt to institutional mandates that extend far beyond the state's borders. The effects of this conundrum and the drive to overcome spatial barriers through a combination of mobile food drops, new LFC recruitment and agency tiering are taken up in the following chapter.

The efficacy of food banks to meet the goals of the federal government and food corporations is directly linked to the capacity of LFCs to subsidize and execute their food waste recovery and hunger relief activities. Cost sharing from the LFC network provides a quarter of food bank operating revenues in West Virginia (Chapter 5). As food and financial resources channel through the larger professionalized institutions of the shadow state, local agencies bearing the collective brunt of the service delivery work are having difficulty keeping up with the growing demands placed on them. The latest FA national survey (Winefield et. al, 2014, p.76) estimates that a staggering $65 \%$ of LFCs across the country worry about continuing their hunger relief services over the next 12 months, with 55\% citing a lack of money as the major threat to their existence. In West Virginia, a state struggling with divestment, fiscal crisis and high food insecurity rates, LFC precarity is a major problem (Morisson, 2011). Despite these local capacity challenges, food banks must continue to push out increasing amounts of food to meet national distribution benchmarks from FA and projected TEFAP increases. Food donations from the state and corporate sector arrive regardless of LFC ability, or willingness, to absorb it all. 
Capturing the food bank's position as institutional broker negotiating these differing demands from above and from below, a West Virginia food bank director summed up the sentiments and pressures within which her staff operates in a meeting with her LFCs. "I know it's not easy, sometimes I feel like a parent, and sometimes I feel like I'm being parented (PO-10: 11.20.15)". LFCs are usually not privy to the many institutional tensions facing food banks, and my extensive observations throughout West Virginia indicate that there is an implicit sense of wariness about their growing power and grip on the emergency food landscape. These feelings often erupt as explicit confrontations. In the same meeting the director also felt compelled to say to her agencies:

"We've got to be locked in this together arm in arm. If you're not paddling with us, you're part of the problem. Team up, we're all in this together [...], my staff are not compensated enough to be yelled at. If you are complaining to my truck driver, my secretary or one of our volunteers it's not helping!" (PO-10: 11.20.15)

As the institutional and operational logics of food banking centralize around FA and the USDA, LFCs must adapt to the demands of a national governance structure they have little concept of to continue their feeding operations. LFCs are by no means docile social actors in this process, they should not be understood as malleable clay in the food bank potter's hands. Instead, the combination of dependency and misalignments between LFCs and their regional food bank create tensions that offer productive potential for thinking about the wider food banking fix, one whose top-down power structure is enrolling local charitable impulses into a national food waste recovery paradigm driven by agro-industrial firms offloading their surplus. LFCs then should be studied and understood within the set of logics and structures that place them at the ends of a vast nodal network that extends through the food bank, into the state, the shadow state and the wider market driven food system. 
As I reviewed in chapters 3 and 4, following rules, making rules, and applying rules from above comes at a time when national governance structures are tightening to ensure that the food banking fix can accommodate increasing flows of industrial food waste evolving sourcing channels. Contractual obligations between the food bank and FA control the measures that define success, and by extension the politics of representation surrounding food waste recovery as hunger relief. These rules are also tied to the profit motives of large food corporations, a fact that is not fully understood by LFCs, yet the corporate cause marketing campaigns that enroll and claim their work is not completely lost on them either. At an LFC coalition meeting a food pantry director was frustrated by misrepresentations in a corporate cause marketing campaign: "I saw an ad from Sam's club saying that if you text them the word "Hunger" they will donate 12 meals to a local food pantry, but that food isn't coming to us, it's going to Mountaineer Food Bank." (PO-1: 11.15.2016)

Food banks must tightly govern LFCs to ensure food quantities are accounted for and meet distribution targets yet are powerless to change the frameworks and measures upon which their institutional legitimacy depends. If they do not execute rules from above, they face the scepter of probation and loss of access to the foods that their anti-hunger network relies on to address food access failures at the local level. My findings clearly indicate that the gears of the public-private national governance structure that shape emergency food networks grind up against a locally diverse volunteer run feeding network producing conflicts that are not experienced by the donors rushing to revalue their waste through charity. Caught between the mandates of their national affiliates and the frustration of their local charities, food banks are left to negotiate and resolve the fraught ideologies of food waste revaluation and hunger relief at different scales. 


\section{Diverse Food Charities}

LFCs affiliated with the state's two food banks can be broken down into three distinct categories $^{37}$. Food pantries provide food for preparation at home. Congregate meal programs (e.g. soup kitchens) serve ready-to-eat meals on site. Backpack programs work with schools to supply K-12 students at risk of hunger with a portion of food over week-ends or extended holidays. There are also differences among LFCs in terms of the number of people they serve, and thus their prominence across the charitable food landscape in the state (Figure 6-2). I turn to a brief overview of the place of each from my experiences encountering these many different feeding programs in the West Virginian context.

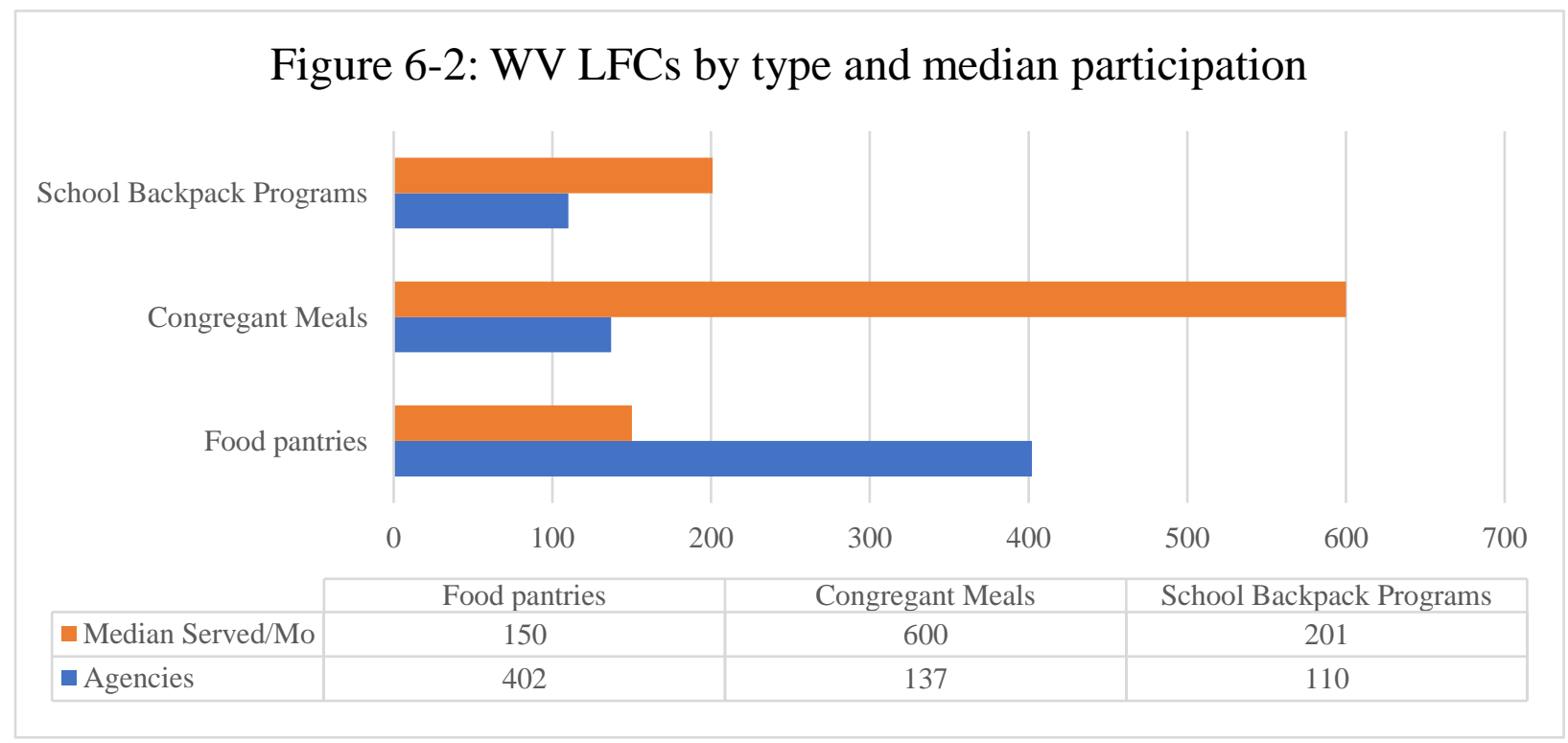

${ }^{37}$ There are approximately 120 meal delivery programs in West Virginia (e.g. meals on wheels) serving homebound seniors and the disabled. These programs play an important role in addressing food insecurity but are connected to a food supply chain that does not include regional food banks. Meal delivery programs are therefore not included in this study. There are also many LFCs operating outside of regional food bank affiliations that are not included in the analysis. 


\section{A. Food Pantries}

There are over 400 food pantries in West Virginia, the largest LFC category in the state. Pantries serve a median of 150 individuals per month distributing boxes of food (usually a 3 -day supply based on household size) for preparation at home. $74 \%$ do not have a paid staff member and depend solely on volunteer labor to run their programs. As such, food pantries maintain extremely variable hours of operation, and the majority are only open once per month during a specified time. Most food pantries establish prerequisites their clients must qualify for to access food. Some of these are informed by the USDA TEFAP means tested program requirements (Chapter 3) which include intake forms, income and address verification. Some set up additional eligibility criteria such as referrals from a third-party agency, or temporal access requirements (e.g. only once per month). Many pantries delineate service territories, while others will serve anyone in need of assistance regardless of their home address. Pantry budgets also vary widely based on levels of congregational or community support and individual personalities soliciting funds. This translates to variable infrastructure across the network as well. Some only have space for dry goods, while others have large cold storage space. Some operate without a budget and rely exclusively on free USDA commodities and volunteers. Other pantries have thousands of dollars to spend on food every month, only some of which is purchased through the regional food bank. These larger pantries usually have paid staff to coordinate logistics. Some food pantries have 'merged' over the past few years pooling local resources to increase their overall service capacity and streamline anti-hunger efforts in the community. This local centralization of feeding activities comes with benefits and drawbacks as the number of food pantry locations decreases but food quality, infrastructure and service hours in the area are often improved. 


\section{B. Congregant Meal Programs}

Meal programs prepare food on a regular, often daily, basis. As such they serve many more people than food pantries, averaging 1,480 individuals per month in West Virginia. Hot Meal programs that source food from regional food banks vary in size and purpose. Large congregant meal programs that are open every day and are usually located in urban areas, often serve a population that may not have regular access to a kitchen. Hot Meal programs that accept USDA TEFAP commodities (chapter 4) are required by law to serve anyone walking through the door regardless of income or resident status. Other congregant meal programs are targeted to specific populations such as daycares, children summer camps, family crisis centers, senior centers or shelters and thus cannot distribute USDA food unless they open their meals to the general public. These programs usually have at least one paid staff member sourcing and preparing food and organizing volunteers. The infrastructure required to run a hot meal program is much more significant than that of a food pantry including kitchen facilities approved by the local health department, cold storage capacity and space to seat many people. Due to the sheer volume of food these programs process, hot meal charities usually have the highest operating and food purchasing budgets and tend to mobilize the most volunteers.

\section{Backpack Programs}

Backpack programs provide a supply of food to children enrolled in school over weekends or extended school breaks. Each program sources, packs and distributes a portion of food for needy students at their partner schools, and usually communicates with the school principal to organize their activities in a way that reduces social stigma for children receiving assistance. Some programs donate food in multiple schools, while others choose to partner with only one. USDA commodities are not appropriate for backpack programs due to the weight of most commodities and the lack of 
verifiable documentation from food recipients, who are often identified as needy by teachers and school staff. LFCs therefore rely exclusively on private funds and private food donations to operate these programs. Many backpack programs order FA donations from the food banks, and some take advantage of their bulk purchasing program to take advantage of economies of scale that reduce their overall food costs. Backpack programs are perceived as a growth area by the two West Virginia food banks and the concept is catching on in large part because children receive the food directly, a vulnerable population that garners significant donor affect.

\section{Other Services}

LFCs are often not exclusively feeding organizations. Many are social service agencies that offer a host of other programs of which food distributions may be only one small part of their overall activities (Figure 6-3). These organizations receive funding to implement programs from the state and private foundations and are unevenly professionalized as depending on their level of integration within other governance structures of the shadow state (e.g. homelessness, addiction services, etc.) Agencies with multiple programs tend to have larger food budgets and draw from the expertise of staffing resources that know how to navigate the non-profit complex and access institutional funding from foundations and state offices. The food banking economy thus feeds off the wider devolution of state responsibilities to non-profit agencies and many LFCs are anchored by other parts of the shadow state. 


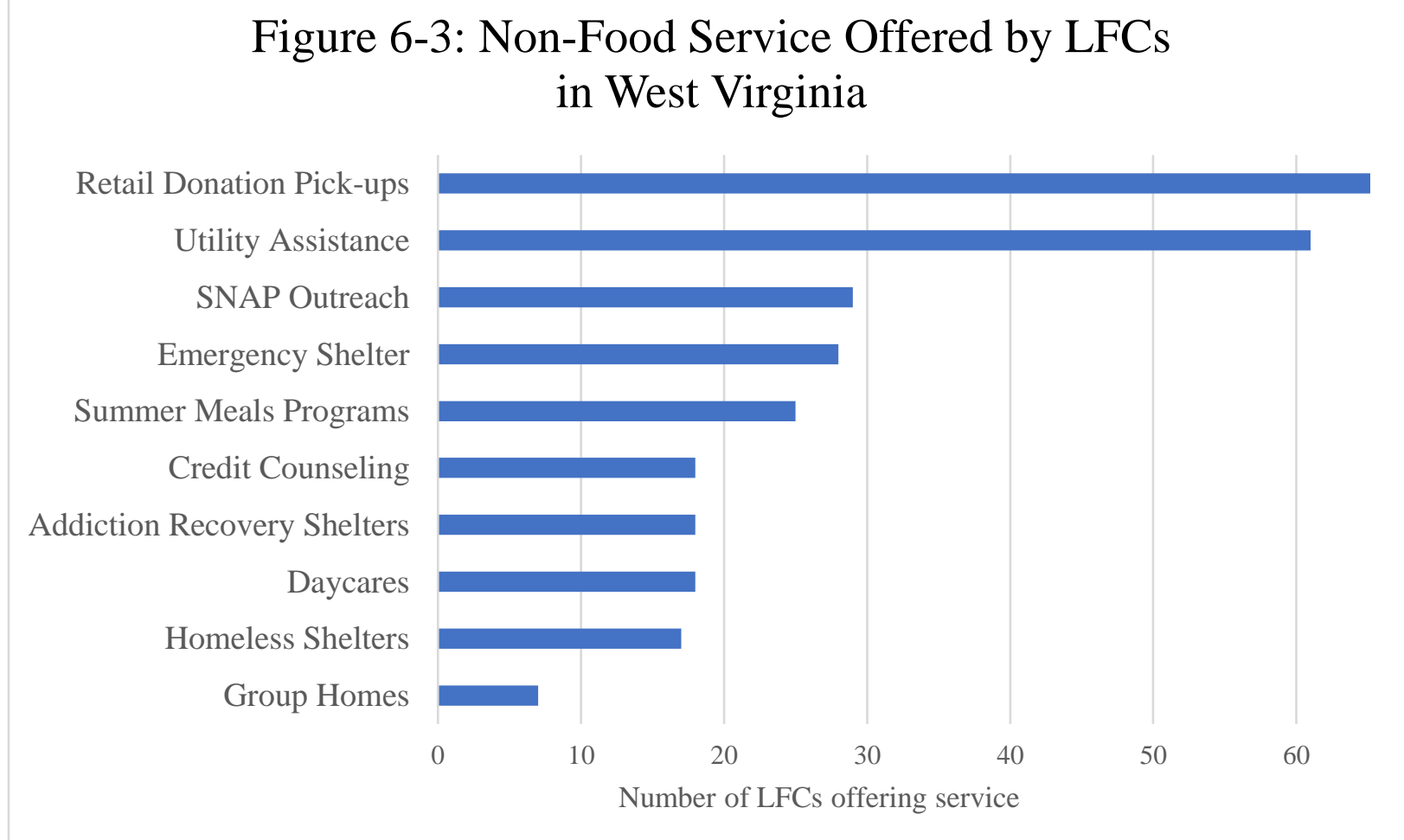

\section{Uneven Development}

Place significantly affects an LFC's capacity to procure and process the foods they distribute in their communities. Counties with higher incomes are more likely to have LFCs that raise more money and thus spend more on food charity per person served (Figure 6-4). While a community's level of disposable income does not neatly correlate to the quantity and quality of charitable food available there, it is a significant factor shaping the willingness of different LFCs to absorb and process recovered food waste from their regional food bank. In Monongalia county for example, median incomes are higher than average across the state. The anti-hunger organization Empty Bowls collects nearly $\$ 100,000$ every year through a one-day fundraising event there. This money is exclusively disbursed to LFCs within that county, providing enhanced financial resources that many of their counterparts across the state do not have access to. Higher incomes also translate to wealthier churches and more giving to charitable causes. As such many 
LFCs in Monongalia county have the capacity to purchase food products on primary markets to supplement oft inadequate food bank offerings. Some very large LFCs operate completely outside of the food bank purview, sourcing exclusively from wholesalers and retailers or building relationships with third party donated food circuits.

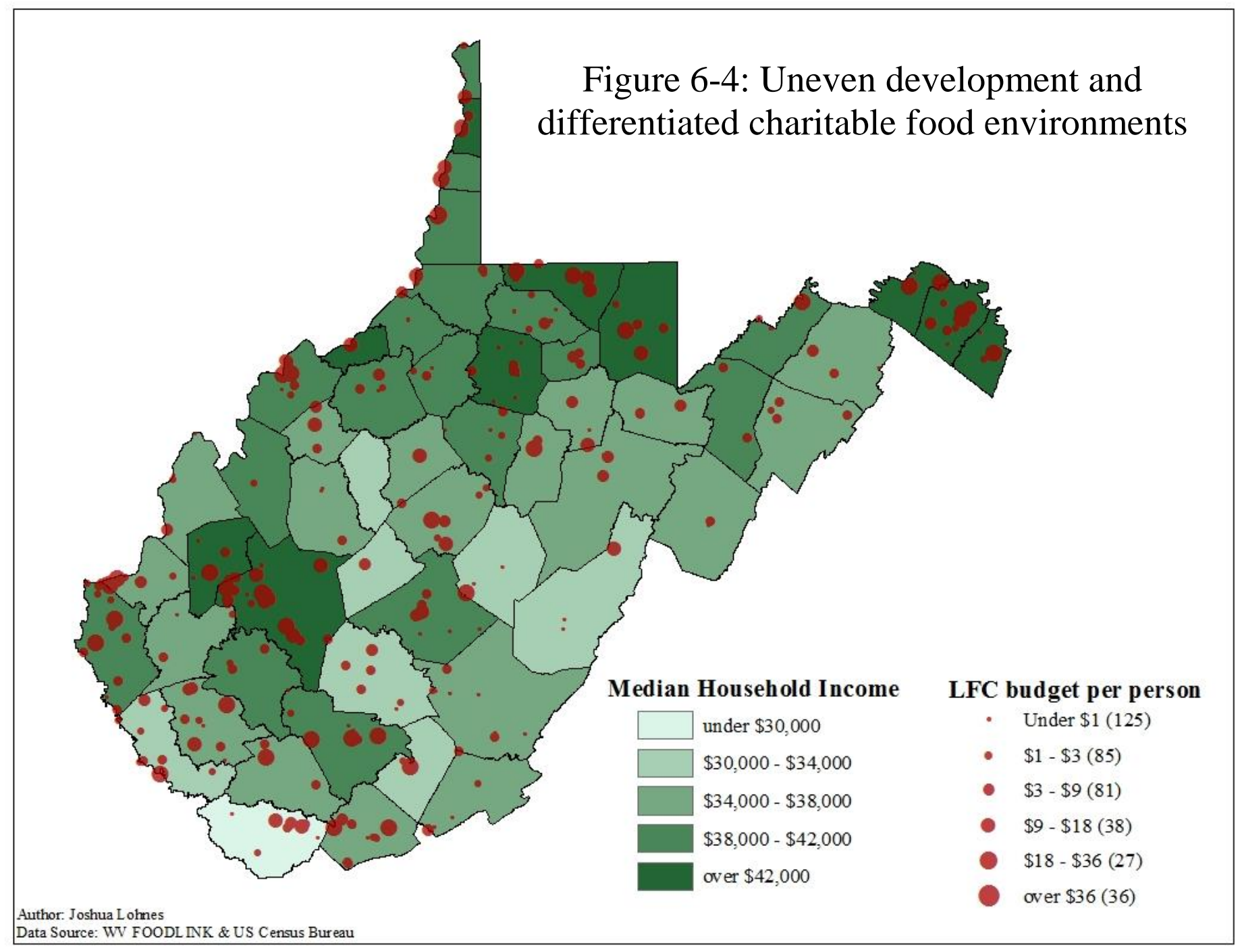

As food banks work to push product to meet FA distribution targets (Chapter 7), they must also contend with the need to cover their operational expenses through agency cost-sharing fees. Financial disparities at the LFC level are thus a serious concern for the two food banks in West Virginia. LFCs with low budgets rely almost exclusively on the food bank. TEFAP is still free of 
charge $^{38}$, but not all agencies are able to reach the requirement thresholds for TEFAP eligibility either: "We are trying to become a TEFAP agency, but we aren't ready yet, we don't have the fridge space. But we would really like to be able to distribute more food" (PO-15, 11.28.16) said one pantry director in Preston county. The cost of TEFAP deliveries are not fully reimbursed by the state (Chapter 3) and must be offset by charging a sourcing fee on private (FA) food donations and their bulk purchasing program (Chapter 5). The average price for FA food is currently 18 cents per pound but this price-point varies based on the types of food available for distribution at any given time and the need to move product. High demand foods such as proteins are often priced higher, while harder to move product and perishables are priced lower, even free at times (Chapter 7).

LFC capacity is extremely variable as each works within the means and social networks at their disposal to offer food rations or meals. Not all LFCs are equally dependent on the food bank for their charitable food operations. 53 agencies in West Virginia reported that they rely exclusively on food banks to source food, and a third are at least $80 \%$ dependent. "If it weren't for Facing Hunger Food Bank we wouldn't be able to survive, they are our life bread!" (PO-10, 11.20.15) said one LFC director in Mingo county, where massive coal layoffs have increased demand for emergency food and decreased funding for charities. Others are less so, drawing on a network of local food and financial donors outside of the FA and USDA governance structures. Many purchase foods from local retailers and wholesalers, supplementing food bank offerings with choices available in primary markets. Most LFCs thus juggle between the food bank, local food

\footnotetext{
${ }^{38}$ Some food banks outside of West Virginia do charge a cost-share fee on TEFAP foods to recuperate costs of running the program. The two food bank directors in the state would rather not resort to increasing financial burdens on vulnerable agencies distributing these public foods but they have hinted that it could become a possibility if they continue to face budget shortfalls.
} 
drives and food retail choices to come up with a price/quality/quantity ratio that makes the most sense for their individual organizational capacity.

"We purchase food from Facing Hunger and receive USDA commodities. The food bank has a lot but it's not always stuff that we can use. We purchase mostly from our wholesaler Brown's in Louisa, KY. We've tried Cisco and Logan's meat company in Huntington but Brown's works with us and gets us good deals." (LFC-9: 7.16.14)

Food banks receive more financial resources and public attention because of the size of their food recovery operations, and the co-branding opportunities afforded by their relationship with FA. However, local food sourcing strategies still dominate the HFN across West Virginia with 58\% of all food procured through the direct efforts of individual LFCs. Food banks in the state then, perhaps surprisingly, are not the primary source of food for the network. Figure 6-5 visualizes the breakdown of food flows by source among $\mathrm{LFCs}^{39}$. The map reveals how the different food sources are also dictated by place based factors, namely the level of funding available and the capacity of local communities to donate. Some places then come to depend more heavily on food bank food than others. LFC purchases account for 35\% of all foods distributed by the HFN in West Virginia, the single largest source if USDA and FA foods are disaggregated. However, the amount of food purchased is also spatially contingent and uneven relative to the financial capacity of each LFC.

39404 LFCs $(85 \%)$ reported food sourcing percentages through the WV FOODLINK survey. Donation and purchase poundage based on yearly food distribution data provided by the two food banks. 


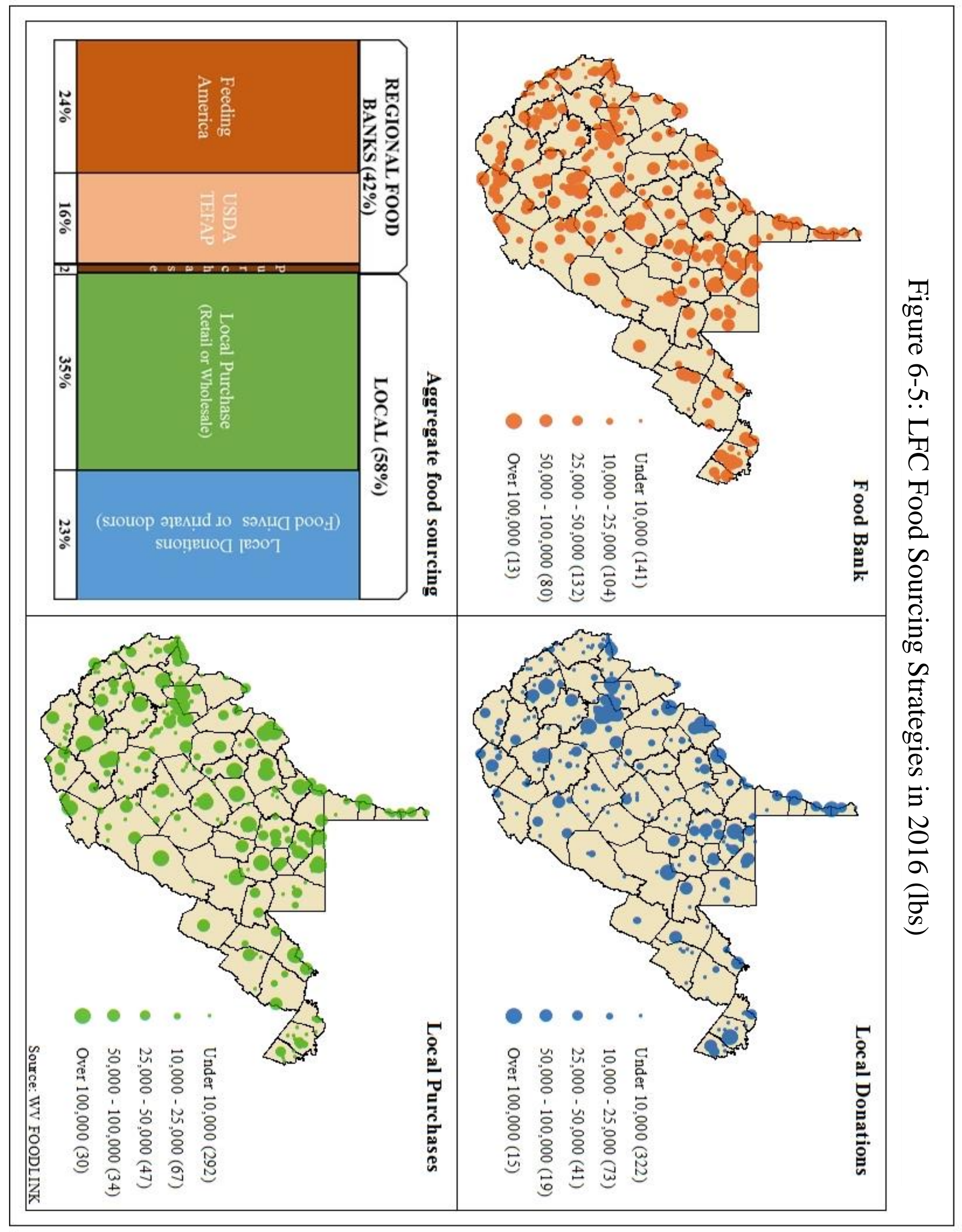




\section{Portals and Barriers to Food Waste Revaluation}

LFCs in West Virginia are fiercely independent entities extremely diverse in their institutional capacities and motivating ideologies. They remain focused on their own operations and usually do not understand their work as part of a wider whole. While many cooperate, they do so in a charitable food context that is also highly competitive and insular. Decentralized LFCs are wary of being misrepresented, of not receiving a fair share from the food bank or missing out on resources that they need to continue serving food insecure households. This individualism is problematic for food banks who are continually trying to cultivate a sense of team spirit in their efforts to feed the hungry. It is in this context of splintered interdependencies that the food banking economy must be understood in the state, particularly as the two food banks struggle to push out the increasing amount of donated product flowing through their warehouses each year.

\section{A. Labor}

The clear majority of LFCs run their food distribution programs solely through the 16,000 volunteers that are mobilized across the state to contribute labor to emergency food operations. The median number of volunteers per LFC stands at 8 , although the number varies widely from place to place depending on the number of people served and the type of program(s) it operates. Volunteers execute a variety of tasks. Some use their personal vehicles to pick up food from local donors and the food bank drop off points. Volunteers also write newsletters, organize fundraisers, process paperwork and food bank reports, source food, stock shelves, prepare or distribute food. $35 \%$ of LFCs in the state operate with at least 1 part-time paid staff member. These workers are usually part of more professionalized organizations with the capacity for additional social service programing (see above), although there are several stand-alone LFCs with paid staff as well. The 
social service wages that paid staff receive are not always adequate to supplement livelihoods and many juggle additional paid employment in addition to their LFC organizing efforts.

"I really want to be doing more of the pantry work, that's where my heart really lies, but you know as a single mother of 3 , the food pantry work is the grant that pays me the least, so I have to focus on the other programs like home visiting instead because that's more money. I hate to say it but... So, I go out once a month, and then my colleague goes out once a month so we're open twice, every other Wednesday. We do opposite Wednesdays from the other pantry in our area." (LFC-10, 3.2.17)

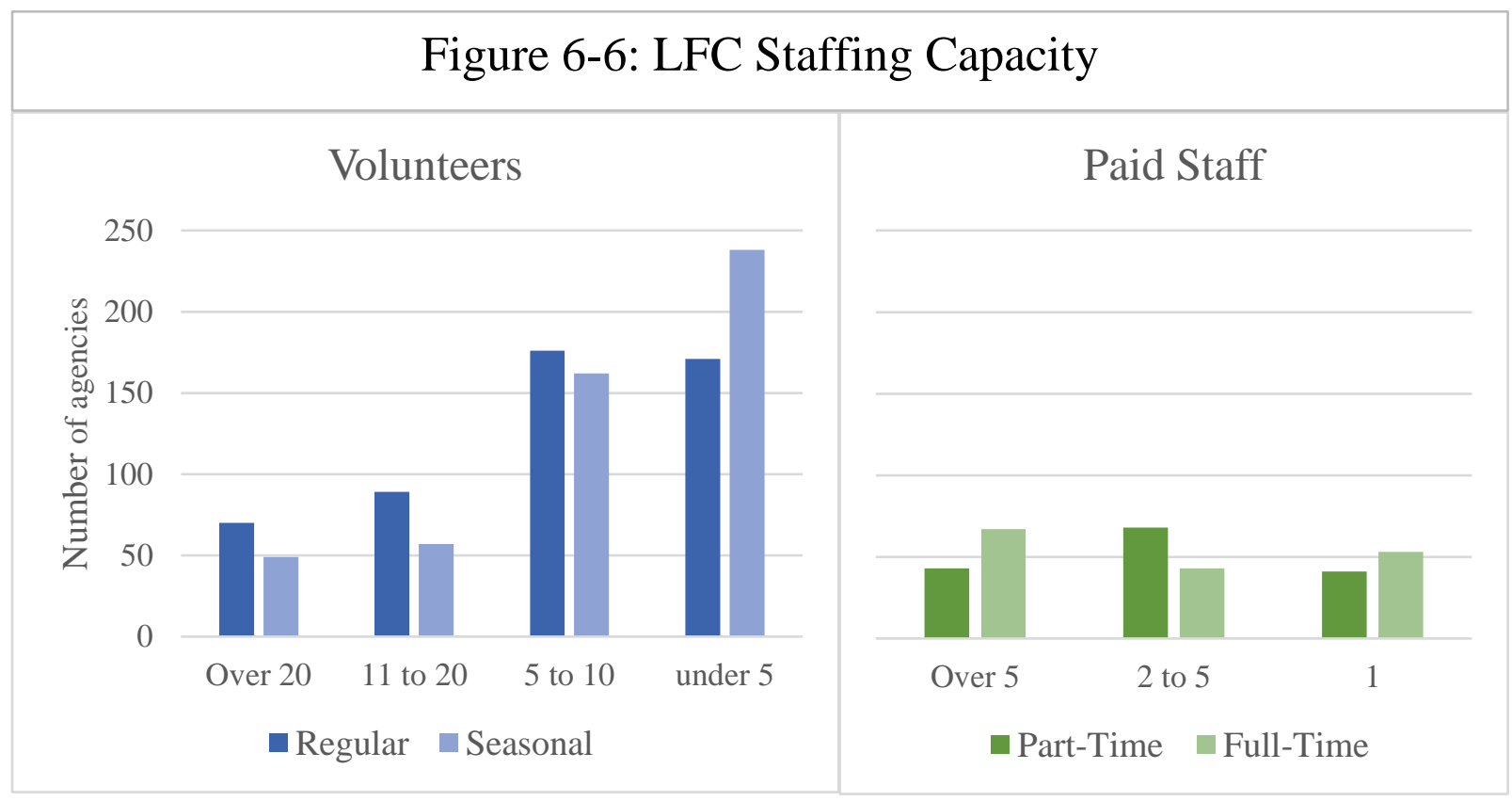

Figure 6-6 details the number of staff that LFCs recruit to operate their feeding programs.

It's important to note that the overwhelming majority of workers across this network are women. I've identified gendered dynamics across the HFN as a significant source of tension in the roll-out of the food banking fix. For example, male pastors often oversee budgets and claim the work of a church's food pantry ministry even as female congregants volunteer to perform the majority of the work of implementing it. Patriarchal mandates extend across scales as well, particularly as 
performance-based metrics and disciplinarian governance structures encounter a logic of success from below that privileges relationships of care over measuring deliverables ${ }^{40}$.

The motivations that drive people to contribute labor to the food banking economy are extremely varied and intersectional. Some participate to resolve a sense of social injustice, others seek to reform perceptions of deviant behavior among the poor, others are answering a call from God. Some feel a responsibility to give back to a system of care that helped dampen their own crises in times of need. For others volunteerism is a way to access or rebuild a sense of community. Some distribute food to gain or maintain power. I encountered two different places in which county commissioners were involved in raising funds for feeding programs in a bid to maintain their political status as community benefactors. The combined differences significantly affect food banks as they work to organize their LFCs to accept the increasing amounts of food waste that they receive for redistribution.

Another barrier facing food banks in their reliance on volunteer labor at the local level is an aging workforce. Younger volunteers warry of reproducing a charitable food model that they understand as problematic or simply not as exciting as the many other causes that compete for their time tend to engage with LFCs within specific organized volunteer settings, not over the long haul. When I asked a young AmeriCorps volunteer why she thought that there were so few young people wanting to take over the management of food pantries her response was telling of the problems facing the food banking economy as it works to recruit a new generation to distribute food to the poor.

"I'm doing this as my AmeriCorps for a year, but don't see myself in this long term honestly. It seems that food pantries are either run by AmeriCorps volunteers or old people.

\footnotetext{
${ }^{40}$ Poppendieck (1998) begins to address gendered dynamics in charitable feeding programs but this remains a grossly under researched dynamic within emergency food programs. While beyond the scope of this dissertation, a study exploring the gendered spaces produced by the food banking economy at different scales would be an important contribution to the literature on charitable food.
} 
Someone passed away at one of the pantries in our county recently and there was no one to take over her work. I don't know how to get young people excited, perhaps it's not enough of a challenge, or not the right challenge. I feel like I could be doing so much more than just giving food away to people especially when, you know, here's your box of Kraft mac and cheese and your Spaghettios." (LFC $11-4.12 .17$ )

She went on to explain how a much more exciting prospect to contribute volunteer time toward would be working to connect local food systems to food insecure households, providing space for people to grow food and provide for themselves rather than depend on handouts. While she expressed that her experience in the pantry was valuable, she did not see it as bringing about lasting social change, even though her pantry provided food to 300 people every month, something that the local food economy would have trouble accomplishing so efficiently.

You just have to get rid of what's on the shelf. I go 3 days a week to Panera to pick up their bread, but my director doesn't want me to go to a local farm to pick up a donation because it's too far, too complicated. But I get it, I mean it's a problem. Not everyone is 20 years old and able to haul a bunch of potatoes, that's just not a reality" (LFC $11-3.16 .17$ )

Dependence on volunteer labor is one of many institutional barriers confronting the roll-out of the food bank fix. The generational gap leading to LFC succession crises is a major concern as those that started emergency food programs in the 1980s and 1990s are no longer physically fit to serve, and LFCs across the state are regularly shutting their doors because no one is willing to take over the burdens of administering the program. The food bank's response is often to recruit new agencies rather than the more difficult job of finding an adequate replacement in the community. "I feel for these agencies that have to shut down because they don't have enough volunteers, but we just don't have the time to run their operations. We do our best to recruit new agencies and that is difficult enough as it is" (PO-3:7.19.14)

\section{B. Operating Budgets}

Another point of contestation confronting food banks is local capacity to fundraise for charitable food programming. The median yearly operating budget for an LFC in West Virginia is 


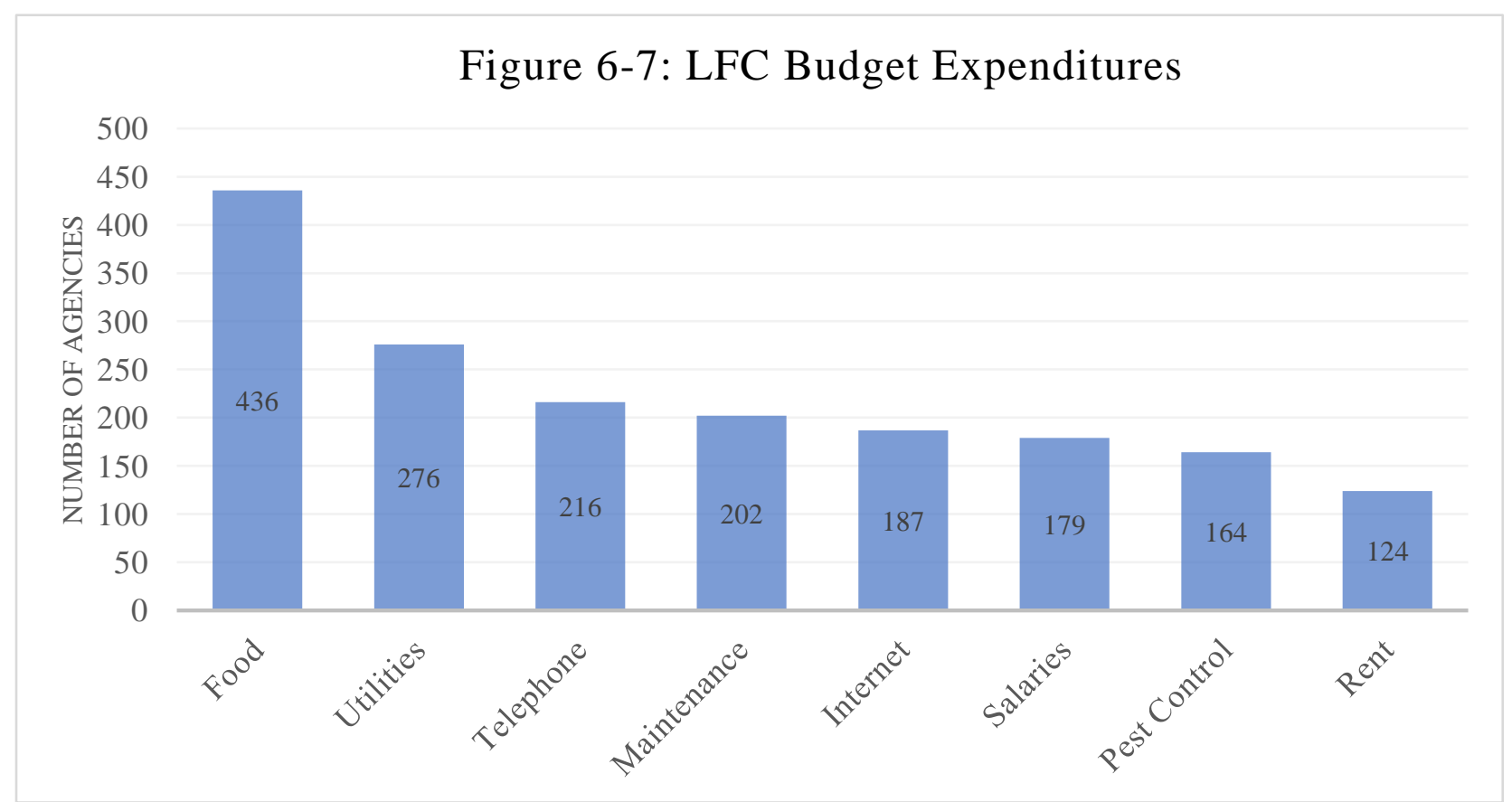

$\$ 15,000$, money that goes toward the costs of sourcing, processing and delivering food donations from the food bank but also toward supplementary food purchases, electric, gas, water, rent and staff salaries (Figure 6-7).

LFCs are highly creative in coming up with strategies to raise money through mailings, special event fundraisers, thrift stores or other parallel revenue generating activities. Yet differences across the network are quite stark here as well, in terms of professionalization, the sources of funding and the strategies used to generate revenue (Table 6-1). 
Table 6-1: LFC Operating Capacity

\begin{tabular}{|c|c|c|}
\hline \multicolumn{3}{|c|}{ Professionalization } \\
\hline Written Budget & 183 & $42 \%$ \\
\hline Fundraising Plan & 50 & $12 \%$ \\
\hline \multicolumn{3}{|c|}{ Funding Sources } \\
\hline Church Donations & 333 & $77 \%$ \\
\hline Individual Donations & 332 & $77 \%$ \\
\hline Grant Funding & 192 & $45 \%$ \\
\hline Client Fees & 59 & $14 \%$ \\
\hline \multicolumn{3}{|c|}{ Fundraising Strategies } \\
\hline Income generating activities & 185 & $43 \%$ \\
\hline Personal Solicitations & 175 & $41 \%$ \\
\hline Direct Mailing & 77 & $18 \%$ \\
\hline Online Fundraising & 62 & $14 \%$ \\
\hline
\end{tabular}

Key differences also emerge when budgets and funding sources are analyzed together.

First, $50 \%$ of agencies operate on less than $\$ 5,000$ per year while nearly $20 \%$ have more than $\$ 100,000$ to develop programing (figure 6-8). The latter are usually providers of other social services such as community centers, senior homes or shelters, though a few well-endowed standalone emergency food programs also operate on large budgets. The disparity in resources is matched by the degree of professionalization of these agencies.

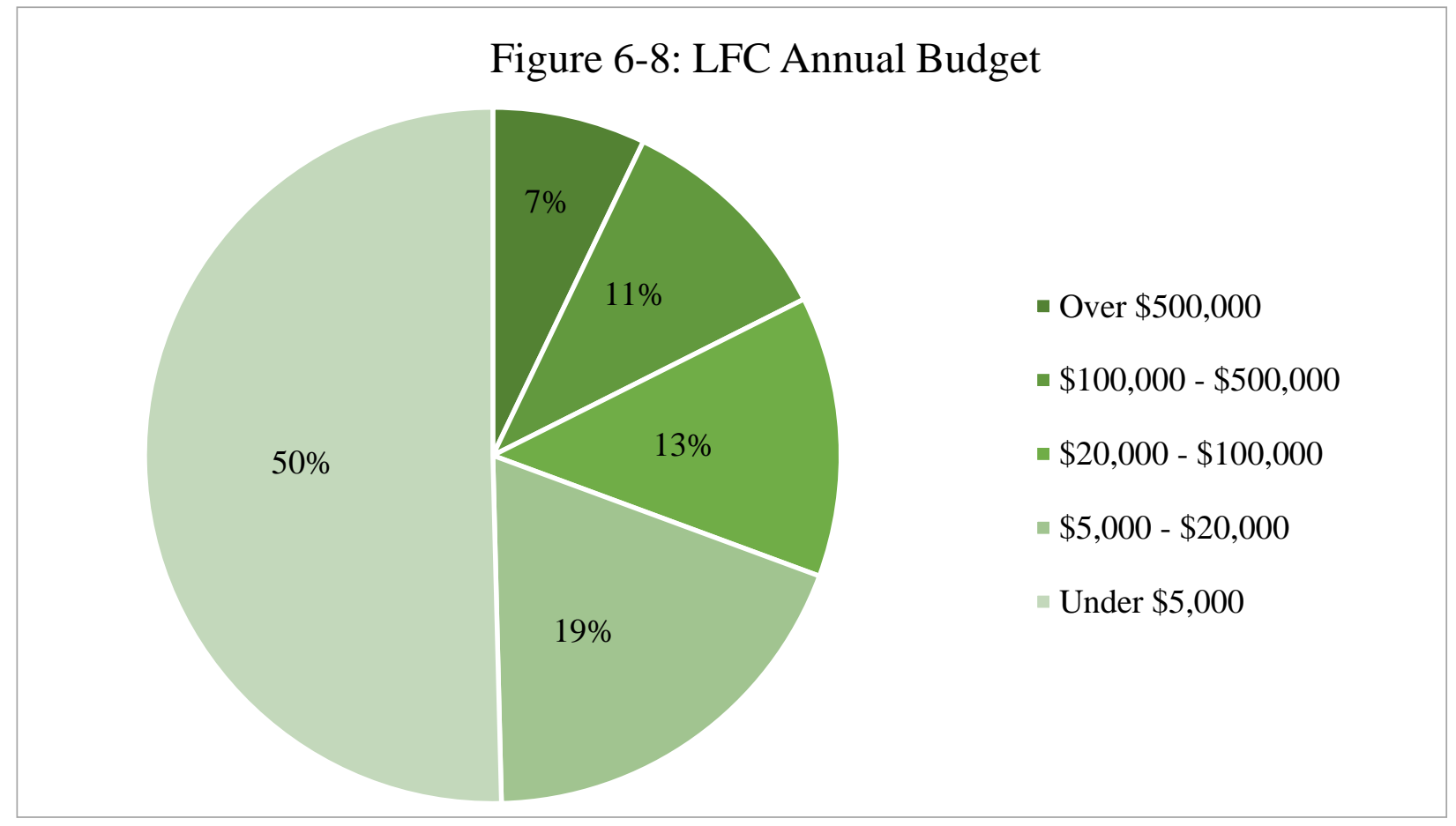


Figure 6-9 visualizes the ratio of LFC funding sources in West Virginia for each LFC revealing the level of dependency of the food banking economy in the state on faith-based alms. Considering the majority of LFCs are housed in or directly affiliated with a church, it is not surprising that $17 \%$ of them are completely dependent on funds from their local congregations. Nearly a third is over $80 \%$ dependent on their local church. As this dependency declines for LFCs, individual donors are the next largest group filling the budgetary void, followed by grants and client fees. Grant awards and client fees are a good indicator of the level of professionalization of individual LFCs, and here too there is significant variation in the overall funding mix.

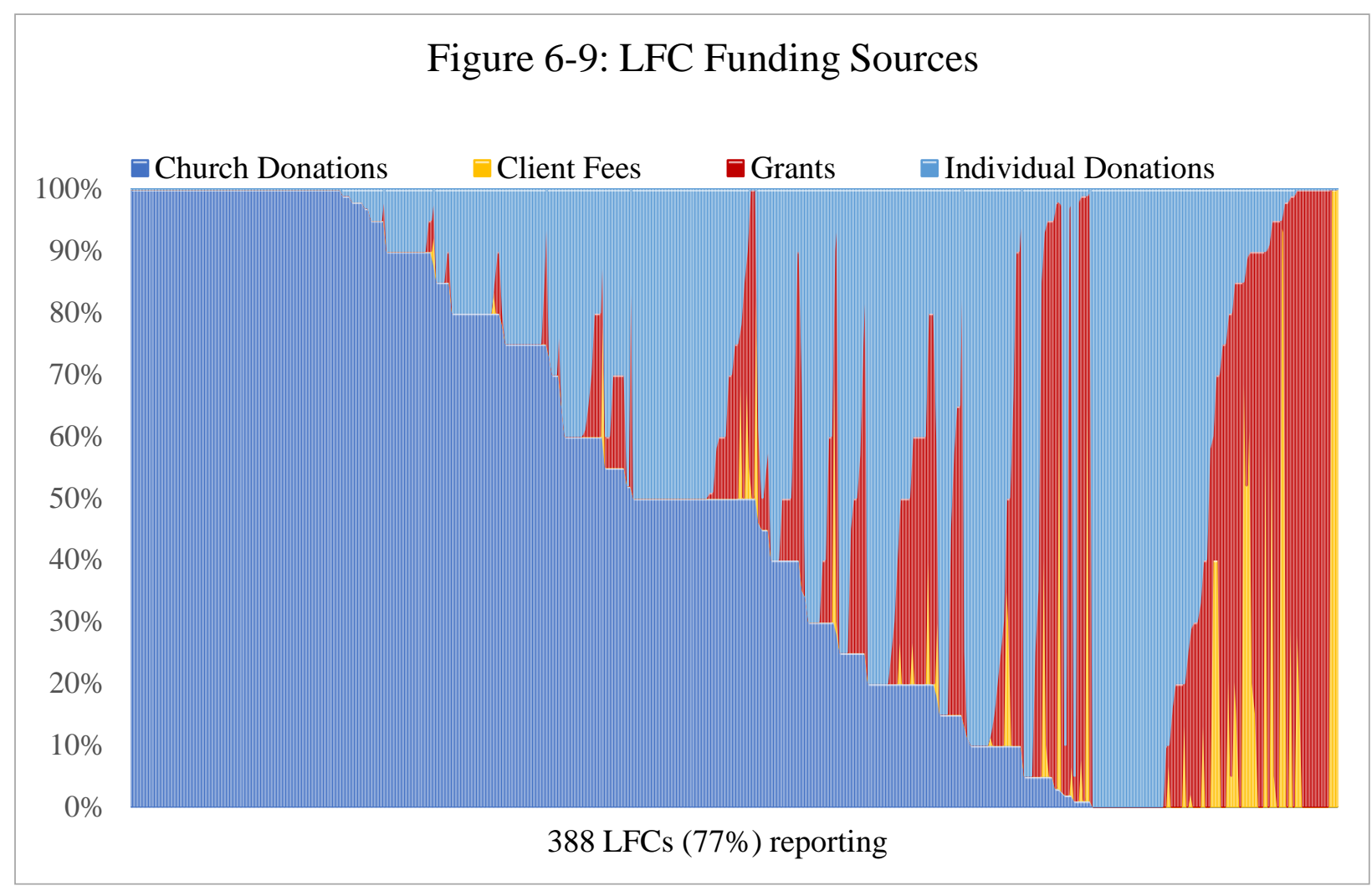

Food banks are not directly involved in fundraising efforts at the local level. Through their yearly agency relations meetings however, they do offer training and assistance for their LFCs in this area. At the MFB Hunger Summit that brings LFC members together over two days every year for example, there are conference sessions on fundraising strategies, grant writing, marketing, 
effective story-telling and administrative best practices. In these sessions LFCs are encouraged to diversify their funding strategies and learn to create budgets and strategic plans that will assist them in securing funding from outside organizations to project and maintain the long-term viability of their organization. Still the struggle to maintain funding is an important one considering nearly a quarter of food bank budgets rely on cost share fees from these local agencies. If local donations decline it becomes significantly more complicated for food banks to fund the trucks delivering industrial food waste across the state.

\section{Physical Infrastructure}

LFC infrastructure is expanding alongside the growth of the food banking economy. This expansion however is happening unevenly (Table 6-2) based on the LFC financial capacity and the ability of LFC directors to solicit funds for new equipment.

\section{Table 6-2: LFC Infrastructure}

\begin{tabular}{|c|c|c|}
\hline \multicolumn{3}{|c|}{ Storage } \\
\hline Refrigeration & 402 & $79 \%$ \\
\hline Extra cold storage capacity & 181 & $45 \%$ \\
\hline \multicolumn{3}{|c|}{ Communication Access } \\
\hline Telephone & 384 & $76 \%$ \\
\hline Internet & 321 & $63 \%$ \\
\hline Fax & 266 & $52 \%$ \\
\hline \multicolumn{3}{|c|}{ Vehicles Access } \\
\hline Pickup Truck & 327 & $64 \%$ \\
\hline Car/SUV & 244 & $48 \%$ \\
\hline Van & 236 & $47 \%$ \\
\hline Large Truck & 117 & $23 \%$ \\
\hline Refrigerated Truck & 13 & $3 \%$ \\
\hline
\end{tabular}

Food storage is the first important differentiating factor. While most have some form of refrigeration the amount of cold-storage space varies tremendously from site to site. The survey used to collect this data did not ask LFCs to specify the amount of space each had available, but $55 \%$ indicated that they were currently operating at full capacity, unable to accept more frozen and 
perishable goods than they already were. Field observation confirmed major differences in storage capacity, both in terms of dry space shelving and refrigeration. Some LFCs have large walk-in coolers and multiple chest freezers, although most operate using household refrigerators. Refrigeration capacity is a growing concern for food banks as more and more of the product that they receive, particularly from retailer donors, is perishable. A food bank director related the quandary of tooling up for increased food flows even as her network of LFCs was not necessarily equipped to accept it all.

"We just got a grant for another refrigerator which is great because our produce and fresh product donations are really taking off. The problem is we could get perishables all day long, but we have to make sure that our network is efficient and ready to take it too." (FB$1,5.14 .14)$

Grants for LFC infrastructure upgrades are limited as funders shy away from directly funding assets, preferring to sponsor programmatic initiatives with measurable impact. Money for infrastructure must then be solicited from local sources or be integrated within some broader programmatic budget narratives, again a practice that requires a degree of grant writing acumen that many LFC directors simply do not have. Many food pantries without refrigeration at all are left behind by their inability to accept perishables. All LFCs accepting TEFAP foods must be equipped with cold storage and thermometers to monitor food temperatures and can be inspected by the food bank and the state to ensure that they meet these standards. LFCs enrolled in agency enabled pickups from FA retailers must also have enough capacity to accept variable flows of food and receive initial certification from the food bank that they meet adequate food safety standards. Still, there are times when these agencies are flooded with product from retailers that they do not have the space to store. A large load of frozen meats for example must be distributed immediately if the LFC is not fully equipped to handle the influx. 
"Sometimes pickups are a lot, and other times it's not that much it's just kind of random. When it's a lot, like the other day when Walmart donated 600 pounds of produce at once, we have 2 pantries in the county that are open 5 days a week so we spread it out and you know rumor spreads quick. People bring their families and friends, we usually always get rid of it." (PO-5.18.15)

Differential access to technology is another important factor along charitable food supply chains in West Virginia. Professionalized food banks are adapting to the rapid pace of $21^{\text {st }}$ century enterprises including just-in-time inventory management systems and electronic ordering and billing. These technological changes however are not always taken up as quickly by LFCs, many of which still prefer to operate using the paper-based systems that they set up years ago. Furthermore, many parts of rural West Virginia still lack broadband access and as of $201637 \%$ of LFCs did not have an internet connection on site. When technology is available, accessing the food bank's ordering system is not always straightforward especially for users that are not familiar with database management software. While it does provide network efficiencies and significant cost savings for food banks, technological integration also comes at the cost of leaving some LFCs behind.

"Communication is an issue. A lot of [LFCs] do not have the internet, we cannot just blast an email with information out to them, and it takes way too long to call. Plus, doing a mailing isn't cheap. A lot of them have the internet but refuse to use it. They are elderly, and they just don't want to do it. Not answering their phones... so actually getting the communication out is difficult, let alone training them on an ordering system." (FB-1: 5.14.14)

Over the course of my fieldwork MFB and FHFB both transitioned to the online Primarius Web Window. They provided trainings at agency relations meetings as they rolled out the transition to the new system with the hopes of leaving time consuming paperwork behind entirely. Each LFC now has a unique identifier and must log-on to the system to order food and provide reports. At the FHFB presentation the agency relations coordinator encouraged his agencies to use 
the new tools, with the implicit threat that if they did not adapt soon it would become very difficult to maintain a relationship with the food bank in the future.

"The new ordering system is here and as of today all of the food is live, meaning what you see on there is pretty much what we have on the warehouse floor. Everything is in there from the time your relationship with us began. You can go in and see all your past order invoices. You can see your upcoming USDA allocations now too, and if you pick up from Walmart or other stores you can submit your poundage reports right in here. This is going to make everyone's life easier. If you have capacity to do this please do it, paper slows me down from doing the other capacity building work that I need be doing with you all" (PO11.20.15)

LFC reaction to the online ordering system has been mixed, but most have caught on to the concept and made due with the new reality. Younger volunteers often provide the technological know-how to input data, and in places where pantries are out of reach of mobile and broadband networks, orders and reporting take place from home or another place where internet is accessible.

Finally, access to transportation is another important differentiating factor for LFCs. Most agencies pick-up food from a central food bank drop off point in their county, and must bring private vehicles to transport their monthly food orders back to their feeding sites. Few food pantries own vehicles outright but rather depend on the personal cars, vans and trucks of their volunteers to haul their load back to their feeding sites. Vehicle access is also increasingly important for agencies that are empowered to pick up food on behalf of the food bank at their FA affiliated retailers. A small fraction of LFCs have refrigerated trucking capacity. Those that do not must purchase coolers and thermal blankets to ensure that products that they pick up, much of which is perishable, stay cold on their way back to their food pantries. This is another cost that is differentiating LFCs along lines of institutional capacity, further segmenting the network between LFCs that can absorb increasing amounts of food waste and those that have reached the infrastructural limits. 


\section{Ideologies}

The final barrier confronting the food banking fix at the local level are the differentiated political ideologies of LFCs. As noted above, the moral impulses that drive actors across the network emanate from the differing philosophies that prompt volunteers to participate in charitable food programming. On one end of the spectrum are those that understand hunger as a structural problem borne out of economic inequality including low wages, rising cost of living, unemployment, debt, disinvestment, lack of transportation etc. On the other end are those that understand hunger as a result of an endemic culture of poverty that must be reformed and are often explicit about their hope to change the behavior of the people they serve.

This latter perspective frames many emergency food recipients as "free-loaders", whose laziness, addiction problems, or lack of education lead them to take advantage of charitable food rather than becoming productive citizens. "The spirit of the devil is in the food pantry" claimed one LFC director, recounting some of the conflicts that arose when volunteers took food not allocated to them and the "double dipping" or "pantry hopping" strategy of soliciting different LFCs in the same month to access free food, a practice perceived by many within the network as unethical. Others do not approach this behavior in the same way. In the same meeting where this LFC director identified individual greed as a problem her agency needed to confront, another retorted: "I feed anyone who walks through my door no questions asked and trust that there will be more food tomorrow, and you know what, there always is!" (PO-4: 5.1.2015).

Within the extremities of these two stances are various interpretations of the politics and policies shaping access to food more broadly including welfare entitlements, real or perceived corruption, resource distribution, physical and mental health. The result of these differing ideologies and programmatic perspectives is that LFCs have a diverse set of rules informing access 
to the foods that they distribute, different pre-requisites to which clients must conform to demonstrate that they are worthy of care. Often the ideologies are spatially reinforced as LFC coalitions form to govern their areas and ensure that people are not "taking advantage of the system". Ideologies of feeding are also informed, though not directly correlated to the labor, budget and infrastructure capacities that I outlined above. LFCs with limited resources often operate based on fears of food shortages, a paradox considering the growing amount of food waste available for distribution from both the federal government and the corporate sector. This scarcity mindset is carried out through LFC hours of operation and service frequency limits (e.g. how many times a household is permitted to solicit food), and the oft arbitrary delineation of LFC service boundaries. Figure 6-10 maps differential access to charitable food resources across the state.

From a food banking perspective, the ideologies underlying food access pre-requisites are one of the most frustrating barriers they face at the local level. With so much food to push out, and increased perishability concerns, the idea that LFCs would limit their distribution frequency or increase the requirements to access this food is antithetical to their mission. Yet because LFCs are independent organizations there is little that food banks can do to overcome these limitations, save sending a mobile food pantry unit, or working with agencies in the area that do not impose as strict eligibility criteria. When agencies mobilize as a coalition to limit access through third-party referrals these dynamics become even more strenuous. I briefly outline and contextualize the four main charitable food access barriers faced by food insecure households at the local level below. These include service frequency, access frequency, geographic location and client pre-requisites. 


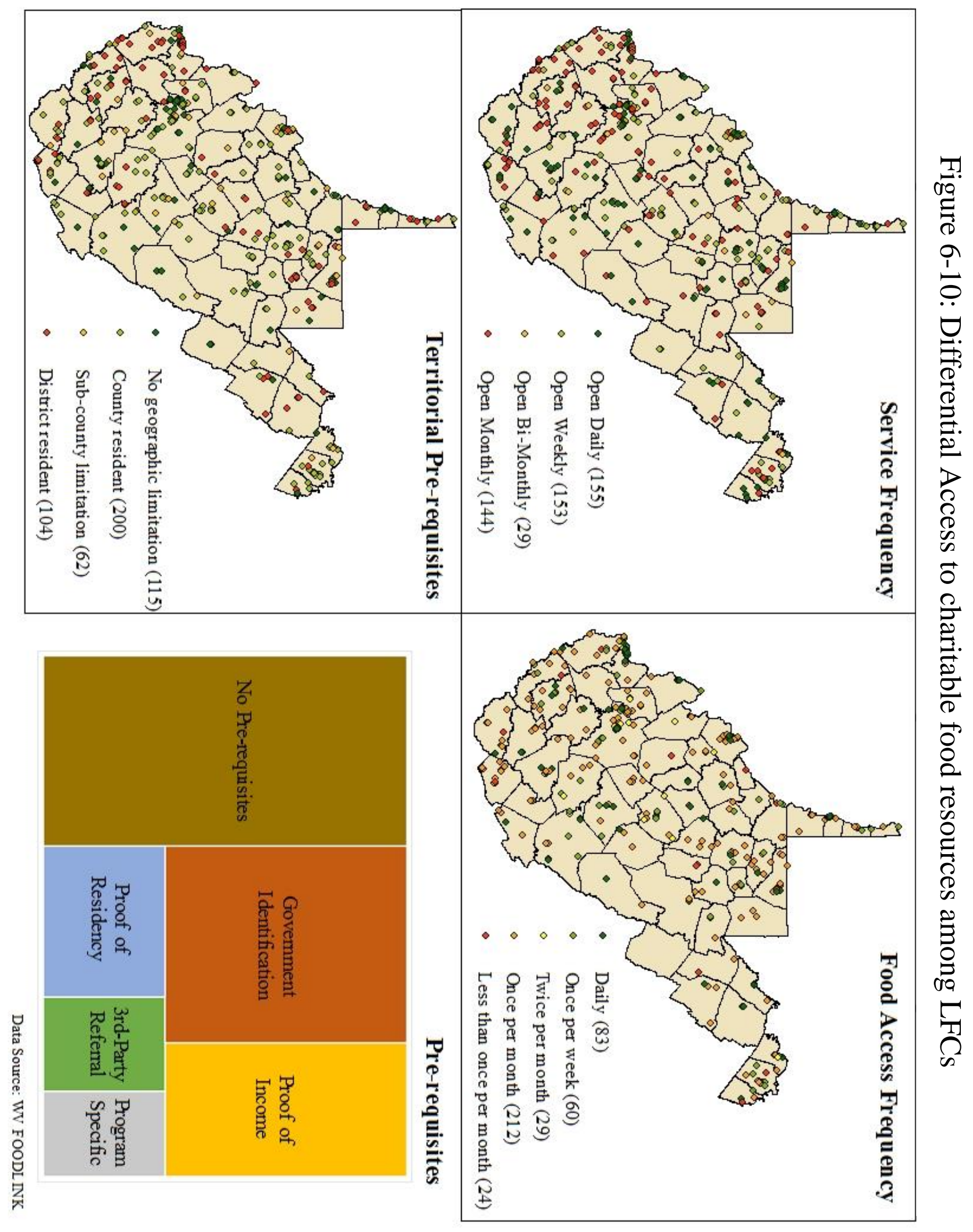




\section{a. Service Frequency}

LFC operating frequency is a critical barrier to expanding the amount of product food banks can distribute. This barrier is increasingly relevant as their operations evolve toward logistics that require rapid product turnover and just-in-time deliveries that match manufacturing and retail donor supply chain shifts (chapter 3). LFC operating times in West Virginia are segmented somewhat evenly. A third are open daily, a third are open weekly, and a third are only open once

or twice a month. Service frequency does not necessarily correlate to the amount of product an LFC distributes, in fact there are many LFCs only open once a month that process over 50,000 pounds of food bank product a year, well above the state median. Yet as the overall food mix evolves from shelf stable to fresh foods, these temporal limitations reduce the number of LFC outlets where time sensitive perishable product can be delivered. The mobile food pantry is a response to this barrier. LFCs empowered to pick-up food from local retailers are also those that have at least weekly operating hours, in fact retailers usually expect agencies to pick up donated product 2 to 3 times a week.

\section{b. Access Frequency}

Most LFCs only allow their clients to access food once a month, some even less. There are various systems in place to monitor these access rules. They are usually in place at the LFC level where folders of all clients track the frequency of visits. TEFAP pantries are mandated to track households accessing federal commodities and the rules at the state recently changed to suggest that LFCs should make efforts to ensure that households only access TEFAP once per month. This is a new rule as of 2017 and has created significant confusion for LFCs that were distributing TEFAP foods more frequently. In other instances, access frequency is determined by a third-party. The most illustrative case in the state is Information and Referral (I\&R) in Huntington. I\&R was 
founded in 1976 as a central clearinghouse for sharing information about clients who access social services in Cabell and Wayne counties. Housed on the third floor of the Huntington public library, any person wishing to access emergency food services in those two counties must first meet with a case manager at I\&R who provides "continuum of care" services and ensures that people are not taking advantage of charitable food (or other social service) resources. I\&R's founding narrative speaks to some of the entrenched ideologies surrounding emergency food relief in West Virginia:

I\&R was started by a group of agencies that felt there needed to be a central database so that the same person didn't go all over town with the same story and take a whole lot of resources. We had one woman who was more clever than perhaps honest who had a bunch of children and she put them in a bunch of houses that were vacant around town and wound up with about 14 Thanksgiving baskets. And the community went 'wait, let's see what we can do about this', so I\&R was created to be a screening house to be sure that everyone that needed it got a fair share."

When someone arrives at I\&R in need of emergency food resources, they receive a slip that refers them to the LFC that is next on their list to receive food. Some pantries have acquired reputations for not providing as much or as high-quality foods as others. An I\&R case worker recounted how he once had a client who begged him not to assign him to the pantry next on the list because he had had a bad service experience there, but that he could not accommodate his request because the rules are to evenly distribute clients across LFCs in the county.

The perceived need to monitor people taking advantage of free food resources is a recurrent theme in different parts of the state. Many LFC directors are concerned that people taking advantage of the system will deplete resources for those who are "truly hungry". For food banks flooded with donated food resources working to meet increasing distribution targets every year the contradiction is frustrating.

"We've struggled with these agencies that request so much information or referrals. We have people who will only distribute every 90 days, but they are ordering food from us every month. If you're doing that you're violating your agreement from us, and I'm going to kick you out if you don't do what you're saying!" 
When the issue of double dipping came up again in the context of USDA rules at MFB Hunger Summit's TEFAP session, the agency relations coordinator summed up his food bank's stance on the limitations imposed on giving food out to people:

Listen, I've been with the foodbank 20 years and I cannot recall one time in 20 years that a pantry has gotten in trouble for feeding somebody. Now if you are a TEFAP pantry you can get in trouble for not feeding somebody, so please if there is need then just fill it.

\section{c. Geographic pre-requisites}

LFCs also place different spatial limitations on people accessing food. Approximately $20 \%$ have no service area boundaries and will serve anyone regardless of their home address. TEFAP pantries are only permitted to distribute food to West Virginia residents, and a previous rule limited their distribution to county residents. Although this rule has recently changed with a new administration at WVDA, this institutional legacy continues to inform many LFC service areas. Nearly half of all agencies serve people with proof of address in their county of operations, while another third have even stricter geographic limitations based on sub-county borders or even neighborhoods. Here again coalitions of food pantries often coordinate service areas across an area. The Wood county emergency food co-op for example organizes LFCs to serve only clients with a proof of address in a specific neighborhood (Figure 6-11). The co-op is another expression of LFCs working to limit people taking advantage of the charitable food system, but in this instance, it takes on an explicit spatial form limiting access to the district level. While this is by no means the norm across the state, urban centers tend to have tighter access rules than rural parts of the state. 
Differentiated feeding ideologies at the county scale may also be contingent on the level of food and funding resources in a given county. In Monongalia county for example, one of the wealthiest in the state, the city of Morgantown does not have stringent geographic access barriers. The city in fact has developed a reputation in the state for being a place that is very easy to access free food. In conversations with food insecure people that have experienced emergency food access barriers in other parts of the state or country many expressed that the LFCs in Morgantown were less draconian than elsewhere. There are also LFC coalitions that exist not to limit access to foods but rather to expand the number of resources available to them for distribution. Food for Preston is one such initiative, where coordination among LFCs through a part-time staff member Figure 6-11: Wood County Emergency Food Co-Op district service boundaries

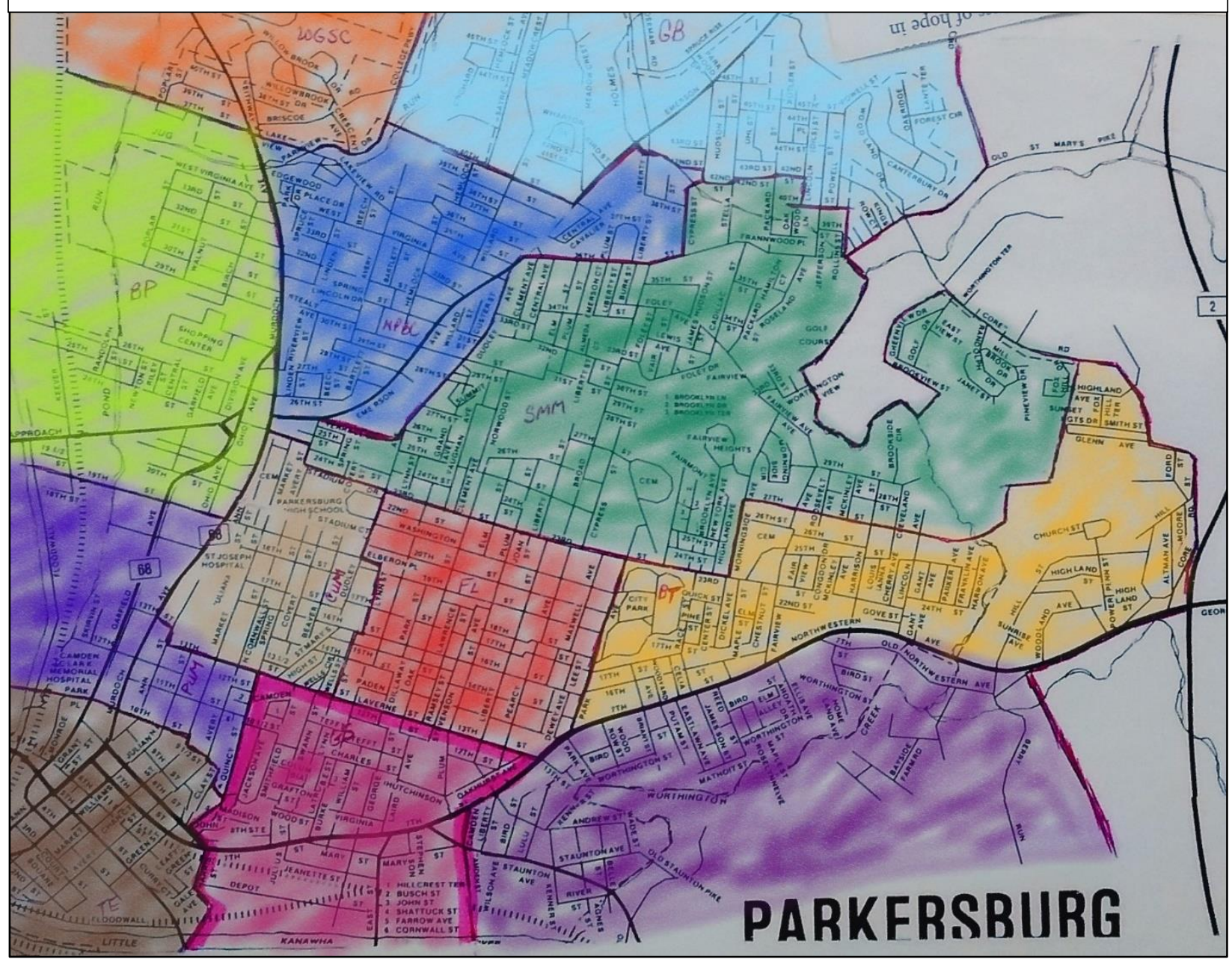


administering a separate non-profit organization to coordinate anti-hunger initiatives across the county has increased the financial resources available to LFCs and coordinated food sourcing strategies among them.

\section{d. Client pre-requisites}

The final barrier to emergency food access across the state of West Virginia are client prerequisites set up by individual food pantries ${ }^{41}$. Third-party referrals and place of residence have been reviewed above. Pantries also often require a combination of different information from people to determine their eligibility to receive food. These include government identification, current proof of address (utility bill, rent receipt etc.), social security numbers, proof of income, registration paperwork, or participation in a religious service. The arbitrary rules surrounding LFC pre-requisite determinations is a constant source of tension and frustration for food banks. The distribution of TEFAP foods is contingent on household income and West Virginia residency requirements. However, the current WVDA rules state that these must be "self-declared", and that in no instance should an LFC require people requesting federal foods to show proof of need or identification. While USDA foods were once limited to specific county residents, they are now available to anyone from within the state, a fact that is having trouble settling in with pantry directors who are used to turning away people that are not from their counties. Furthermore, in absolutely no instance are LFCs to proselytize or pressure clients to partake in religious practices. The WVDA TEFAP coordinator made this explicit in an FHFB agency training meeting:

"We don't police these people. Do they take advantage? Yes. It's not your problem. [...] TEFAP foods belongs to the USDA, it's not your food, it's the federal government's. Also, we appreciate that you are churches and you work hard, but no prayer, you can't bless the government food! If you must pray, or sing a hymn before, during or after distribution,

\footnotetext{
${ }^{41}$ This is almost exclusively a food pantry phenomenon. Congregate meal programs are usually open to anyone, or have very specific populations that they serve. Similarly backpack programs have pre-identified children receiving their donations.
} 
which I do not encourage you to do, you must let people know that they don't have to participate. Plaster it with large posters on the wall." (PO-11.20.15)

Many food pantries do not follow these USDA rules, and the monitoring and enforcement capacity at the state or food bank level is limited because they do not have agents at every distribution site, on each distribution day. There have been LFCs that were cut off from TEFAP for failing to uphold civil rights regulations after a client complaint or a USDA audit, yet this is rare. LFC pre-requisites are further complicated by the fact that any foods sourced from private channels, including FA donations, do not have any specific access regulations tied to them, and LFCs will often use their private stocks to limit access to people without the documentation that they require. In another TEFAP training event an agency relations coordinator made this nuance clear for LFCs frustrated with their lack of ability to monitor clients requesting federal commodities:

"There are a lot of other pantries that do things besides USDA. Are they still able to ask for income? Yes, if they have another program they ask that for, they can still do food bank things, just not USDA commodities so keep in mind, I want to stress that we're only talking USDA foods here, you have much more leeway with the other stuff" (PO-18: 8.8.17)

There are of course many food pantries that have very lenient pre-requisite requirements, some even have none serving anyone coming to them for assistance. The vast differences among LFCs eligibility determinations is another reflection of the diversity of ideologies informing the work of feeding the hungry through charity. While some set up strict guidelines to determine whom is worthy of care, or have ulterior motivations to rectify perceived deviant behavior, others are working to counter these ideas by using their LFCs as a vehicle to pass through as many food resources as possible through their communities. Food banks of course prefer working with the latter as they are also usually the LFCs that tend to be easiest to work with in terms of delivering food resources and meeting their mandated food distribution targets. 


\section{Discussion}

In the nearly 40 years since the Reagan administration first released government cheese and set in motion the institutional scaffold of the contemporary food banking economy (chapter 3), some well-endowed LFCs have gained assets and political power across a fractured social service landscape, even as others struggle to stay afloat. Pine (2016) argues that "size, culture, theory of change, local political culture, and market forces all play a role in determining the form in which organizations in the civic sector engage in the problem of food insecurity" (p.8). Differentiated capitalization across the HFN provides some actors within this anti-hunger assemblage more power to shape practices and discourse than others. The largest food charity in the country is FA, who in turn empowers MFB and FHFB, the two largest food charities in the state, to order the food banking economy in West Virginia.

My review of the geography of LFCs in West Virginia reinforces the idea that these grassroots agencies are the "fragile frontline of nutrition for the poor" (Miewald and McCann, 2014, p.552). They play an important role as cultural producers and social anchors in their communities (McCutcheon, 2015) yet most fail to appreciate their role at the extremities of the vast food waste revaluation network I presented in the previous three chapters. Rather than reflect on the place of their work in the wider food system, their energies are focused on serving, reforming or even disciplining people in crisis through their charitable enterprise.

My state-wide case study demonstrates that research on charitable anti-hunger programming should account for both material and ideological differences among LFCs and the institutional contexts within which they operate their feeding programs. Quantitative data analysis paired with qualitative field observations revealed how differences in program types and cultures including the labor, financial and infrastructure capacities of each LFC, significantly affects the 
work of industrial food waste recovery and redistribution at the food bank scale. Anti-hunger practices at the local scale are also spatially contingent as regional coalitions form to organize and govern the politics of feeding in their locales differently. Highly differentiated food access parameters among LFCs, often reflect opposing ideologies with regards to caring for the poor, creating additional barriers for food banks working to distribute increasing amounts of food waste throughout their territories.

As civil society becomes enrolled into the state and shadow state governing apparatuses, the social construction, and social function of charitable food organizations is adapting to institutional pressures at these different scales. The process is not unfolding smoothly however and the key finding from this chapter is that the local scale is currently the most significant impediment to the rollout of the food banking fix. The food bank scale, governed by FA and the USDA, focuses heavily on commodities and product sourcing, on logistics, on accounting, in sum on ordering food excesses and placing them based on needs defined at the national level. The physical need to move recovered food waste across space is having a material and ideological effect on the HFN, shaping the hegemonic contest over the food banking fix. As the volume of donated food expands, LFC capacity to absorb it all varies from place to place and thus complicates the potential for the food bank fix to revalue food waste on behalf of large agro-food concerns.

Uneven development also significantly impacts the potential for food banks to enroll their LFCs into a logic that conforms with institutional mandates driven by FA and to a lesser extent the USDA. As a response, the two food banks have begun to segment their agencies along lines of institutional capacity, a process that is beginning to inform their long-term strategic planning. The mobile food pantry is also a response to local brick and mortar limitations as are agency enabled retail pick-ups. In the following chapter I argue that strategies to overcome local barriers to food 
waste revaluation are re-organizing the network to adapt to institutional demands from above, grinding the gears of charitable food relief and producing conflicts that are rarely associated with the growing power of the corporate food regime over food provisioning, emergency or otherwise. 


\section{Chapter 7: Overcoming Barriers The Spatial Strategies of the Food Bank Fix}

\section{I. $\quad$ Introduction}

In July 2014, 200 people gathered on the parking lot of the Free Will Baptist Church in Parsley Bottom West Virginia to wait for the arrival of the food truck. Stocked a couple hours away at the Facing Hunger Food Bank (FHFB) in Huntington, the truck carried pallets of USDA commodities including frozen blueberries and poultry supplemented by a bulk unsorted load of cakes, breads, cereals, canned soups, spotted bananas, unshucked corn and multi-vitamins recovered from a Walmart superstore. Most of these foods were either damaged or nearing expiration. As volunteers rushed to recycle and ration these discards for those waiting on their portion, others ordered the line, assigning numbers to each person after they provided information about income and household size. Within two hours each family received an allocation of free food.

After the crowds dispersed, staff and volunteers stayed behind to clean up, share pizza and exchange stories about their work feeding the hungry. The puzzling scene was akin to one I imagined might unfold in refugee camps and disaster zones, not one I expected to be so normalized in rural America. Food giveaways like these however are now common practice across the country, known in food banking circles as "mobile food pantries". As the two regional food banks in West Virginia work to meet the growing demands placed on them to repurpose unsalable foods they are increasingly using this form of direct food distribution. The food truck was in Parsley Bottom that day because FHFB was struggling to meet distribution goals in Mingo county, one of 17 counties within its 4,500-mile service area. Mingo was "in the red" that month (Figure 7-1), well below the pounds per person in poverty (PPIP) ratio used at the time to measure the effectiveness of the food 
bank's hunger relief efforts. This food drop was meant to improve those numbers, distribute more food in the county and maintain compliance with Feeding America (FA) the national affiliate that provides its member food banks with access to food donations, funding and marketing opportunities (chapter 4).

\begin{tabular}{|c|c|c|c|c|c|c|c|c|c|c|c|c|c|c|c|}
\hline & & & Figu & re $7-1: \mathrm{F}$ & Feeding & Ame & ica C & Com & liance & Repo1 & & & & & \\
\hline & & & & & & & & & & xtenuatin & $g$ Circ & umstances & & & \\
\hline County Name & $\begin{array}{l}\overline{\bar{z}} \\
\frac{0}{\rho} \\
\frac{\rho}{2}\end{array}$ & 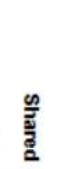 & 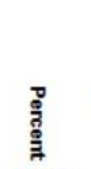 & $\begin{array}{r}\text { Total Pounds } \\
\text { Distributed } \\
\text { to County }\end{array}$ & $\begin{array}{r}2010 \\
\text { Persons In } \\
\text { Poverty }\end{array}$ & PPIP & $\begin{array}{r}\% \text { of } \\
\text { Median }\end{array}$ & 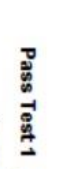 & $\begin{array}{c}\text { Pounds } \\
\text { growth } \\
\text { Year } 1\end{array}$ & $\begin{array}{r}\text { Pounds } \\
\text { growth } \\
\text { Year } 2\end{array}$ & 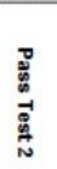 & $\begin{array}{r}\text { PPIP } \\
\text { w/USDA } \\
\text { outside } \\
\text { SA } \\
\text { (Test 3B) }\end{array}$ & 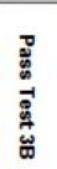 & $\begin{array}{r}\text { Extenuati } \\
\text { ng } \\
\text { Circumst } \\
\text { ance } \\
\text { Present } \\
\text { (Test 3C) }\end{array}$ & ฏ \\
\hline$\overline{B O Y D, K Y}$ & & No & $100.0 \%$ & 418,498 & 8,454 & 49.50 & $65.00 \%$ & Yes & $-45,809$ & 77,351 & No & 49.50 & Yes & No & \\
\hline GREENUP, KY & & No & $100.0 \%$ & 356,157 & 5,443 . & 65.43 & $85.00 \%$ & Yes & 107,470 & 102,356 & Yes & 65.43 & Yes & No & \\
\hline LAWRENCE, KY & & No & $100.0 \%$ & 105,897 & 3,812 . & 27.78 & $36.00 \%$ & No & 89,865 & 16,032 & Yes & 40.81 & Yes & No & \\
\hline MARTIN, KY & & Split & $50.0 \%$ & 46,889 & 2,116 & 22.16 & $29.00 \%$ & No & 5,930 & $-8,295$ & No & 22.16 & No & No & \\
\hline LAWRENCE, OH & & No & $100.0 \%$ & 204,378 & 12,034 & 16.98 & $22.00 \%$ & No & $-41,248$ & 84,650 & No & 38.76 & Yes & No & \\
\hline CABELL, WV & & No & $100.0 \%$ & 924,463 & 19,253 . & 48.02 & $63.00 \%$ & Yes & $-114,975$ & $-79,975$ & No & 48.02 & Yes & No & \\
\hline LINCOLN, WV & & No & $100.0 \%$ & 165,521 & $5,788$. & 28.60 & $37.00 \%$ & No & $-104,906$ & 28,227 & No & 28.60 & No & No & \\
\hline LOGAN, WV & & No & $100.0 \%$ & 393,025 & 7,752 . & 50.70 & $66.00 \%$ & Yes & 79,818 & $-24,992$ & No & 50.70 & Yes & No & \\
\hline MASON, WV & & No & $100.0 \%$ & 208,435 & $4,998$. & 41.70 & $54.00 \%$ & Yes & $-51,761$ & 12,733 & No & 41.70 & Yes & No & \\
\hline MINGO, WV & & No & $100.0 \%$ & 174,254 & 5,775 & 30.17 & $39.00 \%$ & No & $-120,154$ & $-8,737$ & No & 30.17 & No & No & \\
\hline PUTNAM, WV & & No & $100.0 \%$ & 133,626 & 5,657 & 23.62 & $31.00 \%$ & No & $-133,996$ & 23,363 & No & 23.62 & No & No & \\
\hline WAYNE, WV & & No & $100.0 \%$ & 658,227 & 8,576 & 76.75 & $100.00 \%$ & Yes & 188,712 & 77,821 & Yes & 76.75 & Yes & No & \\
\hline Service Area Totals & & & & $3,789,370$ & 89,658 & 42.26 & $55.19 \%$ & Yes & $-141,054$ & 300,534 & Yes & 45.74 & Yes & No & \\
\hline
\end{tabular}

This food distribution was coordinated with the Parsley Bottom Food Pantry which has existed on site for 30 years. The large flat church parking lot was a perfect site to organize a food distribution in this rural mountainous county and the pantry director spearheaded the organization of the event with regional food bank staff. She worked to get the word out across Mingo county, recruit volunteers and even provided extra food to that day's event from her pantry food stocks. Food bank staff had underestimated the number of people that would turn out for free food and did not bring enough for everyone. Mobile food pantries typically boost food stocks for participating charities as sponsoring sites recuperate leftovers. In this case, what began as an expression of bountiful generosity, turned into an awkward exercise in food rationing, a development that did 
not go unnoticed by people waiting at the end of the line who received much smaller shares than those who had arrived first.

The mobile food pantry is a response to institutional pressures "from above", a fix to overcome spatial barriers imposed by traditional brick and mortar food charities, particularly in places where that local capacity is insufficient to meet the demand projected by FA under the updated Meals per Person in Need (MPIN) model. The local charitable food delivery infrastructure that emerged as an ad hoc response to entitlement failure cannot always keep up with the increasing volumes of food waste food banks receive to distribute as hunger relief. Strategies like mobile food pantries are reorganizing local feeding politics, opening new spaces of hunger relief and rearranging the grassroots economies of care that emerged to address food access failures in the 1980s and 1990s (chapter 5).

MPIN is a needs assessment that standardizes food distributions across space based on county level food insecurity rates. Food banks must place a targeted amount of food in each county, and report that distribution back to FA through quarterly poundage reports. Food banks that fail to regularly meet MPIN metrics can be put on probation. Without redress, they might lose their affiliation to FA entirely, along with all the benefits that accrue through that relationship (chapter 4). The FA compliance report speaks to some of the complexity of contemporary food banking under the intensification of FA's governance structure. Green counties are meeting their distribution quotas, while red counties are not. Yellow counties are shared service areas where USDA and FA territories overlap (chapter 5).

FA food banks have become sites of regulation and spatial control that ensure food waste recovery continues to be perceived as a solution to hunger. Institutions governing the shadow state are increasingly relying on spatial technologies to carry out their work, reorganizing the roles of 
state and civil society by producing knowledge and narratives that advance their agendas (Elwood, 2006). As a large parastatal institution (Warshawsky, 2010), FA makes hunger legible to its stakeholders by diluting social complexity into a calculable object of intervention, producing new meanings and political perceptions in the process. This spatial re-ordering also produces discrete territorial spaces that can be governed from a distance. (Scott, 1999, Mitchell, 2001, Hannah, 2009; Crampton, 2010).

In this chapter, I first describe the tools used by FA to implement the territorial ordering of its food banking network. There are two spatial models that FA uses to connect waste and want. The first is the Map the Meal Gap (MMG) study developed in 2010 to assess food insecurity rates at the county scale. The second is the internal Meals per Person in Need (MPIN) metric, that determines how much food should be placed in each county to fill the gap determined through MMG calculations. I argue that FA actively shapes a politics of knowledge that legitimizes the need for expanding charitable food distributions by compelling its member food banks to push out product and spread industrial food waste evenly across space in an effort to maintain quiescence for the ongoing rollout for the humanitarian food network (HFN).

I also analyze the relationship between the tools FA develops from its headquarters and the local realities of distributing increasing amounts of food waste across an HFN that is not fully equipped to absorb it all. FA frames its food insecurity measurements and interventions as hunger relief strategies, yet they must also be understood as governance mechanisms that forces a growthbased model on charitable food supply chains. By defining and shaping the need for food resources in different places, and then filling that need through donated foods that are locked into secondary circuits, FA further justifies the ongoing roll-out of a food banking economy that serves the interests of the corporate food regime at the expense of LFCs revaluing food waste. Specifically, 
I review the tensions between food quality and food quantity that pushing out corporate food waste produces at the local level and the strategies food banks use in an attempt to address demands emanating from above and from below.

\section{Territorializing Hunger Relief}

\section{A. Map the Meal Gap}

Since 2010 Feeding America has entrenched its position as a key player in the shadow state by releasing authoritative county level food insecurity statistics that are more detailed than the state's own measures. MMG is a web based geographic information system (GIS) that provides public information about food access gaps in every US county. The data available includes the number of food insecure households in each county, the number of food insecure children there, and the percentage of households that do not qualify for federal nutrition entitlement benefits because their income is over the means tested poverty threshold. The map provides a monetary figure that would be needed to close the access gap at the county, state and national levels. The map also provides the same information at the congressional district level, empowering antihunger activists with information to advocate for anti-hunger causes with their legislators. MMG lists every FA food bank and their service territories, helping people quickly identify which food bank serves their county of interest (Figure 7-2). It's important to note that the map does not include the LFCs ultimately distributing this food, a lacuna that erases a significant part of the charitable food supply chain, including the labor and funding and other local food resources ultimately sustaining the food banking economy from below. 


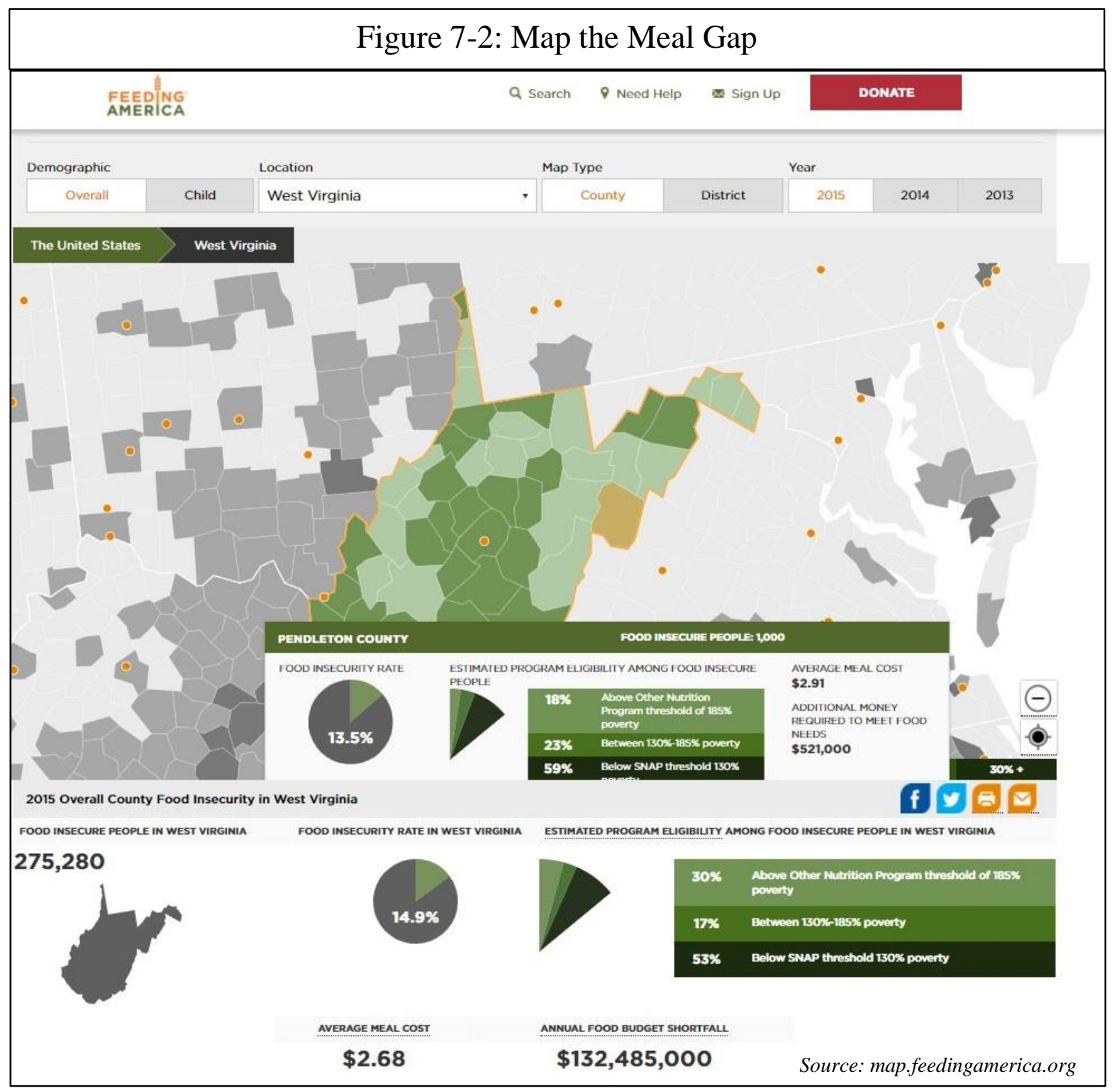

The omission of LFCs is likely also a practical concern since identifying the geographic coordinates of 60,000 volunteer agencies and the volumes of non-FA foods that they distribute would be very difficult. It would also reveal the spatial incoherence of the network as many counties are served by only a few charities, while others might have charities cluster in one place. Public attention on national and regional charitable responses aligned with FA governance 
structures give a privileged voice to large professionalized charities at the expense of local antihunger groups that do not have the funding nor technical expertise to provide counter mapping narratives (Elwood, 2006).

MMG is one of FA's signature studies commissioned to "equip food banks, partner agencies, policy-makers, business leaders, community activists, and concerned citizens with the tools needed to better understand the dynamics of food insecurity at the county level" (Gundersen et. al, 2014, p.385). Drawing from an expanded analysis of the Census Bureau's Current Population Survey (CPS) Core Food Security Model (CFSM), MMG enhances the USDA's food insecurity measurement by expanding the number of variables in the model to more closely align with empirically based social science contributors to food insecurity research. These include unemployment rates, poverty rates, median income, home ownership rates, and race (percent black and percent Hispanic) in a given county. MMG also draws from food pricing information collected by Nielsen to estimate the average meal cost in each county. The authors of the study admit that their coefficient estimates, based on a number of interpolated proxy data sources exclude some key variables and do not take into account local level efforts to reduce food insecurity. Still the assumed scientific rigor of the methodology, and the inherent power of maps to produce truths lends MMG significant rhetorical power (Monmonier, 1991; Pickles, 1994).

MMG displays the scope of the food insecurity problem in the United States, yet the narrative and solutions offered by this state of the art hunger calculator center on charity and the food banking economy, not on the wider structural issues that create the conditions for food access failure such as low wages, high housing and healthcare costs, inadequate pensions etc. MMG promotes the FA network, reifying the territorial frameworks within which FA food banks operate and mobilizing people to take actions that further justify and entrench a secondary charitable circuit 
to absorb the food waste generated by private firms. Beyond MMG's potency in shaping perceptions, public discourse and actions related to hunger relief, this cartography also has practical effects on the internal operations of the food banking economy, and the invisible LFCs ultimately working to raise funds and labor to "close the gap". I now turn to the Meals per Person in Need (MPIN) metric upon which each FA food bank is evaluated, a metric that is tightly linked to MMG.

\section{B. Meals per Person in Need (MPIN)}

The stated goal of MMG is to visualize food insecurity and compare the need for emergency food across space. However, the metric has also evolved into a supply side governance mechanism connecting food waste to specific places identified as needy. Shortly after MMG's deployment, FA began to contractually obligate its food banks to distribute a certain amount of food per person in poverty in each county. The delivery targets were based on US Census poverty estimates and the median food receipts for all FA food banks. This initial Pounds per Person in Poverty (PPIP) metric reorganized distribution patterns, especially for rural food banks with many counties. A food bank director in West Virginia who lived through the transition toward PPIP recounted the effects of data driven measures and new food distribution pressures on her operation:

In 2011 they put it in our contract and hammered us in 2012 over it. In the past we just moved food, you know this agency here is serving a lot of people they need a lot of food. [...] Now we can't let those people in Braxton county have the yoghurt we have to make sure it gets to Calhoun county. Ultimately our job is to get food to people but you've got Feeding America saying you have to get this much food to this place" (FB$2,6.19 .14)$

Every FA food bank submits a quarterly poundage report (QPR) detailing the amount of food distributed in each county categorized by source (TEFAP, donated and purchased). FA draws on those statements to publish an internal report listing the level of food distribution across each food bank territory. Counties that did not reach the minimum threshold are non-compliant, listed 
as red in the food bank's quarterly compliance report. A food bank with a red county is noncompliant, and if the situation is not rectified can lead to probation and eventually termination of their FA contract (chapter 4). This information is also shared across the FA Hungernet food bank intranet system, fostering a sense of competition and encouraging self-discipline across the network. Ensuring that each county remains "in the green" is now critical focus of each food bank director and their staff who must develop strategies to ensure that counties identified as needy at the national level receive the required food allotment for their organization to be deemed successful by their peers and corporate partners.

In 2014, along with the new member contract, FA implemented an enhanced measure to calculate food distributions at the county level named Meals per Person in Need (MPIN). MPIN is based, not on poverty rates, but on MMG food insecurity statistics. The concept of "missing meals" resonates with key stakeholders including the public, food donors, funders and legislators and is thus easily leveraged for anti-hunger advocacy work that FA is involved in. However, when the formula is unpacked, and the in-situ effects of this governance structure are analyzed, the seemingly tidy idea begins to reveal the intent behind the measure. "Meals" are accounted through the total pounds of food distributed divided by a pound to meal conversion factor of $1.2 \mathrm{lbs} . / \mathrm{meal}^{42}$. Meals may also be accrued through a demonstrated SNAP application assistance conducted or organized by a member food banks. It is important to note that the quality of foods distributed is not taken into consideration in the MPIN metric, only the quantity. To address this lacuna, FA developed yet another measure in 2012 named "foods to encourage" (F2E) which include broad categories of 13 product types that often meet the USDA 2010 Dietary Guidelines for Americans (DGA).

\footnotetext{
${ }^{42}$ The poundage to meal determination was derived from the USDA's 2010 What we Eat in America Study a dietary intake study conducted in partnership with the US Department of Health and Human Services.
} 
Many food bankers are puzzled by the idea that pounds of food could somehow turn into meals. A food bank employee from Texas that I met at a national conference expressed his bewilderment considering the product flow he and his team managed in their warehouse.

What I want to know is how those 1.2 pounds per meal is calculated. Because a truckload of onions cannot provide a meal, but is it counted as a meal? I've tried to write [FA] to see if they would try to manage types of foods in the calculation, but I haven't heard back. How can a pound of whatever equal a meal you know? (PO-3.6.17)

FA is using the MPIN metric to frame the success of its national hunger relief efforts among its corporate partners and other stakeholders even as it pushes a growth-based model on the charitable food infrastructure in the United States. The target number of pounds distributed in each county is based on the entire FA network's median food receipts for the previous year. As the amount of food donated to FA food banks across the country rises, so too does the requirement to increase the amount of food in each county, regardless of whether there is more food available in that particular food bank's service territory or not. (Figure 7-3)

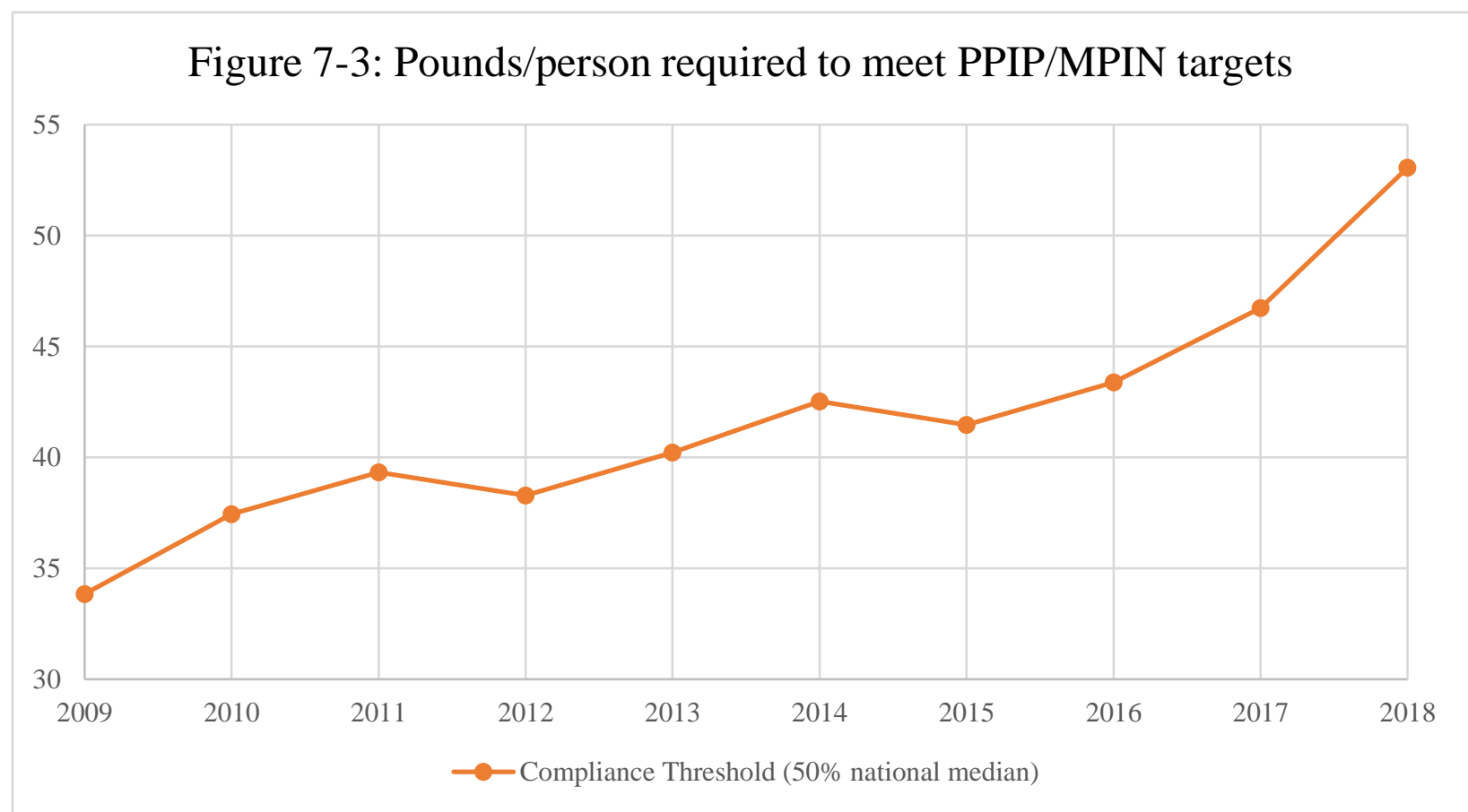


While many counties have no problem absorbing these increased amounts because there is a robust local charitable food infrastructure there, in other places it is much more difficult to meet MPIN targets, either because agencies are not ordering enough food, or there is not a history of resolving hunger through the FA sanctioned charitable food model. For rural food banks like WV, where there are fewer manufacturers, these rising metrics can also be problematic because they do not have the food waste abundance of many of their FA counterparts across the nation:

\begin{abstract}
"The train of thought for food bankers is really different between the urban and rural areas, the haves and have nots. It's easy for a food bank in Minneapolis to say: 'we need higher expectations because we have all this', but they are pushing all of us to meet higher targets. In rural Appalachia we don't have food manufacturers at all, while others have many." (FB-6: 7.18.16)
\end{abstract}

Over the past few years, the amount of food flowing through the food banking economy in West Virginia has increased significantly, but it is not always easy to keep up with distribution expectations at the county level. FA encourages its food banks to recruits agencies in places where there are deemed to be too few to absorb the required amount of food waste or, when there are no agencies available, to execute a mobile food pantry program that can bring their metrics up to compliance. These territorial pressures are not always understood by LFCs and can create conflict between food banks and the grassroots network that they depend on to move donated product.

The nutritional gaze that informs the metrology undergirding MMG and MPIN as an antihunger solution serves an organizational agenda with entrenched interests in the corporate food sector. The overt focus on linking people to pounds of donated food, rather than shaping public policy to address the root causes of food insecurity, draws civil society into food recovery efforts that do not question the historical failure of the food banking economy to address food access failures. The focus on food quantity as the solution to hunger in a food system that is already awash in product is highly problematic. The expert driven metrics make it appear as though progress is being made by measuring how much extra food is needed in a given place, and then filling that 
need. In practice however, it further reinforces the social distance between civil society actors pushing non-profits to recover increasing amounts of food waste and recipients of food aid.

\section{Pushing Product}

It is important to reiterate that food banks receive products that are not apt for retail shelves. While some foods are of good quality and in high demand, others are much less so. Regardless of product desirability, food banks must work to distribute all the foods that they receive to their LFCs, or when local capacity is lacking via mobile food pantries. Food banks must also now contend with the pressures to distribute specific quantities of food in different places based on FA's MPIN metric, a measure based on food poundage moved, not on nutritional quality. The tensions between food quality and food quantity are symptomatic of the contradictions inherent to the food bank fix.

\section{A. Food Quality}

Food banks are under constant pressure to circulate food through their warehouses and use cost share pricing to manage the flow of the different types of foods they receive. When donated product is near or beyond expiration it is imperative that it not sit in place too long. "Potatoes are rough, you know one bad potato and... same with apples, we really need to push those out" (FB8: 3.9.17). Some foods have longer shelf-lives, but even then, the constant influx of product forces food banks to strategize novel ways to push food out the door.

"TEFAP always cycles, right now we are low, but come October we will be packed again. We try to be more aggressive pushing out TEFAP foods, we don't want it to sit here too long. Everything in here is always in transit, always moving. Some produce for example, we give at no cost to our pantries, we push it out, take it and give it for free. We call that a push product. There are also virtual produce items up on our inventory but [LFCs] never know what it's going to be. Virtual items are produce, dairy and bakery at 5 cents a pound. It barely pays for paper but creates internal controls. If it's free they'll take it all. But if we 
set too high a limit it may not go. We're trying to find a balance and found that this works. When it doesn't work quite right we can also push it through our mobiles. (FB-6: 7.18.16)

Although cost share pricing strategies help to bring some coherence to a highly frenetic supply chain, they do not fully resolve problems associated with circulating unwanted product.

Cranberries are good example of the limits confronting the food bank fix in this regard. For the past few years the entire network has been flooded with bonus cranberries from the USDA (chapter 3). The two food banks must push these out even as LFCs are saturated with oversupply of "the cranberry trifecta"; dried, canned and juiced products that are not typically a part of people's regular diets. "It's a problem. You can only take so many pallets of cranberry sauce, we're basically having to force it out right now" (FB-1, 5.14.14). At a food bank training event, an agency relations coordinator was at pains to explain to his LFC members that they should do their best to also push this product out to people that came to them for food:

"We're just like you, this food comes to our warehouse and there is more already in the pipe. We have got to move it. I've been known to try and move some product. If you absolutely can't move it, send it back. If you have a crowd that loves cranberry juice by all means order it! [laughs] I visit your pantries and see juice stacked to the ceiling and come to find out you're just giving one per family. You can give 24 to each family. Push it man!" (PO-17: 8.8.17)

Congregate meal programs "cran-hance" soups, pies and breads, and food pantries provide cranberry based recipe cards to distribute to recipients along with their food boxes. Often consumers have to take the product home whether they want it or not.

"I try to let people choose what they take from the pantry as much as possible, it's important to have them feel like they have a say in what they eat. Today for example they have the choice between chicken noodle soup or chili for the protein, but you know what, everyone is getting cranberry sauce because we have to get rid of that. We can't always ensure nutritional balance because we get what we get when we get it." (PO-4: 5.8.15)

Cranberries have become somewhat of an inside joke across the HFN in West Virginia. The massive dump of America's Original Superfruit into West Virginia's charitable food economy however represents a much larger phenomenon of surplus foods that are difficult to move. 
Donated corporate food waste can also lead to problematic inventory gluts. The amount of food received from FA corporate donors is increasing (Chapter 4) but food qualities are not always following suit. At the food bank level, this translates to pallets of product like Toasted Coconut Sea Salt Triscuits or Swedish Fish flavored Oreo cookies that consumers did not want to buy in the first place. Food retailers offloading their unsorted waste into the food banking economy often distribute foods that may have been wholesome or only slightly damaged when donated but are nonetheless not wanted. An LFC director that regularly picks up food from a national FA retailer recounted:

"We appreciate the variety, but it's not always varied enough. We can't really predict what they are going to give to us. Sometimes it's all meats, sometimes all dried goods, canned foods are often dented. [...] No one wanted the cases of avocadoes and jicamas, once I received a whole bunch of diet sodas. Sometimes the stuff is just unusable. I took the food down to the zoo, and the zoo didn't even want to take it!" (PO-5: 5.18.15)

FA's F2E model incentivizes food banks to distribute more nutritious foods and increase their "impact factor scores". The program is a response to the perception that food charities do not offer healthy foods to their clients. Securing the requisite food categories to improve that score is not always easy for food banks however. The advent of retail donors providing produce and other fresh goods, the choice system auction, and the FA buying cooperatives that offer truckloads of produce at extremely low $\operatorname{cost}^{43}$ have all been helpful to that end. As noted above however, perishable items can only be accepted by LFCs that have the necessary infrastructure to accommodate it.

"Feeding America is regularly saying, what are you doing to help improve nutrition? Well they've been pushing produce for a while now, but you know nudges are all we can get. I can't stand over people and say select this or select this. There are some food banks that will charge regular maintenance on diabetes products (breads, bakery etc.) and cheaper or

\footnotetext{
${ }^{43}$ The Mid-Atlantic Regional Cooperative (MARC) is one of six Feeding America produce hubs. MARC sources fresh produce for over 23-member food banks in a region stretching from Virginia to New England. The collective buying power provides large savings and centralizes logistics for perishable product management and donor relations. MARC receives and redistributes approximately 1.5 million pounds of produce each month.
} 
free on produce and healthier foods. But here we are again, I'm deciding. Should I be the person saying to someone don't pick this loaf of bread?" (FB-9: 5.12.17)

Rather than imposing stricter nutrition standards on corporate donors and governing the flow of food on the supply side, FA lays the burden to resolve nutritional disparities on its food banks. In a context where grant makers are also increasingly interested in nutritional outcomes, food banks feel increased pressures to manage their LFC sourcing strategies. However, LFC capacity to source nutritious foods for their clients is itself dependent on an institutional capacity informed by uneven capitalist development (chapter 6).

\section{B. Food Quantity}

Added to the many food quality pressures facing food banks are resource allocation tensions at the county level. As I reviewed in the previous section, the pressure to push out food in different places is structured through a geography informed by FA's MMG metric, a standard that food banks rely on to measure the success of their hunger relief efforts. When LFC capacity in a county is not sufficient to take the minimum amount of food mandated by FA, the two West Virginia food banks rely on their mobile food pantries to deliver donated product. They also work to recruit new LFCs in counties where they are having difficulty meeting food distribution targets. Again, the need in each county is defined by Map the Meal Gap (MMG) a model developed based on state level census data that is reinterpreted at the county scale. The measurement is scientifically rigorous but remains merely a representation of reality. Because federal data collection timelines and official statistics cannot keep up with local realities, the need measured by FA does not always align with local food insecurity problems on the ground.

"The USDA allocations are not keeping up with reality. We had 2,000 layoffs in our county last year. Multiply that by 5 for an estimate of how many other jobs that has affected. I'm afraid our agency is going to get hit especially hard when all their unemployment checks run out, I don't know how we're going to do it honestly." (PO-10 - 11.20.15) 
LFCs regularly brought up the sense that the need for emergency food in their communities was much larger than official statistics claimed. Whether those statements were made to enhance and legitimize the meaning of their own work is difficult to ascertain, but the sentiment across the HFN in West Virginia is that resources are not always allocated evenly, a sense of injustice that tends to translate to mistrust of the food banks.

"Even though [LFCs] know that these external entities define service areas the perception is that we are being jerks. Their perception of our obligations to external regulatory bodies, that's really what it is our obligations, are grey areas and can be bent if we wanted to. But we can't, well I guess we could but I'm not going to because we are under a lot public scrutiny and we are to be good stewards of the resources given to us." (FB-1: 7.15.14)

The recruitment of additional agencies to push out more product in a non-compliant county can also create problems because it reorganizes the local politics of feeding and potentially disrupts entrenched interests. When FHFB recruited new LFCs in one of their counties the director of an existing LFC was not happy with the fact that she now had to compete over resources with other organizations.

\begin{abstract}
"There is perceived unequitable distribution, it's really a turf war sometimes. We had a very underserved county, so we worked with other organizations to set up feeding sites there and expand the overall amount of resources available. Now there are five agencies there, she is not the only one. She wants all the resources, they all only see their own operation, I understand that but we have had to set up different distribution points because this woman engages in verbal abuse, she's aggressive with my drivers, etc. I told her, if you continue to abuse my staff you will not be getting any more resources. I don't expect you to wear a suit, but I do expect you to be professional". (FB-1: 7.15.14)
\end{abstract}

The food bank's activism at the local scale, while often well intentioned, creates conflicts that are not often seen or heard of in the donor rush to solve food insecurity problems through food waste recovery. Tensions over the quality and quantity of food distributed in different places highlights some of the difficulties that food banks face in relationship to civil society as they work to recover and redistribute food waste. Although MPIN is only one of many factors contributing to these tensions, the potent mixture of rules, institutional power and dependency on decentralized 
food distribution networks to meet increasingly centralized institutional mandates creates problems that are never dealt with by donors. Food corporations receive the benefits of cause marketing campaigns and enhanced tax deductions without ever having to face the significant disruptions and conflicts that their supposed benevolence engenders.

Food bank interventions at the local scale are a recent phenomenon, a reactive response to the need to meet new institutional standards defined at the national scale by FA. The strategies that they use to meet these standards are best-practice recommendations tested in other food bank territories, rolled out in West Virginia to overcome barriers of an extremely fractured and diverse LFC landscape. In the following section I review the strategies currently encouraged by FA to overcome problems associated with an uneven and decentralized network of local agencies that do not always have the labor, budget, infrastructure or feeding ideologies necessary to continue growing the food banking economy.

\section{Strategic Responses}

The two food banks in West Virginia use three strategies to adapt to changing food supply chains and governance strategies that have accompanied the roll out of large corporate retail donors into the FA fold (chapter 4). Mobile food pantries are just-in-time deliveries of mostly perishable product. Agency enabled pick-ups empower LFCs with the requisite institutional capacity to broker food recovery relationships with local retailers on behalf of the food bank. Agency tiering, is a strategy that segments LFCs along lines of institutional capacity to increase the legibility of a food bank's regional network, with regards to its capacity to cover operational costs and push out the increasing amounts of food waste flowing through their warehouses. I review each strategy in detail below and the effects they have on the local politics of feeding. 


\section{A. Mobile Food Pantries}

Mobile food pantries are a direct response to large food retail firm enrollment into food banking supply chains (chapter 4), and the high volumes of perishable product that are salvaged from those sites. Food bank adaptations to the just-in-time imperatives of perishability have led to novel strategies for the HFN to overcome food access barriers in so called "food deserts" (Walker et. al, 2010). Mobile food pantries are public events, advertised well in advance among community groups working with vulnerable households with the promise of free food for anyone who shows up at the pop-up food distribution site. Food banks usually organize these in partnership with an LFC, the latter often subsidizing the costs of the truck and responsible for organizing local volunteers for distribution.

Many food banks now have full-time product flow coordinators to manage these types of events across their service territories. Over the course of my study I attended five mobile food pantry events across West Virginia, both as a participant gathering food resources for my family, and as an observer of an institutional process I was coming to know more and more deeply. Mobile food pantries are somewhat different from the food distributions that take place at traditional brick and mortar food pantry sites. Because retail food waste must be moved quickly, and the food bank does not want to take any food back to its warehouse, there are few eligibility requirements (e.g. verification of income, address etc.) to access this food and the events bring dozens of volunteers and hundreds of poor households together in an exercise of bountiful rationing.

In many regards, the mobile food pantry is reminiscent of the kind of ambulant relief coordinated in disaster zones, a socio-technical solution to what might be called emergency food deserts. The strategy is pushed as a best practice by FA, who praises the innovation wrought by mobile food pantries for allowing "fast and flexible delivery of rescued food and grocery products 
including meat, produce and baked goods $[\ldots]$ in areas of high need in an effort to supplement other hunger-relief agencies in that area" (Feeding America, 2014b). By delivering emergency food resources to unconventional sites, the strategy effectively overcomes geographic barriers imposed by fixed hunger-relief programs.

Emergency food deserts have existed since the advent of HFNs 40 years ago, they are not a new phenomenon. The fact that mobile food pantries addressing this problem have come into vogue only in the past few years, speaks volumes to the complex motivations driving this practice, namely the accommodation of increased volumes of obsolete inventories from food retailers leaning on the FA network of food banks to revalue their perishable food waste (Figure 7-4).

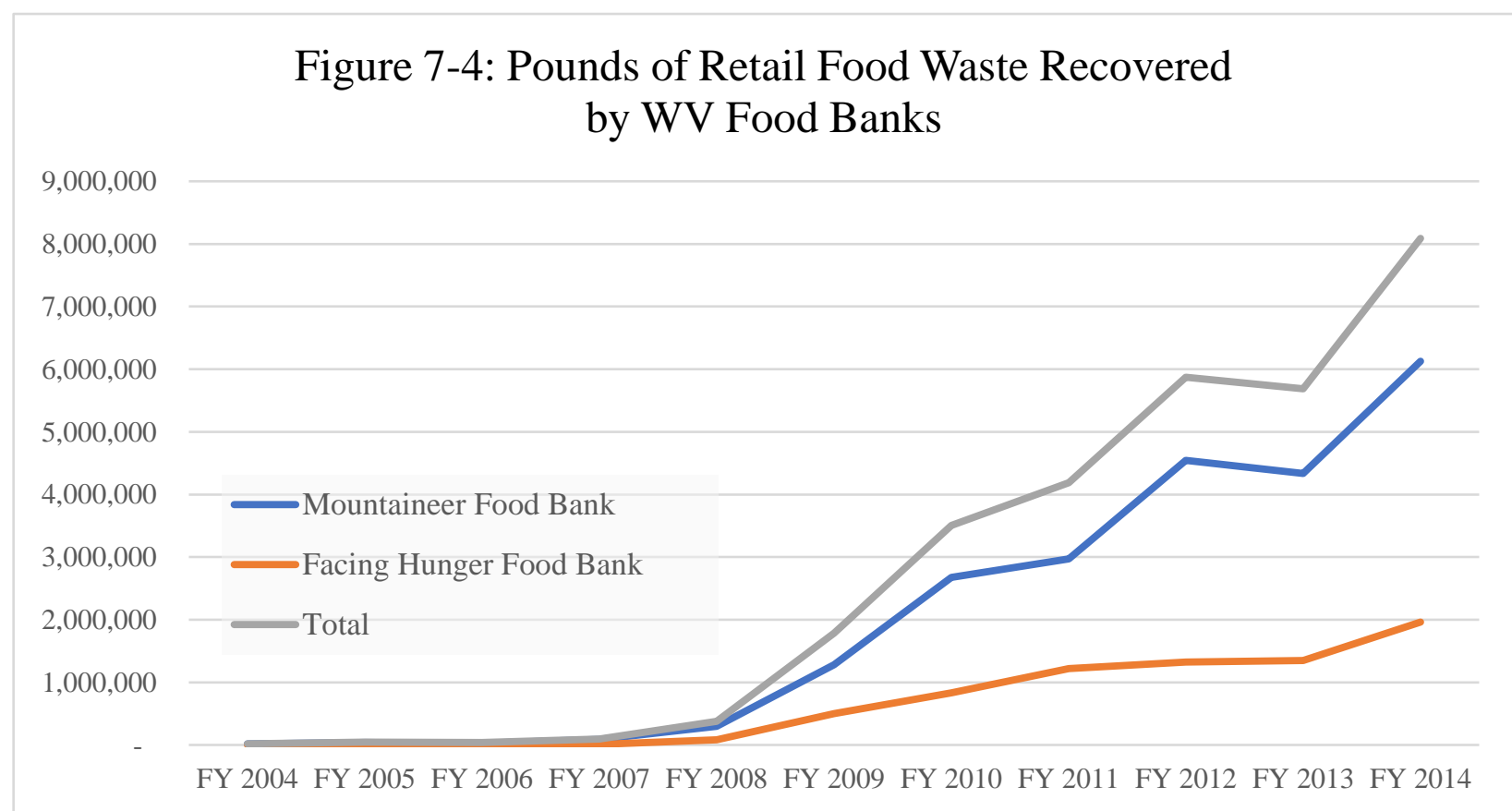

Mobile food pantries help food banks address spatial frictions in their fight against hunger by expanding the geographic reach of its relief work and increasing the overall amount of free food available to poor households. However, they also help FA corporate partners achieve their CSR goals by reducing the temporal, spatial and economic barriers to discarding their retail food waste through charity. When paired with FA's MMG metrology regime, the humanitarian logics 
informing mobile food pantry distributions become more apparent. The contradictions therein also create tensions at the local level. Although the minimum quantity of food that must be allocated to each county is informed by equitable distribution standards, the practice does not always sit well with LFCs who do not fully understand the institutional confines within which food banks operate.

I tell you what people feel that we are really willy-nilly about are the mobile pantries. For example, in Lawrence county we were at $125 \%$ which meant we were in compliance and everyone was being fed really well so we didn't need a mobile there. And then I'm struggling to reach 100 in other counties. So, when we were trying to more equitably provide these things people were getting up in arms. You're just forgetting about us. And I'm going - ugh! So you try to explain that. In your county, let me talk to you about meals per person in need, so they get their picture every quarter what is required of us to be compliant." (FB-9: 5.12.17)

Mobile food pantries are effective strategies to distribute increasing amounts of food waste

flowing through the food banking economy. They are a response to spatial governance pressures within an increasingly regulated food waste accounting regime tied to the demands of the corporate food sector at the national scale. LFCs who partner with food banks to organize and promote these events are not cognizant of the supply side dynamics structuring these free food distributions.

\section{B. Agency Enabled Pickups}

Large corporate food retailers affiliated with FA have also re-organized charitable food landscapes at the local level through the advent of agency enabled retail pickups. The coupling of the HFN with food retailers is producing new territorial ambiguities and misunderstandings as LFCs now compete for access to food resources from local retailers that are tied into a national governance and accounting structure they are often not aware of. Higher capacity agencies are "enabled" by the food bank to pick up on their behalf and must fulfill retailer expectations of regular pickups three or four times a week, a schedule that is not always synchronized with LFC staffing resources. Coordinating these pick-ups then often involves a scalar restructuring as agencies must organize amongst themselves to pick-up and redistribute retail waste. In Preston 
county for example, a part-time coordinator organizes all retail pick-ups in the county by assigning days and times to LFCs involved in the program. She collects poundage reports after each pick-up and sends these back to the food bank. In other places, individual agencies maintain primacy over their relationship with FA retailers, often evolving into mini food banks that then coordinate the redistribution of excess to surrounding food charities.

Because local food environments differ from place to place, the roll-out of the agency enabled retail program exacerbates pre-existing local resource allocation tensions. Those LFCs with sufficient capacity (storage, refrigeration, vehicles, volunteer base, regular opening hours etc.), a proven history of compliance and faithful bookkeeping are deputized to pick up and

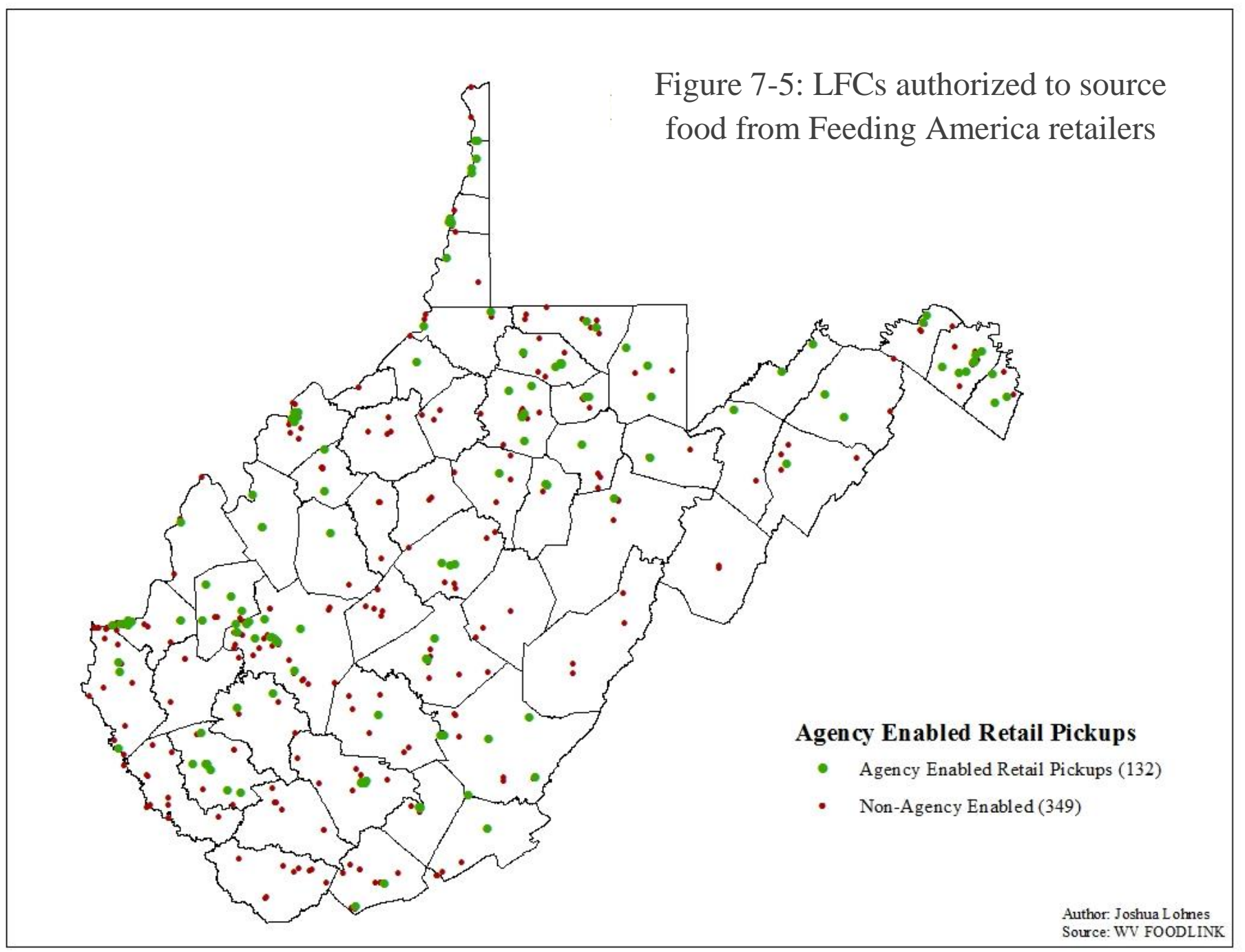


redistribute retail food waste donated by corporations on behalf of their regional food bank. Qualifying LFCs are given contracts to pick up this excess while smaller ones are left out (Figure 7-5). In West Virginia, these food sourcing lines were reorganized in a very short period between 2014 and 2016, creating a new and often incomprehensible geography for LFC directors who feel left out of the retail donation program. "Where's my Walmart? Why can't I pick up donations from the Walmart I shop at?" yelled a pantry director at an LFC training meeting (PO-11.3.15). The frustration in this case was misdirected. The food bank could not have authorized him to pick up at that store even if his agency met all the necessary guidelines. His local Walmart is located within a separate FA food bank service territory, and although just a few miles away from his pantry, he will never have access to the waste generated there unless the thick borders that delineate FA food banking territories are redrawn.

LFCs that have secured a relationship with a corporate food retailer gain access to additional food resources but must also follow up with a significant amount of paperwork because local pickups within the FA donor network count toward a food bank's MPIN compliance. To this end it is crucial that LFCs report the donated foods they have recovered so that their food banks receive the credit for distributing that food and retailers are able to process their tax receipts.

"We have a contractual obligation with Feeding America and we pass those on to the agencies. It reflects poorly on us if they don't report, we need more training for agencies to make them understand why numbers are important. If agencies don't report a Walmart pickup it looks like that store didn't give any food away and their corporate can't get the tax write off [...]. If you're not willing to follow the rules, then we won't work with you anymore There are 10 others in line willing to do so." (PO-11.23.15)

Here again FA's national governance structure grinds against a locally diverse, mostly volunteer run HFN. Food banks must govern their agency enabled LFCs more tightly than ever to ensure food quantities are accounted for to meet distribution targets yet are themselves powerless to change the territorial frameworks and measures upon which their institutional power and 
legitimacy depends. If they do not implement FA distribution rules they face the scepter of probation and loss of access to the foods that their network of LFCs rely on to address food access failures at the local level. Caught between the mandates of their national affiliates and the frustration of their LFCs, food banks are left to negotiate the effects of FA's recommended strategies for hunger relief at different scales.

\section{Agency Tiering}

The third strategy that food banks use to overcome local barriers to food waste revaluation is a process of LFC segmentation. The response to uneven development is to differentiate LFCs along lines of institutional capacity and willingness to contribute to the goals of the food banking economy. The so called "tiering" process works to smooth out a fractured charitable landscape by leveraging the food redistribution potential of well capitalized $\mathrm{LFCs}^{44}$ and in turn dedicating fewer administrative resources to small feeding programs that do not process large amounts of food. The idea is to segment LFCs by program effectiveness (e.g. number of people served), level of unmet

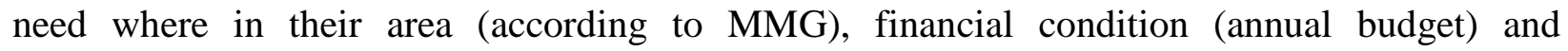
demonstrated willingness to collaborate with the food bank (qualitative relationship). Beyond reducing managerial time, tiering also incentivizes LFCs to lean in and participate more heavily in the food banking economy through volume-based memberships and access to special funding or training opportunities for LFCs that reach a certain threshold of food orders each year. The tiering process brings a sense of coherence to the LFC scale enabling food banks to govern and leverage their network more effectively.

\footnotetext{
44 The capitalization of larger LFCs has been achieved through decades of local charitable investments, fixed capital that plays an important social function as part of the secondary circuit of capitalist fixes (Harvey, 1989). Like food banks, LFCs can thus be thought of as a part of the consumption fund infrastructure that facilitates social reproduction under capitalism. Agency tiering further reinforces uneven development across the HFN by creating the conditions for more investment into LFCs that are already meeting certain capacity thresholds.
} 
For food banks facing institutional pressures from above and from below, segmenting their food distribution channels along lines of institutional capacity makes a lot of sense. The process is encouraged but not yet mandated by FA. Those that I spoke to that had been through the lengthy process of determining which tiering models best fit with their specific food banking geographies explained that it provides a framework through which to develop meaningful partnerships with new agencies by providing them with different membership levels. It also helps food banks focus on the core of their food recovery and redistribution efforts, focusing less time on agencies that might weigh them down administratively. An agency relations coordinator that had spearheaded the tiering process for her food bank in Tennessee explained it this way:

"Tiering helps us focus on growth, we had about 100 agencies that only take less than 10,000 pounds per year. These are the ones you have to have hard conversations with, are you willing to take more food or not? We have now set up an agency agreement that states that in order to be a part of our network they have to distribute a minimum of 10,000 pounds per year." (PO-16: 3.6.17)

The two West Virginia food banks do not yet tier their agencies, although the ideas are beginning to percolate down in the context of tighter fiscal pressures and growing food distribution burdens. MFB has for now intentionally opted not to follow many other FA food banks down the LFC tiering route.

"We don't do tiering in a technical sense, we know who our big players are if we get a truckload of green beans we can send them there and we know they'll take it. We can't lose sight that some smaller agencies are just as important. Look whether you serve 20 or you serve 500 you are a critical part of that community. (FB-6: 7.18.16)

FHFB's service area in West Virginia spans the southern coalfields, a part of the state where LFCs are struggling due to the large demands placed on them from ongoing economic divestment and large layoffs in the area. Furthermore, FHFB is prohibited from fundraising in five West Virginia counties even though it must distribute TEFAP food there (Chapter 5), adding more fiscal 
pressures on its operations. In an exploratory agency tiering meeting with FHFB executive staff their motivations behind tiering LFCs were made clear:

We found that we had 19 members that were purchasing about $50 \%$ of the food available. Then we have really under resourced people who are on the total opposite end of the spectrum, who barely have enough to order a shared maintenance in mixed product boxes, who heavily rely on TEFAP. In the middle are those people that as we have things available they order things online and they will get the mixed products, they will also order when I get a choice load ${ }^{45}$ like from Mondelez, Nabisco, Kellogg and they really snatch those up [...]. So, it's about finding a way to really reward the high end people, encourage them, provide them better deals because they are responsible for the most volume of food going out, but still to take care of the low end. My sense about tiering, how do we get folks to see the advantage of increased spending with us. (FB-8: 3.9.17)

At the yearly FHFB agency meeting in 2015, LFCs were told to expect some possible

changes in the coming years as food banking best practices were being explored:

"Feeding America is recommending that I have one agency relations coordinator for every 100 agencies. We want to have those transition discussions with you. [...] We are realizing that we have many more agencies than is helpful. We are beginning to review a process of consolidating pantries. If one is serving 20 people and another is serving 40 people we want to encourage you to get together. By sharing time and resources you can have better opening hours and it will be easier for everyone with allocations, ordering and reporting" (PO 11.20.15)

In the context of an increasingly centralized food banking economy, the drive to bring a sense of legibility to the HFN from above creates tensions, contradictions and various forms of resistance as food banks and their LFCs struggle over resource management and differing ideologies of hunger relief. Each LFC is imbricated in affective histories that are not easily erased or merged with others. While there are places where smaller LFCs have combined to enhance services in their community these developments were driven from the grassroots, not imposed

\footnotetext{
${ }^{45}$ Food banks source these loads through the Feeding America Choice System, an internal food auction platform designed in 2005 to streamline bulk donations from food manufacturers. The system was designed to resolve product bottlenecks and expand the amount of food donated to the FA network of food banks (Prendergast, 2017). The market functions on principles of supply and demand using fiat money backed by an FA regulatory framework that controls the allocation of resources to each food bank through a system of "shares". Food banks receive shares based on their segmentation into "environmental peer groups".
} 
from above. It remains to be seen how effective FHFB's tiering efforts will be or how local communities will react to membership tiers.

Another motivating factor related to tiering is the need to maintain funding for food banking operations. Food banks would like to gain more control over LFC purchases and are working to convince their LFCs to leverage their economies of scale and the preferential pricing they have through FA corporate partnerships.

"We have folks who we know have much higher resources available to them who by hook or by crook we have managed to get them to, if they are going to purchase, to do so through our purchasing program. I've been going out and getting as low-cost items as I can and then doing a pass through basically that barely increases the amount of pricing that I pay for things to them. And we have people that have found that the best way for them to use resources rather than for them to go to Sam's or to go to Save-a-lot is that they let me buy it, they understand that I can get higher quantities and they get that from me. (FB-8: 5.12.17)

While the strategy makes sense from the food bank's perspective, they are having difficulty getting their purchasing programs to catch on and it still only accounts for a mere $2 \%$ of the overall charitable food sourced in the state. LFCs collectively spent over \$10 million on food purchases in 2016. Only $8 \%$ of that money is captured by the two food banks (including cost-share on donated product). Because the food bank does not capture information on local donations and purchases, these cannot be accounted for in the MPIN distribution targets. If LFC supplemental purchases go through the food bank however they serve the dual purpose of maintaining the food banking operations in place while meeting their growing food distribution goal factors.

\section{Discussion}

The centralization of the food banking economy is confronting tensions across a highly decentralized network of local feeding organizations. Food banks are receiving increasing amounts of donated food waste for redistribution as hunger relief. These foods circulate through the food 
banking economy because they cannot be sold in primary markets and are therefore of highly differing qualities. While some foods are sought-after others are not wanted. Food banks must contend with two contradictory institutional pressures in response to this dilemma.

First, they are increasingly pressured to consider the nutritional value of the foods that they distribute. They bear this burden despite their complete lack of control over the foods received from donors. FA and other grant-makers are increasingly setting parameters on the types of foods distributed, yet do not reciprocate by mandating a quality standard from corporate donors on the supply side. In an effort to control the flow of food through their warehouses, food banks set variable cost share pricing on their products to incentivize LFCs to purchase slow moving (e.g. lower quality) foods, and those that meet certain nutritional guidelines (e.g. produce).

The second institutional pressure is the FA MPIN target used to measure the effectiveness of food distributions at the county level. As a measure of success driven largely to satisfy FA stakeholder demands, MMG and MPIN drive the perception that hunger is being solved through food waste recovery by evenly spreading donated foods across space. The drive for equitable food distribution at the national level however produces tensions that occasional erupt into conflicts between food banks and their LFCs who are not privy to the logics informing the quantity driven metrics food banks must contend with across their service territories.

Added to these institutional pressures from above is the reality that LFCs are not all equally dependent on the food bank to source food. LFCs located in places with higher median incomes tend to receive more donated product from local food drives and have more money to purchase food directly from retailers and wholesalers. For these agencies the food bank is only one of many food sourcing strategies (chapter 6). Food banks in fact only capture a fraction of the $\$ 10$ million dollars spent on food purchases across the network, and there is an ongoing effort to encourage 
LFCs to consider sourcing product through their bulk purchasing programs. Poorer LFCs on the other hand are often heavily dependent on the food banks to stock their shelves but may not have funds to participate in bulk purchasing programs. Uneven development across the HFN therefore significantly affects both the quantity and quality of food available at each LFC location leaving a fractured and highly unequal local charitable food distribution system in its wake.

Within this context, governance changes driven by FA at the food bank scale are impacting the local politics of hunger relief. The mobile food pantry is a reaction to the lack of local capacity to absorb donated food product yet is itself also a fraught enterprise that leads to perceptions of unequal emergency food distribution across the state. Food banks are also being encouraged to tier their agencies to enhance the legibility of their networks. LFC segmentation would incentivize feeding programs that process a lot of food and leave smaller ones that take up managerial time without significant return in terms of their overall contributions to the goals of the food banking economy. The future of food banking in West Virginia may then see the further bifurcation of an already highly diverse network of LFCs as their level of integration differs along lines of institutional capacity.

The focus on building out the local infrastructure to accommodate increased food flows is limiting conversations about addressing the social and economic conditions that lead to food access failures in the first place. The energies expended by local civil society organizations to resolve hunger through industrial food waste recovery reinforces the profit motive of entrenched corporate actors in capitalist food system. As LFCs are enrolled into a national food waste revaluation scheme that they have little institutional understanding of, they push back against the food bank rather than the powers within the food system structuring it, splintering and subverting the potential for a unified response to the need for short-term emergency food resources in the first place. 
The tensions I have exposed in this chapter center on the food bank's drive to overcome spatial barriers through a calculable order. The frictions elicited by these technical interventions at the local scale are helpful to think about the politics of the food banking fix more broadly. LFCs must to a large extent conform to corporatized hunger relief logics or find alternative ways of resolving hunger. To echo Michael Watts (1991) we might think of the grinding contradictions exposed in this chapter as "an opportunity to grasp the ways in which subaltern groups are both subordinate to, and capable of, resisting dominant relations of power" (p.17). Food banks are subordinate to the dictates and directives imposed by FA to overcome crises of food waste and hunger in the capitalist food system. They are also beholden to their network of LFC members on whose behalf food banks ultimately work. Relationships between LFCs and food banks are much stronger than those forged between food banks and their state or shadow state monitors, however as FA's governance structure tightens it strains these relationships in ways that fracture the potential for a coordinated response to corporate power in the charitable food space. Even as the food bank fix legitimizes the corporate food regime then, it also has the potential to push back against it in ways yet untested by collective action. 


\title{
Chapter 8: Food Bank Futures
}

\begin{abstract}
"The challenges we must surmount to [end hunger] are fundamentally, essentially, institutional. We have designed neither our national nor international systems to accomplish food security and end hunger. In fact, we, as individual nations and international organizations, have chosen to give higher priority to other objectives, whether this be trade and the freedoms of multinational corporations, notions of 'modernity' and 'progress' that minimize the role of agriculture, or adherence to certain convictions about the role of government and the place and capacity of the private sector." - Jahi Chappell
\end{abstract}

\section{Revisiting the Food Bank Fix}

Food banks are presumably designed to address food insecurity for low income households. What I have argued throughout this dissertation is that since the early 1980s, these institutions have grown into critical appendages of agro-industrial supply chains. Food banks fix supply-side problems within a capitalist food economy. I've shown how the food bank fix is achieved through a set of institutional relationships that bring the state, the shadow state, food corporations, local charities and philanthropic donors together through humanitarian reason. Humanitarian Food Networks (HFNs) are now the necessary ends of a food system that segments eaters along lines of disposable income. The legal and social codes produced by the food banking economy resolve crises of wasted food and wasted lives (Yates, 2011) by leveraging and reinforcing the idea that feeding the hungry with industrial food waste is an unquestionable moral imperative.

The local canned food drive that still occupies much of the social imaginary surrounding food charity in the United States is implicated in a powerful network of food system actors that contribute to reproduce hunger under capitalism. Although food banks and their LFCs are largely perceived as organizations whose raison-d'être is to feed the poor, my institutional ethnography of the HFN in West Virginia complicates this idea. My analysis has demonstrated that the roll-out of the food bank fix is a fraught and contested part of a moral economy legitimizing the corporate 
food regime. The overt focus on hunger obscures much of the work that food banks perform beyond feeding the poor and the oppositional tensions that the HFN then confronts on a daily basis.

Theorizing the food bank fix shines a new light on the multi-scalar web of social and ecological relationships that structure our food system. My analysis drew attention to the HFN, not only as a problematic expression of neoliberal capitalism, but as a productive and generative field from which to comprehend wider geographies of food and agriculture. The West Virginia case study adds empiricism to the genealogy of food regime theory (McMichael, 2009) and a new optic from which to understand the commodification of food and the current transition toward the corporate environmental food regime (Friedmann, 2005). Food banking is not merely a response to hunger in situ, it is a geopolitical, ecological and nutritional governance project that serves to maintain the hegemony of the capitalist food system under the banner of humanitarianism.

Most agree that a society in which 46 million people depend on charity to survive is unjust, yet they often situate these injustices within a demand side framework, unable to understand them within food production and distribution processes codified into laws and contracts. The heightened focus on food access failures, while important, often obscures the perverse dynamics that enclose massive food surpluses within a scarcity framework. My theory of the food bank fix begins to open a research agenda for posing further questions about the links between hunger, capitalism and humanitarian reason.

By refocusing on the critical role played by the state in the food banking economy (and by extension its relationship to the shadow state), I have highlighted the need for food justice activists and scholars to move away from a myopic focus on food. We must also cultivate and tend to the urgent struggle to rewrite the public policies that shape the institutions governing our food system (Sbicca, 2018). The five data chapters revealed how surplus food transfers are tightly controlled 
by the state and large food corporations to ensure they do not disrupt the scarcity logics and profit imperatives driving the capitalist food system writ large. They also revealed the current limits of the food bank fix at the local scale and the drive to overcome them through systems imposed from above.

In chapter three I focused on the oft underappreciated role that the state plays in the rollout of the food banking economy. Food banks and LFCs are not merely a response to state retrenchment, they are active participants in the restructuring of public welfare as agents of the state. I reviewed the legal structure through which the USDA offloads large volumes of agricultural surpluses into hunger relief networks. Enrolling charities into the state's public-private governance apparatus is, however, ideologically and materially fraught. TEFAP anchors HFNs in place and regulates the distribution of public food resources, ensuring a modicum of rights to people laying claim to federal food. Local TEFAP agencies are often wary of state intrusion into their affairs and bend or break rules to conform to their own ideas of whom is deserving of care. On the material side, the state's reliance on charities to subsidize the costs of distributing surplus commodities, paired with demands for transparency through a complex bureaucracy, adds a heavy administrative burden to food banks and their network of LFCs. These generate resentment toward the state which is often understood as an operational barrier to their hunger relief efforts despite its vital role maintaining the HFN in place.

In chapter four, I analyzed the relationship between large food corporations and food banks by revealing the key role played by Feeding America (FA) as a third-party broker between the two. I explained how FA consolidates power by organizing member food banks under its institutional umbrella and negotiates contracts with large food corporations on their behalf. FA food banks are thus grafted onto an ethical regime that works on behalf of corporate social responsibility 
campaigns. Pledges by large food firms to reduce food waste and end hunger secures cultural legitimacy in the marketplace while improving brand loyalty and increasing shareholder returns. The state is not absent from this process, rather the federal government incentivizes food businesses to donate their waste to charity through a tax regime tailored to corporations. I traced the fair market valuations tied up in the tax brokerage services offered by FA, and the accounting and monitoring regime imposed on member food banks to capture this value. FA's interpretation of the tax code imposes rules that serve to enclose corporate food waste within secondary (charitable) food distribution channels that ensure these gifts will not be resold, maintaining a scarcity framework that protects profit in primary food markets.

My analysis in chapter five turned to the dilemma faced by food banks negotiating the demands of the public and private USDA-FA institutional assemblage in the context of near constant organizational freneticism. Food banks anchor the HFN in place and work to broker and resolve economic, political and moral contradictions that surface as low-paid staff, volunteers and donors work to revalue state and corporate food waste as hunger relief. I showed how the food bank fix is both a solution and a dilemma for the state and food corporations leveraging charitable organizations to stave off crisis because the HFN operates in a state of near constant crisis. The West Virginia case study revealed the precarity of food banking work and the tensions that surface between organizations negotiating an underfunded mandate to reduce hunger through food waste recovery.

Chapter six analyzed the local scale of the HFN highlighting the diversity and ideological incongruities associated with charitable hunger relief in situ. LFCs are the ends of the food banking supply chain. They order, receive and distribute food waste to vulnerable households, yet many of these agencies do not align with the values and motivations driving the food bank fix forward. 
Even in a context of food waste abundance, some LFCs reinforce a scarcity framework by setting limits and pre-requisites that create bottlenecks and frustrate the smooth functioning of this secondary food waste revaluation circuit. I argued that the local scale is thus one of the largest barriers facing the state and food corporations as they leverage the food bank fix to solve problems of food waste and hunger in the capitalist food economy. An ageing LFC volunteer workforce is leading to labor shortages. Low operating budgets and inadequate physical infrastructure is a significant barrier facing food banks as the amount of food they are compelled to distribute continues to rise each year.

Chapter seven then analyzed how the food banking economy works to overcome these barriers through expert driven technical solutions developed by FA at the national scale. Food banks are expanding, conforming to supply side imperatives driven by a corporate food regime that profits from hunger. As the volumes of food waste donated to HFNs increases, and the source of those donations changes, new technical solutions are adopted to reorganize feeding lines and meet food distribution targets imposed from above. Metrics such as Meals per Person in Need, based on FA's Map the Meal Gap measure success based on the quantity of food distributed across space, reinforcing the perception that food banking, charity, philanthropy and volunteerism are viable solutions to hunger. However, strategies such as mobile food pantries, agency enabled pickups and agency tiering all point to efforts to solve a supply-side dilemma in the food system, not necessarily expand access to nutritious foods in any coherent manner.

Taken together these core chapters explained how the food bank fix is governed through rules that determine how food waste is gifted and redistributed along a compassion driven supply chain. Food banks emerged at the dawn of the neoliberal era, liberal humanitarianism (Barnett, 2011) and the corporate food regime (Friedmann and McMichael, 2009). They are now woven 
into the fabric of an industrial food system that accumulates capital by differentiating foodways between social classes. As feeding lines continue to expand, it is critical to attend to the politics of production structuring this secondary charitable food circuit, not merely the politics generating the demand for emergency food. Indeed, food system scholars and anti-hunger advocates must come to realize how tightly the two are linked.

\section{II. $\quad \underline{\text { A Fresh Crisis }}$}

Revisiting events that unfolded over the past year help point to the relevance of my theory of the food bank fix and the potency of this research in helping critical food scholars revisit the shifting moral contracts forged between food producers and consumers in the United States. As I was consolidating my analysis in February 2018, the Trump administration released a federal budget that would drastically reduce Supplemental Nutrition Assistance Program (SNAP) spending by $\$ 213$ billion over the next ten years, a 30 percent cut. Forty-three million people rely on SNAP to access food across the United States and the steep reductions thus had to be mitigated by some programmatic alternative.

The America's Harvest Box proposal would have used SNAP savings to purchase "100percent American grown foods provided directly to households" (Office of Management and Budget, 2018, 15). Any household receiving more than $\$ 90$ in SNAP benefits each month would see their right to cash-equivalent benefits reduced by $40 \%$ and substituted by a box of USDA commodities such as shelf-stable milk, cereals, pasta, peanut butter, canned foods etc. There were very few details accompanying the idea. Private non-profits were championed as efficient innovators of this social safety net reform, yet no funding was allocated to cover food distribution costs. Drawing on the legal and physical infrastructure in place through the TEFAP program, these 
prescriptive food boxes would supposedly be a more cost-effective way for the federal government to provide food resources to its poor citizens.

America's Harvest Box set off a national debate. Some decried the further marginalization of the poor to balance a budget deficit on the heels of a $\$ 1.5$ trillion tax law that reduced public obligations on the wealthy. Others saw in the program a form of centralized state planning that the American public has long been wary of. Food retailers that stood to lose a large amount of revenue from the proposed SNAP cuts also stated their concerns. Yet, across the country there was also deep intrigue and even support. Media outlets described America's Harvest Box by comparing it to Blue Apron or Amazon Pantry, two high end food delivery services. Health advocates supported it because it might enable them to control the nutritional content of food distributed rather than allowing SNAP beneficiaries to make their own choices.

The incitement to discourse around the expansion of America's Harvest Box - commodity food distributions as hunger relief on the demand side - obscured the supply side logics driving the idea. In 2018, producers in the crosshairs of US isolationist policies were suddenly burdened by surpluses that no longer had a market. When America's Harvest Box failed, in July, an executive order released $\$ 12$ billion dollars in federal aid to bail out US farmers caught up in retaliatory tariffs of an escalating trade $\operatorname{war}^{46}$ (Paleta and Dewey, 2018). The short timeline between the America's Harvest Box announcement and the tariff related producer bail-outs raise further questions about the policy links between the food bank fix and political economic pressures of a capitalist food system negotiating permanent crisis.

\footnotetext{
${ }^{46}$ Funding for the purchases was made possible through section 32 amendment of the Agricultural Adjustment Act, or "bonus buys" (chapter 3). The 1935 law mandates that 30\% of all import duties collected from customs receipts are made available to the Secretary of Agriculture for surplus removal and the encouragement of domestic food consumption. When tariffs on steel and aluminum (or any other goods) increase, the pot of money to rescue farmers from food waste crises also increases.
} 
In August a portion of the bailout funds were allocated toward the purchase of $\$ 50$ million worth of fresh milk from struggling dairy farmers. In West Virginia, this translated to $\$ 530,000$ worth of fluid milk (approximately 145,000 gallons) that had to be suddenly pushed out by the food banks to a network of agencies ill equipped to accept such a massive amount of perishable product in a matter of days. In 2019, these bonus food windfalls are expected to increase the volumes of federal food commodities circulating through the HFN in West Virginia nearly fivefold, without any additional administrative funds to move the product.

West Virginia food bank directors, operating in an austere philanthropic environment and already at the limits of their infrastructural capacity, are increasingly frustrated at the dilemma they are facing. They are jointly petitioning the West Virginia Department of Agriculture (WVDA) for state funding increases and organizing a state-wide legislative campaign to draft a bill that would increase administrative funding for their work. At the national level, Feeding America (FA) is channeling anger from its food bank members, leaning in the halls of Congress to explain how trade mitigation commodities place an undue burden on food charities.

Out of this fresh crisis, the rush to fix the problems are further entrenching the food banking economy in place. In West Virginia there is an urgency to upgrade local food agencies (LFCs) refrigeration capacity to accept more perishable product from the federal government. I am currently involved in discussions about the creation of a just-in-time software system to improve the logistics of delivering food to LFCs along trucking routes covering vast geographic areas. All these options envision the further expansion of food banks to accommodate increased food waste flows in the coming years. No discussions are centering on the day when food banks may no longer be needed, raising further questions about their role in solving hunger. 


\section{What about ending Hunger?}

Food banks operate in the space between surplus and scarcity, negotiating its attendant paradoxes. They serve to maintain the stability of primary food markets while mitigating the moral outrage of a profit driven food economy that produces food scarcity through surplus controls that extend into charitable food spaces. HFNs conform to mandates driven by the corporate food regime at the expense of normalizing household level food precarity and hunger. The trade mitigation commodities currently being dumped on HFNs across the country are a case in point. Not only are they creating new vulnerabilities across the network, the compassion and sacrifices made by local hunger relief organizations to fix the latest food waste dilemma are solving problems borne out of competition between nation states over political and economic power, they are not addressing hunger.

The moral imperative to feed the hungry rarely questions the relationship between waste and want. Focusing my analysis on the institutions regulating food waste donations across antihunger networks, I explained how the food banking fix maintains the hegemony of a moral economy of hunger relief that legitimizes misplaced charity and increases the social distance between givers and receivers. Those with an economic and political interest in regulating surplus benefit from the deployment of discourses that reinforce both scarcity and charity. They feed off the sacrifices and compassion of anti-hunger groups to consolidate power and accumulate more wealth. Laying bare these institutional dynamics, the question that now begs to be asked is the following. To what extent does the current food regime need hunger to function?

When I asked a Feeding America executive what would happen to their organization if public assistance benefits expanded and the state ensured the right to nutritious food for all, the answer was telling of the key position that food waste plays in the logic of the institutions driving 
the food bank fix, and how hunger remains a powerful discursive vehicle through which to resolve the overproduction crisis:

"We want hunger to be solved, I mean we wish we could close our doors today. We wish that would happen. That would be the best scenario possible. [FA and its food banks are heavily involved in lobbying for SNAP expansions and claim to work daily toward ending hunger.] I think we would still be interested in dealing with waste, just because we are stewards of making sure product doesn't end up in landfills [...]. I can't see us just saying we're done. I could see us morphing into saying 'fantastic everyone is fed' now we're going to work with waste management companies, innovative composting companies. That's what we want to do, to make sure we're being good stewards of the earth really and of the food that is out there that isn't reaching people in need." (FA-1, 4.23.15)

The food waste problem was never linked back to policy, to the rules and laws that allow an ecologically exploitative and unsustainable food system to continue to generate so much excess. If hunger ended today, would it still be as morally and politically palatable to lay the burdens of resolving the food waste problem on the shoulders of civil society organizations? Again, to what extent does a humanitarian discourse centered on the hungry suffering subject further enable and empower the corporate food regime?

The cynical myth of charitable hunger relief is now being leveraged to fix new social problems. Added to the turn toward an ecological fix, food banks are compelled to become a fix to public health problems linked to food related health disparities among the poor. Many are also collaborating on the development of local food economies to fix problems borne out of the links between global food supply chains and regional food insecurity. How far can the food banking economy continue to morph and evolve under the banner of solving hunger? It is a prescient question, particularly because over the past 40 years of trying, household food insecurity and malnutrition remain as entrenched as ever across the United States. 


\section{Reclaiming charitable food supply chains}

Under the current institutional arrangement food banks cannot solve hunger. Though countless labor hours, resources and systems have been committed to food waste recovery, both problems have expanded in parallel into the $21^{\text {st }}$ century. There is clearly not a lack of food to solve the hunger problem, nor a lack of initiative to come up with innovative solutions to tackle it. Yet the institutional framework in place to distribute the abundance of our harvest encloses and regulates food through distribution channels that reinforce the interests of the capitalist state and powerful firms shaping its policies. It does not have to be so, it could be otherwise. Food charities could be destigmatized and evolve into sites where everyone can access the bounty, a practice already mandated in all TEFAP hot meal programs across the country, and increasingly institutionalized at mobile food pantry events. Rather than restricting whom is worthy of care, allowing everyone to access surplus would be a first transformative step to challenging the scarcity mentality currently permeating our food economy.

Jahi Chappell (2018) offers a solid case for such "active optimism", that another food future is indeed possible. Drawing on his case study of the Municipal Undersecretariat of Food and Nutritional Security (SMASAN) in Belo Horizonte in Brazil, he analyzes how the city's commitment to a right to food in 1993 saw the emergence of programs that forged new links between farmers and consumers, provided nutrition and health education while providing meals to anyone that needed it. There were many growing pains in the process of reforming municipal institutions to achieve the goal of zero hunger, but the study reveals that pathways to change are possible if the political will follows. It also demonstrates the power of reshaping institutions from below, and the practice of listening attentively to the ideas and experiences of those confronting food insecurity and the community-based groups serving them. It is possible to end hunger, to 
forge new solidarities through food, to begin thinking again of food as a commons to be shared rather than a commodity to be owned, sold and gifted in specific ways (Vivero-Pol, 2017).

An emergent network of food banks and LFCs increasingly aware of their role in reinforcing agro-industrial power is organizing and gaining momentum. The stated purpose of the Closing the Hunger Gap (CTHG) movement is to "expand hunger relief efforts beyond food distribution towards strategies that promote social justice and address the root causes of hunger" (http://thehungergap.org, 2018). At their biennial conference in 2017, the keynote speaker Malik Yakini, executive director of the Detroit Black Community Food Security Network, laid out the challenges facing HFNs to the 500 charitable food attendees as follows:

Standing in solidarity we need to make systemic change [...] It's easy to point to systems, but the reality is we need to transform ourselves as well. [...] We don't need saviors, we need to shift from charity to solidarity, empowering those most impacted by food insecurity to be leaders in their struggle. Who is on the board? Who is the Executive Director? Who are in senior management positions? This of course takes bold courageous action. The struggle for social justice has never been easy and have examples of people who have made sacrifices, and we have the same responsibility. (PO-19: 9.11.17)

If the future of the food system will be shaped by the people within the institutions that structure it, any project to close the hunger gap will have to also contend with differential power within and across those institutions. This dissertation has clearly revealed the diversity of organizations that make up the HFN assemblage, the diversity of viewpoints and motivations driving the work of feeding the hungry. The reality is also that some people hold much more power to make and enforce rules than others, power that is not always wielded generously. Sub-altern groups within this structure, like the food banks and charities I have studied in West Virginia seem to be on a trajectory toward expanding their position at the tail end of a supply chain that produces scarcity to secure profit for private firms. Should rules drafted to enclose food waste into revaluation channels serving large food corporations be followed if these are unjust? 
Micro-transgressions to these rules across the HFN are happening every day and are a ripe field of inquiry for future scholarship. While many reinforce a scarcity framework, others bend or break rules to accommodate the needs of people over programs. Over the course of my fieldwork I saw donated food being exchanged for cash as "clients" participated in subsidizing their local charity to cover cost share prices. While the practice is currently forbidden by both the USDA and FA, how might the HFN look different if it were liberated to model its activities after a thrift store or a food cooperative that recirculates economic value and employment opportunities within the community? There are other such transgressions to the rules, including foods travelling far beyond formalized circuits of need. When there is excess at the local level, calls are made to extended family members, neighbors and others that may or may not fit the description of "needy" households. At a mobile food pantry event for example I was given a box of frozen hotdogs to take home. After pushing back with the volunteer explaining that 18 pounds of hotdogs was too much for my freezer to hold and my family to consume, the volunteer retorted: "You have neighbors, don't you? Just give them away, we've got to get rid of them" (PO, 9.21.16).

Food banks are thus at a crossroads. Which future will they choose? Reviewing the contradictions I exposed in the data chapters provides future opportunities to think about ways in which they might take advantage of slippages in the existing institutional framework to reclaim control over charitable food supply chains. Food banks can be key contributors to the food justice and food sovereignty coalitions currently working to build alternative food futures. As individual organizations they are subordinate to dominant relations of power in the food system. Yet, they are also capable of confronting that power because, as I have demonstrated, they occupy a central role in the now essential food waste-qua-hunger relief supply chain. This resistance cannot be an individualized response however, and a project that rewrites the call to charity toward food justice 
(Dixon, 2015) must build solidarities between food banks and their LFCs to push back against the monopolistic dynamics that limit their ability to enact transformative food system change in their communities.

Food banks have the collective capacity to exercise power and demand institutional changes. This will take risks and sacrifices that go against the impulse to solve hunger in the short term with the hope of gaining legitimate community food security in the longer term. Food bank power stems from the essential function that those organizations play in both the accumulation strategy and moral economy of the corporate food regime. The billions of dollars spent on infrastructure to maintain the legitimacy of the capitalist food system through the HFN now positions food banks as key players in global food supply chains. The social services performed by food banks secure quiescence from the poor, who rely on private charity to make ends meet even as public austerity measures push them further and further toward the economic precipice.

If the food bank stopped, not because it disappeared, but rather because it intentionally refused to receive and redistribute state and corporate food waste, its function would be made clearly visible. News headlines and the general public might once again question the relationship between waste and want, the relationship between production and consumption. How might the moment be leveraged to demand social policies from the state that truly begin to end hunger? How might that same moment be leveraged to highlight whom is ultimately benefiting from the largely invisible labor and resources flowing through the food banking economy? How might regional food banks and their anti-hunger allies then be able to advocate for policies that reform our institutions to ensure that every person has the right to access adequate, nutritious and culturally appropriate food? If the food bank stopped, and its freneticism and contradictions were fully revealed, the urgency of the crisis would surely force a renegotiation of our moral contract. 
In the meantime, it is critical to begin envisioning a food system that leverages charitable food supply chains to reclaim sovereignty over our food system (Alkon and Mares, 2012). For too long the role of charity has been left out of food system transformation debates. Yes, there are institutional constraints and power dynamics to confront, but there are also opportunities for innovative collaborations that must be explored further. Such a project cannot be solely focused on food system development however. It must also tend to education and pedagogy so that policy makers, anti-hunger activists, farmers, charitable food directors, donors and recipients of food aid are cognizant of their place in a politics of compassion that reproduces hunger. 


\section{Bibliography}

Alkon, A. H., and Agyeman J. 2011. Cultivating Food Justice: Race, Class, and Sustainability . MIT Press, Cambridge, MA

Alkon, A.H. and Mares, T.M., 2012. Food sovereignty in US food movements: radical visions and neoliberal constraints. Agriculture and Human Values, 29(3), :347-359.

Alkon et. al. 2013. Foodways of the Urban Poor. Geoforum. 48: 126 - 135

Alkon, A. and Guthman, J. 2017. The New Food Activism. U.C. Press

Allen, Patricia. 2004. Together at the Table: Sustainability and Sustenance in the U.S. Agrifood system. Pennsylvania State University Press: University Park, PA

Allen, Patricia. 2007. The Disappearance of Hunger in America. Gastronimica. 7(3): 19-23

Allen, Patricia. 2013. Facing Food Security. Journal of Rural Studies. Vol. 29. pp 135-138.

Allen, P. et. al. 2003. Shifting plates in the agrifood landscape: the tectonics of alternative agrifood initiatives in California. Journal of Rural Studies 19 (1), 61-75

Andress L. and Fitch, C. 2016. Juggling the five dimensions of food access: perceptions of rural low income residents. Appetite. 105:151-155

Anselin, L. 1999. Interactive techniques and exploratory spatial data analysis. Geographical Information Systems, Vol 1, eds: Longley, P.A., Goodchild, M. F., Maguire, D. J., and Rhind, D. W., 253-266.

Araghi, F. 2003. Food regimes and the production of value: some methodological issues. The Journal of Peasant Studies, 30(2), 41-70

Babb, Angela. 2017. Making Neoliberal Consumer Subjects: A Political Ecology of Nutrition Assistance in the United States. Indiana University, ProQuest Dissertation Publishing: 10616708.

Barnett, C. et. al. 2005. Consuming ethics: articulating the subjects and spaces of ethical consumption. Antipode 37 (1), 23-45

Barnett, Michael. 2011. Empire of Humanity: A History of Humanitarianism. Cornell University Press

Barrett, Christopher. 2002. Food Security and Food Assistance Programs. Handbook of Agricultural Economics. 2: 2103-2190

Bassett, Thomas. 1988. The political ecology of peasant-herder conflicts in the Northern Ivory Coast. Annals of the Association of American Geographers. 78(3) : 459-472.

Bedore, Melanie. 2013. Geographies of capital formation and rescaling: $A$ historical-geographical approach to the food desert problem. The Canadian Geographer. 57(2): 133-153

Billo E. 2012. Competing Sovereignties: Corporate Social Responsibility, Indigenous Subjectivity, and Ecuador. PhD thesis, Department of Geography, Syracuse University

Billo, E. and Mountz, A. 2016. For institutional ethnography Geographical approaches to institutions and the everyday. Progress in Human Geography, 40(2), :199-220.

Bloom, J. 2011. American Wasteland: How America Throws Away Nearly Half of Its Food (and What We Can Do About It). Cambridge, MA: De Capo Press.

Bornstein, E. and Redfield, P. 2011. Forces of Compassion: Humanitarianism Between Ethics and Politics. School for Advanced Research Press. 
Bryson York, Emily. 2010. How Feeding America Became the Go-To Cause for Marketers. Ad Age. https://adage.com/article/news/feeding-america-marketers/143647/: Accessed June $30^{\text {th }}, 2017$

Burch, D. and Lawrence, G. 2009. Towards a Third Food Regime: Behind the Transformation. Agriculture and Human Values, 26:267-279

Buzby J and Hyman J. 2012. Total and per capita value of food loss in the United States. Food Policy 37(5): 561-570

Cabili, C. et. al 2013. White Paper on The Emergency Food Assistance Program: Final Report. USDA Office of Policy Support: Special Nutrition Programs Report No. FD-13-TEFAP

Campbell, H. 2009. The challenge of corporate environmentalism: social legitimacy, ecological feedbacks and the 'food from somewhere' regime. Agriculture and Human Values. 26(4): 309-319

Carolan, Michael. 2013. Reclaiming Food Security. New York: Routledge

Carson, E. 2014. Canadian food banks and the depolitization of food insecurity at the individual and community levels. Canadian Review of Social Policy 70: 7-21.

Clapp, J. and Fuchs, D. 2009. Corporate Power in Global Agrifood Governance. MIT Press

Cloke, $\mathrm{P}$ et. al. 2016. The geographies of food banks in the meantime. Progress in Human Geography. 41(6): 703-726

Coleman-Jensen, A. et. al. 2016. Household Food Security in the United States in 2015. ERR-215, U.S. Department of Agriculture, Economic Research Service, September 2016

Coleman-Jensen, et. al. 2013. Household Food Security in the United States in 2012, ERR-155, U.S. Department of Agriculture, Economic Research Service, September 2013

Crampton, Jeremy. 2010. Cartographic Calculations of Territory. Progress in Human Geography, 35(1): 92-103

Cuellar A. and Webber M. 2010. Wasted food, wasted energy: The embedded energy in food waste in the United States. Environmental Science and Technology 44(16): 6464-6469.

Dahrendorf, R. 2003. Forward in J. Kendall. The voluntary sector. London:Routledge. Pp. xiiixvi.

Daponte, B. and Bade, S. 2006. How the private food assistance network evolved: Interactions between public and private responses to hunger. Non-Profit and Voluntary Sector Quarterly 35(4): 668-690

Daponte, Beth, 2000. Private versus public relief: use of food pantries versus food stamps among poor households. Journal of Nutrition Education,32(2).72-83.

Daponte et. al. 1998. Food Pantry Use Among Low-Income Households in Allegheny County, Pennsylvania. Journal of Nutrition Education. 30(1): 50-57

Davis, Mike. 2004. The political ecology of famine: the origins of the Third World. In: Peet, R., and Watts, M. (eds) Liberation ecologies: environment, development, social movements. 2nd ed. London: Routledge: 48-63.

De Castro, J. 1977. The Geopolitics of Hunger. Monthly Review Press: New York

Dickinson, 2017. Free to Serve? Emergency Food and Voluneer Labor in the Urban U.S. Gastronomica, 17(2):16-25

Dixon, B. 2015. Rewriting the call to charity: From food shelf volunteer to food justice advocate. Journal of Agriculture, Food Systems and Community Development. 5(2):71-79 
Donini, A. 2010. The far side: the meta functions of humanitarianism in a globalised world. Disasters, 34: S220-S237.

Eig, Jonathan. 2000. The Urge to Merge hits Charities. As Two Major Nonprofits Wed to Better Tackle Hunger, will the Pot Thicken? Wall Street Journal, April 18, 2000. Accessed $5 / 23 / 2017$

Edwards, Mark. 2012. Food Insecurity in the Western US States. Food Culture and Society. 15(1): 93-112

Ekers, M. and Prudham S. 2018. The Socioecological Fix: Fixed Capital, Metabolism, and Hegemony. Annals of the Association of American Geographers, 108(1):17-34

Elwood, S. 2006. Beyond Cooptation or resistance: Urban spatial politics, community organizations, and GIS-based spatial narratives. Annals of the Association of American Geographers, 96(2):323-341

Elwood S. 2009. Mixed methods: Thinking, doing, and asking in multiple ways. In: DeLyser D,Crang M, McDowell L,Aitken S, and Herbert S(eds) The Handbook of Qualitative Research in Human Geography. Thousand Oaks, CA, Sage.

Essex, Jamey. 2012. Idle Hands are the Devil's Tools: The Geopolitics and Geoeconomics of Hunger. Annals of the Association of American Geographers. Vol. 102, No. 1

Falzon, M.A. ed. 2016. Multi-sited ethnography: Theory, praxis and locality in contemporary research. Routledge

Fassin, Didier. 2009. Les économies morales revisitées, Annales. Histoire, Sciences Sociales, 64(6):1237-1266.

Fassin, Didier. 2009. Another politics of life is possible. Theory, culture \& society, 26(5): 44-60.

Fassin, Didier. 2011. Humanitarian Reason: A Moral History of the Present. University of California Press: Berkeley, CA

Feeding America. 2014. Feeding America calls for Senate passage of the America gives more act.

Available at: www.feedingamerica.org/hunger-in-america/news-and-updates/press-room/pressreleases/feeding-america-calls-for-senate-passage-of-America-Gives-More-Act.html. Accessed April $4^{\text {th }}, 2015$.

Feeding America. 2014b. Mobile Food Pantry Program. Available at: https://www.feedingamerica.org/our-work/hunger-relief-programs/mobile-food-pantryprogram. Accessed October $4^{\text {th }}, 2014$.

Feeding America. 2015 Annual Report. http://www.feedingamerica.org/about-us/about-feedingamerica/annual-report/ Accessed: September 23rd, 2016.

Feeding America. 2017 Annual Report. https://www.feedingamerica.org/sites/default/files/aboutus/financials/2017-feeding-america-annual-report.pdf Accessed: August 15 ${ }^{\text {th }}, 2018$

Feeding America. 2018. Meal Connect. http://www.mealconnect.org. Accessed September $1^{\text {st }}$, 2018.

Fisher, Andrew. 2017. Big Hunger: The Unholy Alliance between Corporate America and AntiHunger Groups. MIT Press: Cambridge, MA

Fitting, Elizabeth. 2011. The Struggle for Maize: Campesinos, Workers and Transgenic Corn in the Mexican Countryside. Duke University Press.

Food Research Action Council (FRAC). 2016. http://www.frac.org/wp-content/uploads/foodhardship-report-households-with-children-sep-2016.pdf. Accessed: September $23^{\text {rd }}, 2016$ 
Forbes. 2017. The 100 largest U.S. Charities. https://www.forbes.com/top-charities/list/. Accessed: August $14^{\text {th }}, 2017$

Friedmann, H. and McMichael, P. 1989. Agriculture and the state system: the rise and fall of national agricultures, 1870 to the present. Sociologia Ruralis, 29(2): 93-117

Friedmann, H. 2005. From colonialism to green capitalism: social movements and the emergence of food regimes. In: F.H. Buttel and P. McMichael, eds. New directions in the sociology of global development. Research in rural sociology and development, Vol. 11. Oxford: Elsevier 229-67

Gallup-Healthways. 2013. State of American Well-Being: 2013 State Ranking and Analysis

Galt, R.E., 2013. Placing food systems in first world political ecology: A review and research agenda. Geography Compass, 7(9): 637-658.

Garasky S, et. al. 2004. The food environment and food insecurity: Perceptions of rural, suburban, and urban food pantry clients in Iowa. Family Economics and Nutrition Review, 16(2):4148

Gibson-Graham, J.K. 2006. The End of Capitalism (as we knew it): A feminist critique of political economy. University of Minnesota Press

Gille, Z. 2013. From risk to waste: global food waste regimes. The Sociological Review, 60(S2) $: 27-46$.

Glasser, I. 1988. More than Bread: Ethnography of a Soup Kitchen. University of Alabama Press

Global Food Banking Network: https://www.foodbanking.org : Accessed: June 8 ${ }^{\text {th }}, 2016$

Goodman, D. and Watts, M.J. 1997. Globalising food: Agrarian questions and global restructure. London: Routledge.

Goodman, D. et al. 2012. Alternative Food Networks: Knowledge, Practice and Politics. Routledge

Gottlieb R. and Joshi, A. 2010. Food Justice: MIT Press

Graddy-Lovelace, G. and Diamond, A. 2017. From supply management to agricultural subsidiesdand back again? The U.S. Farm Bill \& agrarian (in)viability. Journal of Rural Studies, 50: 70-83.

Gramsci, A. 1971. Selections from the prison notebooks of Antonio Gramsci. London: Lawrence and Wishart.

Gundersen et. al. 2011. The Economics of Food Insecurity in the United States. Applied Economic Perspectives and Policy. Vol 33 (3): 281-303

Gundersen, C. et. al. 2014. Map the meal gap: exploring food insecurity at the local level. Applied Economic Perspectives and Policy, 36(3), :373-386.

Guthman, Julie. 2004. Agrarian Dreams: The paradox of organic farming in California. UC Press

Guthman, Julie. 2008. Neoliberalism and the making of food politics in California. Geoforum. 39:1171-1183

Guthman, Julie. 2011. Weighing In: Obesity, Food Justice and the Limits of Capitalism. UC Press.

Hannah, Matthew. 2009. Calculable Territory and the West German census boycott movement of the 1980s. Political Geography, 28:66-75

Harvey, David. 1982. The Limits to Capital. Basil Blackwell: Oxford

Harvey, David. 1989. The Condition of Post-Modernity. Blackwell: Oxford

Harvey, David. 2001. Globalization and the Spatial Fix. Geographische Revue. 2:23-30. 
Hart G. 2004. Geography and development: Critical ethnographies. Progress in Human Geography 28(1): 91-100.

Hayes-Conroy, A. and Martin, D.G., 2010. Mobilising bodies: visceral identification in the Slow Food movement. Transactions of the Institute of British Geographers, 35(2), :269-281.

Henderson, G. 2004. 'Free' food, the local production of worth, and the circuit of decommodification. Environment and Planning D. Vol. 22. : 485-512.

Herbert S.1997. Policing Space: Territoriality and the Los Angeles Police Department. University of Minnesota Press

Heynen, Nik. 2008. Bringing the body back to life through Radical Geography of Hunger: The haymarket affair and its aftermath. ACME: An International E-Journal for Critical Geographies, 7(1): 32-44

Heynen, Nik. 2009. Bending the Bars of Empire from every ghetto for survival: The Black Panther Party's radical anti-hunger politics of social reproduction and scale. Annals of the Association of American Geographers 99 (2), 406-422

Holt Giménez E and Shattuck A. 2011. Food crises, food regimes, and food movements: Rumblings of reform or tides of transformation? Journal of Peasant Studies 38:109-144

Hoynes, H. and Schanzenbach, D. 2015. US Food and Nutrition Programs. National Bureau of Economic Research. Working Paper 21057.

Hyndman, Jennifer. 2000. Managing Displacement: Refugees and the Politics of Humanitarianism. University of Minnesota Press

Jacobs, Candice. 2016. The Emergency Food Assistance Program (TEFAP) Distribution National Survey: A Nationwide profile of state TEFAP programs and distribution practices. Washington State Department of Agriculture. AGR 609-574 (N/8/16)

Jarosz, L., 2008. The city in the country: Growing alternative food networks in Metropolitan areas. Journal of rural studies, 24(3):231-244.

Jessop, Bob. 2002. The Future of the Capitalist State. Polity

Kapoor, Illan. 2013. Celebrity humanitarianism: the ideology of global charity. Routledge, London

Katz, Cindi. 2001. Vagabond capitalism and the necessity of social reproduction. Antipode, 33(4):709-28

King, Brian. 2009. Commercializing conservation in South Africa. Environment and Planning A 41(2): 407-424

Lang, T. and Barling, D. 2012. Food security and food sustainability: reformulating the debate. The Geographical Journal. 178: 313-326

Levedahl et. al. 2014. Comparing the Emergency Food Assistance Program and the Food Stamp Program: Recipient Characteristics, Market Effects, and Benefit/Cost Rations. USDA ERS: Report No. 689

Lindenbaum, J., 2016. Countermovement, Neoliberal Platoon, or Re-Gifting Depot? Understanding Decommodification in US Food Banks. Antipode, 48(2), :375-392.

Lipsky, M. and Thibodeau, M. 1988. Feeding the Hungry with Surplus Commodities. Political Science Quarterly. 103(2):233-244.

Lohnes, J. and Wilson B. 2018. Bailing out the Food Bank? Hunger Relief, Food Waste and Crisis in Central Appalachia. Environment and Planning A: Economy and Space, 50(2): 350-369 
Martin, Douglas. 2005. John Van Hengel, 83, dies; Set up First Food Bank in the U.S. New York Times, October $5^{\text {th }}, 2005$. https://www.nytimes.com/2005/10/08/us/john-van-hengel-83dies-set-up-first-food-bank-in-us.html: Accessed February 12 ${ }^{\text {th }}, 2016$

Marx, K., 1976. Capital: Vol. 1 (B. Fowkes, Trans.). New York: Vintage. (Original work published 1864/72.).

Maye, D. and Kirwan, J. 2010. Alternative food networks. Sociology of Agriculture and Food, 20: 383-389

McCutcheon, P., 2015. Food, faith, and the everyday struggle for black urban community. Social \& Cultural Geography, 16(4), :385-406.

McIntyre et. al. 2016. "In"-sights about food banks from a critical interpretive synthesis of the academic literature. Agriculture and Human Values, 33, : 843-859

McMichael, P.2009. A food regime genealogy. Journal of Peasant Studies. 36(1) 139-169.

Mena et. al. 2011. The causes of food waste in the supplier-retailer interface: Evidences from the UK and Spain. Resources, Conservation and Recycling 55(6): 648-658.

Miewald, C. and McCann, E. 2014. Foodscapes and the geographies of poverty: sustenance, strategy and politics in an urban neighborhood. Antipode, 46(2):534-556

Middleton, N. and O'Keefe, P. 1997. Disaster and development: the politics of humanitarian aid. Pluto Press.

Mitchell, Katharyne. 2017. Education, race and empire: a genealogy of humanitarian governance in the United States. Transactions of the Institute of British Geographers, 42(3):349-362.

Mitchell, Timothy. 2001. Rule of Experts: Egypt, Techno-politics, Modernity. University of California Press: Berkeley.

Milligan, Christine. 2007. Geographies of Volunteerism: Mapping the Terrain. Geography Compass, 1/2: 183-199

Monke, Jim. 2016. Farm and Food Support under USDA's Section 32 Program. Congressional Research Service. RL34081.

Monmonier, Mark. 1991. How to Lie with Maps. University of Chicago Press

Morrison, J.C., 2011. The Sustainability of Hunger Relief: Analysis of Emergency Food Providers in Low Access Counties of West Virginia. M.A. Thesis: West Virginia University.

Mountz A. 2010. Seeking Asylum: Human Smuggling and Bureaucracy at the Border. University of Minnesota Press.

Nally, David. 2011. The biopolitics of Food Provisioning. Transactions of the Institute of British Geographers. Vol. 36, No. 1. : 37-53

Nestle, M. 2002. Food politics: how the food industry influences nutrition and health. Berkeley, CA: University of California Press.

Nevins. 2001. Operation Gatekeeper: The rise of the "Illegal Alien" and the making of the USMexico boundary. Routeldge.

O'Brien et. al. 2004. The Charitable Food Assistance System: The Sector's Role in Ending Hunger in America. America's Second Harvest

O'Brien, D.L. and Aldeen, H.T. 2006. Hunger in America 2006. Mathematica Policy Research (No. 4920).

Oliveira, Victor. 2015. The Food Assistance Landscape: FY 2014 Annual Report, EIB-137. U.S. Department of Agriculture: Economic Research Service 
Paleta, D and Dewey, C. 2018. White House readies plan for $\$ 12$ billion in emergency aid to farmers caught in Trump's escalating trade war. Washington Post: July 25 $5^{\text {th }}, 2018$.

Pallister-Wilkens, Polly. 2018. Hotspots and the geographies of humanitarianism. Environment and Planning D: Society and Space. Online First. https://doi.org/10.1177/0263775818754884

Parfitt et. al. 2010. Food waste within food supply chains: Quantification and potential for change to 2050. Philosophical Transactions of the Royal Society of London. Series B, Biological Sciences (365): 3065-3081.

Patel, Raj. 2012. Stuffed \& Starved: The Hidden Battel for the World Food System. Mellville House Publishing: Brooklyn, NY

Peck, J. and Tickell. A. 2002. Neoliberalizing Space. Antipode. 34 (3):380-404.

Pickles, John. 1993. Ground Truth: The Social Implications of Geographic Information Systems. The Guilford Press: New York.

Pimbert et. al. 2001. Global restructuring, agri-food systems and livelihoods. Gatekeeper Series: International Institute for Environment and Development Sustainable Agriculture and Rural Livelihoods Programme

Pine, A. and Bennett, J., 2014. Food access and food deserts: the diverse methods that residents of a neighborhood in Duluth, Minnesota use to provision themselves. Community Development, 45(4):317-336.

Pine, Adam. 2016. Confronting Hunger in the USA: Searching for Community Empowerment and Food Security in Food Access Programs. Routledge

Pollan, Michael. Voting with your fork. New York Times: May 7 $7^{\text {th }} 2006$. http://pollan.blogs.nytimes.com/2006/05/07/voting-with-your-fork/: Accessed 9.23.2016

Poppendieck, Janet. 1998. Sweet Charity? Emergency Food and the End of Entitlement. Penguin Books: New York.

Poppendieck, Janet. 2014. Breadlines Knee Deep in Wheat. Food Assistance in the Great Depresssion. UC Press: Berkeley

PR Newswire. April 18, 2000. ConAgra Partners with America's Second Harvest as it Merges with Foodchain to Rescue Hundreds of Millions of Pounds of Food; Just-In-Time Technology at the Heart of Largest Nonprofit Merger Ever. Retrieved from Nexis Uni June $30^{\text {th }}, 2018$.

Razavi, S. and Staab, S. 2012. Global Variations in the Political and Social Economy of Care: Worlds Apart. Routledge.

Reid-Henry, S.M. 2013. Humanitarianism as liberal diagnostic: humanitarian reason and the political rationalities of the liberal will-to-care. Transactions of the Institute of British Geographers, 39(3): 418-431.

Ribot, J. and N.L. Peluso. 2003. A theory of access: putting property and tenure in place. Rural Sociology, 68(2): 153-181

Ribot, J.C., 1998. Theorizing access: forest profits along Senegal's charcoal commodity chain. Development and Change, 29(2), : 307-341.

Riches, Graham. 1986. Food Banks and the Welfare Crisis. Love Printing Services: Ottowa, ON

Riches, G. and Silvasti, T. 2014. First World Hunger Revisited: Food Charity or the Right to Food? Palgrave Macmillian. 2nd Edition. 
Richey, L.A. and Ponte, S. 2011. Brand Aid: Shopping Well to Save the World. University of Minnesota Press.

Richey, L.A. and Chouliaraki, L. 2017. Everyday Humanitarianism: Ethics, Affects and Practices. New Political Science, 39:2, 314-316

Rose, Nikolas. 1999. Powers of Freedom: Reframing Political Thought. Cambridge University Press: London

Sayer, Andrew. 2010. Moral Economy and Political Economy. Studies in Political Economy, 69(1):79-103

Sbicca, Joshua. 2018. Food Justice Now. University of Minnesota Press

Schroeder. Richard. 1997. "Re-Claiming” Land in The Gambia: Gendered property Rights and Environmental Intervention. Annals of the Association of American Geographers. 87(3): 487-508

Scott, James. 1976. The Moral Economy of the Peasant. Yale University Press: New Haven.

Scott, James. 1999. Seeing like a state: How certain schemes to improve the human condition have failed. Yale University Press: New Haven.

Sen, A. 1982. Poverty and famines: an essay on entitlement and deprivation. Oxford university press.

Shamir, R. 2008. The age of responsibilitization: on market-embedded morality. Economy and Space, 37(1):1-19

Shannon, Jerry. 2014. Food deserts Governing obesity in the neoliberal city. Progress in Human Geography, 38(2), :248-266.

Shannon, J. et. al. 2016. Growth in SNAP retailers was associated with increased client enrollment in Georgia during the Great Recession. Health Affairs. 35(11): 2100-2108.

Shapira, Ian. 2018. Food stamps may become like Blue Apron. In the great depression they started with blue coupons. Washington Post: February $13^{\text {th }}, 2018$.

Sharon, P. et. al. 2011. When even the 'dollar value meal' costs too much: food insecurity and long-term dependence on food pantry assistance. Public Administration Quarterly 35.1:2658

Short, Kathleen. 2015. Current Population Reports: The Supplemental Poverty Measure: 2014. United States Census Bureau.

Slocum, R., 2007. Whiteness, space and alternative food practice. Geoforum, 38(3): 520-533.

Slocum et. al, 2011. "Properly, with love, from scratch": Jamie Oliver's Food Revolution. Radical History. 110: 178-191

Smith, Neil. 1984. Uneven Development: Nature, Capital and the Production of Space. University of Georgia Press.

Smith, Dorothy. 1987. The everyday world as problematic: A feminist sociology. Northeast University Press

Stuart, T. 2009. Waste: Uncovering the Global Food Scandal, New York: W. W. Norton

Tarasuk, V. and Eakin, J. 2005. Food Assistance through "surplus" food: Insights from an ethnographic study of food bank work. Agriculture and Human Values. 22 (2): 177-186

Thieme T.A. et. al. 2015. Geographies of corporate practice in development: Contested capitalism and encounters. Geoforum, 59:215-218 
Thompson, E.P. 1971. The Moral Economy of the English Crowd in the 18th Century. Past and Present. No. 50: 76-136

Tomlinson, I. 2013. Doubling food production to feed the 9 billion: a critical perspective on a key discourse of food security in the UK. Journal of Rural Studies 29: 81-90

Tsang, S., A.M. Holt, and E. Azevedo. 2011. An assessment of the barriers to accessing food among food-insecure people in Cobourg, Ontario. Chronic Diseases and Injuries in Canada 31: 121-128.

U.S. Bureau of Labor Statistics. 2015. https://www.bls.gov/data/\#unemployment. Accessed 9.3.2015

U.S. Congress. 1996. Bill Emerson Good Samaritan Food Donation Act. (H.R.104-661).

U.S. Congress. 2014a. Agricultural Act of 2014 (H.R. 2642).

U.S. Congress. 2014b. 113th Congress. Fighting Hunger Incentive Act of 2014. (H.R. 4719).

U.S. Congress. 2015. 114th Congress. Consolidated Appropriations Act, 2016. (H.R. 2029).

U.S. Congressional Budget Office. 2014. 104th Congress. Fighting Hunger Incentive Act of 2014. (H.R. 4719.)

U.S. Deparment of Agriculture - Economic Research Service. 2017. Supplemental Nutrition Assistance Program (SNAP) Linkages with the General Economy. https://www.ers.usda.gov/topics/food-nutrition-assistance/supplemental-nutritionassistance-program-snap/economic-linkages/\#econactivity. Accessed 11.12.17

U.S. Internal Revenue Service. Charitable, etc. contributions and gifts. Code of Federal Regulations 26-170.

Van Zuiden, S. 2012. The good food fight for good Samaritans: The history of alleviating liability and equalizing tax incentives for food donors. Drake Journal of Agricultural Law 17(1): 237-262

Venkat, Kumar. 2011. Climate Change and Economic Impacts of Food Waste in the United States. International Journal of Food System Dynamics. 2(4) 431-446

Vernon, James. 2007. Hunger: A Modern History. Harvard University Press

Vivero-Pol, José Luis. 2017. Food as Commons or Commodity? Exploring the Links between Normative Valuations and Agency in Food Transitions. Sustainability, 9,442:

Wainwright, J. and Mann, G. 2018. Climate Leviathan: A political theory of our planetary future. Verso

Walker et. al. 2010. Disparities and access to healthy food in the United States: A review of food deserts literature. Health \& Place, 16(5), :876-884.

Warshawsky, Daniel. 2010. New power relations served here: The growth of food banking in Chicago. Geoforum. 41:763-775.

Warshawsky, Daniel. 2011. FoodBank Johannesburg, state, and civil society organizations in post-apartheid Johannesburg. Journal of Southern African Studies, 37(4), :809-829.

Warshawsky, Daniel. 2016. Food waste, sustainability, and the corporate sector: case study of a US company. The Geographic Journal. 182(4):384-394

Watts, Michael. 1983. Silent violence: food, famine, and peasantry in Northern Nigeria. University of California Press, Berkeley CA

Watts, Michael. 1991. Entitlements or Empowerment? Famine and Starvation in Africa. A review of African Political Economy, 51:9-26. 
Watts, M. \& Bohle, H. 1993. Hunger, Famine and the Space of Vulnerability. Geojournal. 30(2): 117-125

Watts, Michael. 1994. Development II: The privatization of everything? Progress in Human Geography, 18(3):371-384

Weizman E. 2012 The least of all possible evils: humanitarian violence from Arendt to Gaza. Verso, London

Wilson, Bradley. 2010. Indebted to Fair Trade? Coffee and Crisis in Nicaragua. Geoforum. 41(1): 84-92

Winefield et. al. 2014. Hunger in America Report. Feeding America.

Winter, M., 2003. Geographies of food: agro-food geographies-making reconnections. Progress in Human geography, 27(4), :505-513.

Wisner et. al. 1983. Hunger: A polemical Review. Antiope. 14(3): 1-16

Wolch, Jennifer. 1990. The shadow state: Government and Voluntary Sector in Transition. New York: Foundation Center

Wolford, Wendy. 2010. This Land is Ours Now: Social Mobilization and the Meaning of Land in Brazil. Duke University Press.

Wright, Melissa. 2006. Disposable Women and other Myths of Global Capitalism. Routledge. 